\title{
Rolf Lettmann
}

\section{Die Abstracta „um" und „razum“ bei Belinskij}

\section{Semasiologische Untersuchungen}

Verlag Otto Sagner München · Berlin · Washington D.C.

Digitalisiert im Rahmen der Kooperation mit dem DFG-Projekt „Digi20“

der Bayerischen Staatsbibliothek, München. OCR-Bearbeitung und Erstellung des eBooks durch den Verlag Otto Sagner:

http://verlag.kubon-sagner.de

() bei Verlag Otto Sagner. Eine Verwertung oder Weitergabe der Texte und Abbildungen, insbesondere durch Vervielfältigung, ist ohne vorherige schriftliche Genehmigung des Verlages unzulässig. 


\section{SLAVISTISCHE BEITRÄGE}

Unter Mitwirkung von M. Braun, Göttingen · P. Diels, München - J. Holthusen, München - E. Koschmieder, München - W. Lettenbauer, Freiburg/Br. J. Matl, Graz

F. W. Neumann, Mainz $\cdot$ K.-H. Pollok, Regensburg · L. Sadnik-Aitzetmüller, Graz $\cdot J$. Schütz, Erlangen

HERAUSGEGEBEN VON † A. SCHMAUS, MÜNCHEN Technische Redaktion: P. Rehder, München

Band 49 


\section{ROLF LETTMANN}

\section{DIE ABSTRACTA ${ }_{n} U M^{n}$ UND ${ }_{n}$ RAZUM ${ }^{n}$ BEI BELINSKIJ}

Semasiologische Untersuchungen 
ISBN 3876900581

Copyright by Verlag Otto Sagner, München 1971

Abteilung der Fa. Kubon \& Sagner, München

Druck: Alexander Großmann

8 München 19, Ysenburgstr. 7/1 


\section{INHAL TSVERZEICHNIS}

Erster (hinführender) Teil

0.00 Einleitung 9

0.10 Zielsetzung 9

0.20 Abgrenzung des Themas 10

0.30 Zur Methode 13

0.31 Technisches 16

$\begin{array}{lll}0.40 \quad \text { Literatur } & 17\end{array}$

1. Kapitel

Vorbelastung der Wörter 'um' und 'razum' durch die Sprachgemeinschaft (das Lexikon) und den einzelnen Sprecher (Belinskij)

1.10 Die Bedeutungen von 'um' und 'razum' 21

1.11 Etymologie 22

1.12 Aussagen zeitgenössischer und späterer Lexika 23

1.13 Abgel eitete Wörter $\quad 30$

1.14 Erstarrte Wendungen $\quad 34$

1.15 Zusammenfassung $\quad 35$

1.20 Vissarion Grigor'evic Belinskij (1811 - 1848) 37

1.20.0 Voraussetzungen der nachhaltigen Sprachbeeinflussung durch den einzelnen Sprecher $\quad 37$

1.21 Allgemeine Einschätzung Belinskijs 39

1.22 Standorte - vor allem literaturtheoretische 44

1.23 Zusammenfassung mit Blick auf den zweiten Teil
dieser Arbeit

2. Kapitel

Deduktion einer Methode der Semasiologie aus den

Prămissen der Allgemeinen Sprachwissenschaft

2.10 Die Prămissen der Allgemeinen Sprachwissenschaft 59

2.20 Die Prămissen der Semasiologie 62

2.30 Inhaltsfreie Kategor isierung der Redegebilde nach $\mathrm{Kr}$ iterien der syntaktischen Logik 72

2.31 Logisches in der Syntax $\quad 72$

$\begin{array}{lll}2.32 & \text { Strukturale Gliederung } & 78\end{array}$

2.40 Kritik 83 
Zweiter (ausfuhrender) Teil

0.00 Einleitung 85

0.10 Abgrenzung des Belegmaterials 91

1. Kapitel

"UM"

1.10 Kaum spürbare Eindämmung des Bedeutungsbereichs 93

1.11 'um' in prädikativer Funktion 93

1.12 Generell implizierte Aussagen 96

1.13 Auf Grund hoher absoluter Bezugsvariabilität

leicht vereinbare determinier ende Prädikationen $\quad 96$

1.20 Merkliche Begrenzung des Bedeutungsbereichs 101

1.21 Naheliegende hochspezialisierte determinierende Prädikationen

101

1.22 Relationale Urteile 111

1.30 Starke Einengung des Bedeutungsbereichs 121

1.31 Semantisch fernliegende determinierende Prădikationen

122

1.32 Relationale Urteile

1.40 Konsolidierung der aktuellen Bedeutung durch Anhebung partiell implizierter Prädikationen oder Beziehungsglieder

$\begin{array}{lll}1.41 & \text { Determinierende Urteile } & 129 \\ 1.42 & \text { Relationale Urteile } & 132\end{array}$

2. Kapitel

"RAZUM"

2.10 Kaum spürbare Eindămmung des Bedeutungsbereichs

2.11 'razum' in pradikativer Funktion

2.12 Dem Begr iff 'razum' nahezu generell implizierte Prädikationen

(2.13)

2.20 Merkliche Begrenzung des Bedeutungsbereichs 138

2.21 Aus anderen Bedeutungsfeldern entlehnte determinierende Prädikationen

$\begin{array}{lll}2.22 & \text { Relationale Urteile } & 138\end{array}$

2.30 Starke Einengung des Bedeutungsbereichs 142

2.31 Aus anderen Bedeutungsfeldern entlehnte determinierende Prädikationen

2.32 Relationale Urteile 
2.40 Konsolidierung der aktuellen Bedeutung durch Anhebung jeweils partiell implizierter Prädikationen oder Beziehungsglieder

2.41 Partiell implizierte determinierende Prădikationen

2.42 Partiell implizierte Beziehungsglieder

Zusammenfassung

155

Literaturverzeichnis 


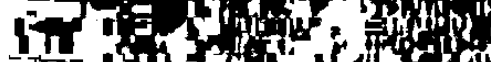

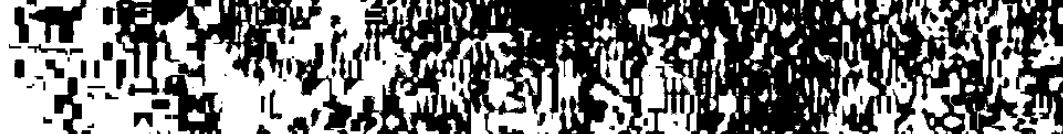

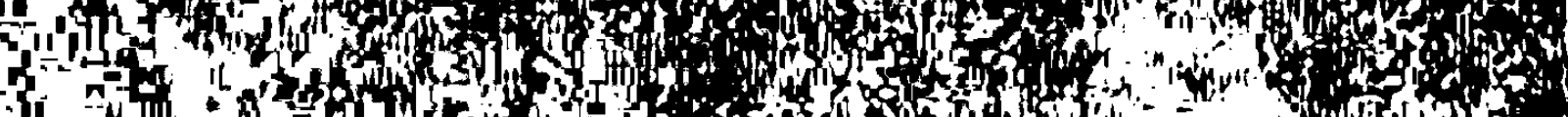
-

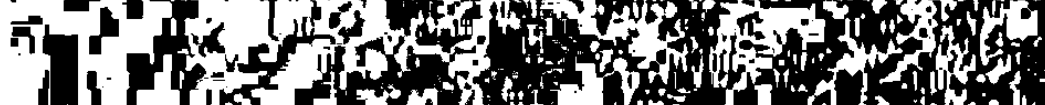

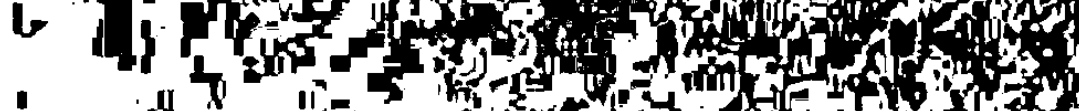

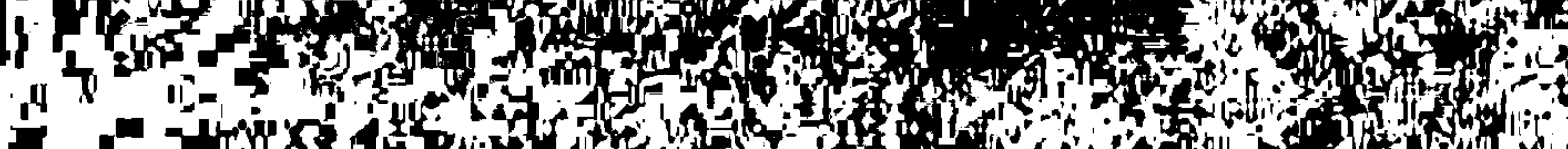

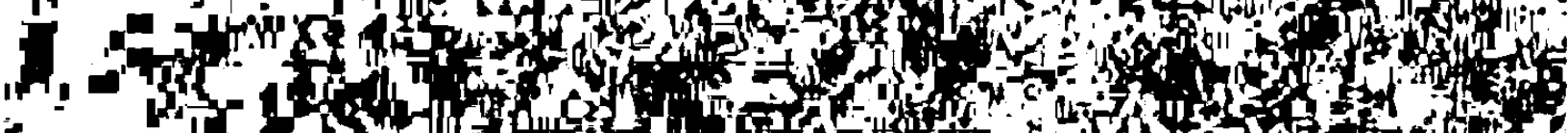

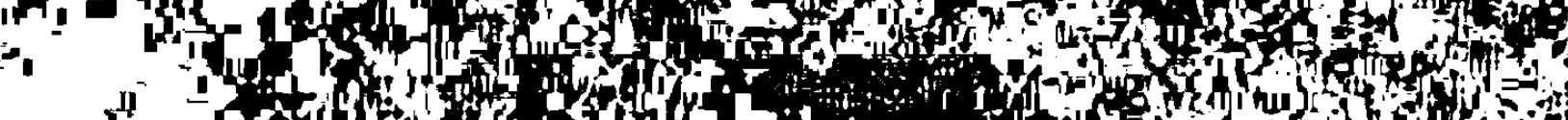

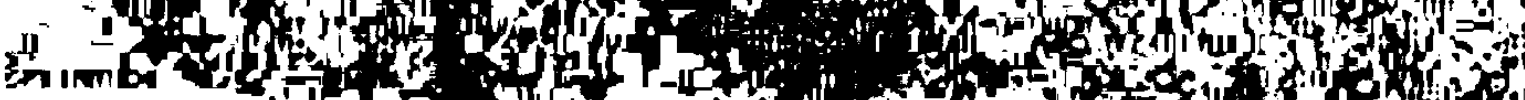

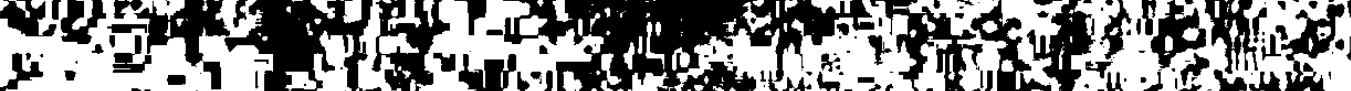

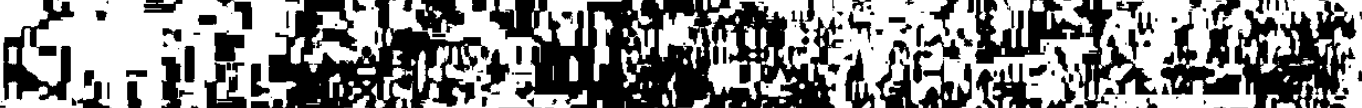

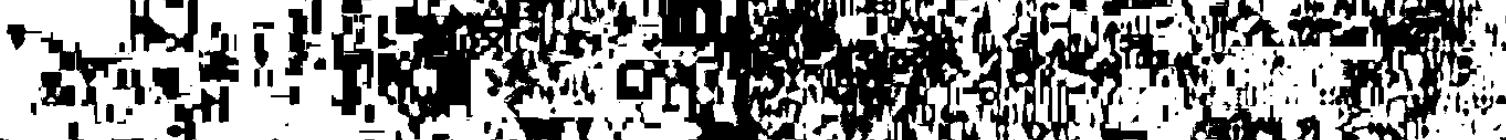

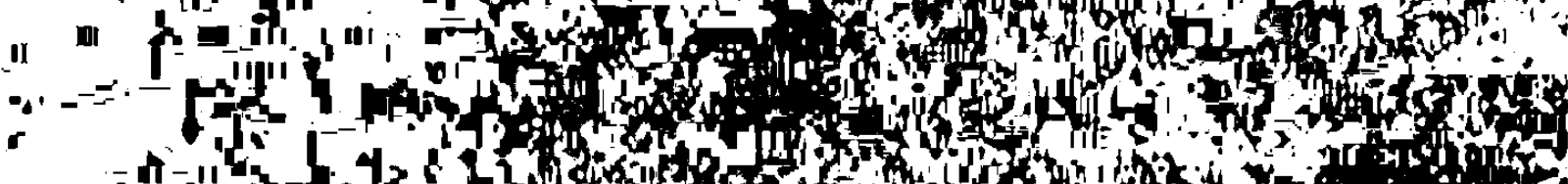

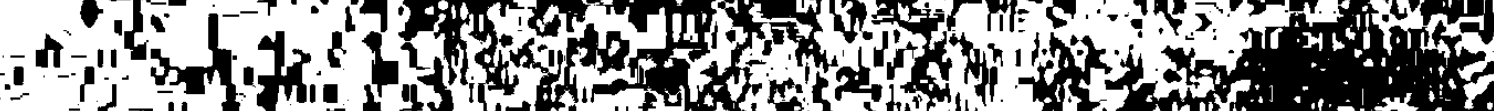
a 1 G - 112 "L it

c mile

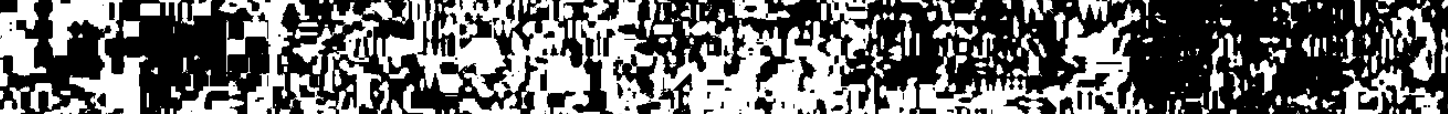

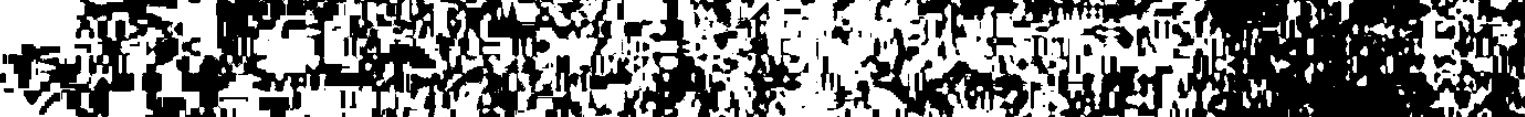

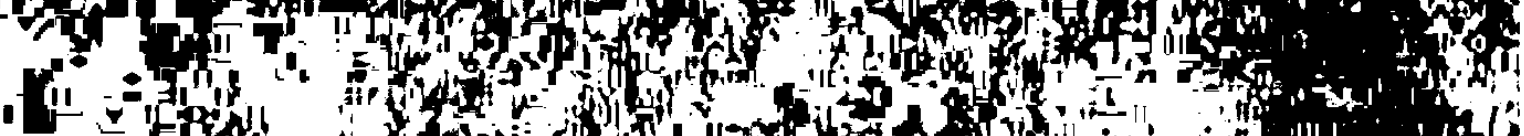
-12 1

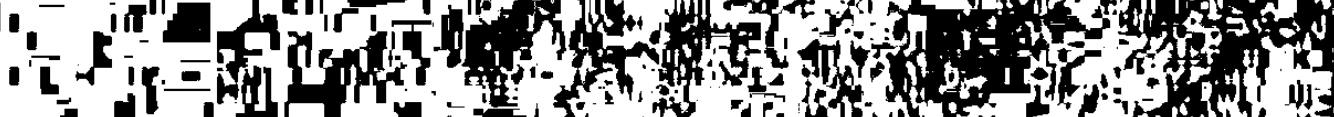
te

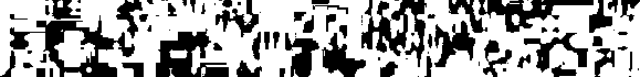

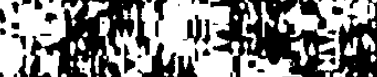

3 ,

- I.

II-19d

iI

1 Non

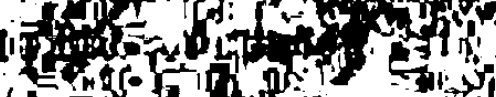

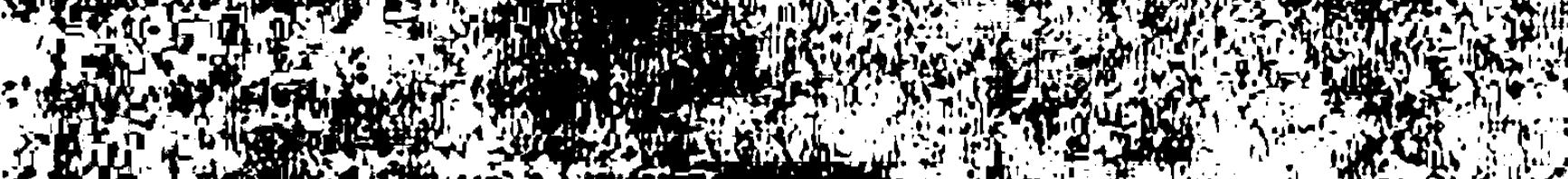
-40

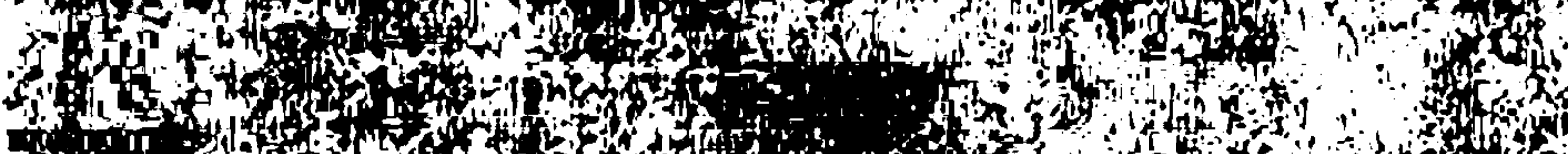

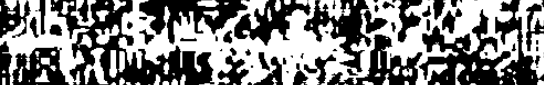

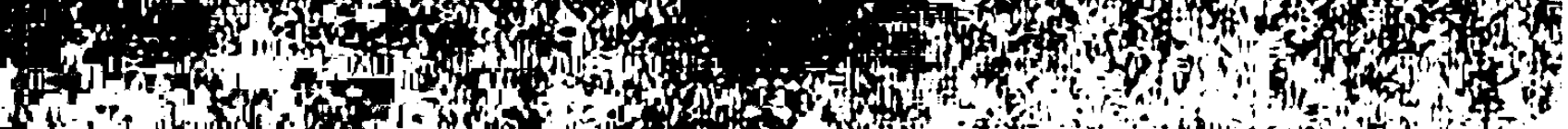

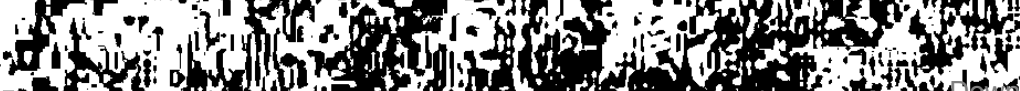
Hix 
ERSTER TEIL

\subsection{Einleitung \\ 0.10 Ziel setzung}

Als Ergebnis dieser Arbeit strebe ich eine differenzierende Gegenüberstellung der Denkinhalte an, die Belinskij in seinen Werken mit den Wortern 'um' und 'razum' ausgedrückt hat.

Mit der.Lősung dieser Aufgabe sollen Wege aufgezeigt werden, die zur Erschließung der Bedeutungsbereiche bestimmter Wörter aus beliebiger sprachlicher Umgebung führen.

Die folgende Unter suchung ist also zweisträngig: Die mehr auf einen Beitrag zur Geistesgeschichte gerichtete Frage nach Umfang und Ort des Denkraumausschnitts, den 'um' und 'razum' begreifen, wird zusammen mit der sprachwissenschaftlich orientierten Frage gestellt, wie und mit welcher Genauigkeit der Bedeutungsspielraum eines sprachlichen Zeichens überhaupt vermessen werden kann. Die Antworten müssen in einem Prozeß gegenseitiger Erhellung und Kontrolle gewonnen werden; ich möchte also weder die theor etischen Erörterungen semasiologischer Probleme nur als methodologische Anmerkungen noch die Auseinandersetzung mit 'um' und 'razum' lediglich als Ilustration einer Theorie verstanden wissen. Gemessen an der üblichen, oft leider alternativ gefaßten Einteilung der Philologie, ist diese Arbeit auf halbem Wege zwischen Sprachwissenschaft und Geistesgeschichte angesiedelt, aber m. E. ist das der Ort einer semasiologischen Analyse. Von den dabei auftretenden Methodenkonflikten wird noch die Rede sein.

Die Frage, w a $s$ mit einem Wort in einem bestimmten Zusammenhang gemeint ist, impliziert die Frage, wie es Träger gerade dieser Bedeutung geworden ist, d. h. - bei synchron-strukturalistischer Betrachtung - welche Komponenten immer und überall im Redegebilde zusammenwirken müssen, damit das per definitionem vieldeutige Zeichen 
möglichst eindeutig ubermittelt wird. Die Frage der diachronischen Semasiologie nach dem Werdegang einer bestimmten Bedeutung interessiert hier nur am Rande, aber eine inhaltsbezogene Bedeutungsfor schung hat auch dann eine Raum-Zeit-Dimension, wenn sie punktuelle Fixierung ihres Gegenstandes vorgibt.

Um das Terrain abzustecken, auf dem hier vorgegangen wird, halte ich es für sinnvoll, immer wieder die Mutmaßungen aufzuzeigen, die Thema und anschließende Fragestellung enthalten. Daß dabel gelegentlich 'Binsenweisheiten' ausgesprochen werden, kann um der Vollstăndigkeit willen in Kauf genommen werden. Je schărfer diese Erwar tungen umrissen werden, desto deutlicher werden sich auch die Wege der Verfahren abzeichnen. Deduktives Eingrenzen einer Unter suchung ist selbstverständlich kein Novum in der Philologie, aber ich meine, daß konsequenter von dieser Möglichkeit Gebrauch gemacht werden sollte; und es ist sicher - bei allen sonstigen Vorbehalten - ein Verdienst der 'axiomatisier enden' Sprachwissenschaft, darauf ständig hinzuweisen. Der Versuch, die Basis determinierender Prämissen so weit wie möglich auszubauen, ist ein wesentliches Anliegen dieser Arbeit. Ob die Tragfähigkeit dieses Fundaments hinreichend ist, läßt sich endgulltig erst im letzten Kapitel sagen, aber sie kann im voraus zumindest glaubhaft gemacht werden.

\subsection{Abgrenzung des Themas}

Das Thema dieser Arbeit schließt die Voraussetzungen ein, daß

a) die Wahl von 'um' und 'razum' sinnvoll,

b) die Beschrănkung aư Belinskij zulăssig ist,

c) die Bedeutungen adäquat im Deutschen wiedergegeben werden können.

0.21

zu a)

' um' und 'razum' werden allgemein als die russischen Worter für das mit 'Verstand' und 'Vernunft' Gemeinte aufgefaßt; wir dürfen daher eine ăhnlich zentrale Stellung im russischen Denken erwarten. Die Unterstellung, daß wir es mit Polen eines wesentlichen Sinnbezirks zu 
tun haben, und daB deshalb eine Ausgrenzung statthaft ist, kann mit dem Hinweis auf die philosophischen Stromungen in der ersten Halfte des 19. Jahrhunderts in Deutschland und deren Auswirkungen auf Rufland plausibel gemacht werden. 'um' und 'razum' sind wurzelverwandte, nur durch ein Präfix geschiedene Worter. Die Frage, wieweit das 'von Bedeutung' ist, rechtfertigt allein schon eine Untersuchung. Von der Wortbildung her (gleiche perfektivier ende/steigernde Vor silbe; ver schiedene Wurzel) entspricht eher das Wortpaar 'rassudok - razum' dem deutschen 'Ver stand - Vernunft'. Obgleich es in dieser Arbeit nicht um Über setzungsmoglichkeiten ins Russische geht, bleibt festzuhalten, daß ein zweites Wort mit der Grundbedeutung 'Verstand/Vernunft' existiert. Hier schließen einige Fragen an, die zu gegebener Zeit formuliert werden. 'um' und 'raz$u^{\prime}$ werden aus einem großßeren Sinnbezirk isoliert, d. h. gegen andere Worter abgegr enzt. Es ver steht sich von selbst, daß Träger ähnlicher oder gar gleicher Bedeutungen ebenso in die Betrachtung einbezogen werden wie Wrrter, die 'um' und 'razum' Entgegengesetztes meinen. Die Analy se wird natürlich nur so weit vordringen, wie es für die Bedeutungen von 'um' und 'razum' notwendig ist.

\subsection{2}

zu b)

Was mit 'um' und 'razum' gemeint ist, wird aus den Werken Belinskijs erschlossen. Obgleich sein Rang im russischen Geistesleben umstritten ist, sind seine Verdienste um die russische Sprache durchweg selbst von Tschizewskij - anerkannt worden; er ist ein repr äsentativer Sprecher der dreißiger und vierziger Jahre des 19. Jahrhunderts in Rußland. Die Angriff spunkte der Kritik sind für diese Unter suchung Ansatzpunkte: gerade weil Belinskij sich gleichermaßen in philosophischen Horhen wie in feuilletonistischen Niederungen bewegt hat, gerade weil er auf fast allen zeitgenઠssischen Denkbahnen Irgendwann fortzuschreiten ver suchte, bietet er sich hier an. Er spricht nicht nur eine um begriffliche Klarheit bemühte Gelehrtensprache, sondern auch unreflektierte Umgangssprache. Es ist zu erwarten, daß Belinskij die Bedeutungsmöglichkeiten der Worter weitgehend dur chgespielt hat. 
Unter der Voraussetzung einer großen Horer-/Leserzahl laßt sich die Beschrănkung auf einen Sprecher außerdem noch mit der jedem Sprechen innewohnenden Kommunikationsabsicht rechtfertigen; ein Spr echer wird die Zeichen wathlen, die nach seiner Auffassungach seine Horer benutzen wirden, wollten sie das Gleiche ausdrücken.

\subsection{3}

zu c)

Die Unterstellung, daß sich die Bedeutungen russischer Worter adăquat im Deutschen wiedergeben lassen, besagt nicht mehr und nicht weniger, als daß Übersetzung grundsătzlich mbglich ist, daß jeder in einer fremden Sprache formulierte Denkinhalt auch in der eigenen Sprache ausgedrückt werden kann.

Mit dem Hinweis, daß die Prămisse interlingualer Konstanz des Gemeinten ${ }^{1}$ für die Allgemeine Sprachwissenschaft unabdingbar ist, wird zwar das Problem des Übersetzens nicht aus dem Weg gerăumt, aber es ist einleuchtend, daß mit Hilfe eines angemessenen Zeichenaufwands der Sprache B eine unmißverstăndliche Wiedergabe des in der Sprache A Gedachten und Gesagten mø̈glich ist, daß die asymptotische Annăherung hinreichend weit getrieben werden kann.

Zwischen den Zeichen der einen und der ander en Sprache besteht so gut wie nie eine eindeutige Relation; das gilt besonders für den hier interessier enden Bereich der sogenannten Abstracta. Wenn ich Synonyma als seltene Ausnahme ausklammere, dann kann ich die Bedeutung eines russischen Wortes also nur dadurch wiedergeben, daß ich das inhaltlich nächstllegende deutsche Wort mit Hilfe anderer Zeichen in die Denkraumposition des russischen steuere. Da auch in ein und derselben Sprache das, was ein Wort bedeutet, nicht mit einem Wort zu sagen ist, also Wiedergabe der Bedeutung nur durch Vergleich mit einem inhaltlich zwar verwandten, aber nie identischen anderen Zeichen geschieht, wird die Frage zweitrangig, welcher Sprache dieser Maßstab entnommen wird;

Axiom Koschmieders; $\nabla$ gl. Tell I, Kap. 2 dieser Arbeit. 
in jedem Fall liegt ein Akt des Über setzens vor ${ }^{2}$.

\subsection{Zur Methode}

Es liegt in der Natur der Sache, daß die beiden Kernfragen nach der Bedeutung und dem Bedeuten nicht isoliert gesehen werden können. Für die Methode einer semasiologischen Analyse ist es aber entscheidend, bei welcher der Fragen angesetzt wird. Der Ansatz ist grundsătzlich hier wie dort möglich:

a) Die Bedeutung, die auf Grund der vorausgesetzten Kenntnis der Sprache (spontan, intuitiv) verstanden worden ist, wird durch einen Blick auf die Umgebung, auf die Art und Weise des Bedeutens bestătigt, m.a.W.: der Behauptung folgt der Beweis. Aber die Argumentation dreht sich im Kreis. Pointiert sieht das so aus: Das Wort A bedeutet a 1, weil das Nachbarwort B, das - weil A a 1 bedeutet - nur b 2 bedeuten kann, für $A$ keine andere Bedeutung als a 1 zuläßt (z. B. in der Redewendung 'kühler Verstand' o. å.). $\mathrm{Daß}$ die Ergebnisse dieser 'Beweise' richtig sind, ist der Sprachkenntnis des Autors, nicht seinen Schlußfolgerungen zu danken ${ }^{3}$.

So kommt man also nicht weiter, wenn man über den Wortinhalt hinaus etwas über die Modalităten des Bedeutens erfahren will. In diesem Fall scheint mir ein Zurückgehen auf die im Redegebilde repräsentierten Denkakte unumgänglich zu sein:

b) Sprache ist Absprache über Bedeutungen und Bedeutensweisen, dem umfangr eichen 'Lexikon' steht relativ wenig 'Grammatik', der Grammatik noch weniger an logischen Zuordnungsweisen gegenüber. Die Bedingungen des Bedeutens sind - als das Allgemeinere, die Bedeutungen Übergr eifende - weitgehend inhaltsfrei $\mathrm{zu}$ beschreiben.

In einem Gespräch Ende 1967 nannte der polnische Autor und Über setzer Witold Wirpsza das Über setzen eine Kritik der Sprache des Originals mit den Mitteln einer anderen. Sinngemäß übertragen heißt dann Beschreibung einer Bedeutung: $\mathbf{K r i t i k}$ des Trăgerwortes mit anderen Wortern.

Als Beispiel sei hier nur die inhaltlich verwandte Dissertation Siegbert Latzels genannt. 
Whalt man das Bedeuten zum Ausgangspunkt, entscheidet man sich also für ein mehr deduktives Vorgehen, dann kann ein ubertragbares, weil an wortunabhăngigen Denkweisen orientiertes Glederungsprinzip semasiologischer Unter suchungen gewonnen werden. Ich ziehe diese wenn man so will: strukturale - Methode noch aus einem ander en Grunde vor: ich hoffe, allgemeingültige Maßstäbe für die Fehlerbetrachtung intuitiv erfaßter Bedeutungen zu erhalten.

Daß dieser Methode Grenzen gesetzt sind, daß eine gewisse methodische Elastizităt unumgănglich ist, wird das zweite Kapitel zeigen. Schlieflich darf die Theorie nicht unflexibler sein als das Objekt, auf das sie angewendet wird. Ohne die Verdienste des Strukturalismus in der Linguistik, besonders auf dem Gebiet der Phonologie und Morphologie, schmallern zu wollen, muß diese Forschungsrichtung sich den Vorwurf gefallen lassen, die Bedeutungsseite der Sprache mit der Bemerkung, sie sei als Objekt einer exakten Wissenschaft ungeeignet, allzu leichtfertig beiseite geschoben zu haben ${ }^{4}$. Es ist sicher forderlicher, sich dem Methodenkonflikt zu stellen, statt den For schungsgegenstand nach den Grenzen der Methode auszurichten.

Im zweiten Kapitel werde ich aus den Prämissen der Allgemeinen Sprachwissenschaft (2.10) die besonderen der Semasiologie (2.20) ableiten und diskutieren und versuchen, von dort aus ein Gliederungsprinzip nach noetischen Kategorien zu entwickeln (2.30).

Vorher (Kap. 1) werde ich dem nachgehen, was zu Sprache und Sprecher vorliegt. Man darf hier m. E. von zwei Vorbelastungen sprechen, die den Bedeutungsbereich in Grenzen halten, die in der aktuellen, den Bereich fast abdeckenden Rede jedoch nur geringe Spuren hinterlassen: zum einen von der Vor eingenommenheit der unter suchten Wrrter durch die Sprachgemeinschaft und zum ander en von der Vor eingenommenheit des Sprechers durch seinen geistigen Standort.

Vgl. hierzu Stephen Ulmanns Nachtrag zur zweiten Auflage seiner 'Grundzige' (a.a.O. , S. $277 \mathrm{ff}$, , besonder s S. 292ff.). Ullmann bedauert den Verlust jedes humanen Bezuges (S. 293). 
Das Wörterbuch verzeichnet den Bedeutungsspielraum, in dessen Grenzen die Sprachgemeinschaft das Wort verwendet. Die Lexikographie entscheidet statistisch darüber, welche Bedeutungen in diesem Raum zentral und welche peripher sind. Das ist zwar für den einzelnen Sprecher prinzipiell unverbindlich, aber er kann, um verstehbar zu bleiben, diese Rangfolge nur mit Mühe verănder n. Um die spezifische Akzentsetzung Belinskijs vergleichend darstellen zu können, werde ich die Lexik von 'um' und 'razum' im Abschnitt 1.10 des ersten Teils anführen und auch einige Sătze auf das benachbarte 'rassudok' und die deutschen Entsprechungen verwenden. Parallel zu diesem Abschnitt werde ich unter 1.20 Belinskijs Standort, besser wohl: Belinskijs Laufbahnen zu skizzieren versuchen. Ich halte es in diesem Zusammenhang für statthaft, in den Koordinaten der geistigen Konstitution, selbst in manchmal fragwür digen Kategorisierungen, wie z.B. Belinskij als Westler, tendenziöser Kritiker und Literaturtheor etiker, als Schellingianer, Hegelianer, Sozialutopist etc. eine Analogie zum Bedeutungskatalog zu sehen, den ein Wörterbuch zu einem Wort verzeichnet. Hler wie dort liegen in der Abstrahierung Fehlerquellen, die aufzudecken eine der Aufgaben des zweiten Teils sein wird.

Die Resultante aus allgemeinem Inventar und besonder er Synthese wird als S̄til sichtbar. So gesehen sind die beiden Kapitel des zweiten Teils, die der Bedeutungsanalyse vorbehalten sind, auch eine auf 'um' und 'razum' ausger ichtete Stil unter suchung.

Diese beiden Kapitel sind gleich gegliedert. Der besser en Überschaubarkeit wegen und um Wiederholungen zu vermeiden, empfiehlt es sich, die differ enzier ende Gegenüberstellung der Bedeutungen nicht in einem übergr eifenden dritten Kapitel vorzunehmen, sondern bereits im zweiten nach jedem größeren Abschnitt. Der zusammenfassende Schlußteil wird so von verwirrenden Einzelheiten befreit und kann auf das Wesentliche beschrănkt werden, d.h. auf die Kommentierung des persönlichen Bedeutungswandels, auf eine rückblickende Kritik der Methode, des geistesgeschichtlichen und sprachwissenschaftlichen Ertrags. 


\subsection{Technisches}

Eine sprachwissenschaftliche Arbeit wird nicht unerheblich durch die Terminologie erschwert. Es scheint, daß die Fachausdrücke immer wieder in den Sog des For schungsgegenstandes geraten und selbst Objekt der wissenschaftlichen Bemühungen werden. Die Begr iffe sind jedenfalls sehr viel flüssiger als z. B. in der Literaturwissenschaft. Es scheint mir deshalb nützlich zu sein, die hier unterstellte Bedeutung der wichtigsten Termini beim er sten Auftauchen in einer Fußnote festzuhalten. Im Zuge der methodischen Anntherung der Linguistik an die naturwissenschaftliche For schung sind eine Füle mathematischer Begriffe eingeflossen, die noch verankert werden müssen. Soweit sie Bestand des philologischen Wortschatzes geworden sind, haben sie oft an Prägnanz ver loren, weil sie meist willkirlich - soweit das jeweilige mathematische Verständnis aktualisiert wird - aus einem Begr iff sapparat gelöst und zudem in einer 'unexakten' Wissenschaft eingesetzt werden. Wenn ich in dieser Arbeit entsprechende Termini verwende, dann möglichst im mathematischen Sinne und nicht in irgendeiner 'ubertragenen' Bedeutung und unter weitgehender Einbeziehung des Bedeutungsfelds: Wo Funktionen sind, da kann 'abgeleitet' und 'integriert' werden, da gibt es 'Grenzwerte', 'Lücken' und 'Sprünge'; 'gerichtete Größen' ermöglichen die Ermittlung und Darstellung von 'Resultanten' usw.. Ähnliches gilt für physikalische Begriffe wie 'spezifisch', 'Affinität', 'Pol' u. ă.

Dieser Arbeit liegt die 1959 abgeschlossene dreizehnbändige Akademieausgabe der Werke und Briefe Belinskijs zugrunde. Ich habe daraus sämtliche Sătze mit 'um' und 'razum' exzerpiert; unberücksichtigt blieb der 13. Band, der die Artikel enthalt, die Belinskij nicht mit letzter Sicherheit zugeschrieben werden können.

Selbstverstăndlich wird diese Unter suchung nur mit einer Auswahl des Materials belegt. Um einer seits die Umgebung, in der die beiden Worter stehen, mitzuteilen, andererseits aber den Text nicht mit umfänglichen Zitaten zu überladen, habe ich mich entschlossen, den Zusammenhang in indirekter Rede wiederzugeben und nur den wesentlichen Kern wörtlich und in russischer Sprache - transliteriert nach dem üblichen 
Verfahren - zu zitieren.

Zitate aus der genannten Belinskjj-Ausgabe werden unmittelbar mit eingeklammerter römischer Band- und arabischer Seitenzahl gekennzeichnet. Auszüge aus der Sekundärliteratur sind in den Anmerkungen mit Verfassernamen und Kurztitel belegt.

\subsection{Literatur}

Es ist kaum möglich, die gesamte Literatur im Einzugsbereich dieser Arbeit auch nur zu nennen, geschweige denn zu besprechen. Ich möchte hier nur kurz das Maßgebliche notieren und Akzente im Literaturverzeichnis setzen:

$\mathrm{Da}$ ich nicht die Absicht habe, einen wesentlichen Beitrag zur Belinskij-For schung zu leisten - dazu ist die Basis zu schmal - kann ich mich auf einige wenige neuere Arbeiten über ihn beschränken. Eine vor zügliche Studie bietet Scheibert in seiner Geschichte der russischen revolutionären Ideologien: Von Bakunin zu Lenin. Bowman legt in seiner Belinskij-Monographie den Akzent auf das sozialkritische Moment in seinem Werk. Zum weltanschaulichen Werdegang Belinskijs und seinem Verhăltnis zu den zeitgenössischen philosophischen Strömungen waren die (schon älteren) Arbeiten Jakovenkos und Tschizewskijs zum russischen Hegelianismus und Setschkareffs zum Einfluß Schellings recht ergiebig. Die Flut der Veröffentlichungen in der Sowjetunion und in den sozialistischen Ländern, besonders nach dem 100. Todesjahr 1948, ist meistens durch das Bestreben gekennzeichnet, Belinskij für die Ideologiegeschichte zu gewinnen und das, was nicht in das Bild des großen Vorläuf ers, in den zwangsläufigen Werdegang eines positiven Helden paßt, zu eliminieren. Diese Literatur war für meine $\mathrm{Zwecke}$ ungeeignet. Fragen der Literaturtheorie sind bei René Wellek und sehr ausführlich auch in Küppers' Dissertation zur 'Theorie des Typischen in der Literatur' beleuchtet worden. Belinskijs schwankende Beziehung zur Religion hat Bernhard Schultze ausführlich beschrieben, überschătzt dabei aber weit den Stellenwert dieser Fragen.

Das einzige deutsch-russische Worterbuch in Belinskijs Bibliothek ${ }^{5}$ 
war das auf Adelung basier ende "Vollständige Deutsch-Russische Lexicon ..". Den von Belinskij benutzten "Slovar' Akademii Rossijskoj" (1806ff.) konnte ich leider nicht einsehen. Als Studie zum Sprachgebrauch in der ersten Hanfte des 19. Jahrhunderts kann der "Slovar' jazyka Puskina" angesehen werden. Zur Wortgeschichte waren vor allem Miklosichs und Sreznevskijs Worterbïcher nützlich. Die Etymologie von 'um' und 'razum' ist an keiner Stelle befriedigend gründlich entwickelt worden, am besten noch von Vasmer, aber auch hier vermisse ich einen Hinweis auf die Beziehung zwischen den beiden Wortern. Das "Indogermanische etymologische Worterbuch" Pokornys ist von bestechender Ubersichtlichkeit, beinahe verdăchtiger Gradlinigkeit. Die lexikalischen Bedeutungen von 'um' und 'razum' nach 1850 habe ich in den Worterbiichern von Dal'; Ušakov und im "Slovar' sovremennogo russkogo literaturnogo jazyka", sowie in den zweisprachigen Worterbiichern Pawlowskys, Lepings und Bielfeldts verfolgt.

In den übrigen Slavinen bin ich den Ter mini * um und "raz(roz-)um in den jeweils maßgeblichen Lexika nachgegangen. $\mathrm{Zu}$ den deutschen Wor tern um Vernunft und Verstand habe ich außer dem Grimm schen Worterbuch vor allem Dornseiff benutzt.

Die Auseinandersetzung mit der sprachwissenschaftlichen Literatur ist ein Gegenstand des 2. Kapitels. Hier nur soviel:

Bei dem von mir eingeschlagenen Weg lag eine Orientierung an der Literatur zu syntaktischen Fragen und zur Sprachtheorie nahe. Koschmieders "Beitrăge zur Allgemeinen Syntax" und Franz Schmidts "Logik der Syntax" waren für den theoretischen Teil dieser Arbeit anregend. Die Dissertation des Koschmieder-Schülers Wolf Thümmel ist nicht nur methodisch bemerkenswert; sie bietet auch eine hervorragende Auseinander setzung mit den sprachwissenschaftlichen For schungsrichtungen.

Hăufig greife ich auf Cassirers grundlegende "Philosophie der symbolischen Formen" und die in manchen Punkten anschließenden Arbeiten Peter Hartmanns ("Theorie der Sprachwissenschaft" und "Das Wort als Name") zurück.

Von den Standardwerken der Semasiologie hebe ich Ullmanns 
"Grundzüge der Semantik" hervor. Im Unter schied zu Kronassers

"Handbuch der Semasiologie" wird der synchronischen Betrachtensweise der gehörige Platz eingerăumt. 
(1) $0^{2}$

$4-$

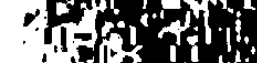

(if tof

(1010

s.t.

$1+10$ m.

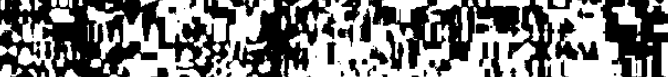

(2)

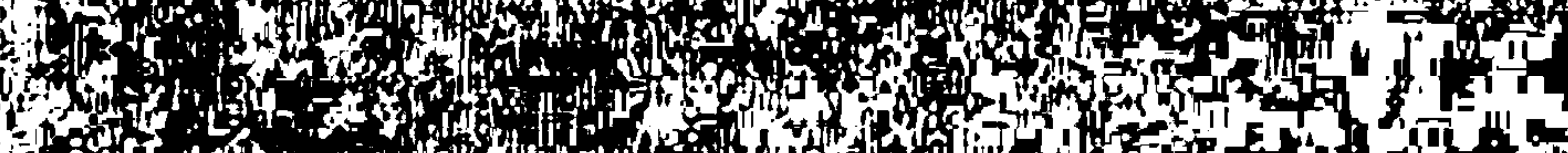
now

Q.n. (4)

3 for $x^{2}$

in 10

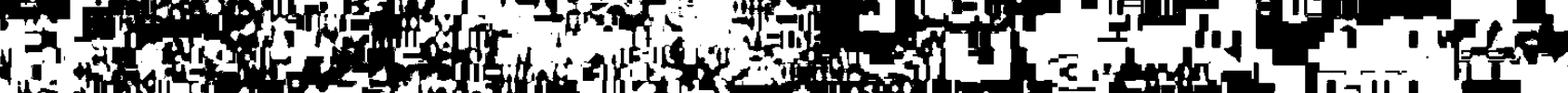

Fon

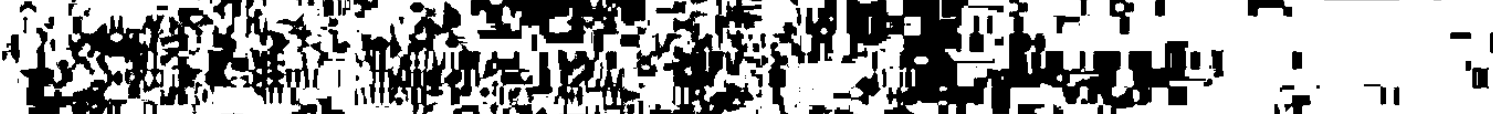

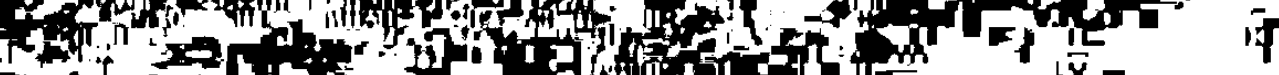

1ii (1)

$=6 \mathrm{c}$

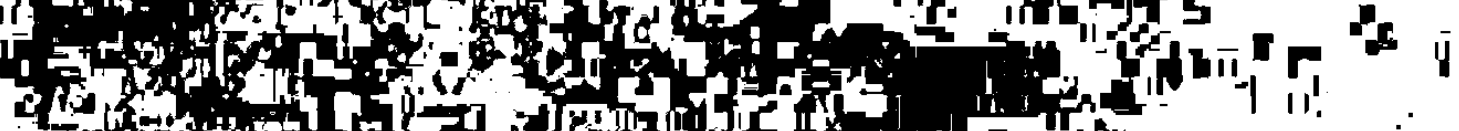

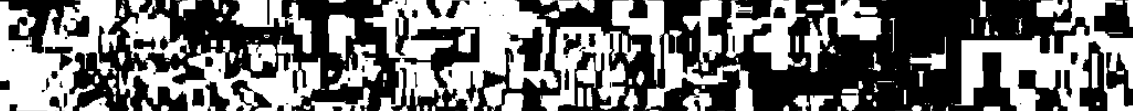

A

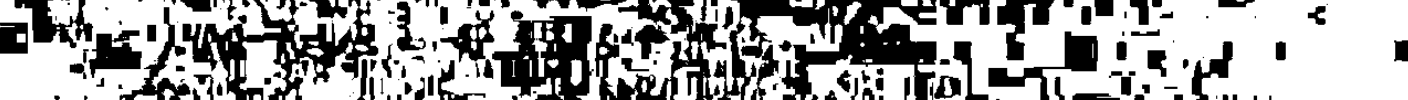

and

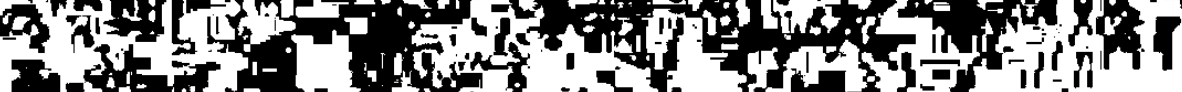

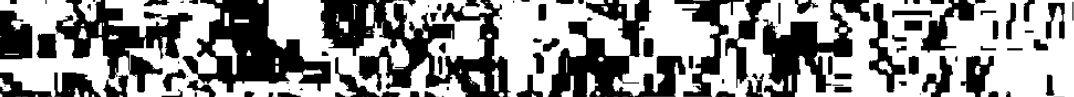

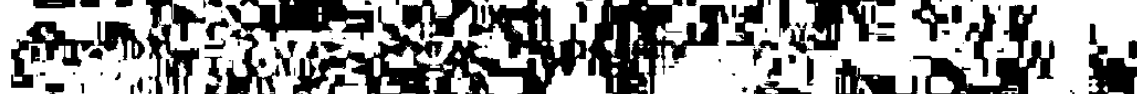

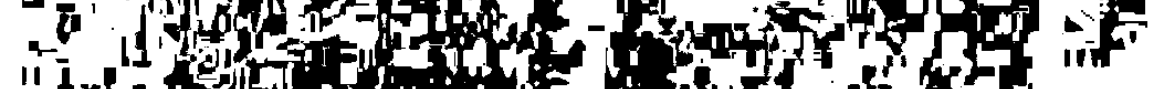

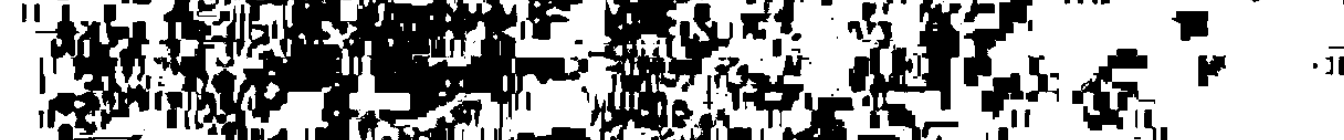

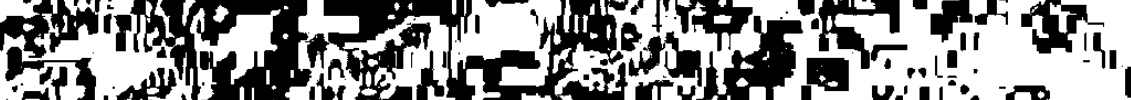

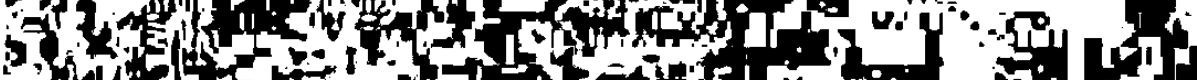

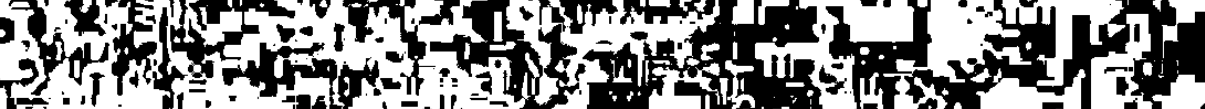

41 on

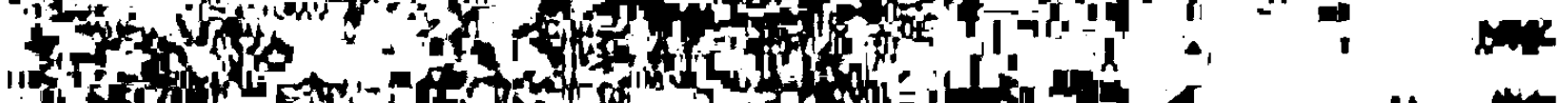

- isto

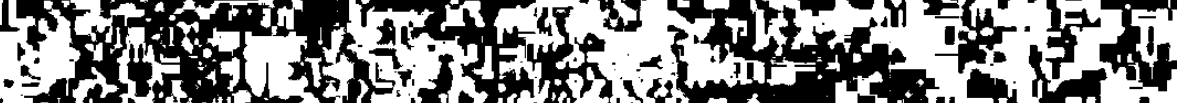

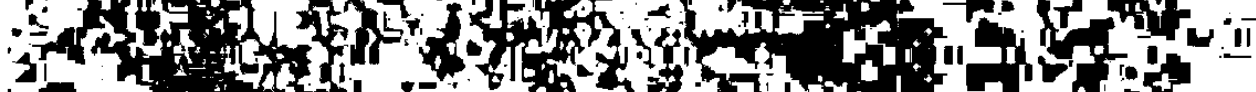

a

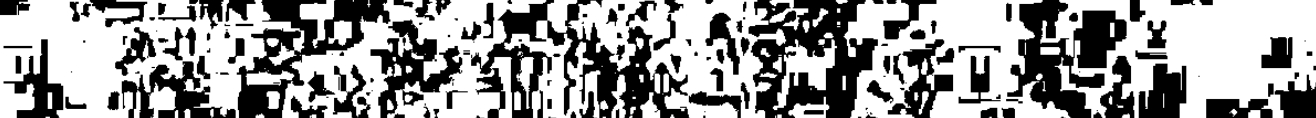

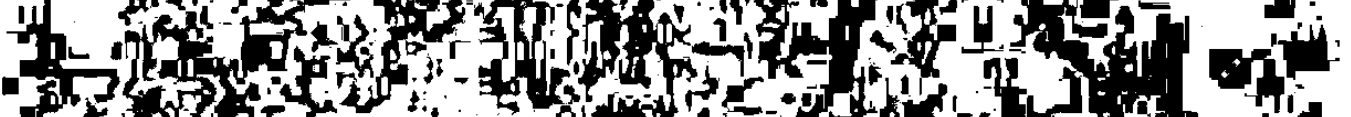

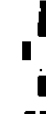

Mingtit

1.tenting 


\section{Kapitel}

Vorbelastung der Worter 'um' und 'razum' durch die Sprachgemeinschaft (das Lexikon) und den einzelnen Sprecher (Belinskij).

Der Stellenwert, den die Vorbelastungen der Worter durch Sprachgemeinschaft und Sprecher in der Reihe der Komponenten haben, die zur Bedeutungsspezifizierung im aktuellen Redegebilde zusammenwirken, kann nur grob geschätzt werden. Versteht man aktuelle Bedeutung als Einkreisung des Wortes durch Kontexte (Satz, Auf satz, 'Ansatz'), dann gehorren diese Voreingenommenheiten zur weiter en Umgebung, zum äußersten Ring, der in der Rede um ein Wort gelegt ist.

\subsection{Die Bedeutungen von 'um' und 'razum'}

Dieser Abschnitt ist notgedrungen flüchtig: Die Geschichte der Bedeutungen von 'um' und 'razum' ist die Geschichte der entsprechenden Begriffe; sie kann nicht auf wenigen Seiten geschrieben werden. Die Kräfte, die auf die Begriffe gewirkt haben, sind - wenn überhaupt - nur auf Grund eingehender For schungen zu erfassen; über die Tiefe der jeweiligen Prăgung wird man sich kaum einigen können. Daß diese Begr iffe auf dem Boden eher regressiver Orthodoxie anders wachsen als auf dem Feld im ganzen progressiver Philosophie, daß sie in einer ausgeprägten Ver standeskultur besser gedeihen als in einer mehr emotional bestimmten Atmosphäre, im Rahmen einer praktischen Vernunft anders aussehen als eingespannt in einen philosophischen Maximalismus, liegt auf der Hand, das auszuwiegen, ist eine Arbeit für sich.

Es war nicht anders möglich, als sich in diesem Abschnitt auf Material aus zweiter Hand, nämlich auf Worterbücher zu stützen. Der Ertrag ist mäßig, denn in einsprachigen Wörterbüchern geschieht die Erklärung der Wortbedeutung in Wortern des gleichen Bedeutungsfeldes, das im gleichen Klima gewachsen ist. Aber selbst wenn in zweisprachigen Lexika ein russischer Lexikograph hinter 'um' 'Verstand', 'ratio', 'raison' oder 'reason', ein deutscher Verfasser hinter 'Verstand' 'um' schreibt, ist damit noch nicht gesagt, daß sie auch die entsprechenden Begriffe meinen. Wahrscheinlicher ist, da $\beta$ in die fremdsprachigen Ausdrücke das Ver stăndnis der scheinbaren eigensprachigen Entspr echung getragen 
wird. Allerdings kőnnen diese Fehlerquellen durch Heranziehung möglichst vieler Lexika zum Teil umgangen ẉerden.

Vorlăufig halte ich fest, daß ein Russe, selbst wenn er meint, sich auf den gleichen Denkbahnen wie sein deutscher oder franzosischer Zeitgenosse zu bewegen, in Wörtern und Begriffen denkt, in Wörter und Begriffe über setzt, die ander 8 geprägt sind. Anhand von Belinskijs Sprachgebrauch werde ich dieses Anderssein genauer beschreiben konnen.

1.11

Etymologie und Vorgeschichte der Wurzel ${ }^{x}$ um weisen eine - in vielen Sprachen anzutr effende - Bedeutungsübertragung von der sinnlichen Wahrnehmung auf geistiges Erkennen und Bewußtwerden nach.

Die Ableitung aus idg. ${ }^{x} a u-m o s{ }^{6}$ ist überzeugend; ${ }^{x} a u-1$ ist in der Grundbedeutung in slav. "avé-, z.B. in russ. 'jav-it" etc. überliefert " Der Prozeß der Bedeutungsausweitung muß schon sehr früh abgeschlossen gewesen sein: Für das Baltische ist dem Wort 'um' sinnăhnliches, urver wandtes ${ }^{*}$ aumas $>1$ it. 'umas ${ }^{\circ}$ belegt ${ }^{8}$.

Ein kurzer Vergleich des Altkirchenslavischen, das ich hier als gem einslavische Basis ansetze, mit den einzelnen slavischen Sprachen zu verschiedenen Zeiten macht die dauerhafte Bindung $z w i s c h e n$ den Wör tern Mum und "raz(roz-)um und ihren Sinnbezirken deutlich, deren Binnenund Außengrenzen jedoch fließend sind" 9 .

UM

Altkirchenslavisch (Miklosich)

animus

ratio

Verstand

RAZUM

mens suffragium ratio sensus

Russisch (2. H.19.Jh.) (Dal') intellectus

Vernunft

Holub: 'umêti $\ldots$ k ide. ${ }^{x}$ au-mos ... schopnost vnimati

Vasmer REW: “um; “javit".

Berneker SEW: 'ave

8 Fraenkel LEW: 'aumas'

9 Soweit in den einsprachigen Lexika die deutschen oder lateinischen Entsprechungen verzeichnet sind, habe ich nur diese angefuhrt. 
UM

Polnisch (2. H. 19.Jh.)

(Linde)

Cechisch (heute)

(SI. spis. jaz. C. )

Sorbisch (2.H.19.Jh.)

(Pruhl)

Bulgarisch (heute)

(Rečnik 1959)

Serbokroatisch (heute) (Ristic)
Vernunft

(veraltet)

Verstand

Verstand (wum)

Vernunft

(veraltet)

Verstand

(sposobnost na

Coveka da misli)

Vernunft

Verstand
RAZUM

Vernunft (rozum)

Verstand

Ver stand (rozum)

Ver nunft

Ver stand (rozom, ns.)

Vernunft (rozum, os.)

Vernunft

(visša poznavatelna

dejnost)

Verstand

Vernunft

\subsection{2}

Eine absolute Chronologie der Bedeutungsverengungen und -erweiterungen ist kaum möglich, da der Umfang der Bedeutung direkt abhängig ist vom Umfang des Gesichtskreises der Sprechenden. Mit einer starken Phasenverschiebung muß gerechnet werden.

Im Russischen war der qualitative Unter schied zwischen 'um' und 'razum' lange Zeit kaum bewußt, und auch heute wird im naiven Sprachgebrauch hăufig nicht unterschieden. 'um' hatte die weitere Bedeutung ${ }^{10}$ : in das Gesamt der Geisteskräfte waren die der Seele, des Gefühls und Gemults, auch die des Instinkts (des 'tierischen Verstandes') einbegr iffen. Ein Rest von 'Sinnlichkeit' schwang mit. Was 'um' unter anderem bedeutete, war durch die Vor silbe raz- im Wort 'razum' ausgegrenzt: das Denk- und Erkenntnisvermögen. Wann diese Differenzierung in den slavischen Sprachen erfolgte, kann man schwerlich ermitteln. In den frühesten überlieferten Texten sind beide Wörter anzutreffen. Die Bedeutungspole liegen so dicht beieinander, daß man von einer fast konzentrischen Einbettung des 'razum'-Bedeutungsfeldes in den 'um'-Ber eich sprechen kann. Vergleicht man ein Wörterbuch des Altrussischen mit einem zur Gegenwartssprache, ist man zunăchst geneigt, von einer $\mathrm{Be}-$ deutungsverdichtung zu sprechen: so hat z.B. 'um' das Moment des Seelisch-Gefühl smäßigen abgestoßen. Aber dieser (relativen) Konzen- 
trierung wirkt die wesentlich stärkere (absolute) Ausweitung infolge der geistigen Durchdringung des betr effenden Denkraums entgegen.

Mit zunehmender Differenzierung des Denkens verschieben sich die Bedeutungspole der Worter 'um' und 'razum' gegeneinander. In dem Maße, wie die Weitung des Blickwinkels das Bedeutungsspektrum spreizt, wächst der Abstand zwischen den Wörtern, zeitweise so sehr, daß deren Sinnkerne zu Gegensătzen auseinanderklaffen und sich andere Worter abgeleitete, komponierte und bedeutungsverwandte - dazwischenschieben können. Zwischen 'um' und 'razum' zeichnet sich ein Rangunterschied zwischen niederem und höherem Erkenntnisvermögen ab.

'um' ist im 19. Jahrhundert als philosophischer Terminus nur noch bedingt anwendbar: die Bedeutungsweite ist in der aktuellen Rede nur schwer einzudämmen; spezifische Merkmale fehlen. Weil man 'um' überall verwenden kann, wo von der geistigen Ausstattung des Menschen die Rede ist, besagt es für sich genommen nicht mehr viel, d.h. 'um' ist stărker auf die Absicherung durch die sprachliche Umgebung angewiesen als 'razum', braucht zur Erlangung begrifflicher Prăgnanz kräftige attributive Stützen.

Bemerkenswert ist, daß 'razum' nicht - wie in der Bedeutungsentwicklung ähnlich zugeordneter Worter oft zu beobachten ist ${ }^{11}$ - in den Sog des zerfließenden 'um' geriet und dessen Position einnahm, sondern daß ein verhălnismăßig junges Wort 'rassudok' nachrückte ${ }^{12}$. Das steigernde Präfix 'raz-' scheint 'razum' durch die Assoziation des Besonderen, Un-gemeinen stabilisiert und vom 'gemeinen' 'um' entrückt zu haben. Der Begriff 'razum' lag im 19. Jahrhundert - sicher auch als Folge des einfließenden deutschen Idealismus - nicht mehr im Einzugsbereich von 'um'.

Zum sogenannten 'Synonymenschub' $\nabla$ gl. Kronasser, S. $136 f$.

Vgl. hierzu S.29 . Geistig vergleichsweise wenig beanspruchte Sprachen, wie z. B. das Sorbische, kennen 'razsud-' nur im ur sprünglichen Bereich von 'urtell -' etc. Dagegen ist z. B. im Polnischen (mit einer langen abendländischen Tradition) 'rozsqdek' in der Bedeutung 'Verstand' fest verankert und hat 'um' vollig verdrängt. Vgl. Mrongovius, der 'um' bereits 1835 als veraltet anfuhrt. 
Die schon für das Slavische allgemein festgestellte stabile Bindung zwischen *um, x raz(roz-) fum und dem mit ihnen Gemeinten wird durch einen Vergleich der Wrrterbücher aus verschiedenen Epochen und zu den verschiedenen Stationen der russischen Wortgeschichte im großen und ganzen bestătigt. Einige Einschränkungen sind nötig: Ob ein Wort eine Bedeutung trăgt oder nur tragen kann, ist ein Unterschied, den Lexika nur ungenügend darlegen kסnnen. Das, was ein Wort in erster Linie bedeutet, ist nicht frei von dem, was es in zweiter Linie und in erstarrten Wendungen meint. Das Aufzeigen der Grundfunktion eines Wortes sagt noch nichts über die möglichen Ableitungen, ubber die Flexibilităt.

Wenn in altrussischer Zeit unter 'razum' die Fähigkeit zu denken und zu erkennen verstanden wurde, dann ist das sicher auch heute noch richtig. Voreilig wăre der Schluß, daß die Bedeutung unverăndert geblieben ist; mit einer Parallelverschiebung des Bedeutungsfeldes, das die Wrrter "myslit" und 'poznavat" ebenfalls umgreift, muß gerechnet werden. Aber diese 'Metamor phose' eines Sinnbezirks wird man kaum als Bedeutungswandel jedes beteiligten Wortes bezeichnen können.

Obgleich ' um' $^{\prime}$ und 'razum' - vor allem in den letzten $200 \mathrm{Jahren}$ zentrale Begriffe unterschiedlicher Denkprozesse waren, ist das den verschiedenen weltanschaulichen Systemen eigene Ver ständnis der Funktionen nur im Verband absichernder Beiwörter zu übermitteln. Selbst bahnbrechende Gedanken - ich denke an den Einbruch des deutschen Idealismus oder des Marxismus - haben offensichtlich die lexikalischen Positionen nur unwesentlich verschoben und den (relativen) Stellenwert im Begr iff sf eld des Geistig-Seelischen kaum angetastet.

\subsection{2 .1}

An der folgenden auszugsweisen Gegenüberstellung einiger Lexikonartikel kann nur die relative begr iffliche Konzentration deutlich gemacht werden, nicht aber die gegenlăufige absolute Expansion.

Am Anfang des 19. Jahrhunderts sind die Bereiche 'duša' und 'razum' abgetrennt; 'um' wird als die Sphäre der Erkenntnis der objektiven Wirklichkeit, der logischen Schluffolgerungen verstanden. 'um' ist "die eine Seite des Geistes", und zwar die "niedrigste Stufe'der Er- 
kenntnis $^{13}$. In der Bedeutung 'ein Mensch, der sich durch seine geistigen Făhigkeiten auszeichnet hat sich die alte, weitere Bedeutung erhalten.

UM

SREZNEVSKL (vorpetrinisch)

duša, sovokupnost ${ }^{\circ}$ duchovnych sil

sposobnost myslit ${ }^{\circ} i$ poznavat', razum

mysl'

razumenie

ponimanie

znanie

umenie

rassudok

obraz myslej

promysel

pricina

osnovanie
SL. JAZ. PUŚKINA DAL

(1. H.19.Jh.)

(2. H.19.Jh.) (Gegenwart)

myslitel'naja sposobnost ${ }^{\prime} \mathrm{c}-\mathrm{a}$

soznanie rassudok

celovek, charakter izuemyj ego umstvenny mi, intell ektual 'ny mi sposobnostjami zvanie pozna- myslit', sposobnosti stavlenijach, c-a, sposobnost' suzdenijach; myslit'

smy sl

razum

(vo 2-m zn.) obscee na- sposobnost' $\varepsilon-a$ vatel'noj i otrazat' dejstvizakljucitel'noj tel'nost' $\nabla$ predrassudok

soznanie my slitel'naja dejatel'nost' normal'noe, zdorovoe sostojanie soznanija, rassudka, psichiceskoj dejatel'nosti

celovek, charakterizuemyj po ego umstvenny $m$ sposobnostjam

Russisch-deutsche Wrrterbiicher:

UM

HEYM

(ca. 1800)

Vernunft

Ver stand

raison

l'entendement, espr it
PAVLOVSKL

(ca. 1900)

Verstand

Vernunft

(nur noch selten)
BIELFELDT

(Gegenwart)

Verstand

Geist

Denkf ăhigkeit

Heym ordnet 'um' und 'razum' ein und demselben Sinnbezirk zu; kaum verwunderlich bel einem Franzosen des ausgehenden 18. Jahrhunderts. Bielfeldt trifft genau die drei wichtigsten Über setzungswörter. 
Deutsch-russische Wrrterbücher

VERSTAND

VOLLST.D. -R. LEXICON

(ca. 1800)

um

razum

smysl

ponjatie

tolk
PAWLOWSKY

(ca. 1900)

um

rassudok

smy sl

tolk
LEPDNG

(Gegenwart)

um

rassudok

smysl

tolk

Am "Vollständigen Deutsch-Russischen Lexicon" wird deutlich, daß 'rassudok' erst im 19. Jahrhundert als Ubersetzungswort für 'Verstand' gebräuchlicher wurde. Im 20. Jahrhundert ist 'rassudok' fast durchweg zweite Entsprechung. Der hăufige Zusatz des Adjektivs 'zdravyj' weist auf die Nahe zur Vernunft hin und ist wohl als Absetzung vom 'blutlosen' 'um', vom kalten Intellekt zu verstehen. Auf 'um' scheint sich das negative Begleitgefühl des trockenen Rationalismus, auch das der kleinlichen Klügelei zu legen. An den Ableitungen wird das noch stärker spürbar.

\subsection{2 .2}

Die Herabsetzung des Wortes und Begriffes 'um' geht mit einer Herauf setzung von 'razum' Hand in Hand. Als Bezeichnung des besonderen Vermögens, übergr eif ende Zusammenhänge zu begreifen und zu bewerten, wird es da mehr und mehr vermieden, wo 'nur' von kausalen Beziehungen die Rede ist.

RAZUM

\section{SREZNEVSKLJ SL.JAZ. PUŚKKNA DAL'}

sposobnost ${ }^{\circ}$ poznavat $^{\circ}$ i myslit ${ }^{\circ}$

um

rassuditel 'nost'

razumenie

ponimanie

poznanie sposobnost ${ }^{\prime} c-a$ poznavat', myslit";

um intellekt rassudok, sposobnost ${ }^{\circ}$ rassuzdat', rassuditel 'nost' duchovnaja

sila, mogušcaja pomnit (postigat', poznavat'), sudit' (soobrazat', primenjat', sravnivat ${ }^{\circ}$ )
SL. AN SSSR

vyssaja stupen' poznavatel'noj dejatel'nosti $\mathbf{c}-\mathbf{a}$, sposobnost' logiceski myslit', osmy slat okružajusccuju dejstritel'nost' 
SREZN EVSKXJ

znanie

my $\mathrm{gl}^{\circ}$

obraz myslej

soglasie

socuv stvie

obsuzdenie

rassmotrenie

ob-jasnenie

opr edel enie

smy 81

znacenie

soderzanie

DA'

SL. AN SSSR

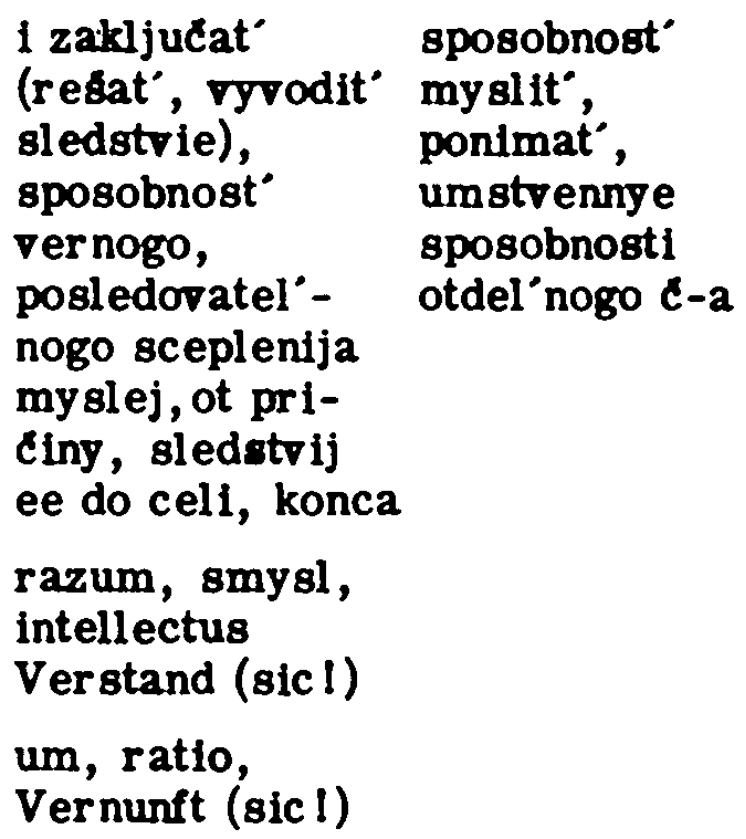

Russisch-deutsche Wörterbücher:

RAZUM

HEYM

Vernunft

la raison

le bon sens

Ver stand

1 'entendement

1 'intelligence

l'espr it
PAVLOVSKUJ

Ver stand

Bedeutung

Sinn
BIELFELDT

Verstand

Vernunft

Deutsch-russische Worterbilcher :

VERNUNFT

VOLLST.D. -R. LEXICON

razum

um

rassudok
PAWLOWSKY

razum

(gesund) rassudok
LEPING

razum

zdravyj rassudok

In den zweisprachigen Worterbüchern sind Widersprüche: Pavlovskij setzt im deutsch-russischen Teil 'Vernunft' als 'die Făhigkeit zu denken und zu urtellen, als das Vermögen, das Übersinnliche zu erkennen, als das sittlich-geistige Vermögen' deutlich von 'Verstand' ab 
und übersetzt korrekt mit razum, rassudok'. Unter dem Stichwort 'razum' führt er im russisch-deutschen Teil nur 'Verstand, Bedeutung, Sinn' an.

Die Reihenfolge der Ubersetzungswörter Bielfeldts ist ungewöhnlich. Das Wort, das für Bielfeldt in erster Linie 'Vernunft' bedeutet, ist 'rassudok'. Nach meinen Ermittlungen steht Bielfeldt mit dieser Akzentsetzung allein.

Es empfiehlt sich, kurz auf das Stichwort 'rassudok' einzugehen. An den Worterbuchern ist dessen rasches Vordringen ins Zentrum des Sinnbezirkes um 'um' und 'razum' ablesbar. Bei Sreznevskij fehit es, Puskin verwandte den Ausdruck im Sinne der angewandten 'Urteil skraft' als "sposobnost' zdravo, trezvo myslit', smotret' na vesci, byt' rassuźditel'nym; voobsce sposobnost' myslit', rassuzdat', ponimat'; zdravyj smysl" ${ }^{14}$; er verstand sie offensichtlich als einen Teil der Vernunft. (In den vom deutschen Idealismus beeinflußten Kreisen Rußlands das darf ich hier vorwegnehmen - wurde das Gegensatzpaar Vernunft : Ver stand fast durchweg mit razum : rassudok wiedergegeben.) Dal' legt den Akzent noch auf 'Urteil' ("rassużdenie, sposobnost' pravil'no rassuzdat', postigat', soobrazat'; zdravyj um lli smysl") ${ }^{15}$.

Pavlovskij betont das 'Gesunde': "gesunder Verstand, gesundes Urteil, Überlegungskraft". Das der Vernunft eigene Werten schwingt hier und da mit. Im "Slovar' sovr emennogo russkogo literaturnogo jazyka" steht an erster Stelle: "sposobnost' logiceski myslit", rassuzdat"; razum". Bielfeldt führt als Hauptbedeutung 'Vernunft', dann 'Verstand', 'gesunder Menschenverstand' an.

Aus den Angaben des Akademie-Worterbuchs und Bielfeldts könnte man schließen, daß 'rassudok' in der Gegenwart die Position von 'razum' im Sinne der höchsten geistigen F'ahigkeit des Menschen eingenommen habe. Den Beweis kann ich hier nicht erbringen, gebe aber das weltanschaulich bedingte Ver stăndnis derartiger Termini zu bedenken. Die Uberzeugung, da $\beta$ alle Phänomene rational erklärbar sind, wird sich eine andere Bezeichnung für das höchste Erkenntnisvermögen suchen als das - vor allem im Idealismus -

Slovar' jazyka Puskina: 'rassudok'

Dal': 'rassudok' 
sehr stark mit Bezligen zum Ober sinnlichen ausgestattete Wort 'razum'. So lst ja z. B. auch das Wort 'Urtell skraft' zwar veitgehend Synonym zu 'Vernunft', abor sachlicher, mehr terminus technicus. Unter diesem Gesichtspunkt sind Vorbehalte gegeniber all den Worterbüchern angebracht, die im Rahmen einer doktr inăren Ideologie, d.h. hier: in sozlalistischen Låndern entstanden sind, weil hier aft 'Sprachregelung' betrieben wird und sich die Herausgeber hăufig nicht damit begnügen, den tatsächlichen $\mathrm{Ge}$ brauch aufzuzeigen, sondern durch entsprechende Auswahl des Materials einen irgendwie 'fortschrittlichen' propagieren.

\subsection{3}

Die Ableitungen aus der Wurzel *um sind zahlreich; ich habe etwa 250 gefunden, davon rund 70 Verbindungen mit xazum- ${ }^{16}$. Hinzugezthlt werden musten die erstarrten phraseologischen Wendungen, die, wenn auch mehrteilig, die Funktion eines Einzelwortes haben ${ }^{17}$. Ich hielt es für entbehrlich, hier alle Ableitungen anzufuhren und beschrănke mich auf die bei Bielfeldt verzeichneten. Da ich fast alle von Bielfeldt erwathnten, dagegen kaum eines der dort nicht genannten bei Belinskij gefunden habe, scheint mir diese Beschränkung ger echtfertigt zu sein.

Die Kurzlebigkeit vieler Ableitungen ist wohl damit zu erklăren, da $\beta$ die deutlichere Bedeutungsnuancierung des aktuellen Redegebildes die winzigen Graduierungen durch Prafigierung, Sufigierung und Komposition uberlagert.

\section{${ }^{\star}$ UM}

$\begin{array}{ll}\text { bezumec } & - \\ \text { bezumie } & - \\ \text { bezumnyj } & - \\ \text { bezumstro } & - \\ \text { bezumstrorat' } & - \text { wahnsinn- } \\ \text { vysokoumnyj } & - \\ \text { zaumnyj } & - \text { klugeln- } \\ \text { izumitel'nyj } & - \\ \text { izumit'(sja) } & - \\ \text { izumlenie } & - \text { außerordentlich }\end{array}$

16 Die Wrrter wurden vor allem im "Russischen rücklaufigen Wరr terbuch" ermittelt, das den Wortschatz der Lexika Dal's und Usakovs verzeichnet.

O.S. Achmanora spricht folgerichtig von 'potentiellen Wortern' (S. 571). 


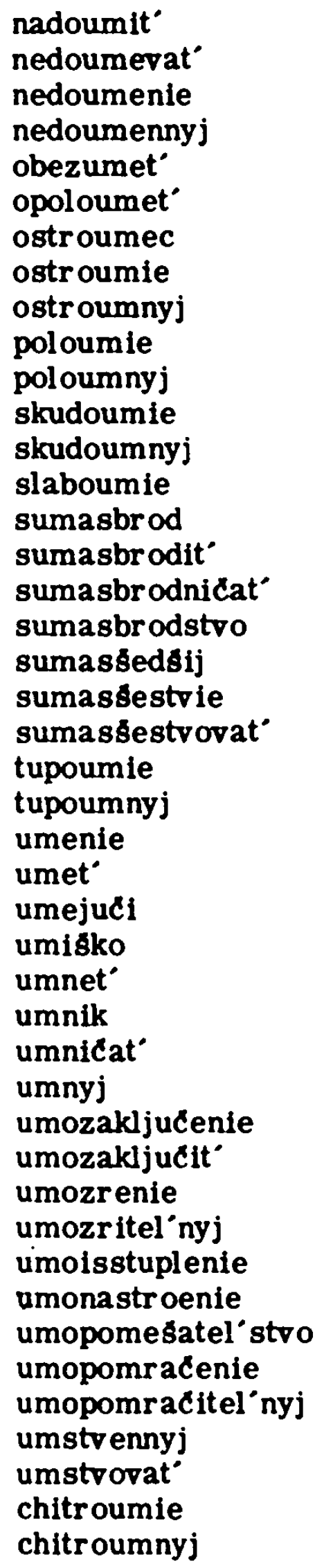

- auf einen Gedanken bringen

$-$

$-$

- verlegen-, zwetfel-

- gleichsam den Verstand verlieren

$-$

- scharfsinn-, witz-

$-$

- schwachsinn-, halbgescheit

$-$

- geistig arm

-

$-$

- unuberlegt

$-$

- geistig wegtreten

-

- stumpf sinnig

-

- können

- 'kl eines Licht'

- klüger werden

- 'neunmalklug'

- gescheit

-

- schluffolgern

- spekulativ

- außerste Erregung

- Geistesr ichtung

- Geistesgestörtheit

- Umnachtung

$-$

- geistig, Geistes-

- höchst abstrakt

- spitzfindig

Ableitungen gestatten oft Rückschlüsse auf die Wertschătzung des mit dem Grundwort Bezeichneten:

$\mathrm{Da} \beta$ ein Mensch über 'um', über das Vermögen zu denken und zu 
erkennen verfügt, bedarf keiner Erwâhnung. Wenn 'um' oder 'umnyj' attributiv verwendet werden, wird damit nicht diese Selbstver ständlichkeit bezeichnet, sondern schon ein besonderes MaB an 'um': dieser Mensch ist gescheit, diese Handlung ist klug, dieses Werk mit Verstand ausgefuhrt worden. Der Mensch hat ein 'normales' Quantum 'um'; wortreich ist das Abweichen vom Durchschnitt bezeichnet:

'bez-' nennt das zeitweise oder dauernde völlige Fehlen. Ein Mensch, der den Verstand verliert: 'obezumet", ist ein 'bezumec', ein 'bezumnyj celovek', seine Eigenschaft: 'bezumie', sein Tun: 'bezumstro/bezumstvovat". Plastischer sind die Vor stellungen, die hinter den weitgehend gleichbedeutenden, aber mehr auf einzelne Handlungen bezogenen Wörtern 'sumasbrod-', 'sumassed-' etc. stehen.

Aber der Ver standesausfall muß nicht total sein: ein Mensch kann 'die Hăfte seines Verstandes verlieren': 'opoloumet", kann 'poloumnyj" werden, kann 'geistig verarmt': 'skudoumnyj', 'ein kleiner Geist': 'umisko', 'schwachen Ver standes': 'slaboumnyj' oder 'nicht ganz' in dessen Besitz, also 'verlegen', 'unschlüssig', 'im Zweifel' sein: 'nedoumennyj'. Es gibt Ereignisse, die einen 'um den Verstand bringen': 'izumit", also in 'Bestürzung' und 'Erstaunen': 'izumlenie' oder gar in 'Verzückung' und 'Raserei' versetzen: 'umoisstuplenie'. Die Ausdrücke für 'Verwirrung' und 'Trübung' des Verstandes : 'umopomesatel'stro', 'umopomracenie' sind zahlreicher als die besonderer geistiger Klarheit. Dem 'Stumpfsinn': 'tupoumie' steht der 'Scharfsinn': 'ostroumie' gegenüber. Wenn das bloße Wort 'um' schon auszeichnet, laufen Steigerungen Gefahr, ins Ironische umzukippen. Ein Mensch kann zwar klüger werden: 'umnet", aber ein 'vysokoumnyj' oder 'zaumnyj' oder gar 'chitroumnyj" ist bereits über das Ziel hinausgeschossen, und die Worter "umstrovanie/umstrovat" sind nicht nur ein wenig gespreizte Wortbildungen, sondern auch dem Begleitgefuhl nach 'gekünstelt'. Ein 'um' ist ein 'kluger Kopf', ein 'umnik' nur noch ein 'Schlaukop'.

In den Plural 'umy' kann nur die Nebenbedeutung 'intelligenter Mensch, Kopf' gesetzt werden.

Jüngere Komposita sind die vornehmlich in der gehobenen Umgangs- und Gelehrtensprache entstandenen 'umozakljucenie/umoza- 
kljuçat", 'umozrenie/umozritel'nyj', 'umonastroenie' und umoprosvescenie' (Schluffolgerung, Spekulation, geistige Ausrichtung, Geistesbildung) ${ }^{18}$. 1.13 .2

Die Zahl der Ableitungen von 'um' ist etwa dreimal so groß wie die der von 'razum'. Exstarrte Wendungen gibt es kaum; Bielfeldt halt unter dem Stichwort 'razum' keine für erwăhnenswert. Fünfmal so hăufig sind die Ausdrücke, die das tellweise oder gänzliche Fehlen von 'um' bezeichnen. Das ist nicht verwunderlich: wo 'um' fehlt, fehlt erst recht 'razum', aber wenn 'razum' nicht vorhanden ist, kann es durchaus noch 'um' geben. 'razum' bezeichnet die 'hervorragenden' Merkmale von 'um'. Ist der qualitative Unter schied nicht bewust, wird 'razum' als Aufgipfelung empfunden; im reflektierten Gebrauch sind 'um' und 'razum' Begriffe ver schiedener Ebenen, die in einem eher korrespondier enden als unmittelbar en Verhălnis zueinander liegen.

\author{
${ }^{\circledR}$ RAZUM \\ blagorazumie \\ blagorazumnyj \\ vrazumitel'nost' \\ vrazumitel'nyj \\ vrazumit' \\ vrazumlenie \\ neblagorazumnyj \\ nevrazumitel'nyj \\ nedorazumenie \\ nerazumie \\ nerazumnost' \\ nerazumnyj \\ obrazumit \\ podrazumevat' \\ razumenie \\ razumet ${ }^{\circ}$ \\ razumnik \\ razumnost ${ }^{\prime}$ \\ razumnyj \\ urazumet $^{\circ}$
}

- Vernunft, Einsicht, Weisheit

- verständlich, ubberzeugend

-

$-$

- unklug

- unver stăndlich, unklar

- Mißver stăndnis

- Torheit

$-$

- jdn. zur Vernunft bringen

- verstehen, im Geiste vor sich haben

- Făhigkeit zu begreifen

- verstehen, meinen mit

- kluger Mensch (auch ironisch)

$-$

- vernunftbegabt

- begreifen, verstehen

Vgl. hierzu Hüttl-Worth: Die Bereicherung des russischen Wortschatzes im 18. Jh., Glossar, Stichwort "um-' pp. 
Wenn jemand eine 'Torheit' begeht, etwas 'Unvernüntiges' tut: 'nerazumie/nerazumnost'/nerazumnyj', dann schwingt unausgesprochen mit, daß dieser Mensch doch sonst 'ganz vernünftig' ist, daß er es hätte besser machen können, wenn er mit Vernunft an die Sache herangegangen wäre.

'blagorazumie' steigert 'razum' zu 'Einsicht', 'Uberlegenheit'; die Negierung 'neblagorazumnyj' ist die mildeste Bezeichnung eines 'nicht sehr klugen' Tuns.

Etwas 'überzeugend darlegen', 'jemanden überzeugen': 'vrazumlenie/vrazumit'/vrazumitel'nyj' ist die tiefer gehende 'Belehrung', die das Moment des Einsichtigmachens in die Notwendigkeit enthælt. 'razumet'/razumenie' ist das Verstehen mehr abstrakter Zusammenhänge; "umet" hat dagegen die (mehr praktische) Bedeutung 'sich auf etwas verstehen'. 'umnyj' bezeichnet das Gescheite, in sich Schlüssige; 'razumnyj/razumnost" schlieft die Bewertung mit ein.

\subsection{4}

In den phraseologischen Wendungen haben sich sehr hăufig Randbedeutungen verfestigt. Oft wird man mit dem vieldeutigen, aufgeweichten deutschen Wort 'Sinn' über setzen.

1. (Sinn)

byt' bez uma

$\checkmark$ ume li ty?

byt' $v$ ume

$\checkmark$ svoem ume

$\checkmark$ zdravom ume

chvatat'sja,

vzjat'sja za um

prijti na um

(der zat ${ }^{\prime}$ ) na ume

$\nabla$ ume net

iz uma von

bez uma delat ${ }^{\circ}$

sto golor, sto umov

cto na ume, to i na jazyke
- von Sinnen, hingerissen sein

- bist du bei Sinnen?

- bei Sinnen sein

- zur Besinnung kommen

- in den Sinn kommen

- im Sinn, im Kopf haben (behalten),

- bzw. nicht ...

- 'wie weggeblasen'

- etwas ohne Sinn und Verstand tun

- hundert Kopfe, hundert Sinne was er im Sinn hat, trägt er auch

- auf der Zunge

2. (Verstand, Denkvermögen)

prilozit' uma

uma ne prilozit'
- seinen Ver stand auf etwas lenken

- nicht begreifen 
svodit' s uma

schodit' s uma

ubytkd um dajut

zadny m umom dumat'

um za razum zachodit
- um den Ver stand bringen

- den Ver stand verlieren

- 'durch Schaden wird man klug'

- etwa: der Ver stand hinkt nach

- 'der Ver stand umgeht die Vernunft' (vor lauter Błumen den Wald nicht sehen)

3. (Eigensinn)

2it' svoim umom

- einen eigenen Kopf haben

on sebe na um

- er hat es faustdick hinter den Ohren

\subsection{5}

'razum' deckt sich weitgehend mit dem deutschen Begriff 'Vernunft'. Es ist als höheres Erkenntnisvermögen vom niederen des 'um' abgesetzt.

Der deutsche Begr iff 'Verstand' ist enger, damit schärfer gefaßt als 'um'; 'Verstand' ist stärker auf 'Vernunft' ausgerichtet. Die Bedeutungen von ' $\mathrm{um}^{\prime}$ 'reichen weit in die Bedeutungsfelder 'Geist, geistig' und 'Sinn' hinein.

Wo es um begriffliche Prägnanz geht, nimmt 'rassudok' den Platz von 'um' ein. 'rassudok' entspr icht einerseits dem Bedeutungskern von

'Verstand', konkurriert aber ander erseits als Bewertungsinstanz mit 'Vernunft/razum'. 


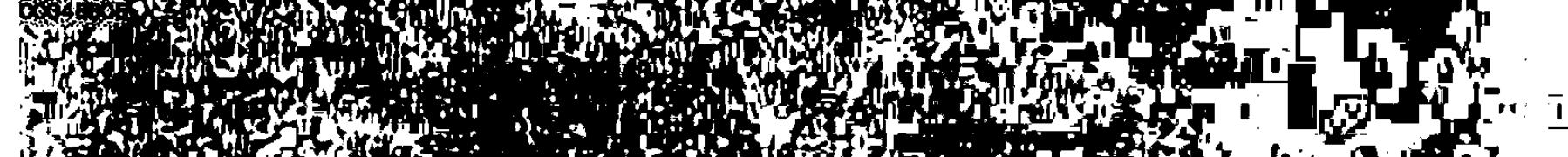

Afs

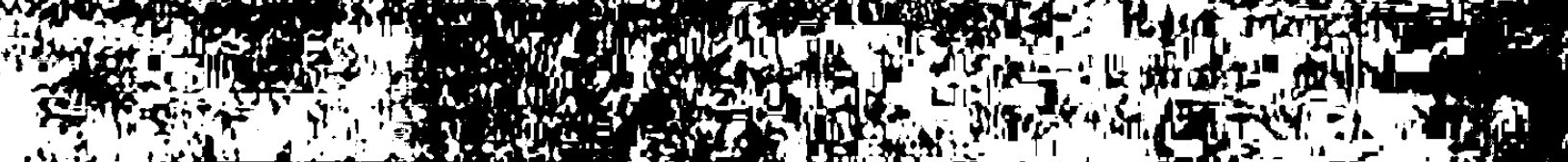

iso

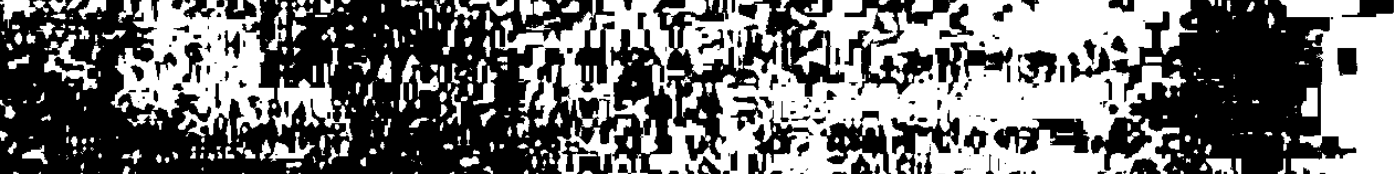

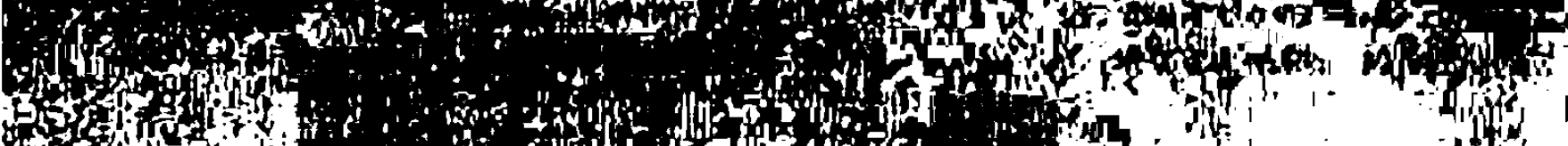

fe

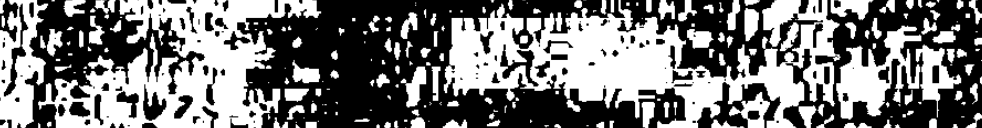

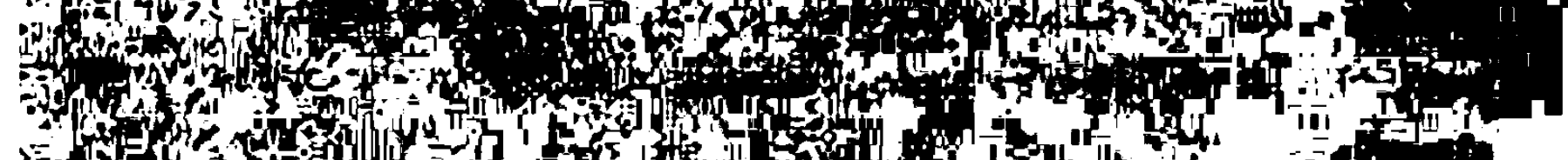
$=50$ for

ind

a. 15

w

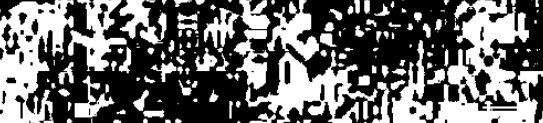
for 0 at

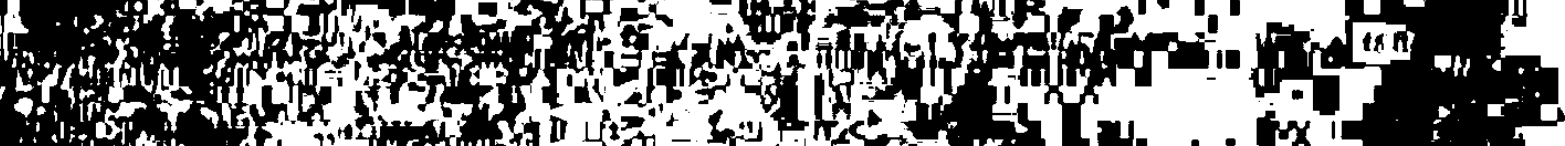

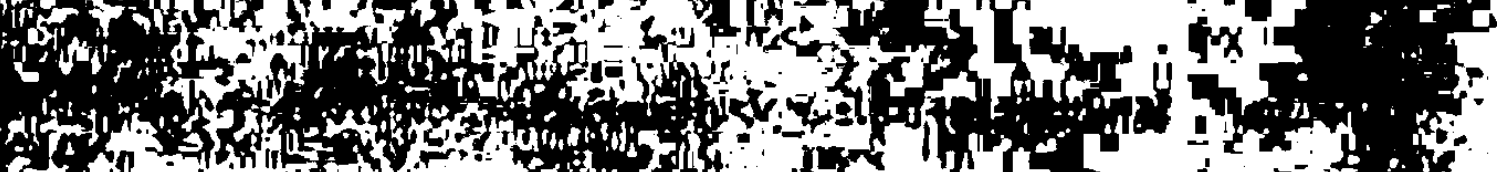

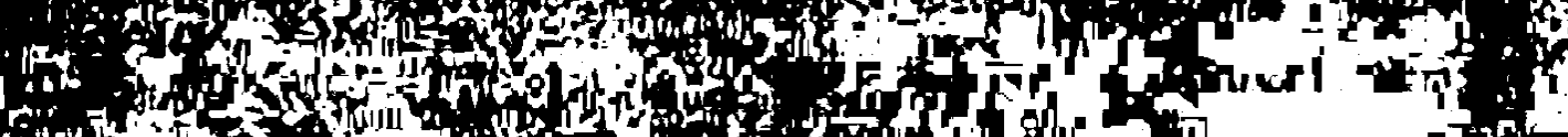

ath

3.

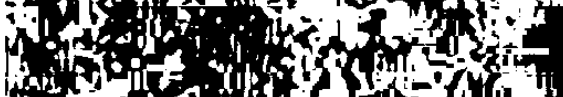

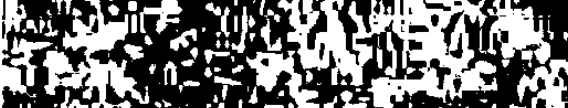

fats

ast

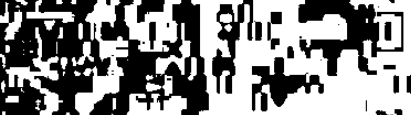

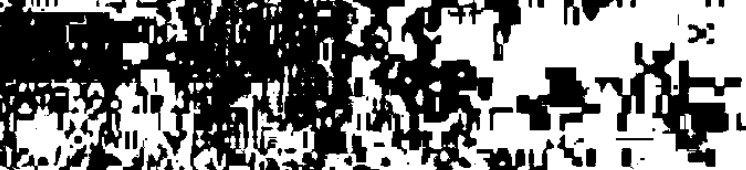

f

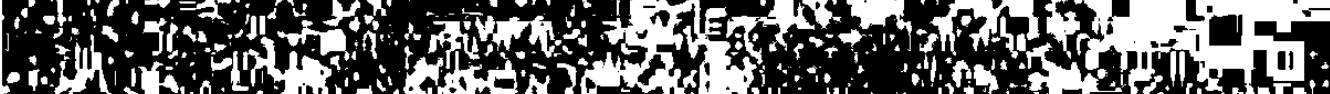

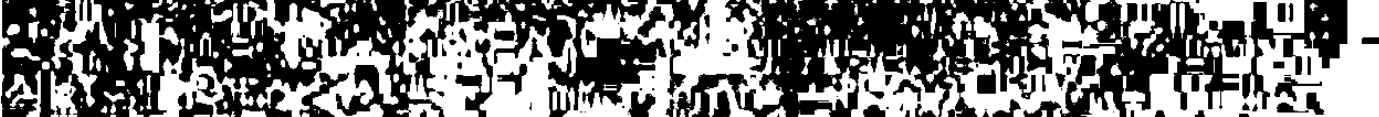

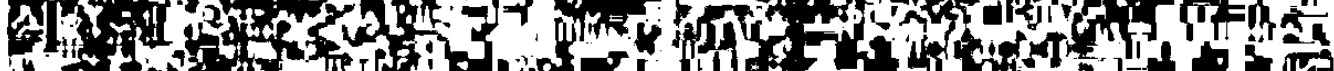

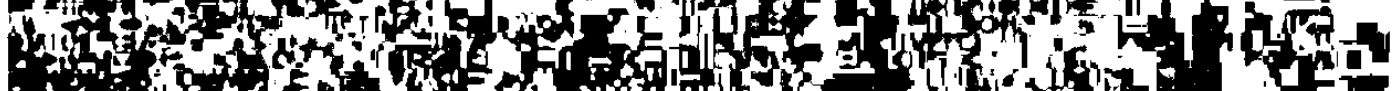
H

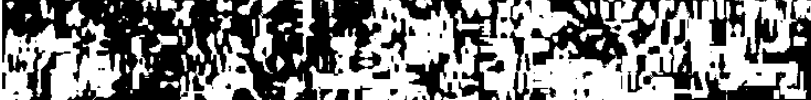

\section{i)} 27, 30

(1)

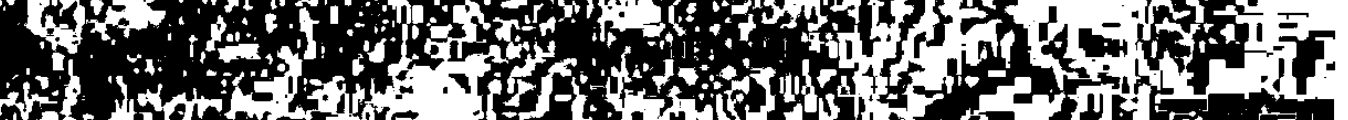

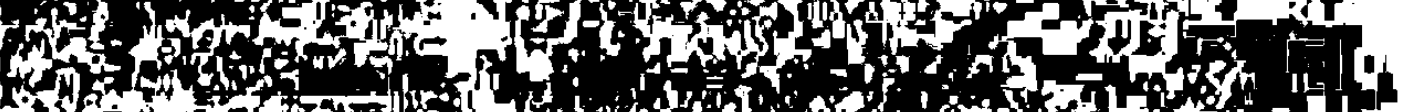

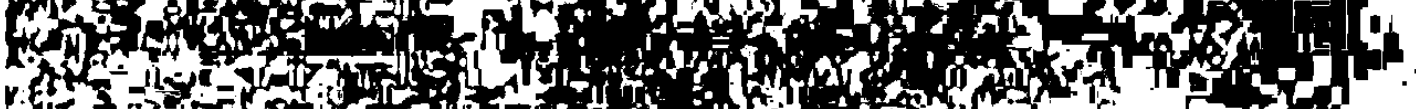
r.tis

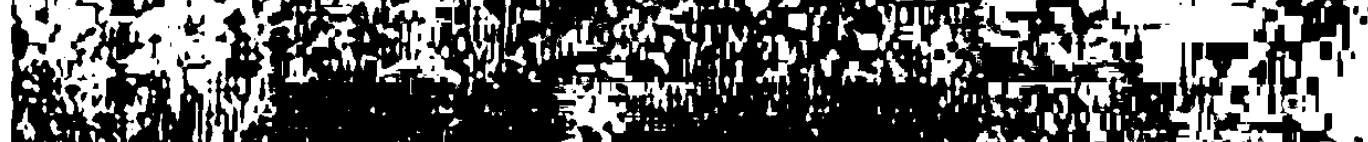

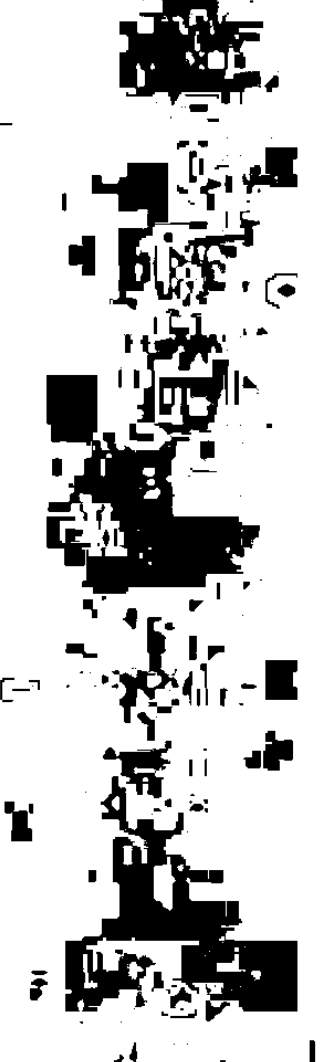

. 
1.20 Vissarion Grigor'evic Belinskij (1811 - 1848)

1.20 .0

Im ersten Abschnitt dieses Kapitels wurde versucht, die vom Worrterbuch gezogenen Grenzen der Bedeutungsbereiche zu beschreiben; die folgende kurze Belinskij-Monographle soll einige Aufschlüsse über die aus dem einzelnen Sprecher heraus wirkenden Komponenten geben, die die statistische Norm - vor allem der sogenannten Abstracta - mehr oder weniger verăndern kbonnten.

Prinzipiell liegen dem verhălnismaßig spontanen Bedeutungswandel, mutatis mutandis, die gleichen Gesetzmäigkeiten zugrunde, die die historische Semantik fü die langfristige, allgemein akzeptierte Verschiebung erarbeitet hat. Ich brauche die erfor schten Ursachen und Auswirkungen hier nicht zu rekapitulieren ${ }^{19}$. Von den Möglichkeiten der 'prtvaten' Wortverwendung seien zwei augenf allige hervorgehoben: die Unter - oder Uberschreitung der Lexikon-Grenzen. Meistens als Folge geringen Wortschatzes, der wiederum fast immer aus einem undiffer enzierten Denken resultiert, wird das Wort durch Einsatz in gewohnten und ungewohnten Zusammenhängen verschlissen, nichtssagend, weil vielsagend; es kann schlieflich nur noch auf Beifügungen aller Art gestützt Bedeutung tragen. Verfügt dagegen der Sprecher uber einen großen Wortschatz, wird er das einzelne Wort im allgemeinen in seinem Bedeutungsspielraum einengen; es ist praziser, weil fester an das Bezeichnete gebunden.

Die Beispiele sind selten, daß ein einzelner Sprecher einen elgentlichen Bedeutungs wandel initilert, d.h. die in der Sprachgemeinschaft vereinbarte Struktur des Bedeutungsber eichs nachhaltig ver andert.

Es bedarf schon eines sehr starken Anstoßes, um die einer solchen Veränderung folgende Kettenreaktion auszulösen. So leicht geraten die Nachbarworter nicht in Bewegung. Wenn z. B. in einem Bereich durch Verschiebung des Bedeutungspols aus der Mitte an die Peripherie

Ich verweise vor allem auf Ulimann, S. 159f. und Kronasser, S. 82ff. 
die nun entfernter liegende Grenze zurückgenommen und die nunmehr nahe vorgerückt werden muß, dann kann in den meisten Fallen nur ein stabllisier ender Redezusammenhang die gewollte Grenzziehung gegen die natürliche Resistenz der Nachbarwörter behaupten. Von einem Bedeutungswandel kann aber nur dann die Rede sein, wenn das betreffende Wort ohne attributive Stultzung die neue Bedeutung trăgt. Nur unter den Voraussetzungen einer außerordentlichen Popularităt und Treue zum unterstellten ungewöhnlichen Sinn kann ein Einzelner diesen dann auch im 'Lexikon' durchsetzen.

Popularität ist heute, im Zeitalter der Massenmedien, sicher etwas anderes als vor hundert Jahren. (Entsprechend zahlreich sind heute Beispiele für einen relatív spontanen Bedeutungswandel, für Umfunktionierung durch Werbung und Propaganda. ) Popularităt kann im 19. Jahrhundert nur Breitenwirkung in einer Gruppe, Kasse bedeuten, die für den Zeitgeist irgendwie reprăsentativ, damit in der Sprachgemeinschaft tonangebend ist 20 .

Zu den Bedingungen eines - am gewöhnlichen Zeitmaß sprachlicher Entwicklung gemessen - plötzlichen allgemein angenommenen Bedeutungswandels gehört außer der Breitenwirkung und Konstanz der Ver wendung eine gewisse Aufnahmebereitschaft der Sprachgemeinschaft; die andere, die neue Bedeutung muß sozusagen in der Luft liegen, die zeitgemăße Definition des Wortes uberfallig sein.

Dann wird auch die Frage zweitrangig, ob die neue Bedeutung Produkt gedanklicher Vertiefung oder irrationaler Überzeugung ist; die Bedeutung muß einleuchtend sein, und ihre Chance, sich durchzusetzen, ist desto größer, je simpler die Begründung ist. Hinzu kommt, daß Breitenwirkung Hăufigkeit des Wortgebrauchs impliziert, diese Hăufigkeit aber nur selten mit einem prăzisen Begr iff vereinbar ist. Fehlt die Breitenwirkung, dann kann man nur von einem 'privaten'

Bekannt sind die Abweichungen vom Lexikon in den Sprachen kleiner, homogener Gruppen (Beruf sstände, Studenten, auch Familien etc.). Diese Gemeinschaften sind hier natülich nicht gemeint, weil deren eigentümliche Wortbenutzung nur zur Beschreibung eines partikularen Interesses taugen kann. Entsprechend kann von einem Bedeutungswandel nicht die Rede sein, wenn er auf ein bestimmtes 'Lager' beschränkt bleibt. RolfLettmann - 9783954793501 
Bedeutungswandel sprechen. Um den Autor zu verstehen, 1st dann oft die Kenntnis seines speztfischen Lexikons notwendig, weil die abweichende Bedeutung nur Eingewethten selbstver standlich ist und der Außenstehende, dem nicht das ganze Werk gelăufig ist, den Zugang nur mit Hilfe eines mehr oder weniger komplizierten Interpretationsaktes finden kann 21 .

1.21

Bei allem 'Streit um Belinskdj': Wirkungsbreite spricht inm niemand ernstlich ab, auch nicht, daß er - ich darf das vorlăufig einmal so nennen - zeitgemäß war. Geistige Wendigkeit und brillante Sprachbeherrschung lassen den eigenwilligen Einsatzton Wortern vermuten, und es gibt auch einen Fundus immer wiederkehrender Vokabeln (Schlüsselworter) und stehender Wendungen 22 . Eine nachhaltige Beeinflussung der russischen Sprache durch Belinskij ist also nicht auszuschließen. Meßbar ist auf Grund der Werkanalyse der private Bedeutungswandel; eine generell akzeptierte Verschiebung im Umkreis der hier untersuchten Worter kann, wenn überhaupt vorhanden, nicht mit Sicherheit auf Belinskij zurückgeführt werden. Das gilt z. B. für die deutlich erkennbare Anreicherung russischer Worter in den dreißiger und vierziger Jahren des vorigen Jahrhunderts mit dem Gedankengut des deutschen Idealismus: Bekannte Wrrter, hier und da mit ebenso bekannten ungeworhnlich komponiert, kehren, nachdem sie als Ubersetzungsworter philosophisch aufgeladen wurden, mit einer neuen Bedeutungsdimension in die Alltagssprache zurück. Mehr, als daß Belinskijs

21

Es geht hier im Grunde um die Frage nach dem Textausschnitt, der ein Wort semantisch konsolidiert. Spezialworterbücher z. B. zu Puskin oder Mickiewicz oder Studien zu Schlüsselwörtern einzelner Autoren wie die vorliegende sind so gesehen Verzeichnisse möglicher Ferneinflüsse aus der Tiefe des Gesamtwerks (der geistigen Heimat pp.), die in die Eingrenzung einbezogen werden müssen, wenn die direkte Eindämmung (durch die unmit telbare sprachliche Umgebung) Lücken offen läßt.

Beispiel : topoi oder 'priemy'.

So auch Tschizewskij, S. 217. 
Anteil an dieser Ausweitung betrăchtlich ist, kann man nicht sagen ${ }^{23}$. Und dieser Anteil ist wohl gerade deshalb so groB, well Belinskj zwar seinen Wortern treu blieb - vor allem in den letzten zehn, den produkttvsten Jahren - , er aber die ur sprünglich strenger gefaßten Wörter unbekümmert dem jeweiligen Denken anpaßte: sie blieben im Gesprăch, wurden durch hăufigen Gebrauch gebrăuchlich. Weniger die Durchsetzung einer neuen Bedeutung, sondern lediglich das Durchspielen der Bedeutungsbereiche, die wechselnde Schwerpunktblldung sind für Belinskijs Spracheinfluß charakteristisch.

A's bemerkenswertes Beispiel sei hier 'dejstvitel "nost" genannt, das einer seits von Belinskij in Absetzung von der 'Idee' zum bloB Abbildenden, zum bloB Daseienden verflacht (so auch im Zusammenhang mit dem denkwïrdigen Satz "Alles Wirkliche ist vernünf tig" etc. ), andererseits eben wegen der Korr espondenz mit dem Metaphy sischen zur allgegenwätigen, unentrinnbar en Schicksalsmacht dămonisiert wurde: "ein Ungeheuer" (XI, 285); gleichbedeutend mit "Gott" (XI, 387) usf.

Hierzu: Tschizewskij, S. $221 \mathrm{ff}$.

Tschizew skij beschäftigt sich ausführlich mit Belinskijs "Wortfetischismus" ( $\nabla \mathrm{gl}$. S. 215, 217) und führt einige Beispiele aus dessen besonderem Wortschatz an. Ich komme in Teil II darauf zurück.

Zum Stichwort 'Unmittelbarkeit' zitiert Tschizewskij jedoch einen zur Anprangerung untauglichen Beleg, bzw. er ubersetzt sinnentstellend: "Jede Vernünftigkeit muß, um vernünftig zu werden, zuerst als Unmittelbarkeit erscheinen, als unmittelbare Offenbarung. " (Ebd. S. 217). Etwas dffferenzierter drückt sich Belinskij nun doch aus: "... dolżna javit'sja sperva kak estestvennost' (sic!), kak neposredstvennoe otkrovenie" (II, 331). Obgleich beide Wor ter manchmal (unter Hegels Einfluß) fast synonym verwendet wurden, ist hier ter Unter schied doch eklatant.

Die Anreicherung des russischen Wortschatzes mit weltanschaulichen Termini stieB auf den Widerstand einiger Zeitgenossen Belinskijs. Noch 1847 verteidigt er sich in seinem großen Literaturrückblick mit der sicher richtigen Bem erkung, daß eben neue Ideen neue Wörter mit sich brächten $(X, 282)$ und ein treffendes Fremawort besser sei als ein unglücklich erdachtes russisches (ebd.). Belinskij spricht sich in diesem Zusammenhang für die Beibehaltung des Wortes 'progress' aus gegen puristische Ver suche, statt dessen 'uspech' oder 'postupatel'noe dvizenie` durchzusetzen. 
Hier und da sind Uberstrapazierungen nachweisbar, aber im allgemeinen reichte die Elastizit der Worter zur Abdeckung der von Belinskij unterlegten Inhalte aus, denn sein Denken war so sprunghaft nun auch wieder nicht; es blieb zeitlebens im - wenn auch weitgefaßten Rahmen einiger Schlüsselworter, besser : dialektisch verknüpter Schlüsselwortpaare im Umkreis der Merkmale 'Starrheit und Bewegung', 'Kante und Wäme', 'Notwendigkeit und Zufall', 'Allgemeinheit und Besonderheit', 'Verstand und Gefuhl' u.a. . Es gibt durchaus so etwas wie einen stabilen Kern der Weltanschauung Belinskijs, und vieles, was er in rhetorischer Pointierung zu Gegensătzen auseinanderzerrte, war für ihn so himmelweit nicht geschieden und, weil dialektisch gesehen, doch eben Verknüptes.

Auf den ersten Blick in sein Werk und in die (westliche) Sekundär literatur aber scheint gerade das Unstabile, zwischen Extremen Schwan. kende, der sprunghafte Wechsel des Standorts für ihn typisch zu sein, das hastige Aneignen der Ideen, die 'en vogue' waren, das ebenso rasehe Verwerfen, Bekenntnis zu einem Philosophen als Attitude, nicht als sinngebende Mitte. Das Schreiben über alles und jeden hat ihm manchmal den Ruf des universal Gebildeten ${ }^{24}$, weit hăufiger den des 'Hans Dampf in allen Gassen' eingetragen: "Belinskij lebte geistig über seine Verhâltnisse" ${ }^{25}$. Die Einschătzung durch Puškin gilt als im Grun. de nicht überholt:

"Wenn er (Belinskij) mit der Unabhăngigkeit seiner Meinungen und seinem Scharfsinn mehr Kenntnisse, mehr Belesenheit, mehr Beachtung der Tradition, mehr Umsicht verbände, mit einem Wort: mehr Reffe, dann würden wir in ihm einen wirklich bemerkenswerten Kritiker haben" 26 .

24 Das gilt fast durchweg für die sozialistische Literatur, aber auch z. B. für Jakovenko und die vorrevolutionären Biographen IvanovRazumnik und Vengerov.

25 Scheibert, S. 171. Daß Belinskij den Grund zur geistigen Unselbstăndigkeit des russischen Denkens (S. 172) gelegt habe, scheint mir ubertrieben zu sein. Er ist sicher ein Beispiel; aber Stankevid Bakunin, Herzen waren in der russischen Intelligencija doch wohl einflußreicher.

Puskkin: Pis'mo k izdatelju (23.4.1836), a. a. O., Bd. 7, S. 441. 
Die Vielfalt der Fragen und Probleme, denen sich Belinskdj gestellt hat, sicherten inm ein großes Publikum: er hatte vielen etwas zu sagen. Im Ostblock ist er noch heute - fast mit der Autorităt eines sozialistischen Klassikers - in fast jedem Zusammenhang zitierbar. Entsprechend umfangreich ist die Literatur uber thn, die "Belinskij als..." , "Die Ansichten Belinskijs..." o. a. im Titel füren ${ }^{27}$. Andererseits năhrte gerade diese Vielfalt die Skepsis, den Verdacht, einen Blender vor sich zu haben, einen notorischen Alles- und Besserwisser, der vieles aufgreift, aber nur wenig begreift.

Der größte Teil des - gemessen an der kurzen Schaffensperiode von etwa fünfzehn Jahren - sehr umfangreichen Werkes Belinskijs ist von den meisten Interpreten als unbedeutend abgetan worden, expressis verbis im Westen: "... neben einzelnen geistreichen Einsichten unendliche Plattheiten" ${ }^{28}$, stillschweigend im Osten. Die Lektüre der noch immer lesenswerten Arbeiten vermittelt den Eindruck einer gewissen Disziplinlosigkeit. Und das nicht nur im Sinne unkonzentrierter und lückenhafter Diktion, sondern auch als Mangel an thematischer Beschränkung verstanden. Unverhofft und kaum begründbar entgleisen Rezensionen zu Traktaten über die eine oder andere weltbewegende Frage, werden, wie Tschizewskij anmerkt, auch bedeutungslose Be-

Auf eine Auseinander setzung mit der sozialistischen Literatur verzichte ich hier. Die Kanonisierung Belinskijs zum überragenden Philosophen, der ein halbes Jahrhundert abendlăndischer Philosophie durchdrungen, überwunden und weitergeführt habe (so Brodskij, S. 35), kann als typisch angesehen werden. Was nicht ins Bild des großen Vorlauufers paßt, wird dialektisch ins Positive verkehrt. So habe Belinskij z. B. in der Phase der sog. Aussöhnung lediglich die bestehenden Verhătnisse als historisch notwendiges Moment der gesellschaftlichen Entwicklung betrachtet. Die Anerkennung der gegenwärtigen Zustănde sei die notwendige Anerkennung des zu negierenden Negativen gewesen (so etwa Evcuk, S. XXIIf.) . Das ist cum grano salis richtig, aber aus dem Körnchen Wahrheit werden allzu üppige Pflanzen gezogen.

Scheibert, S. 171 . 
sprechungen von unbedeutenden Büchern förmlich von philosophischen Schlagwörtern durchtrănkt ${ }^{29}$, al so zum Anlaß unangemessenen Tiefgangs genommen. Das Anliegen schlăgt durch, verbiegt das primär gestellte Thema und wirft sich selbst zum Gegenstand auf. Das Anliegen ist, um es mit einem Gemeinplatz zu sagen, so alt wie die Menschheit: Es geht Belinskij im Grunde um den Standort und die Aufgaben des Intellektuellen in einer hulf ebedürftigen Welt. Die Lösungsvor schläge sind bei natherem Hinsehen nicht hinreißende und alles Wider sprüchliche lösende Weissagung - mag Belinskij auch das Zornige und Rechthaberische, die weitausholende Geste des modernen Propheten gehabt haben -; die große Offenbarung, das alles überdachende Denkgebăude fehlte. Um im Bild zu bleiben: seine Gebăude waren trotz vieler angeflickter Răume, vorgesetzter glănzender Fassaden zu eng, hatten einen kleinstadtischen, oft spießbiurgerlichen Zuschnitt.

Die hăufig engstirnige, manchmal blinde Verbissenheit in diese Anliegen und in ihrem Gefolge die Intoleranz, eine wahrhaft "inquisitorische", wie Scheibert meint ${ }^{30}$, gegenüber dem Ander sdenkenden ist nur als leidenschaftliche Suche nach Antworten auf an tberforderung grenzende Herausforderungen zu ver stehen; diese Herausforderungen (ich whl de dieses zunächst wertfreie Wort, well es sowohl das Erstrebens-, Nachahmenswerte als auch das zu Uberwindende meinen kann) lassen sich unter wenigen Stichworten zusammenfassen:

/ Das "Erbe des Alten Rußland", al s Inkarnation des "patriarchalischen Drucks" (Scheibert), der 'Provinz', des Generationenkonflikts einer seits, ander er seits als Zeichen für das zukunftsträchtige spezifisch Russische.

/ Die eigene physisch-materielle und intellektuelle Konstitution.

/ Die Hauptstădte: das aufgeklärte, das geistige Rußland, dessen Spaltung offenbar wird, aber auch die elende Vorstadt.

Der Eindruck des Unstabllen entpuppt sich als Verăndern der Optik, als Parieren mit immer neuen Mitteln auf im Grunde gleichbleibende Konfrontationen. Was Belinskij nicht gelang: die Distanzie-

Tschizewskij, S. 209.

Scheibert, S. 172; thnlich Tschizew skij, S. 207f., der sich dem ber ühmten Urteil Samarins anschließt. 
rung, das Spielerische, das den Herausforderungen das Bedrohliche genommen hătte, der Bewaltigung das Verzwetfelte, das Leidenschaftliche, das der nüchternen Betrachtung oft den Weg verstellte. Aber wie einer Sache Herr werden, wenn die Mittel, bevor uberhaupt richtig erprobt, ungeduldig als untaugliche aber Bord geworfen werden?

\subsection{2}

Belinskij wuchs in der Provinz auf. Das Milieu des Elternhauses der Vater war Landarzt - war kleinbürgerlich. Von den Menschen dieser Schicht, in der die Familie getreues Abbild der feudalen Gesellschaftsordnung war: autorităr, auf Konservierung bedacht, mißtrauisch gegen alles Neue, jeden Widerspruch, jedes Anderssein streng ahndend, Gott und Zar bedenkenlos ergeben, waren keine Revolutionen zu erwarten; total angepast, lebten sie in einer durch Dogma und Ukaz eingezăunten, heilen, weil abgeschlossenen Welt, entwicklungsf remd, damit man sich im Morgen so leicht zurechtfand wie im Heute. Der Briefwechsel Belinskijs mit seiner Familie zeigt das Gewicht dieser Bürde, die er zeitlebens trug ${ }^{31}$. Aus diesen Jugendjahren in der Provinz, in Cembar (1815-25), in Penza (1825-29) hat Belinskij wohl nur das Bild des stump in dieser Atmosphäre Verhafteten bewahrt. Die andere, aus einem sentimentalischen Verhältnis der Stadt zum Land erklärbare Vorstellung vom Russen, vom gewitzten, bildbaren, mit gesundem Menschenverstand begabten, lag in der Luft. Belinskij griff diese Fiktion auf, setzte seine Hoffnungen auf eine literarische Erfindung, die mit dem Anspruch auftrat, das typische Rußland zu treffen, die den Russen mit Geradheit des Denkens und Aufrichtigkeit des Fuhlens ausstattete. Diese Menschen beneidete Belinskij um thren Gott, um eine Glăubigkeit, die nicht wie ein Mantel, als etwas Äußeres angelegt wird, sondern von innen her Stärke und Wärme verleiht.

Man könnte dieser ambivalenten Einschätzung des Russen, einer Ambivalenz, die auch Belinskijs Einstellung zu ander en Erscheinungen

Hierzu ausführlich: Schultze, V. G. Belinskij, S. $39 f$. 
kennzeichnet, das Prădikat der differenzierenden Anschauung geben, wenn nicht dieses 'Sowohl-als-auch' in Belinskijs Äußerungen allzu leicht zu einem kategor ischen 'Entweder-oder' entartete, zu einer fast launischen Uberzeichnung des einen und Vernachlässigung des anderen. Fließende Ubergänge sind eben nur aus einer bestimmten Entfernung heraus zu erkennen. Was als Vorurteil den Russen gegenüber so leicht bei der Hand ist: das Verdăchtigsein des Kompromisses auf Belinskij trifft es zu.

Es gab eine Herausforderung, die wie keine unmittelbar und im letzten Lebensjahrzehnt allgegenwartig war: die Krankheit. Das jahrelange Lungenleiden wird nicht zuletzt Ur sache der Unrast und der daraus resultier enden Oberflăchlichkeit gewesen sein. Aus der Angst, die wenige Zeit könne ungenutzt vertan sein, weniger aus mangelnder geistiger Kapazitä, leitet sich die oft blinde, nur auf stark Konturiertes reagierende Wißbegier ab.

Angemerkt werden muß die ungesicherte materielle Existenz, ein wesentlicher Faktor des 'bewußt seinbestimmenden Seins'. Bowman schreibt mit Recht, daß es für einen Caadaev oder einen Fürsten Odoevskij leichter war, zu einem "klaren intellektuellen Verstăndnis der Übel der russischen kulturellen Formlosigkeit" zu kommen, wenn man die "Finsternis, in der das Volk lebte" nur aus der Ferne betrachtete und nicht, wie Belinskij, in deren Schatten ${ }^{32}$ leben mußte. Es ist müBig zu fragen, was Größere als Belinskij mit leeren Taschen, ohne das Unabhăngigkeit gewăhrende Portef euille beguiterter Familien geschrieben hătten und jemandem gerecht werden, kann nicht heißen, nach mildernden Umstănden suchen. Aber vielleicht sollte man die Fulle von Aufsătzen und Rezensionen, die um und nur um des Honorars willen geschrieben wurden und oft entsprechend schlecht waren, schlicht ubergehen, statt sie Belinskij anzukreiden und, bevor man die philosophische Durchtrănkung belangloser Artikel anprangert, bedenken, daß

Bowman, S. 32. 
diese Gedanken oft nur deshalb so deplaciert sind, weil sich der geeignete Rahmen nicht verkaufen ließ. Diese Betrachtungsweise ist heikel, aber ohne diesen Blickwinkel bleiben Lücken im Bild. Mangelnder Abstand karn eben beides bedeuten: enge Einseitigkeit, die Unfahigkeit zu objektivier en, ins große Ganze einzuordnen und Ergriffenheit, die Făhigkeit, sich leidenschaftlich zu engagieren. Es ist wohl doch "das große Her $z^{\prime \prime} 33$ - Venger ov überschrieb eine Abhandlung so - , das Belinskij von der "etwas hohlen, ausschließlichen Intellektualităt" 34 eines Bakunin, auch wohl eines Herzen unter schied.

Nach Moskau kam Belinskij mangelhaft vorber eitet, sehr belesen zwar, aufgeschlossen und mit scheinbar unbegr enzter Aufnahmefăhigkeit begabt, aber sein Wissen war nicht koordiniert, sein Lerneifer ungezielt, ein etwas wahlloser Bildungshunger. Zwar hatte Belinskij das Glück gehabt, in Penza die Freundschaft eines Gymnasialprofessors zu gewinnen, ein en Förderer seiner Anlagen, und auch in $\dot{C}$ embar war er nicht gänzlich vom kulturellen Rußland abgeschnitten ${ }^{35}$; dort hatte ihm die Bibliothek Verwandter zur Verfügung gestanden. Aber das Angelesene war noch nicht in ein Gedankengebăude eingebracht worden. Obgleich von ander er Herkunft als die meisten Moskauer Intellektuellen, wurde Belinskij ohne Vorbehalt akzeptiert. Stankevic und sein Kreis waren ihm Mittler, Übersetzer vor allem ${ }^{36}$, der deutschen Philosophie: Herder, A.W. Schlegel, Schelling, Fichte, spăter Hegel.

Venger ov: Velikoe serdce, S. $247 \mathrm{ff}$.

Scheibert, S. 175.

Hierzu ausführlich: Bowman, S. 31ff. und Venger ov, S. $298 \mathrm{ff}$.

$\mathrm{Zu}$ den Sprachkenntnissen Belinskijs, unter deren Mangelhaftigkeit er zeitlebens litt, die zu erwerben er sich nie die Zeit nahm, vgl. Bowman, S. 37. Wellek mißt der unzureichenden Kenntnis des Deutschen (und Französischen) nicht eine so große Bedeutung zu, da hinreichend viele Über setzungen vorgelegen hătten (S. 245). Wellek unter schătzt $\mathrm{m}$. E. das Moment der voreingenommenen Auswahl. Belinskij war eben nur das - und meistens schon kommentiert - zugänglich, was z. B. Katkov, Nadezdin, später Bakunin lesens- und über setzenswert er schien. 
Bezugdoses Theor etisieren blieb Belinskij fremd. Theorie war ihm immer nur - und damit steht er keineswegs allein - als anwendbare denkbar, Kunst als nutzbringende, belehrende, aufklärende. Man muß m. E. das Verhaltnis von Denkmodell und Wirklichkeit bei Belinskij ganz vor dergründig als Typisierung der realen Erscheinungen, resp. Aư spüren des Typischen in der Realitä sehen. Der Ver such, die zeitgenössischen philosophischen Strömungen zum Maßstab für Belinskij zu nehmen, scheint mir untauglich zu sein. Um bei ihm von klar geschiedenen Perioden dieses oder jenes Einflusses zu sprechen, fehlt ganz einfach die Durchdringung der Weltanschauungen. Auf der stăndigen Suche nach einer Autorităt zur Bestătigung seiner Meinungen griff Belinskij das aus den Denkgebăuden heraus, was in sein Konzept paßte. Oft begnügte er sich mit der bloßen Nennung eines großen Namens, um mit dem Gewicht, dem 'Wallungswert' des zitierten Kronzeugen jeden Zweifel an den eigenen Aussagen zu ersticken. Es ist viel geliehener Glanz in Belinskijs Werk. Bowman nennt das "intellektuelle Abhăngigkeit"; Scheibert bezeichnet Belinskij als einen "Geist, der ernsthaft und vergeblich um geistige Unabhängigkeit rang" 37 . Das ist richtig, richtig ist aber auch, daß die Anziehungskraft dieser heterogenen Vorbilder nicht vermochte, Belinskij von den Grundzügen seiner Anschauung abzuziehen, daß er den stabllen Kern seiner Überzeugungen oft lediglich verbrămte, zeitgemåß aufputzte, ihnen den Anstrich von Philosophie gab.

Belinskij legt die Periodisierung seiner Schaffenszeit nahe, weil er sich selbst nach westeuropăischen Denkern kategorisierte, aber das Bekenntnis zu einem Philosophen besagt noch nichts über den Grad der Verarbeitung seiner Ideen. In letzter Zeit ist René Wellek den Einstufungen entgegengetreten:

"Nor can one distinguish nead periods in Belinskys critical development: there was no definitely Fichtean, Schellingian, Hegelian, or Feuerbachian period in his criticism. From the very beginning of his writing, from the 'Literary Reveries' (1834) to the last

Bowman, S. 41; bzw. Scheibert, S. 171 . $^{\circ}$ 
annual survey of Russian literature (1847), Belinsky uses the same categories, concepts, and procedures, the same basic theor etical idiom whatever his shifting emphasis and whatever his political convictions. Only in the last ftve years of his life can one discern a definite change" 38 .

Wellek gesteht abschließend Belinskij das Verdienst zu, die Doktrinen des deutschen Idealismus der Tradition der russischen Kritik übermittelt zu haben ${ }^{39}$, aber eben Doktrinen; in dieser, die Differenzierungen verdeckenden Verkürzung wird das ursprüngliche Denkmodell zum Dogma, das zur Erklärung von allem und jedem herhalten muß. Die Endstation 'Utopischer Sozialismus' - als ein vom Ansatz her maximalistisches Programm - scheint zwangslăufig zu sein. Aber die Năhe Belinskijs zur Realităt, leicht als Nachteil angekr eidet, zeigt hier eine posittve Seite: sie wirkt auf die Theorie korrigierend, zwischen den Theorien vermittelnd, bewahrte Belinskij vor der Radikalită.

Es paßt in das Bild eines Debütanten aus der sogenannten Intelligencija, daß er mit der Negierung des Vorhandenen beginnt, daß er sein Konzept auf dem leergefegten Tisch ausbreitet: "Wir haben keine Literatur".

Mit diesem vielzitierten, keineswegs originellen Satz ${ }^{40}$ beklagt Belinskij weniger den Mangel an Literatur in Rußland als vielmehr den Mangel an russischer Literatur, an Literatur, die 'ins Volk geht'. Die pessimistische Einschätzung der zeitgenössischen russischen Literatur geht Hand in Hand mit der Erwartung einer literarisch fruchtbaren Zukunft; und das durchaus in Anlehnung an Herders ex-oriente-lux-Prophezeiung. Der Grundtenor der 'Literaturnye mectanija' ist optimistisch; im traditionsfreien Raum kann unbelastet eine zeitgemäße Kunst erblühen. "Wir haben keine Literatur, ..., aber in dieser Tatsache sehe ich das Unterpfand unserer künftigen Erfolge" $(1,101)$. Es ist die Antithese von Asche und Phönix; die Negation zu negieren, wird der Dichter auf-

Wellek, S. 244 .

ebd., S. 264.

40 Vgl. Müller: Kireevskij, S. 94 und ebd. Anmerkung 37. 
gerufen, thm - besser: der Literatur ${ }^{41}$ - weist Belinskij eine Schlüssel funktion zu. Der Dichter seiner Vor stellung ist ein später, ein pragmatischer Nachfahre dessen, der Priester war, der König werden sollte.

Die 'mectanija' sind ein Debüt par excellence: Belinskij zeigt, was er weiß. Unter diesem Titel - er ist weit genug gefaßt - lassen sich alle Lesefrüchte bequem unterbringen. Belinskij wendet sich gegen eine trocken lehrhafte Verstandesliteratur, aber auch gegen alle pseudoromantische Volkstümelei. Literatur versteht Belinskij zeitlebens als Institut der Aufklärung, Aufklärung weniger als Wissensvermittlung, vielmehr als Bewußtseinsbildung ver standen. Aus zwei Quellen soll der Dichter schöpfen: aus dem Verstand und dem Gefühl und beide zur Vernunft vereinigen.

Von einer Literaturtheorie im Sinne eines geschlossenen Sy stems kann man bei Belinskij nur insofern sprechen, als er in seinen Kritiken sie machen etwa vier Fünftel seines Werks aus - gewisse grundsätzliche Anforderungen an das literarische Produkt stellt. Wellek nennt Belinskij den "ersten russischenKritiker von mehr als lokaler Bedeutung", schränkt aber gleich ein, da $\dot{B}$ ihm "Belinskijs Position als Literatur theor etiker in einer allgemeinen Geschichte der Kritik ... weit weniger bedeutend" er scheine ${ }^{42}$. Der Weg von einer - wie Wellek meint ${ }^{43}$ romantisch-idealistischen zu einer praktischen, wissenschaftlichen, positivistischen Betrachtung der Literatur entbehrt nicht der inneren Konsequenz. Parallel dazu verlăuft der Weg, auf dem Belinskij das Ziel eines mündigen Rußland suchte. Der anfängliche Optimismus, der Glaube an die Möglichkeit der Aufklărung und Bildung des Volkes, die Hoff -

41 Es wăre eine Studie für sich, auf die feinen Unterschiede zwischen 'literatura' und 'poèzija' einzugehen. Belinskij versteht unter 'literatura' einerseits alles Geschriebene mit gesell schaftlicher Funktion, im engeren Sinne Dichtung als Ausdruck des Volkes (in Absetzung von 'Gesellschaft' im Sinne der 'beau monde'), 'poézija' hat bei Belinskij leicht den Nebensinn des Elitären.

Wellek, S. $243 f$.

ebd., S. 244. 
nung, daß die Änderung der gegenwärtigen Zustănde dann von selbst kăme, wurden von zunehmender Resignation und Verbitter ung aufgezehrt. Den spăter en Griff zu revolutionăren Ideen tat Belinskij wohl weniger aus der rationalen Überzeugung, daß Reformen deshalb sinnlos sind, weil sie nicht in die Dialektik der Geschichte passen, weil Wandlung nur als qualitativer Sprung quantitativer Untragbarkeit, als Revolution geschehen kann, sondern vielmehr aus Ungeduld, als Moralist.

Der Wert alles Geschriebenen wurde von Belinskij zunehmend daran gemessen, was es für den gesellschaftlichen Fortschritt leistete. Aber es wäre falsch, im späten Belinskij einen Vorläufer jener 'Sozialistischer Realismus' e tikettierten Theorie zu sehen. Noch in seinem letzten großen Literaturrückblick auf das Jahr 1847 betont Belinskij, daß Kunst in erster Linie Kunst sein müsse und erst dann Ausdruck des Geistes und der Ausrichtung der Gesellschaft in einer bestimmten Epoche sein könne $(\mathrm{X}, 303)$.

Das Konzept einer eigenwertigen Kunst mit sozialer Funktion ist im Grunde schon an den 'mectanija' abzulesen, wenn man sie von der romantisch-idealistischen Verbrämung befreit: Der Dichter habe vor der "ewigen Idee..., die sich in zahllosen Formen als das gewaltige Schauspiel absoluter Einheit in unendlicher Vielfalt manifestiert" $(I, 30)$ nicht in staunender Kontemplation zu verharren, sondern als unbewußtbewußter Schöpfer am Reproduzieren dieser Idee teilzunehmen, denn "für diese Idee gibt es keine Ruhe; sie lebt unaufhörlich, d.h. sie schafft unablăssig, um zu zerstören, und zerstört, um zu schaffen" (ebd.). Mit dürren Worten: Der Dichter braucht ein Gespür für die Zeichen der Zeit und muß sie an die Gesellschaft weitergeben, indem er in der Darstellung des Alltäglichen, der Natur etc. die Hinweise auf die Idee, das Weltprogramm aufdeckt, das Typische zeigt. 'Wir haben keine Literatur' heißt dann, daß Belinskij in Rußland niemanden sah, der die Bestimmung des Volkes (im Sinne Herders) erkannte und vermittelte. "Die Literatur muß Symbol des inneren Lebens eines Volkes sein" (I, 29). Folgerichtig beschließt Belinskij den Aufsatz mit der Forderung: "Was wir also heute brauchen, ist nicht eine Literatur,..., sondern Aufklărung" $(\mathrm{I}, 102)$. 
Setschkar eff spricht von einer "Schellingstimmung" 44 , die die Aufsătze bis etwa 1837 einhulle; er erkennt in der im Gogol -Aufsatz 1835 ge äußerten Ansicht Belinskijs, daß die künstlerische Produktion "zielvolle Ziellosigkeit, unbewußtes Bewußtsein, freie Notwendigkeit" $(I, 285)$ sei, "fast wörtliche Schellingzitate". Die Absicht, in einem poetischen Symbol irgendeine Idee auszudrücken, sei durchaus bewußt und gezielt. Aber weder die Wahl der Idee noch ihre Entwicklung hänge vom Willen des Dicl ters $a b^{45}$. Das bewußte Ziel des Dichters, die (ewige) Idee in einem Sym bol zu fassen und dem Leser begr eifbar zu machen, heißt doch nichts anderes, als die Gesellschaft mit ihrem historischen Sein und Werden vertraut zu machen, so wie es von der Vor sehung (vom Weltgeist, oder wie die Umschreibungen des irrationalen Urgrundes immer lauten mögen) dem Volk bestimmt ist. Ziellosigkeit, Unbewußtheit und Notwendigkeit sind als Verzicht auf eigene Zielsetzung, als gläubige Erfüllung einer für vernünftig erachteten Idee zu interpretieren. Reduziert auf 'Doktrinen' besteht dann zwischen Herders leichtfertiger Verheißung einer Führungsrolle der Slaven und dem Mythos der Sozialutopisten und Marxisten von der Zwangslăufigkeit der Geschichte nur ein geringer Unterschied.

Von hier aus ist Belinskijs anf ängliche Ablehnung der Volksdichtung ver ständlich. Sie drückt das Nicht-mehr-Zeitgemäße, das VorPetrinische aus und steht dem Fortschritt im Wege. Belinskij verkennt, daß gerade die Aufarbeitung der Volksdichtung einen wesentlichen Beitrag zur nationalen Bewußtwerdung leisten kann, und der Rückblick die Ber eitschaft steigert, das mutmaßlich Kommende zu antizipieren. Negativ wird auch die trocken gelehrte Aufklärungsdichtung beurteilt, weil Faktenanhäufung den Blick auf das hic et nunc versperrt. Die Vermittlung enzyklopădischen Wissens ist erst dann sinnvoll, wenn der Mensch 'zu Bewußtsein' gekommen ist.

Bereits 1835 setzt Belinskij in dem schon genannten Auf satz "O russkoj povesti i povestjach g. Gogolja" (I, 259ff.) die 'real'naja poèzija'

Setschkareff, S. 89.

ebenda 
als die zeitgemäße von der 'ideal'naja' ab (I, 262). Es komme auf die Darstellung des Lebens in seiner "Schăndlichkeit, Nacktheit, seiner Mißgestalt, aber auch in seiner triumphier enden Schönheit" an (I, 267). Nicht das Ideal des Lebens solle abgebildet, die Idee nicht - wie noch in den 'mectanija' sehr vage gefordert - in irgendeinem Symbol vorgestellt werden, sondern die Wahrheit, denn nur "wo Wahrheit ist, da ist auch Dichtung" (ebd.), und "wenn die Darstellung des Lebens wahr ist, dann ist sie auch volkstümlich (narodno)" (I, 295). Nur "narodnost"; die unumwundene Objektivierung des Gegenwärtigen in der Dichtung, ver mag den Menschen aus bewußtloser Befangenheit im Leben zu befreien und zur Erkenntnis der Wirklichkeit zu führen. Das Volk muß mit seinen Anlagen vertraut sein, um sie in die Zukunft projizieren zu können ${ }^{46}$. Die Fichtesche Gleichung, daß Selbsterkenntnis Gotteserkenntnis sei, steht hinter der Überzeugung Belinskijs, daß die Kenntnis des eigenen (sozialen) Seins die Idee des Weltablaufs sichtbar macht, es quasi nur der Hochrechnung der in einer 'real'naja poèzija' dargestellten Fakten bedarf.

Das Verhảtnis von Sein und Bewußtsein, anfänglich als funktionales mit der Variablen 'Sein' gesehen, wird Ende der dreißiger Jahre von Belinskij nicht mehr als ein im einen oder ander en Sinne kausales, sondern als ein synthetisches verstanden: Das gegenwärtige Sein kommt zu Bewußtsein; das Bewußtsein der Gegenwart setzt, das jetzige Sein negier end, das zukünftige. Mit Blick auf die Literaturtheorie bestätigt Kuippers diese Anschauung: Belinskij habe eine Synthese von realer und idealer Dichtung ver sucht. Weil seiner Meinung nach nur das Wirklichkeit habe, was dem Ideal entspreche, sei reale Dichtung insof ern ideale, als der Realismus nur mit Bezug auf das Ideale sinnvoll sei (und insofern dann 'sentimentalische' Dichtung ist) ${ }^{47}$. Wenn z. B. die häßliche, mit dem Ideal inkongruente Realität dargestellt wird, so kommt ihr des-

\footnotetext{
46

Nach Belinskijs Meinung verhüllt das Leben mit seiner Buntheit die Wirklichkeit. Es muß sozusagen 'durchschaubar' gemacht werden, damit die Wahrheit sichtbar wird. Vgl. I, 262.

Vgl. Küppers, S. 1391.
} 
halb Wirklichkeit zu, weil sie das notwendige (Negativ-) Korrelat zur Idealität ist.

Wellek meint, Belinskij habe sein kritisches System in zwei Riehtungen entwickelt. Einer seits sei für ihn das Kunstwerk Ausdruck einer Zeit, ihrer Strömungen etc., ander er seits ein selbständiges Ganzes, sinnlicher Ausdruck einer Idee in Einheit von Inhalt und Form. Unter Hegels Einfluß habe Belinskij den Gesichtspunkt der historischen Bedingtheit mehr und mehr verdrängt und Kunst als zeitlose Gestaltung von Menschheitsschicksalen angesehen ${ }^{48}$. Zu dieser Auffassung kann man anhand von Belinskijs Shakespeare-Inter pretationen (1 838) ${ }^{49}$ kommen. Er sieht in Shakespeares Schöpfungen eine "Wiederholung des Weltganzen, aber als bereits bewußtes und darum freies Abbild" (II, 288), betont dann aber wenig später, jede Gestalt sei "ein lebendiges Abbild, ohne alles Abstrakte an sich, sondern gleichsam ganz und ohne alle Berichtigungen und Umarbeitungen der alltăglichen Wirklichkeit entnommen" (II, 290). Diese Wirklichkeit ist nur die zeitgemäße Einkleidung zeitloser Menschheitsschicksale. Den hohen Rang der Werke Shakespeares sieht Belinskij eben darin, daß sie sowohl Ausdruck einer Zeit, als auch selbständiges Ganzes, sinnlicher Ausdruck einer zeitlosen Idee, daß sie "Denken in Bildern" sind. Zwar hat Belinskij aus seinem Hegelverständnis heraus, daß es auf der Welt doch im großen und ganzen ver nünftig zugehe, dem Dichter das subjektive Mitleiden nur dann gestattet, wenn er die Mißstände auch in ihrer objektiven Notwendigkeit sah ${ }^{50}$, aber daraus kann schwerlich ein l'art pour l'art-Standpunkt abgeleitet

Vgl. Wellek, S. $248 f$.

Belinskij sah am 30.11.1837 bzw. 12.4.1838 Mocalov bzw. Karatygin in der Rolle des Hamlet. Vgl. die Auf sätze: "Gamlet" drama Sekspira. Mocalov v roli Gamleta" (I, 253ff.); "G-n Karatygin na moskovskoj scene v roli.Gamleta"(II, 363ff.) und "Gamlet, princ datskij, socinenie Šekspira" (II, 424).

"...wer das Leiden beklagt, der steht nicht über ihm, kann nicht dessen vernünftige Notwendigkeit sehen, sondern sieht in ihm nur das Zư alllige..." (III, 418). 
werden. In dem bekannten Auf satz aus dem Jahre 1839 "Mencel", kritik Gete" (III, 385ff.) wendet sich Belinskij zwar scharf gegen die Ansicht, daß die Kunst der Gesellschaft zu dienen habe, unterstreicht aber im gleichen Atemzug die Aufgabe der Kunst, die Gesellschaft zu belehren, "den Geist der ihr angehörenden Individuen mit erhabenen Eindrücken und edlen Gedanken vom Guten und Wahren (zu năhren)", "das Gewissen ebenderselben auszudrücken". "Sie (die Kunst) dient der Gesellschaft nicht als irgendetwas für sie Existierendes, sondern als etwas an und für sich Seiendes,..." (III, 397). Belinskij bauscht hier Gegensătze auf, die im Grunde für thn keine waren. Ob man die Einwirkung auf die Gesellschaft nun Dienst oder Herrschaft nennt, ändert im Falle der Kunst an der Sache wenig. Nach wie vor ist der Kïnstler Organ des untver sellen Lebens im Schellingschen Sinne. So weit war der Schritt von Schelling zu Hegel für Belinskij nicht: Hinter der 'Idee, die sich in bunter Vielfalt ăußert' und der 'Vernunft, der allwaltenden, die als Wirklichkeit begreifbar wird', steckt ein sehr ähnliches Denkklischee.

$\mathrm{Da} \beta$ die in stăndiger Bewegung begriffene Idee zu einem vernünftigen Ziel hinstrebt, kann für die Gegenwart nur bedeuten, daß auch sie eine vernünftige $W i r k l i c h k e i t$ ist, ein vernünftiges Moment im Prozeß der Verwirklichung, denn "weder in der Natur noch in der Geschichte herrscht blinder Zufall, sondern strenge, unwandelbare innere Notwendigkeit" (Ï',591, Ideja iskusstva, 1841). Von hier aus ist die 'Versöhnungsphase' verständlich. Andere als die bestehenden sozialen Verhätnisse mußten für Belinskij 'unvernünftig' sein. Entsprechend schreibt er auch am 7. August 1837 an Kanov, daß Rußland noch die Amme brauche und seine Hoffnung in der Aufklärung, nicht in Umstürzen oder Verfassungen liege (XI,148f.). Es bedurfte - im Sinne Belinskijs - einer Übergangszeit, einer Art Diktatur der Intelligenz, die ihr fortschrittliches Gedankengut in kleinen Dosen, abgewogen von einer wohltătigen Zensur, verabreicht. Auch das Argument mag noch plausibel sein, aber Belinskij - zum Extrem neigend - schüttete das Kind mit dem Bade aus. Scheibert hat zumindest für diese Phase recht: "Belinskij hat nicht vermocht..., das Problem von Notwendigkeit und Freiheit als solches 
überhaupt zu fassen" ${ }^{51}$. Spăter habe er dann erkannt, daß es damals 52 nötig gewesen wäre, auch die Idee der Negation zu entwickeln, ohne die die Geschichte in einen "stagnierenden und stinkenden Sumpf" versänke (XI, 576; an Botkin 11.12.1840).

Die platte Deutung des Satzes aus Hegels Vorrede zur Rechtsphilosophie von der Vernünftigkeit des Wirklichen und der Wirklichkeit alles Vernünftigen bestătigt die schon geäußerte Vermutung, daß Belinskij die Idee wohl stes nur als verschlüsseltes Programm eines zwangsläufigen Weltablaufs gesehen hat. Den zeitlebens ungebrochenen Glauben an eine sinnvoll gefügte Weltordnung darf man als Klammer ansehen, die die ursprünglich heterogenen Anschauungen zusammenhält. Belinskij hat lediglich die Rolle des ordnungstiftenden Prinzips unterschiedlich besetzt.

Mag das Akzeptieren der Zeitumstände als zwar üble, aber notwendige Durchgangsstufe noch als gedankliche Konsequenz erklärbar sein, so ist der Schritt darüber hinaus zum Wohlgefallen an der Situation wohl nur aus einer emotionalen Disposition Belinskijs heraus ver ständlich. Auch er hatte sein 'Kaukasuserlebnis': den Sommer 1837 verlebte Belinskij in Pjatigorsk. Aus der Distanz sah die Welt harmonischer aus; die großzügige Konzeption Hegels war eingängiger, wenn nicht die tausend Ungereimtheiten des Alltags, die tausend einzelnen Schicksale den Blick auf die vernünftigen Grundlinien versperten. Belinskij hatte die entscheidende Begegnung mit Hegels Philosophie außerhalb der Stadt, in der Erhabenheit des Kaukasus, bei den Bakunins in der Idylle, höhergestimmt noch durch die Gegenwart der Schwestern Bakunins. Daß der Bruch mit Hegel in Petersburg geschah, bestätigt die enge Wechselbeziehung zwischen Bewußtseins- und Seinslage im Leben Belinskijs. Und dieser Bruch war auf die Dauer unvermeidbar, denn so sehr sich Belinskij bemühte, die Welt vernünftig anzusehen, -

Scheibert, S. 186.

Gemeint ist der berühmt-berüchtigte Auf satz zum Jahrestag von Borodino (II, 240ff.). 
sie sah ihn unvernünftig an. Belinskij konnte und wollte nicht um eines abstrakten Prinzips, um des 'Allgemeinen' willen das individuelle Leid, das - wenn auch nur zeitweise - Unrecht hinnehmen.

Er versuchte, sich vom philosophischen Bestimmtwerden freizumachen, band sich aber nach kurzem sozialutopistisch-anarchistischen Geplänkel im historisch-materialistischen Determinismus erneut. Es wäre irrig, nun von Belinskij eine Literaturtheorie zu erwarten, die das Geschriebene allein an dem mißt, was es zur Überwindung der gegenwär tigen Mißstände und zur Antizipation eines besseren Morgen leistet. Aber der am Idealismus orientierten Theorie der 'real'naja poézija', die mit der Darstellung des Typischen als 'my slenie $\mathrm{v}$ obrazach' die Verbindung zur Idee gewăhrleistete, setzte er eine naturalistische Auffassung entgegen, in der das dichterische Bild als bloßes Beispiel nurmehr auf die empirische Wirklichkeit bezogen sein sollte. Küppers verweist auf den Wandel im Sprachgebrauch Belinskijs: Mit der Loslösung von der idealistischen Kunstphilosophie habe er das Wort 'obraz' mehr und mehr durch 'kartina' verdrängt, um auch sprachlich den Abbruch der Beziehungen zur Idee zu demonstrieren ${ }^{53}$. Man soll diesen Wortwechsel nicht überschătzen. Die Wendung 'my slenie $v$ obrazach' taucht auch später noch auf, wird auch da von Belinskij verwandt, wo der Dichter auf die Beleuchtung und Erklärung der Realitat hic et nunc verpflichtet wird: "Jetzt Dichter sein heißt - in dichterischen Bildern denken (myslit' poeticeskimi obrazami) ... Notwendig ist eine starke Teilnahme an den Fragen der der zeitigen Wirklichkeit" ( $\mathrm{X}, 39)$. Hier sind offensichtlich 'kartiny' gemeint, wo 'obrazy' geschrieben steht.

In den letzten Jahren seines Lebens war Belinskijs Blick fast ausschließlich auf die sozialen Verhăltnisse seines Landes fixiert, auf Erscheinungen also, denen er sich zeitlebens năher gefühlt hatte als z. B. der Buntheit der Natur oder fernen kosmischen Harmonien. Vielleicht sind nicht zuletzt deshalb diese letzten Jahre seine produktivsten; vielleicht spricht er deshalb in dieser Zeit mit der größten Überzeugungskraft, die entscheidend in die fünfziger und sechziger Jahre ausstrahlte.

Küppers, S. 141. 


\subsection{3}

Vom zweiten Teil dieser Arbeit, also von der Betrachtung zweier wahrscheinlich zentraler Wörter (Begriffe) dürfen wir die Bestätigung der folgenden, meines Erachtens wesentlichen Züge Belinskijs erwarten:

1.) Die als Orientierungshilfen aufgegriffenen, an und für sich oft unvereinbaren Weltanschauungen hat Belinskij auf Programme des Weltablaufs reduziert und konnte sie so zu einer leidlich kontinuierlichen geistigen Entwicklung fügen, einer Entwicklung, die durch fortschreitende Ent-Idealisierung gekennzeichnet ist, Entidealisierung auch als Ernüchterung verstanden, als Verkirzung der 'ewigen Idee', der 'allwaltenden Vernunft', die an der Vielfalt der Natur, der Weite des Kosmos ablesbar sind, zu einer materialistischen Konzeption der Geschichte, die mit den sozialen Verhältnissen dialektisch verknüpft ist.

2.) Belinskij ger iet mit seinen Leitlinien in Konflikt, weil

a) ihm yeitgehend das Problem von Notwendigkeit und Freiheit unzugänglich blieb,

b) er die Diskrepanz zwischen Idee (Programm) und Wirklichkeit nicht mit der Hoffnung auf eine ferne Kongruenz über spielen wollte und konnte.

Bellnskij war es rational und gefühlsmăßig nicht möglich, die momentane Disharmonie als eine vorübergehende, im großen Ganzen sich endlich aufhebende zu begreifen. Daß das in den meisten Fällen auf eine Humanisierung, eine Erwärmung kalter Theorie hinauslief, muß nachdrücklich angemerkt werden. Die Eigenschaft der herzlichen Teilhabe am Einzelschicksal hat Belinskij vor extremen Positionen, vor einem Dogmatismus bewahrt. Man mag ihm Oberflăchlichkeit des Denkens vorwerfen, auch Wider sprüchlichkeit - wenn man ihn an seinen großen, für ihn viel zu großen Vorbildern mißt - : Tiefe der Einfühlung und Aufrichtigkeit in der Zielsetzung kann man ihm nicht absprechen.

Das sind Merkmale eines Menschen, der mehr in die Breite als in die Tiefe wirkt, der mehr fragt, anregt als endguiltig löst. Folglich fehlen grundl egend neue Definitionen überkommener Begr iffe, die nach- 
haltige Verschiebung von Wortbedeutungen. Wahrend seiner ganzen Schaf.fenszeit hat Belinskij an einer Vor stellung von der Konstellation der geistig-seelischen Krafte des Menschen festgehalten, die durch eine dialektische Spannung zwischen Kopf und Herz und der versöhnenden Mitte 'Vernunft ${ }^{\circ}$ bestimmt ist. Es besteht die Gefahr, den Rang der hier unter suchten Wörter zu über schätzen, aber der erwăhnte stabile Kern der Weltanschauung Belinskijs scheint mir doch am deutlichsten in seinem Begriff der Vernunft (razum) als ein durch das Gefühl (čuvstvo, serdce) erwărmter Verstand (um, rassudok) zum Ausdruck zu kommen. Das Gefühl, die Einfühlung öffnet den auf das Endliche, das vorderhand Greifbare begrenzten Verstand für das Unendliche, das mutmaßlich Kommende und wirkt so korrigierend, weil wertsetzend, sinn- und richtunggebend ein. Auf der anderen Seite hat die Vernunft bei Bel inskij die Dimension der Humanisierung rational gewonnener Theorien, weil das Gefühl, das Mitfühlen den einzelnen Menschen in das abstrakt Kategorische des Verstandes einbezieht. 


\section{Kapitel}

Deduktion einer Methode der Semasiologie aus den Prämissen der Allgemeinen Sprachwissenschaft.

\subsection{Die Prämissen der Allgemeinen Sprachwissenschaft}

Diese Prämissen sind meines Wissens zuletzt von Wolf Thümmel zusammenhängend formuliert und diskutiert worden ${ }^{54}$. Diese Angaben sind als empirisch hinreichend gesichert anzusehen. Weil es Aufgabe dieser Arbeit ist, die Gültigkeit der daraus deduzierten besonder en semasiologischen Prämissen nachzưweisen, kann ich mich hier auf eine Wiedergabe der Leitsätze Thümmels beschränken: Unstimmigkeiten in den Grundlagen würden sich in den Ableitungen zeigen.

(1) Die Menschensprache ist ein Zeichensystem (S/signum-System), dessen Zeichen akustisch sind, von menschlichen Sprechwerkzeugen artikuliert werden und einer Gemeinschaft zur Kommunikation dienen 55 .

Thümmel, S. 35ff. Er faßt die Ergebnisse der Forschungen Koschmieders zusammèn, vgl. dessen "Strukturbildende Eigenschaften" (Beiträge, S. 153ff.) und "Das Allgemeingültige der Syntax" (ebd., S. 369ff.).

Thümmel, Prämissen 1 und 2.

Das 'sprachliche Zeichen' wird durch die folgenden Prämissen für meine Unter suchung hinreichend definiert. Einen vorzüglichen Überblick über die Zeichentheorien gibt Thümmel a.a.O., S. 55-82

Das bekannte Bühlersche Organonmodell

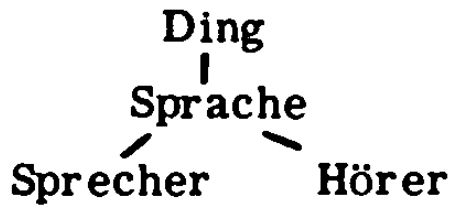

ist 1. Axiom jedes Zeichensystems. Die hier genannten drei differentiae specificae zum genus proximum 'Zeichensy stem' sind als Eingrenzung des Gegenstandes der Sprachwissenschaft unerläßl ich (vgl. Koschmieder, "Sprache und Geist", Beiträge, S. 142). Es ist dem Linguisten nicht möglich, z.B. das, was Funke im Anschluß an Marty als "äußere Sprachfor m" begreift (Funke, S. 24): das $\mathrm{Klangliche,} \mathrm{die} \mathrm{Gebärden,} \mathrm{die} \mathrm{Schrift} \mathrm{etc.,} \mathrm{des} \mathrm{weiteren} \mathrm{die}$ Sprech-/Schreibsituation, der Hintergrund - das geistige, gesell schaftliche $\mathrm{Kl}$ ima etc., in seiner 'Bedeutung' für den einzelnen Sprechakt zu erfassen. Diese der Sprache beigegebenen Zeichensysteme müssen vom Sprachwissenschaftler zunächst ausgeklammeI werden, womit keineswegs ausgeschlossen wird, daß dann vom 
(2) Kommunikation setzt die Absicht voraus,

a) akustisch verstanden zu werden,

b) mit dem akustisch verstăndichen Zeichen den intell ektuellen Inhalt ( $\mathrm{V}$ intentum: das Gemeinte) zu übermitteln ${ }^{56}$.

(3) Es gibt nahezu unendlich viele I, die in jeder Sprache durch ein oder mehrere $S$ ausgedrückt werden können 57 .

(4) Das S-Sy stem besteht aus Inventar und Synthese 58 .

(5) Ein I kann mehreren S, kann aber auch keinem $S$ zugeordnet sein 59 .

(6) Ein S kann mehreren I, muß aber mindestens einem I zugeordnet $\operatorname{sein}^{60}$.

(7) In jeder Sprache gibt es S, die bestimmten I, und I, die bestimmten $\mathbf{S}$ fest zugeordnet sind. Diese I sind bezeichnet, sind Designata (D). Die bezeichneten I bilden das für die jeweilige Sprache besondere System (das interlingual variable D-System). Auf Grund der Mehrdeutigkeit des Zeichens ist das Bezeichnete nur im ein-

S-System 'Sprache' - aber eben vom S-Sy stem aus! - Rückschlüsse auf Außer sprachliches statthaft, für den Philologen sogar unerläßlich sind.

Das ist vergleichbar mit der werkimmanenten Interpretation in der Literaturwissenschaft. Aber sowenig man an ein sprachliches Kunstwerk unter völliger Absehung vom Autor herangeht - es ist einfach geheuchelt, wenn man so tut, als ob er unbekannt wäre - , sowenig kann man in der Semasiologie von den Vorbelastungen der Sprache durch Außersprachliches absehen, wenn man den bestimmten Bedeutungsspielraum eines bestimmten Wortes erfor schen will.

Wie gesagt: diese Arbeit ist zweisträngig; eine gewisse methodische Inkonsequenz ist unumgänglich.

Thümmel, Prămisse 3. "Grundsătzlich gibt es nichts, was nicht I eines oder mehrerer sprachlicher Zeichen sein kann" (a.a.O. , S. 44).

Thümmel, Prämsse 4. Die interlinguale Konstanz des Gemeinten ist ein Sprache konstituier endes Axiom. Ander Z Zeichensy steme (Code, Flaggen etc. ) sind eben auch deshalb keine Sprache, weil sie nur eine beschrănkte Zahl von I übermitteln können.

Thümmel, Prămisse 10.

Thümmel, Prämisse 6.

Thümmel, Prămisse 7. 
gr enzenden Zusammenhang (Synthese, Relevanzstellung) mit dem Gemeinten identisch ${ }^{61}$.

(8) Das Verháltnis von S, D und I ist prinzipiell beliebig und durch die jeweil ige Konvention bestimmt ${ }^{62}$.

61 Thümmel, Prămisse 8.

"Jedes Element des $D$ ist stets ein I, aber nicht jedes $I$ ist in jeder Sprache ein Element des D, sondern die Elemente des $D$ stellen in jeder Sprache eine eng begr enzte Auswahl der unendlichen Möglichkeiten des I dar und bilden ein System von Funktionen ebenso wie die $S$ ein System von Formgestalten bilden. Wăhrend also das invariante I für alle Sprachen dasselbe ist, bilden $S$ und $\mathrm{D}$ das eigentliche, für jede Sprache individuell gebaute mor phologisch-syntaktische Sy stem" (Koschmieder: "Die strukturbildenden Eigenschaften. ..", Beiträge, S. 160; Hervorhebungen von mir.). So gesehen ist es $\mathrm{m}$. E. einleuchtend, von einer Haupt- (D) und Nebenfunktion (nicht bezeichnetes 1 ) des S zu sprechen. (Vgl. Koschmieder, ebd., S. 165 und "Zur Bestimmung der Funktionen grammatischer Kategorien", Beiträge, S. 12f.)

Mit dem S 'Präsensendung' ist in erster Linie die 'Gegenwart' bezeichnet (D/Hauptfunktion). Das I 'Futur' z. B. auszudrücken, ist eine Nebenfunktion des S 'Prăsensendung'.

62 Thümmel, Prämisse 9. 


\subsection{Die Prämissen der Semasiologie}

Die Beantwortung der Kernfrage der Semasiologie nach der Bedeutung des Wortes ist möglich,

(A) wenn das S- und D-Sy stem der unter suchten Sprache bekannt sind, d.h. die Zeichen und das damit Bezeichnete (Hauptfunktion), im besonderen: das Wort und dessen Grundbedeutung ${ }^{63}$,

(B) weil jedes Gemeinte, jede Bedeutung auch in ein und derselben Sprache auf mehrfache Weise bestimmt werden können.

Insofern ist die Bedeutungslehre eine der Laut-, Form- und Satzlehre übergeordnete Diszipl in (so auch Kronasser, S. 23).

'Haupt - oder Grundbedeutung' definiere ich als die Bedeutung, die dem größten Teil der Sprachgemeinschaft beim Hören/Lesen des Wortes als erste gegenwärtig ist. Wissemann hat in seinem Aufsatz "Erlebte und abstrahierte Wortbedeutung" auf die Erscheinung hingewiesen, daß der Hör er eines isolierten Wortkör pers zunächst nur eine Bedeutung erlebt, obgleich sich mehrere Bedeutungen abstrahieren lassen (Wissemann nennt als Beispiel 'Korn') (Ähnliches gilt wohl auch für grammatische Kategorien.). Wissemann ver sucht, mit dieser im Experiment gewonnenen Erfahrung die "weitverbreitete Auffassung" zu widerlegen, daß "nur das Wort im sinngebenden Zusammenhang als bestimmter Begr iff sträger zu gelten (habe)" (Kainz, Psychologie der Sprache I, S. 89, zit. nach Wissemann, a. a.O., S. 199). Wissemann meint, daß der Hörer das Wort zunăchst satzfrei mit einer Bedeutung verbunden haben müsse, bevor er es in einen Zusammenhang einbetten könne (ebd., S. 200). Das ist richtig, aber der Hörer verknüpft m. E. das isolierte Wort doch nur deshalb mit einer Bedeutung, weil er es in Sătzen kennt.

Zum Unter schied von 'Gemeintes', 'Bedeutung', 'Funktion': Das Zeichengefüge (Kombination von Symbol - und Feldwerten) ist Trăger eines $\mathrm{Ge}$ m e int $\mathrm{e}$.

Das Wort (Zeig-bzw. Symbolwert) hat eine Bedeutung und eine Funktion.

Grammatische Kategorien (Feldwerte) haben eine Funktion. Hierzu: Koschmieder, "Zur Bestimmung der Funktion...", Beitrăge, S. 23f. Hartmann unter scheidet im ăhnl ichen Sinne "anordnende" (grammatische Formen) und "angeordnete" ('Namen') Kategorien. Vgl. Hartmann, Das Wort als Name, S. 9. 
Das heißt:

(C) Die Beschreibung des Gemeinten eines Zeichengefüges, enger: der Bedeutung eines Wortes ist Wiedergabe 'mit anderen Worten', ist ein Akt der Übersetzung nach dem Schema: $S_{1}>D_{1}>I>D_{2}>S_{2}$, wobei es gleichgültig ist, ob $\mathrm{D}_{2} / \mathrm{s}_{2}$ der selben Sprache oder Sprachperiode wie $S_{1} / D_{1}$ entnommen sind oder anderen ${ }^{64}$.

Wenn die Kenntnis des Wortes und seiner Grundbedeutung vorausgesetzt wird, dann kann weder das eindeutige Wort noch das unendlich vieldeutige Gegenstand der Semasiologie sein, d.h. sie geht von der endlichen Vieldeutigkeit des sprachlichen Zeichens, von der 'Unschärfe der Bedeutung' aus:

(D) Das isolierte Wort ist vieldeutig; es hat einen Bedeutungsbereich ${ }^{65}$, als dessen Mitte das Bezeichnete (D) angesehen werden kann.

Die Prämissen E bis I sind Ableitungen aus dieser Prämisse D; es scheint mir deshalb erforderlich zu sein, auf die zitierte 'Unschärfe' der Wortbedeutung etwas näher einzugehen. Als Ursache wird durchweg der abstrakte Charakter des Wortes angeführt ${ }^{66}$. Die 'wesensgemăße

Auf Grund der interlingualen Konstanz des Gemeinten, die Koschmieder in "Das Gemeinte" (Beitrăge, S. 103ff.) bewiesen hat, ist Über setzung grundsătzlich möglich. Vgl. auch: ders., "Das Problem des Über setzens", ebd., S. 107ff., besonders S. 110-112.

Ich ziehe die Bezeichnung 'Bedeutungsspielraum' vor, weil das zwar weniger metaphorische und daher als Terminus vielleicht tauglichere Wort 'Bedeutungsber eich' leicht mit 'Bedeutungsf eld' verwechselt wird. Erdmann spricht in diesem Zusammenhang von einem "Grenzgebiet, das einen Kern umschließt" (Erdmann, S. 5). Das Bild ist nicht sehr glücklich gewahlt, denn das Grenzgebiet ist in den meisten Fallen erheblich größer als das umgrenzte Gebiet, das Wort erheblich weitreichender als der begr iffliche Kern.

Vgl. z. B. Baldinger, S. 22.

Unhaltbar ist m. E. Schaffs Argumentation: "Die sprachlichen Zeichen sind nicht deshalb ungenau, weil sie unvollkommen wären..., sondern weil zwischen der starren, die Erscheinungen der Wirklichkeit unter irgendeinem Gesichtspunkt klassifizierenden Einteilung und dieser Wirklichkeit selbst ein Verhältnis der Inadäquatheit 
Ungenauigkeit ${ }^{67}$ der Sprachmittel überhaupt ergibt sich aus den Prămissen 3, 5 und 6, in denen u.a. die Dișkrepanz zwischen der sehr großen Zahl ${ }^{68}$ der intellektuellen Inhalte und dem beschränkten Zeichenvorrat angesprochen ist.

Mit dem geringen Inventar einer Sprache kann die Füle des Meinbaren artikuliert werden; die S-Schicht kann die I-Ebene lückenlos dekken, und zwar nach Prămisse B sogar mehrfach, was mit der 'Doppelfunktion des Wortes' begründet werden kann, auf die Hartmann in seiner Arbeit "Das Wort als Name" 69 ausführlich eingeht:

1. können unter einem Wort mehrere Sachen ${ }^{70}$ gruppiert sein; das Wort ist "typisierend-sachbezogen" 71 .

besteht. Denn diese Wirklichkeit entzieht sich durch thre Verănderlichkeit, ... jeglicher starren Klassifikation" ("Unscharfe Ausdrücke und die Grenzen ihrer Präzisierung"; Essays.... , S. 65ff., hier: S. 78). Schaff verkennt das Spezifische des Zeichensystems 'Sprache', das per definitionem (sh. Prămissenkatalog) elastischer als die Wirklichkeit ist. Eine Konsequenz der Anschauung Schaffs wäre, daß der Satz nicht die Ebene der Bedeutungsbegrenzung, sondern der -erweiterung der betelligten Wörter ist.

Vgl. Hartmann, Theorie, S. 255, 9.131.

Obgleich die Zahl der I theoretisch unbegrenzt ist, muß das Wort 'unendlich' vermieden werden. Die Aussage Humboldtg z. B. "Sie (die Sprache) muß... von endlichen Mitteln einen unendlichen Gebrauch machen" (a.a.O., S. CXXM) ist logisch nicht haltbar: 'Unendlich' dividiert durch eine noch so große Zahl von S ergäbe für jedes $S$ unendl iche Vieldeutigkeit. Die unsinnige Behauptung, daß ein Wort isoliert überhaupt nichts bedeute, wäre dann nur konsequent. Aber dann wăre auch jeder Einschränkungsversuch in der Synthese (des Satzes) absurd. Wenn Koschmieder in "Das Gemeinte" (Beiträge, S. 104) schreibt: "Alle G (Gemeinten) bil den eine geordnete, abzăhlbare, unendliche Menge", dann wird zwar deutlich, daß er die logische Problematik zu umgehen ver sucht, aber Zăhlbarkeit und Unendlichkeit sind eben doch einander ausschließende Gegensătze.

69 Hartmann, Das Wort als Name, S. $41 \mathrm{ff}$.

70 Der Einfachheit halber wird im folgenden mit 'Sache' alles bezeichnet, was Gegenstand einer 'Benennung' sein kann. (So auch Hartmann, ebd., S. 9, Anmerkung 2).

ebd., S. 52, \&55. 
Beispiel: Der Verstand, die geistige Făhigkeit, das Urteilsvermögen der Menschen A, B und C werden russisch 'um' genannt.

Durch Synthese können Nuancen gesetzt werden.

2. können mehrere Wörter auf eine Sache bezogen werden; diese Wörter sind "nuancier end-sachbezogen" 72.

Beispiel: Das geistige Vermögen des Menschen A kann russisch 'um', 'razum', 'rassudok', 'tolk' genannt werden. Durch Synthese können die Nuancen aufgehoben werden.

Hartmann resümiert: "Es gibt nur Wörter für Typen, sei es für Typen von Sachen oder für Typen von Nuancen" 73 und verweist damit auf den "abstraktiven Charakter" 74 des Wortes. Das Wort kann verstanden werden als der Nenner, auf den eine zählbare Menge von gemeinten Sachen oder Nuancen gebracht werden können.

Hartmann greift auf Gedanken Cassirers zurück, die bereits Anfang der zwanziger Jahre entwickelt wurden: Das Wort ist 'symbolische Form' (Cassirer); es zeichnet sich durch seine "Sachentzogenheit", die "Variabilität in der Bezugnahme" vor allen anderen Zeichen aus (Hartmann) ${ }^{75}$. Im Wort ist "die Identität zwischen Wirklichkeit und Symbol (getilgt)" (Cassirer) ${ }^{76}$. "Die Nennung (liegt) grundsătzlich über den Sachen" (Hartmann) 77.

Die Bestimmung des Wortes als vages Symbol ${ }^{78}$ besagt, daß ein Wort zwar auf eine Sache (Sachgruppe, Sachverhalt) durch einzel sprachliche Konvention ausgerichtet ist, aber dabei offen für andere Inhalte bleibt. Weder ein Sy stem nur leer er Hüllen, noch ein Gefüge

ebd., S. $53, \S 56$.

ebd., S. 58.

75

Hierzu besonders: ebd., S. $42-51$.

Cassirer, S. 137.

77 Hartmann, Das Wort als Name, S. 39.

78 Cassirer, S. 44. 
nur eindeutiger Zeichen kann'Sprache' genannt werden ${ }^{79}$. Die Bindung der Wörter an eine Hauptbedeutung ist unterschiedlich fest. Der Anschein, daß Wörter, die in erster Linie sinnlich Wahrnehmbares benennen, durch die Vorstellbarkeit stärker determiniert seien als solche, die vornehmlich ${ }^{80}$ Abstraktes bezeichnen, wider spricht der Beobachtung, daß sogenannte Konkr eta in den meisten Fallen auch in unanschaulichen Sinnbezirken einsetzbar sind (und durch Verfestigung der Übertragung oft $z u$ 'Abstracta' wurden, dagegen Benennungen für Abstraktes kaum ins Gegenstăndliche gezogen werden können; sie sind fester an das Benannte gebunden, weil sie Merkmale 'verkörpern', Prädikationen implizieren, die wegen ihrer Komplexivităt kaum oder nicht übertragbar sind. Die Einteilung des Wortschatzes in Konkr eta und Abstracta ist wenig brauchbar; hier sind Gliederungskriterien, die in der I-Ebene angebracht sind, auf die S-Ebene übertragen worden. Wörter sind immer abstrakt: "Der Name ist den Fakten gegenüber 'abstraktiv', wenn man von seiner (ideellen) Einheit gegenüber der (faktischen) Vielheit ausgeht" ${ }^{81}$. 'Ein Stück Wirklichkeit wiedergeben ${ }^{82}$ heißt ja nicht Wirklichkeit sein. Insofern ist auch die Gliederung des Wortschatzes nach Feldern problematisch. Zwar ist es zulăssig und nützlich, in der Ebene des Gemeinten und der Bedeutung Sinnbezirke anzusetzen, diese Grenzen dann aber in den Wortschatz übertragen, heißt die Freiheit der Bezugnahme einengen. Die folgenden Sătze Jost Triers können als programmatisch für die Feldtheorie angesehen werden:

Das heißt nicht, daß diese Extremformen ausgeklammert sind. Zeigwerte sind z. B. fast unbeschränkt beziehbar, während z. B. Eigennamen eindeutig sein können. Im allgemeinen muß man von einer "relativen Autonomie des Wortes" (Baldinger, S. 22), von "relativer Unabhängigkeit" (Ullmann, S. 57) sprechen. Vgl. auch die Prämissen 3,5 und 6.

'Unentschiedene' Wörter wie 'begreifen', 'Geist' wird man in synchronischer Betrachtung zu den Homonymen zăhlen. Hartmann, Das Wort als Name, S. 47; vgl. auch ebd., S. 49. nicht reales Sein, sondern schafft intell ektuelle Symbole" (Der deutsche Wortschatz..., S. 2). 
"Das Wortfeld ist zeichenhaft zugeordnet einem mehr oder weniger geschlossenen Begriffskomplex, dessen innere Aufteilung sich im gegliederten Gefüge des Zeichenfeldes darstellt, in ihm für die Angehörigen einer Sprachgemeinschaft gegeben ist. Dies in einem inhaltlich zusammengehörigen Teilausschnitt des Wortschatzes eben dem Wortfeld - sichtbar werdende Gefüge ist also die äußere, zeichenhafte Seite der begrifflichen Aufteilung, die jener Begr iff skomplex, Begriffsblock Begr iffsbezirk durch und für die Sprachgemeinschaft erfährt" 83 .

Hier wird die notwendige Vieldeutigkeit des Wortes, die es zum spezifisch sprachlichen Zeichen macht, übergangen und der Anschein einer 1 : 1 -Entsprechung zwischen S- und I-Schicht erweckt; die Hauptbedeutung entscheidet über die Zugehörigkeit zum einen oder ander en 'parataktisch' oder 'syntaktisch' aufgebauten Feld ${ }^{84}$. Zwar über schreiten längst nicht alle Wörter die Grenzen des Sinnbezirks, aber in dieser Verallgemeinerung ist die Äußerung nicht haltbar. Es ist verschiedentlich darauf hingewiesen worden, daß das Wortfeld den Wörtern als Wörter nicht gerecht werde, weil kaum ein Wort nur einem Feld angehöre und Überschneidungen sozusagen in der Natur der Sache lägen: "Dem Wort erwächst vielmehr gerade aus dem ihm und gerade nur ihm eigenen Verknüpfen von Wortfeldern seine besondere 'Bedeutung'. Eine Betrachtungsweise nach 'Feldern' muß das Wortganze und damit auch ein Anschauungsganzes zerreißen" 85 .

Sinnbezirke, Bedeutungsfelder haben zwar ihren Wortschatz, die Farben 'blau' und 'grün' z. B. werden zwar mit den entsprechenden Wörtern benannt, aber diese Wörter können doch auch die Befindlichkeit von Sachen anzeigen, die - weil optisch nicht wahrnehmbar gar keine Farbe tragen können.

Trier, Der deutsche Wortschatz..., S. 1.

Diese Modelle, die Porzig aufzeigt (a.a.O., S. 117ff.), sind die găngigsten. Porzig ver sucht, der Tatsache Rechnung zu tragen, daß ein Wort mehreren Feldern zugehört.

Hager, S. 17; ähnlich Thümmel, S. 43, der auf die Problematik der Grenzziehung eingeht. Ähnlich auch S. Öhmann, S. 72ff., besonders S. 83. Auf Trier bezogen schreibt Smelev: "Der schwache Punkt der For schungen J. Triers liegt da, wo er die Funktionen des Wortes in verschiedenen Kontexten ignoriert" (a.a.O., S. 26). 
Der fallige Eimwand, daß der Einsatz von Wortern in fremden Sinnbezirken eben ein metaphorischer sei, besagt nicht viel: Wenn nahezu unendlich viel Meinbares mit wenigen Zeichen zur Sprache kommen soll, dann kann das zwischen den durch das S-Inventar fixierten "Nennstellen" 846 (Designata) liegende Gemeinte nicht anders als 'metaphorisch' ausgedrückt werden, zumal die Dichte dieser Deutepunkte im Sachber eich unterschiedlich groß ist. Die Meinung Triers, daß ein Wort nur kraft seines Feldes bedeute ${ }^{87}$, ist strenggenommen nur dann richtig, wenn das Gemeinte eines Satzes dem gleichen Sinnbezirk angehört wie die Grundbedeutungen jedes beteiligten Wortes. Wird ein Wort aber z. B. zum Ausdruck einer Bedeutung herangezogen, die nicht (feldzuweisende) Hauptbedeutung ist, dann ist es geradezu notwendig, das Wort von seinem 'eigentlichen' $\mathrm{Be}$ deutungs-/Wortfeld abzuziehen. So führt die Eigenart der Sprache, auch Abstraktes so zu behandeln, als ob es sinnlich Wahrnehmbares wäre, zu Redegebilden, die den Haupt-Sachbezug des einen oder anderen Wortes tilgen.

Die Wörter bedeuten kraft des Sachbezugs (Feldzugehörigkeit des Gemeinten) der Rede, die Hartmann folgerichtig als "Bezugsgefüge" definiert $^{88}$.

Nun ist es nicht so, daß die Feldtheor etiker diese Schwierigkeiten nicht gesehen hätten, aber es hilft $m$. E. nicht weiter, wenn den Nebenbedeutungen, den Übertragungen etc. dadurch Rechnung getragen wird, daß dieses Wort dann eben mehreren Feldern ${ }^{89}$ zugehört oder die Vorstellung der Mehrdimensionalităt herangezogen wird. Das ursprünglich klare Bild des (physikalischen) Feldes, der Pole, Kraftlinien etc. ver liert an Prăgnanz, wird theor etisch unhandlich.

Hirtmann, Das Wort als Name, S. 66.

Trier, Der deutsche Wortschatz..., S. 5. Hartmann, Das Wort als Name, S. 31.

Es gábe einen fal schen Sinn, würde man Triers These dahingehend abwandeln, daß das Wort 'kraft se in e r Felder' bedeute; man bedenke, wieviel Feldern z.B. das Wort 'grün angehören müßte. Es fallt auf, daß die Feldtheorie durchweg mit Beispielen illustriert wird, die durch einen besonders festen Sachbezug gekennzeichnet sind: Hausgerăte, Militărwesen etc., und vor allem 'Abstracta'. 
Bei der Lösung der (mehr onomasiologischen) Frage, wie ein bestimmter Sachbereich sprachlich wiedergegeben wird, wenn man also die Sprache von der I-Ebene aus ansieht, 'Namen um eine Er scheinung bündeln ${ }^{90}$ will, ist es methodisch konsequent, vom 'Feld' auszugehen. Die Feldtheorie kann wenig leisten, wenn ein bestimmtes Wort auf seine Bedeutung hin, wenn von der S-Ebene aus das Gemeinte erschlossen werden soll, es also um die 'Gruppierung von Sachen unter einen Namen' geht. Das Zeichen hảlt sich buchstáblich nicht an die Kategorisierungsmodelle der I-Ebene, der Sachen und Begriffe. Allgemein kann man sagen, daß überall da, wo Sprachwissenschaft sich die Beschreibung einzelsprachlicher Erscheinungen als Aufgabe stellt, sie nicht von dem ausgehen kann, was allen Sprachen gemein ist, d.h. von der I-Ebene ${ }^{91}$. Die Mehrdeutigkeit des Wortes wird im Redegebilde aufgehoben; in der Terminologie Hartmanns: "Das Idealkorrelat eines Zeichens wird durch Applikation mit dem Realkorrelat verbunden" ${ }^{92}$. Wir können diese Zeichensynthese als Proze $\beta$ der Zeichenvervielfaltigung und zahlenmäßigen Anpassung des Inventars an die Menge des Meinbaren ansehen; Eindeutigkeit ist demnach nur im synthetischen Zeichen zu erreichen ${ }^{93}$.

90 Hartmann, Das Wort als Name, S. 52. Sh. auch S. 64 dieser Arbeit. Vgl. Thümmel, S. 120.

93 Vgl. Erdmann: "Die Wortbedeutungen bedingen sich gegenseitig und schränken einander ein" (a.a.O., S. 43). "Die Kunst aber, unzweideutig klar zu sprechen oder zu schreiben, besteht darin, Wörter und Wendungen so zueinander zu fügen, daß sie sich gegenseitig eindeutig machen, daß sie den Hörer oder Leser zwingen, jeden Ausdruck nur im gewollten Sinn aufzufassen" (ebd., S. 44).

Unter 'synthetischem Zeichen' verstehe ich das Redegebilde, die sprachliche Nachbarschaft, die das unter suchte Wort semantisch konsol idiert. Ich vermeide hier den sehr viel weiter en Begr iff des 'Kontates', weil in thm Sprachliches und Außersprachliches vermischt ist. Wie unscharf dieser Begr iff ist, zeigt zum Beispiel die Definition N. N. Amasovas, die von der "unmittelbaren Redeganzheit" spricht (a.a.O., S. 22: "Kontekst, t. e. neposr edstvennoe recevoe celoe, èlementom kotorogo javljaetsja dannoe slovo"). Um diesen Begriff brauchbar zu machen, spricht Amasova von 
"Niemals (ist) das einzelne Wort, sondern erst der Satz der wahrhafte Trăger des sprachlichen Sinnes: denn in thm erst enthüllt sich die ursprüngliche Kraft der Synthesis, auf der alles Sprechen, wie alles Verstehen zuletzt beruht" 94 . Der Satz ist das Produkt der Tătigkeit (energeia) Sprache, der "Arbeit des Geistes, den artikulierten Laut zum Ausdruck des Gedankens făhig zu machen" ${ }^{95}$. Dem Satz als Einheit der 'parole' steht das Wort als Einheit der 'langue' gegenüber.

Die Einführung des artikulierten Lautes (ergon) - die Nennung also - ist nur die erste Dimension der von Koschmieder dreidimensional gedachten sprachlichen Noetik ${ }^{96}$. Sinnvoll gemeint werden kann nur, wenn das Benannte in einem Sachverhalt gesehen, wenn es in einen Sachverhalt gestellt, d.h. in Raum und Zeit verankert wird und eine Leistungsdirektive erhălt (Kundgabe, Auslösung, Darstellung). Diese drei Dimensionen können nur ausnahmsweise in e in e m Wort sein; was gemeint ist, kann man nur mit einem Wort sagen, wenn es satzwertig

ver schiedenen Stufen (Kontext 1. und weiteren Grades), vom konstanten (postojannyj) und variablen (peremennyj) Kontext. Aber auch dann ist die terminologische Trennung $\mathrm{zwischen}$ 'innerer und äußerer Sprachfor $\mathrm{m}^{\prime}$ nicht deutlich genug.

Die steigende Verschwommenheit des Begriffs beklagt mit ahnlichen Argumenten Ullmann, S. 56.

Cassirer, S. 105.

ebd., S. 104. Cassirer bezieht sich auf Humboldts grundlegende Arbeit "Über die Ver schiedenheit des menschlichen Sprachbaues" (1836). Die berühmte Feststellung, daß die Sprache "kein Werk (Ergon), sondern eine Thătigkeit (Energeia)" (Humboldt, S. LVM) sei, besagt, daß es das, was dann später von de Saussure als 'langue' von der 'parole' (Saussure, S. 17f.) abgesetzt wird, eben nur als künstliche Isol lerung, als "todtes Machwerk wissenschaftlicher Zergliederung, zerstreutes Chaos von Wörtern und Regeln" (Humboldt, S. LVII) gibt, daß der determinierende Prozeß 'Sprechen $^{\circ}$ - man muß das m. E. dialektisch sehen - das vage Sy stem 'Sprache' negiert: Zum Ausdruck des Gedankens wird das Wort erst fahig, wenn die Fretheit in der Bezugnahme getilgt wird.

96 Koschmieder, "Die noetischen Grundlagen der Syntax", Beitrăge, S. 70ff., besonders S. 79 . 
(Kundgabe, Auslösung) oder auf der magischen Stufe der Identität von Zeichen und Sache gebraucht wird 97 .

Aus der vorangegangenen Diskussion der Vieldeutigkeit des isolierten sprachlichen Zeichens ergeben sich für die semasiologische Praxis weitere Prämissen:

(E) Weil nur das synthetische Zeichen Träger eines eindeutig Gemeinten sein kann, ist das einfache Wort nur in Opposition zu anderen Zeichen eindeutig.

(F) Wenn das synthetische Zeichen Eindeutiges meint, dann ist auch die Bedeutung jedes Einzelzeichens dieses Gefüges eindeutig.

(G) Das Wort bedeutet kraft des Sachbezugs des synthetischen Zeichens.

(H) Die aktuelle Bedeutung eines Wortes ist der Bruchteil seines Bedeutungsber eichs, der im Gemeinten des synthetischen Zeichens relevant ist.

(I) Die lexikalische Bedeutung ist die Summe der in einer hinreichend großen Zahl von Redegebilden freigelegten Bedeutungen dieses Wortes.

Hartmanns Feststellung, daß es nur Wörter für Typen gibt, muß gemăß Prămisse $D$ dahingehend ergänzt werden, daß ein Wort in der Regel für mehrere Typen steht. Daraus ergibt sich eine vorlăufige Gliederung des Bedeutungsber eichs:

1) Typen (Sach- und Nuancengruppen), für die ein Wort steht.

2) Untergruppier ungen verschiedener Art.

3) Individuationen eines Typs, einer Untergruppe (Realisationen der Spezies).

Auf dieser Stufe ist das sprachliche Zeichen eine zum Signal tendier ende Extremform. Vgl. Cassirer: Für die "naiven und unreflektierten Äußerungen des sprachlichen Denkens" sei es bezeichnend, daß "der Name einer Sache und diese selbst. . . untrennbar miteinander ver schmolzen" sind (S. 21). 
2.30 Inhaltsfreie Kategorisierung der Redegebllde nach Kriterien der syintaktischen Logik

Im Anschluß an die Feststellung, daB das semantisch konsolidierte synthetische Zeichen der Ort eindeutiger Sachausrichtung der beteiligten Einzelzeichen ist, stellt sich die Frage, auf Grund welcher Kriterien die - nach Prámisse H sehr zahlreichen - Redegebllde geordnet werden können. Im Interesse einer Systematisierung der beschreibenden und vergleichenden Semasiologie liegt ein allgemeingilltiges Prinzip der Kategorisierung. Weder die von vornherein inhaltsbezogen ar gumentier ende, entsprechend nach Bedeutungen glieder nde Methode noch der Ansatz bei der einzel sprachlichen Syntax erfüllen diesen Anspruch.

2. 31

Ich gehe davon aus, daß die Bedingtheit der Wortbedeutung im Redegebilde mit der Bedingtheit der bedeuteten Sache im (erlebten, bemerkten) Sachverhalt korrespondiert. "Der Akt der begrifflichen Bestimmung eines Inhalts geht mit dem Akt seiner Fixierung in irgendeinem charakteristischen Zeichen Hand in Hand" ${ }^{98}$. Dieser Satz ist reversibel und lautet für unsere Belange modifiziert dann so: Der Akt der Fixierung eines Inhalts (Sachverhalts, Tatbestands) in irgendeinem charakteristischen (synthetischen) Zeichen geht mit dem Akt seiner begr iffichen Bestimmung Hand in Hand.

An dem komplexen Vorgang der Transponierung des 'gegebenen Seins' in 'intellektuelle Symbole ${ }^{-99}$ inter essiert uns der Schritt, der dem Sprechen unmittelbar vorausgeht, der Schritt, der es ermöglicht, daß eine Sache zur Sprache kommt: das Urteil. Die darin konstatierte (der sachlichen und sprachlichen Koordinierung parallele) logische Bedingtheit des Begr iff $s$ ist dem Sachverhalt wie dem Satzinhalt gegenüber abstrakt, d.h. auch: sach- und bedeutungsfrei zu beschreiben. "Logik determiniert die Form, nicht den Inhalt des Satzes;... Die

Cassirer, S. 18. ebd., S. 5. 
Logik der Syntax ist... ontisch neutral" ${ }^{100}$. Aber gerade deshalb ermöglicht logisches Urteilen sowohl das Gliedern der Realität durch Ablösung gleicher Verhaltensweisen/Tatbestănde von verschiedenen Sachen, als auch die Systematisierung des Inventars einer Sprache durch Isolierung gleicher Funktionen von verschiedenen Zeichen. Folglich kann man das synthetische Zeichen als Gefüge mit Bezug auf ein Meinen und ein Gemeintes, auf Bedeuten und Bedeutung begreifen, d.h. die angesprochene Denkform (Operation) vom Denkinhalt (Produkt) abtrennen. W a s gemeint ist, können wir erst dann mit Bestimmtheit sagen, wenn wir wissen, wi e es gemeint ist ${ }^{101}$. In dieser Weise vorzugehen, wäre im

\section{Franz Schmidt, Logik, S. 105.}

101 Um nicht mißverstanden zu werden, komme ich noch einmal auf das in der Einleitung zur Methode Gesagte zurück:

Das übliche Verfahren, die Bedeutung als Behauptung dem Beweis anhand der Nachbarzeichen voranzustellen, führt durchaus zu richtigen Ergebnissen (man kennt, d.h. man spricht und versteht die Sprache). Aber das Ergebnis einer solchen Arbeit besteht 'nur' in einer wohlgegliederten Beschreibung eines oder mehrerer Wortinhalte. Zugunsten dieses praktischen Ertrags wird der the or et is che Beitrag vernachlässigt. Nach Kronassers Meinung ist dieser theor etische Beitrag nicht Auf gabe der Semasiologie. Ihr obliege "nicht die Klärung der Frage nach den wesensmäßigen Beziehungen zwischen Wort und Inhalt oder Wort und Sache" (a.a.O., S. 77). Das sei Gegenstand der Erkenntnistheor ie oder gar der Metaphysik (!). Kronasser verkennt, daßz. B. die Erforschung der Ursachen des Bedeutungswandels Wissenschaften bemüht, die weit weniger mit der Linguistik zu tun haben als die Erkenntnistheorie. Noch entschiedener weist Güntert jegliche sprachimmanente Betrachtungsweise in der Semasiologie von sich: "Semasiologie muß historisch betrieben werden" (im Sperrdruck!, a.a.O., S. 49). Güntert meint, "daß es ein verhängnisvoller Irrtum" sei, daß manche die Sprache "an sich und um ihrer selbst willen" betrachten wollen (ebd.). So wie sich der Strukturalismus den Vorwurf gefallen lassen muß, um der 'Reinheit der Lehre' willen die Inhaltsseite der Sprache vernachlasssigt zu haben, so muß man auf der anderen Seite der diachronisch-inhaltsbezogenen Sprachwissenschaft die Abweisung der strukturalen Betrachtungsweise vorhalten. Wie auch an der Diskussion der Feldtheorie ersichtlich, kann von keiner Methode ein Alleingültigkeitsanspruch aufrechterhalten werden. Mehr Wechselseitigkeit $z$ wischen den noch weitgehend in Schulen polarisierten Lehrmeinungen wäre effektiver. 
Hinblick auf das der Analyse immanente Verfahren der Schluffolgerung konsequent.

Nun ist eine Gliederung der Redegebilde nach Weisen des Bedeutens nur dann sinnvoll, wenn eine Beziehung zum Inhalt der Bedeutung hergestellt werden kann. Mit den folgenden Uberlegungen soll plausibel gemacht werden, daB eine relativ feste Bindung zwischen einer bestimm ten Bedeutensweise und einer bestimmten Bedeutung besteht:

Das Wort kann (ich sehe hier zunächst von den Wörtern ab, die in mehrer en Sinnbezirken eingesetzt werden können) per definitionem auf eine Klasse von Sachen (Typ) und auf eine einzelne Sache (Individuation) bezogen werden, d.h. (Prămisse H) : das Redegebilde bestimmt den Grad des Blickwinkels auf den Bereich. Im Extremfall verengt sich der Winkel gegen $0^{\circ}$ : das Wort ist punktuell auf die Individuation eines Typs fixiert. Die größte Weite des Blickwinkels ist abhăngig von der Dichte der Nennstellen im Sinnbezirk ${ }^{102}$. Wenn die verschiedenen Bedeutungen eines Wortes Bruchteile seines Bedeutungsber eichs sind, dann können die Bedeutungen nach dem Umfang dieser Bruchtelle unterschieden werden.

Die spezielle Bedeutung zeichnet sich gegenüber der allgemeine ren durch höhere Merkmalsdichte aus, was auf die Binsenweisheit hinausläuft, daß die Zahl der Merkmale einer Spezies umgekehrt proportional der Zahl ihrer Vertreter ist. "... dem einzelnen Wort oder Sprachmittel stehen gegenüber

a) bei nur einem gemeinten Gegenstand: das Mehr, die Vielzahl seiner Eigenschaften oder Entstehungsgründe...,

b) bei jeder Klasse (Gruppe von Stuicken): die mehr Stücke dieser Art" 103 .

Das Maß der begrifflichen Konzentrierung wird in einem mehr oder weniger komplexen Gefüge potentieller und aktueller Urtelle 104

Hartmann, Das Wort als Name, S. 66.

103 ebd., S. 44.

104 Dem potentiellen Urteil fehlt zum vollen Urtell "das Moment der Behauptung, das ausdrückl iche Betr effen eines gemeinten Sachverhalts" (Franz Schmidt, Logik, S. 23). 
repräsentiert; damit ist das "Gerüst" 105 für den Aufbau des Satzes gegeben. Aber der Schluß vom syntaktischen Aufwand, der zur semantischen Konsolidierung notwendig ist, auf den Grad der Spezifizierung ist nur bedingt zulässig, denn nicht alle Urteile werden syntaktisch als aktuelle oder potentielle Sătze realisiert. Es ist möglich, daß ein einfacher Satz die spezielle Bedeutung eines beteiligten Wortes wiedergibt. Wenn die hier vorgetragene These stimmt, dann müßten sich hinter diesem einfachen Satz außer dem unmittelbar angesprochenen Urteil weitere Urteile verbergen. Dieser Gesichtspunkt muß also in die angestrebte Gliederung einbezogen werden.

Wie unterscheidet sich der Satz, der Träger realisierter und assozijerter Urteile ist, von anderen Sătzen? Auf Grund der Variabilităt der Bezugnahme (Prämisse D) können Wörter miteinander verbunden werden, der en Hauptbezugspole miteinander unvereinbar sind. Die Kataly satorfunktion nimmt ein sogenanntes tertium comparationis wahr. Der Zeichensynthese muß also der Vergleich der beiden benannten Sachen mit einer gemeinsamen dritten vorausgegangen sein, und zwar handelt es sich bei diesem Urteil meistens um ein subjektives Werturteil; über das tertium comparationis werden Subjekt und Prädikation mit einem gemeinsamen Merkmal belegt, das weder dem einen noch dem anderen Begriff objektiv wesentlich ist. Man kann drei Modelle sinnvoller ${ }^{106}$ syntaktischer Verknüpfung festhalten:

Die benannten Sachen sind objektiv

1) vereint (flüssiges Wasser) =

2) vereinbar (kaltes Wasser)

3) unvereinbar (lebendiges Wasser) /

Offensichtlich sind mit diesen potentiellen Urteilen (Sätzen) auch Grade der begr ifflichen Präzisierung bzw. der Bedeutungsverengung benennt: Modell 1) ist tendenziell uneingeschränkt typennennend, Modell 2) (nuancen-) eigenschaftsbezogen (objektiv) gruppennennend, Mo-

ebd. , S. 22.

106 Hier ist also nicht vom 'hölzernen Eisen' die Rede. 
dell 3) wertbesetzt (subjekttv) artnennend. Uber die 'semantische Entfernung 107 entscheiden zudem die Hohe der begrtfflichen Organisation, der Grad und die Richtung der Spezialisierung der Pradikation im Vergleich zum Subjekt. 'flüssig' und 'kalt' z. B. sind begrtfllich schwach organisiert, d.h. der Tatbestand des Flüssig-, Kaltseins ist merkmalsarm, aber 'flüssig' ist auf das Bedeutunggfeld hin spezialisiert, dem auch 'Wasser' angehört; 'kalt' ist dagegen bezugsvariabler, subjektneutraler. Das stark wortinhaltsbezogene Kriterium der begriffichen Organisation wird ausfuhrlicher im zweiten (angewandten) Teil dieser Arbeit zur Sprache kommen.

Da die Sprache auch mit Unanschaulichem so umgeht, als ob es anschaulich (begreif-bar) wăre, und zwar - Porzig hat darauf hingewiesen durch räumliche Koordinierung ${ }^{108}$, verbergen Verknüpfungen sogenannter Abstracta mit raumangebenden Wortern nur selten unausgesprochene Urteile. Ein Gedanke kann zwar 'an sich' nicht 'in den Sinn kommen', aber da dieser Tatbestand nicht anders als durch Wörter der Bewegung im Raum (Präposition, Verb) ausgedrückt werden kann, werden hier 'Gedanke', 'in' und 'kommen' und ähnliche Fügungen als vereinbar im Sinne des Modells 2) angesehen. $\mathrm{Da}$ es gewisse Schwierigkeiten der Grenzziehung geben kann, wird uns an kommenden Beispielen beschaftigen.

Ein kurzer Rückgr iff auf die von Koschmieder erarbeiteten drei Dimensionen der sprachlichen Noetik ist erforderlich: Es sind

1) die Dimension der Operation der Nennung,

2) die Dimension der Operation der ontologischen Verzeitung,

Vgl. hierzu Fulipec, S. 108ff. Er hat sicher recht, wenn er schreibit, daß das Verb 'rezitieren' nur im Märchen auf das Substantiv 'Elefant' bezogen werden könne. Diese Feststellung kann dahingehend umgekehrt werden, daß eben die Unver einbarkeit von Subjekt und Prádikation, der Unterschied der begr ifflichen Organisation (Höhe und Richtung) die Sonderbedeutungen beider Worter bewirken.

"Wo sie (die Sprache) Inneres meint, muß sie gleichsam in Äußeres ubber setzen"...". . die Sprache über setzt alle unanschaulichen Verhältnisse ins Răumliche" (Porzig, S. 209). Ähnlich auch Güntert, S. $73 f f$. 
3) die Dimension der sprachlichen Leistungsdir ektive ${ }^{109}$.

Damit ist der Rahmen abgesteckt, in dem sich das Meinen eines Sachverhalts abspielt, damit sind die Schritte sprachlicher Realisierung des Urteilskomplexes abgesteckt. Mit diesen Gesichtspunkten kann eine immer noch vorläufige - Ordnung in den Urtell skomplex gebracht werden.

Als eine Studie zur Nennoperation kann Hartmanns Schrift "Das Wort als Name" angesehen werden. Er schreibt, "daß durch Benennung die Sachen benutzbar, verfügbar werden". "Die Sachen sind durch die Zugabe eines Namens zum geistigen Bestand erhoben, als 'Gegenstand' neugeschaffen". Das sei Folge einer "bestimmten veränderten Einstel lung zum Objekt". Diese "Blickwinkel-Verengung" gehe Hand in Hand mit einer "Intentionsbündelung" und "Intensitätssteigerung". Die Intensität gehe "rein vom Subjekt" aus ${ }^{110}$. Die Dimension der Nennung gewăhrt einen weiter en subjektiven Spielraum als die Dimension der ontologischen Verzeitung. Die Benennung kann gewohnt oder ungewohnt sein, d.h. an den objektiven sachlichen und sprachlichen Gegebenheiten orientiert sein oder aber einen "subjektiven Bewertungsvorschlag" 111 enthalten, und das sowohl in Bezug auf die Sache (das Wasser, das Naß), als auch auf ihre Eigenschaft, ihr Verhalten (kalt, lebendig). In der Nennoperation wird also neben der namentlichen Erfassung der Sache häufig auch schon ein Urteil ausgesprochen; in der Nenndimension geschieht die subjektive Stellungnahme 112 .

Die Operation der ontologischen Verzeitung besteht wesentlich im Erfassen eines Sachverhalts (Tatbestands); sie ist Beurteilung der Koordination von benanntem Sachtyp und benanntem Verhaltenstyp. Die Operation der Raum/Zeit-Einordnung ist stärker objektorientiert, d.h.

\footnotetext{
109 Koschmieder, "Die noetischen Grundlagen... ", Beiträge, S. 80.

110 Hartmann, "Das Wort als Name", S. 32 und Anmerkung 58.

111 ebd., S. 76.

112 Vgl. ebd., S. 73.
} 
das Verhalten determiniert weitgehend den Beurteilungsmodus, die Syntax die Beschreibungsweise.

Der Unter schied der Toleranzgrenzen (der stilistischen Variationsbreite) auf einen banalen Nenner gebracht: Es gibt weniger Verhaltensweisen als Sachen, weniger 'Syntax' (Feldwerte) als 'Lexikon' (Wörter, i. e. Sy mbol - und Zeigwerte).

Die dritte Dimension der Leistungsdirektive interessiert in der Semasiologie weniger. (Bei năherem Hinsehen zeigt sich übrigens, daß in ihr die Toleranzgrenzen am engsten gezogen sind.) Ob die Unterscheidung in Darstellung, Kundgabe und Auslösung überhaupt erforderlich ist, scheint mir fragwürdig zu sein. "Sie sind Momente an der Darstellung", meinte schon 1929 Dempe in seiner Erörterung der Sprachtheorie Bühlers. Ich schließe mich der Auffassung an, "daß die primäre und allein wesentliche Sprach- oder Satzfunktion eben die Darstellungsfunktion allein ist" ${ }^{113}$. Kundgabe und Auslösung sind m. E. 'unwesentlich', weil hier die Ausrichtung auf das Gemeinte in den meisten Fallen durch außer sprachliche Mittel geschieht ${ }^{114}$.

\subsection{2}

Die Einführung einer Symbolschr ift für die dem Satz zugrundeliegenden möglichen (nahezu unendlich kombinierbaren) Urteil sprozesse ist nicht nur der besseren Überschaubarkeit wegen notwendig, sondern auch Voraussetzung eines eventuellen Einsatzes datenverarbeitender Maschinen ${ }^{115}$. Die von mir verwendete Formalisierung der Redegebilde weicht selbstverstăndlich von den Mustern ab, die in der Allgemeinen Syntax entwickelt worden sind ${ }^{116}$. Der Textausschnitt wird so groß

\section{Dempe, S. 41.}

114 Vgl. auch S. 71, Anmerkung 97 dieser Arbeit.

115 Über die Erfahrungen mit der Auswertung eines kleinen Tells meines Materials durch einen Computer (Siemens 3002) werde ich an ander er Stelle berichten. Die seinerzeit gewăhlte Symbolschrift mußte den Dateneingabemöglichkeiten (COBOL) angepaßt werden. Hier kann eine vereinfachte Form angewandt werden.

116 Vgl. Koschmieders Auseinander setzung mit F. Schmidts "Logik der Syntax" in: "Das Allgemeingültige der Syntax", Beitrăge, S. 209f., besonders S. $220 f$. 
gewăhlt, wie es für die semantische Konsolidierung des untersuchten Wortes jeweils notwendig ist; er unter-oder uberschreitet also den Satz. Formalisierung:

Das inter essierende Wort wird zur Benennung des Subjekts (S) oder der Prädikation (P) eines aktualen $(S, P)$ oder potentiellen $(s, p)$ Urteils herangezogen.

Bezeichnete Sache und bezeichnetes Verhalten, bzw. die Hauptbedeutungen der gewăhlten Wörter sind sachlich vereint $(=)$, objektiv ver einbar (-) oder unver einbar (/).

Die logische Verbindung zwischen Subjekt und Prädikation geschieht durch Identifizierung (i), Determinierung (d), Relativierung ( $r$ ) - kopulativer (rkp), adver sativer (rad), komparativer (rkm) oder kausaler (rks) Art.

Beispiel: S-i

Das unter suchte Wort bezeichnet das Subjekt eines aktualen Urteils. Das Subjekt wird durch die Prädikation mit einer Eigenschaft, Tätigkeit, einem Verhalten identifiziert.

Das mit den Prädikationswörtern Bezeichnete ist mit dem im Subjektswort Benannten sachlich vereinbar.

Die möglichen Positionen des mit dem unter suchten Wort benannten Begr iffs im einfachen Urteil lassen sich in dieser Symbolschrift überschaubar festhalten:

$\begin{array}{llll}\mathbf{S}=\mathbf{i} & \mathbf{S}=\mathbf{d} & \mathbf{S}=\mathbf{r} & \mathbf{s}=\mathbf{i} \\ \mathbf{P}=\mathbf{i} & \mathbf{P}=\mathbf{d} & \mathbf{P}=\mathbf{r} & \mathbf{p}=\mathbf{i} \\ \mathbf{S}-\mathbf{i} & \mathbf{S}-\mathbf{d} & \mathbf{S}-\mathbf{r} & \mathbf{S}-\mathbf{i} \\ \mathbf{P}-\mathbf{i} & \mathbf{P}-\mathbf{d} & \mathbf{P}-\mathbf{r} & \mathbf{p}-\mathbf{i} \\ \mathbf{S} / \mathbf{i} & \mathbf{S} / \mathbf{d} & \mathbf{S} / \mathbf{r} & \mathbf{s} / \mathbf{i} \\ \mathbf{P} / \mathbf{i} & \mathbf{P} / \mathbf{d} & \mathbf{P} / \mathbf{r} & \mathbf{p} / \mathbf{i}\end{array}$

Hieraus eine brauchbare Gliederung abzuleiten, d.h. eine Gliederung nach dem zu erwartenden Grad der Bedeutungsspezifizierung, ist nur anhand einer Art Wahrscheinlichkeitsberechnung möglich. Daß ich hier so etwas wie 'ökonomischen Einsatz' der Sprachmittel unterstelle, ist nicht unproblematisch. Prägnanz des Stils wird sozusagen vorausgesetzt. Aber m. E. ist die Quote der Abweichungen von der stilistischen Norm wegen der dem Sprechakt innewohnenden Kommunikationsabsicht so klein, daß sie in Kauf genommen werden kann. 
Zwei Beispiele:

1) Das russische Wort 'um' ist durch kein Adjektiv (potentielles Urteil) näher bestimmt und wird zur Aussage über ein sachlich und begr ifflich verwandtes Subjekt herangezogen (Typ P-d): 'um' wird höchstwahrscheinlich eine sehr allgemeine Bedeutung tragen.

2) 'um' ist durch ein ungewöhnliches Adjektiv bestimmt (d.h. 'um' ist Subjekt eines potentiellen Urteils, dessen Prädikation mit dem Subjekt unvereinbar ist (Typ s/d)); dieser Verbindung ist ein Urteil spr oze $B$ vorausgegangen (Vergleich mit dem tertium comparationis). Diese Verbindung ist darüber hinaus Bestandteil des Subjekts oder der Prädikation wenigstens eines weiter en Urteils. 'um' wird Träger einer spezielleren Bedeutung sein.

Die Prognose stützt sich auf folgenden Gedankengang:

a) Der Prădikatsbegr iff kann dem Subjektsbegr iff im bejahenden Urteil nicht anders als vollinhaltlich zugeordnet werden, d. h. das interessier ende Wort ist in dieser Position in einem positiven Darstellungssatz Trăger seiner allgemeinen Bedeutung.

b) Sătze für identische Urteile haben Definitionswert. Es empfiehlt sich deshalb eine gesonderte Behandlung dieser Redegebilde. Relationale Sătze enthalten zwei aufeinander bezogene Urteile, eine zweiseitige Prädikation. Der Grad der Bedeutungsspezifizierung wird im allgemeinen höher sein als in Bestimmungssătzen, also Trägern determinierender Urteile, die nicht ausdrücklich die Abgrenzung zu anderen, den Vergleich mit anderen Begriffen enthalten.

c) Potentielle Urteile sind in wenigstens ein weiteres Urteil eingebettet. Sind Subjekts - und Prädikationsbegr iff sachlich unvereinbar, ist mindestens ein (in der Nennoperation angesprochenes) Urteil vorausgegangen. Die Sătze vom Typ $s(p)-.$. stehen für einen wenigstens zweigliedrigen, die vom Typ $s(p) / .$. für einen dreigliedrigen Urtell skomplex. Ein weiteres Urteil implizieren auch die Typen $S(P) / \ldots ;$ nur die Sătze vom Typ $S(P)-\ldots$ stehen für nur ein Urteil und werden die Bedeutung nur schwach begrenzen.

Um diese Prognosen formalisieren zu können, führe ich das mathematische Zeichen > 'größer als' in dem Sinne ein, daß die voranstehende Position die sachliche oder die logische Verbindung, die allgemeine Be- 
deutung stärker einengt als die nachstehende.

Prognose:

1) $\mathrm{s}>\mathrm{s}>\mathrm{p}>\mathrm{P}$

2) $\mid>->=$

3) $\mathrm{i}>\mathrm{r}>\mathrm{d}$

Die folgende Gliederung der semasiologischen Analyse des Wortes A beginnt mit den Sătzen, die wahrscheinlich die allgemeine Bedeutung übermitteln und schließt mit den Redegebilden, die voraussichtlich eine sehr spezielle Bedeutung von A zulassen.

1.

1.10

1.11

1.11 .1 .

1.11 .2

1.11 .3

usw.

$1.11 .11 / 21 / 31$

$1.11 .12 / 22 / 32$

$1.11 .13 / 23 / 33$

1.12

usw.

1.13

usw.

1.20

usw.

2.

usw.
A in Prädikatsfunktion

in einem aktualen Urteil

$Z$ wischen $S$ und $P$ besteht eine wesenhafte Bedeutungsbeziehung

Verzweigungen auf Grund der begr iff liehen Organisationshöhe, -richtung

identifizier ende Urteile determinierende Urteile relationale Urteile

$\mathbf{S}$ und $\mathbf{P}$ sind objektiv ver einbar

$\mathrm{S}$ und $\mathrm{P}$ sind objektiv unvereinbar

in einem potentiellen Urteil

$A$ in Subjektsfunktion
$\mathbf{P}, \mathrm{p}$

$\mathbf{P}$

$P=$

$P=\mathbf{i}$

$P=d$

$P=r$

P.

P/

p

S, $\mathbf{s}$

Es wird hăufig nötig sein, die Sătze, denen das Wort $A$ in zweiter oder dritter Linie angehört, in die Betrachtung einzubeziehen. Wollte man die Abhăngigkeiten zweiten oder dritten Grades in der abstrakten Gliederung berücksichtigen, würde die schon jetzt kaum überschaubare Zahl der Punkte vollends unhandlich.

Weil a) das bestimmte Wort nur in einem Teil der möglichen Positionen belegt sein wird und b) die entscheidende Determination des Bedeutungsbereichs in der unmittelbaren sprachlichen Umgebung geschieht, die Abhăngigkeiten höheren Grades also zunächst unberücksichtigt bleiben 
können, ist für das konkrete Beispiel eine überschaubare Gliederung möglich.

Die einzelnen Stufen des Vorgehens sind aus der folgenden Zusammenstellung der Entscheidungsebenen, die das zu analysier ende Redegebilde durchlauf en muß, abgeleitet worden.

I. Urteil sf unktion
1. Prädikation
2. Subjekt

II. Art des Urteils

0.10 aktual

0.20 potentiell

III. Art der Beziehung zwischen Subjekts- und Prädikatsbegr iff
0.01 vereint
0.02 ver einbar 0.03 unvereinbar

IV. Begriffliche Organisationshöhe
0.00 .10 vergleichbar hoch
0.00 .20 unter schiedl ich hoch

V. Art der Verknüpfung von Subjekt und Prädikat

0.00 .01 determinierend 0.00 .02 identifizier end 0.00 .03 relational

Beispiele:

Durch Addition der Kennziffer $n$ ist der Gliederungspunkt fixiert, damit der Stellenwert innerhalb der Bedeutungen nach dem Grad der Spe$z$ if izierung ablesbar.

a) 1 .

0.10

0.01

0.00 .10

1.11 .11

b) 2 .

0.20

0.03

0.00 .20

0.00 .02
0.00 .01

A ist Bestandteil der Prädikation eines aktualen Urteils; $\mathrm{zw}$ ischen $\mathrm{S}$ und $\mathrm{P}$ besteht eine wesenhafte $\mathrm{Be}$ deutungsbeziehung. $S$ und $P$ sind vergleichbar hoch organisiert. $\mathbf{P}$ determiniert $\mathbf{S}$.

ist die Kennziffer für eine wahrscheinlich minimale Bedeutungsspezifizierung. z. B. : "Der Schwimmer (S) schwimmt im Wasser (P)"

A ist Subjekt eines potentiellen Urteils. S- und P-begr iff sind objektiv unver einbar.

Es gibt ein Organisationsgef alle.

$S$ wird mit $P$ identifiziert.

2.23.22 ist die Kennziffer für eine wahrscheinlich hochgradige Spezifizierung. z. B.: "lebendiges (p) Wasser (s)" 


\section{2. $40 \mathrm{Kritik}$}

Das Ideal, daß alle einem Gliederungspunkt subsumierten Redegebilde Trăger ein und derselben Bedeutung sind, daß der erste Punkt die 'ganz allgemeine', der letzte die 'ganz spezielle' Bedeutung sammelt, wird mit Sicherheit nicht erreicht werden. Ein und dieselbe Bedeutung wird in verschiedenen Gliederungsgruppen auftauchen, wobei ein und dieselbe allerdings oft nur heißt, daß der Bedeutungsunter schied 'bedeutungslos' ist, weil Stufen gedacht werden, wo die Übergănge fließend sind. Deshalb und im Interesse des praktischen Ertrags einer Bedeutungsanalyse empfiehlt es sich in der Angewandten Semasiologie, die theor etisch gewonnenen - Gliederungspunkte, die vergleichbare Bedeutungen erwarten lassen, zusammenzufassen. Das ist methodisch inkonsequent, kann aber auch als zwischen Theorie und Praxis vermittelnder Kompromiß ver standen werden.

Eine Gliederung, die nur auf dem aufbaut, was allen Sprachen, allem Sprechen gemeinsam ist, sieht zwangsläufig von vielen Momenten $a b$, die Einfluß auf die Bedeutung nehmen.

Um nur einige schlagwortartig zu nennen:

1.) Die Intensităt der Sachbindung.

Verben und Adjektive z. B. sind als Verhaltensbestimmung, Prädikation schwächer gebunden als Substantive, sogenannte Konkreta nicht so stark wie sogenannte Abstracta. Es gibt so etwas wie spröde und elastische Wörter. Ob eine Wortverbindung gewohnt oder ungewohnt ist, läßt sich generell nicht entscheiden. Dazwischen liegen viele Abstufungen von 'noch vereinbar' bis zu 'kaum möglich' usw. Das ist weitgehend eine Frage des Stils. Die z.B. durch eine unübliche Adjektiv/Substantivver bindung bewirkte Blickwinkelverengung ist also wahrscheinlich unterschiedlich stark.

2.) Es ist durchaus denkbar, daß zwei gleichgroße Ausschnitte des Bedeutungsbereichs Unterschiedliches bedeuten, d.h. daß der gleiche Auf wand an noetischen Operationen evtl. entgegengesetzte Bedeutungen gleicher Merkmalsdichte konsolidiert. 
3.) Es ist auch nicht auszuschließen, daß ein vielgliedriger Redekomplex nur eine allgemeine Bedeutung übermittelt, weil jeder der Sătze den Bereich kaum merklich antastet. Auch das ist eine stilistische Frage.

Die von mir vorgeschlagene Gliederung ließe sich noch verfeinern; ich nehme keineswegs in Anspruch, alle Möglichkeiten deduktiver Erschließung ausgeschöpt zu haben. Aber die genannten Einwände wären auch durch noch stärkere Differenzierung kaum auszuschließen. Auf andere Mängel wird noch am gegebenen Beleg hinzuweisen sein.

In der folgenden Bedeutungsanalyse der Wörter 'um' und 'razum' sehe ich im Hinblick auf diesen ersten Teil Fehlerbetrachtungen. Ob die Fehlerquote in Kauf genommen werden kann, wird sich am Schluß herausstellen. Nun ist zwar die Anwendung auf nur zwei, zudem verwandte Wör ter nicht repräsentativ, aber die Zahl der Abweichungen lăßt doch wohl Rückschlüsse auf die Tauglichkeit dieser Methode zu. 


\section{ZWETER TEIL}

\subsection{Einleitung}

Ein Wort hat so viele aktuelle Bedeutungen wie es Sătze mit ihm gibt; jeder neue Satz hat dem Inhalt oder Umfang nach neue Bezugspole freigelegt, die hier auf die wenigen (Nuancen-) Nenner eines über schaubaren Katalogs der lexikalischen Bedeutungen gebracht werden sollen. Die Gruppierung gewinnt ihre Kriterien aus den Operationen der Nennung und der ontologischen Verzeitung. Die Operationen werden unter schiedlich stark bemüht: $\mathrm{Da}$ der weithergeholte Name für eine Eigenschaft, für ein Verhalten (1. Operation), die der beurteilten/besprochenen Sache nur schwerlich zukommen (2. Operation), mehr von den Operationen fordert als der sich quasi von selbst einstellende, der naheliegende Name für eine Äußerung, die der Sache wie selbstverständlich anhaftet, ist wohl hinreichend deutlich gemacht worden.

Die Eigenart der Sprache, mit Abstraktem so umzugehen wie mit sinnlich Wahrnehmbarem, und zwar vorwiegend mit Hilfe räumlicher Vor stellung, durch Anschaulich-machen, verleiht den mit dem Sinn für Raum und Form zusammenhängenden Wörtern bei vergleichbarer Organisationshöhe des bezeichneten Begriffs eine besonders große Bezugsvariabil ităt. Abgesehen von dieser Bevorzugung des Perspektivischen ist selbstver ständlich jede sensuell-quantitative Aussage durch Bindung an Abstraktes zur qualitativen Aussage făhig. Den noetischen Operationen wird allerdings umso mehr abverlangt, je weniger das in der Aussage Bezeichnete räumlich vor stellbar ist.

Das zu einem Sachverhalt/Tatbestand Zusammentretende ist von begr iffl ich unter schiedlicher Komplexivität. Der gegenüber dem Subjekt höher oder geringer oder einfach in eine andere Richtung spezial isierte Prădikationsbegr iff spannt den Subjektsbegr iff nicht einfach in die eigene Begrenztheit/Weite, in den spezifischen Sachbezug ein, sondern es geschieht - abhängig von der Festigkeit der Verankerung - oft so etwas wie ein Spannungsausgleich. 
Die von Haus aus profane Prádikation zu einem erhabenen Subjekt muß dieses nicht herabziehen; der umgekehrte Vorgang ist hăufiger, aber auch nicht zu verallgemeinern. Die Aussage 'cholodnyj" z. B. 'ver sachlicht', indem sie 'um' zur Bezugnahme auf Spürbares zwingt. Gleichzeitig wird aber 'cholodnyj" durch die Bindung an ' um' von den gewohnten Sachen abgezogen und als Zeichen für die Qualität der Empfindung genommen. Die hier wirkenden Mechanismen und sprachlichen Gewöhnungen scheinen mir zum 'Unlogischen' der Sprache zu gehören und eine verallgemeinernde Semantik erheblich zu hemmen.

Es war ferner vermutet worden, daß das erste, das unmittelbar einbettende Urteil die Bedeutungsrichtung entscheidet. Die geringen Modifizierungen der folgenden Aussagen können fast immer vernachlässigt werden, müssen sogar meistens um der Über sichtlichkeit des zu erstellenden Bedeutungskatalogs willen unberücksichtigt bleiben. In die immer noch große $Z$ ahl der Aussagen muß man mit Oberbegr iffen eingr eifen, die jeweils ein besonderes Maß an Distanziertheit und/oder Unter schied der begr ifflichen Organisation (Höhe und Ausrichtung) zwischen Subjekt und Prädikation vertreten, die also vergleichbar stark die noetischen Operationen fordern.

Z.B. kann man 'bemerkenswert', 'vorzüglich', 'ungewöhnlich' unter dem Gesichtspunkt zusammenfassen, daß sie begr ifflich schwach organisiert, an keinen bestimmten Sachbereich gebunden sind, daß sie sich also durch hohe absolute Bezugsvariabil itat auszeichnen, daß sie, ohne eine bestimmte bildliche Vor stellung zu erwecken, ein positives Wertempfinden vermitteln.

Dagegen sind 'glänzend', 'klar', 'hell', 'kalt', 'kräftig', 'riesig' z. B. auf bestimmte Sachbereiche hin spezialisiert. Sie sind nicht so bezugsvariabel, daß sie leicht die Grenzen ihres Bedeutungsfeldes verlassen. An diesen Wörtern hăngen ziemlich konkr ete Bilder.

Als bekannt vorausgesetzt war die Grundbedeutung, d.h. die mit der Einfuhrung des Namens/Symbols geleistete vage Beurteilung, die Kenntnis der identischen Urteile also, genauer: der in der Benennung implizierten, weil das Sein der benannten Sache konstituierenden Prädikationen. Das Wissen um die besondere Weise des Verfügbar seins der Sache, des Begriffs, des Wortes muß die am Ende des ersten Teils vorgeschlagene Gliederung modifizieren (womit nichts gegen der en prinzipielle Anwendbarkeit auf jedes erdenkliche Wort jeder erdenklichen Sprache gesagt ist). Die schematisch übergestülpte Gliederung wäre 
unausgewogen, der eine Punkt kaum, der andere unhandlich dicht besetzt. Denn es gibt in jeder Sprache Zeichen, die yornehmlich prädikativer Natur (z. B. Verben, Adjektive) und solche, die in erster Linie Subjektbestimmung (Nomen) sind. In die dichtbesetzten Abschnitte der Analy se wird man weitere Kriterien einbringen, so z. B. die Beziehung zwischen Subjekt und Prädikation nicht nur auf Ver eintheit, Vereinbarkeit und Unvereinbarkeit hin ansehen, sondern eine feinere Stufung wählen; die Aspekte Organisationsgefalle, metaphorische Dichte, Intensităt des Nebensinns usw. können einbezogen werden.

Unbedingt notwendig, aber nicht so leicht differ enzierbar sind die mit einem Wort vereinten Aussagen, die wesenhaften Bedeutungsbeziehungen, wenn dieses Wort für mehrere Begriffe stehen kann. 'um' ist z. B. in der Wendung 'sklad uma' (Geisteshaltung) ein anderer Begriff als in 'um analiziruet' (Verstand). Sowohl das Vorhandensein einer Haltung, Veranlagung als auch die Tatsache der Analyse wird man als im jeweiligen Begriff impliziert ansehen, aber eben nicht in 'um' schlechthin. Dagegen ist das potentielle Urteil 'kačestva uma' von allen an 'um' bindbaren Begr iffen aussagbar. Die Unterscheidung in 'partiell impliziert' und 'generell impliziert' liegt nahe. Darin sind die Prognosen auf das Maß der Bedeutungsspezifizierung schon mitgenannt.

Es ist im allgemeinen nicht Gegenstand der Sprache, das Selbstver ständliche zu sagen, nicht Aufgabe des Satzes, das in der Nennung des Subjekts bereits Mitgenannte an die Oberfläche zu heben. Auf einen Satz wie: "Der Geist hat bestimmte Eigenschaften" ist die unwirsche Reaktion denkbar: "Was heißt das. Selbstverständlich hat der Geist Eigenschaften". Die Aussage scheint also nichtssagend, weil hinsichtlich der Bedeutung leistungslos resp. indifferent zu sein. Aber in der aktuellen Rede sind vergleichbare Sătze hăufig. Als Fortsetzung der fiktiven Hörerreaktion ist die Aufforderung an den Sprecher wahrscheinlich, sich doch genauer $z u$ ăußern, und zwar "in dieser Richtung"; d.h. irgendwie hat der vorder hand so überflüssige Satz doch schon auf eine Blickwinkelausrichtung hingewiesen, die Auf merksamkeit gelenkt. Die Bedeutungsweite des Wortes 'Geist' ist zwar zunächst noch unangetastet, zwar kann es noch auf 
jeden Ausschnitt seines Bereichs ausgerichtet werden, aber es ist schon eine Auswahl unter den Aussagen getroffen worden.

Man mag es spitzfindig nennen: aber die erste, iber die Implikationen der Nennung hinausgehende Beurteilung einer Sache schlăgt sich in der Einsetzung in eine grammatische Kategorie nieder. Das Hineinstellen in das Paradigma der Deklination oder Konjugation spezifiziert die in der Nennung vage bestimmte Weise des Verfügbarseins. Die bloße Nennung (nominativ oder infinitiv) macht die Sache überhaupt er st sprachlich behandelbar; das Versetzen in einen obliquen Kasus oder eine finite Verbform (wie immer das auch einzelsprachlich geschieht) ist ein erster Schritt ontologischer Verzeitung, erkennt die Sache als eine wirkende oder eine irgendwie der Einwirkung ausgesetzte. Was ich meine, will ich kurz am Paradigma von 'um' darlegen:

um (Nominativ)

Das so Benannte ist etwas an und für sich Seiendes. (Im Gegensatz z. B. zu "umet", 'umnyj", was nur an Seiendem sein kann.):

$\begin{array}{lll}\text { umu } & \text { (Dativ) } & \text { ) sind Positionen des Ausgesetztseins. Die } \\ \text { um } & \text { (Akkusativ) } & \text { ) Wörter/Sachen sind der Einwirkung frei - } \\ \text { ume } & \text { (Präpositiv) } & \text { ) gegeben; an ihnen geschieht etwas. } \\ \text { uma (Genitiv) } & \text { ) sind janusartige Positionen; ausger ichte!t } \\ \text { umom (Instrumental) } & \text { ) und ausrichtend, benutzt und benutzend. }\end{array}$

Die Leistungskraft der Bedeutensweise 'Kasus' ist offensichtlich unterschiedlich stark. Generelle Aussagen sind problematisch, da die Vor schriften der einzel sprachlichen Syntax die semantische Grundfunktion oft durchkreuzen. Soviel darf man sagen: Im Russischen (in idg. Sprachen) bereiten Dativ und Akkusativ auf relationale Urteile vor, Nominativ, Genitiv, Instrumental und Präpositiv (Lokativ) auf determinier ende. Der Nominativ schreibt das Subjektsein vor; Genitiv und Instrumental sind diesbezüglich indifferent; Präpositiv bzw. Lokativ legen die Prädikativfunktion freä.

Die bloß weichenstellenden Aussagen rechnet man am besten zu den Kataly sator en/Relatoren relationaler Urteile. Wird jedoch von einem Wort etwas nur partiell Inbegr iffenes ausgesagt - z. B. 'sklad uma' dann wird schon eine tatsächliche Blickwinkelverengung geleistet; es wird signalisiert, welcher Begr iff in der folgenden Rede vom interessier enden Wort - in diesem Falle 'Geist' - angesprochen werden soll.

Die semantische Analyse erfordert vom Verfasser eine unübliche Einstellung zur Sprache. Er richtet der Gewohnheit entgegen sein Augenmerk auf ein bestimmtes Wort, wăhrend sonst nur das mit einem Satz 
Gemeinte gehört/gelesen wird und die Bedeutungen der am Satz beteiligten Wörter ungefragt sind. Es besteht die Gefahr, daß diese Konzentrierung zu einem verfảlschten Hören, zu einer vom Sprecher nicht intendierten Auslegung führt. Um das an einem Beispiel zu erläutern:

Die folgenden - z.T. nicht sehr schönen Sătze - seien auf denselben Tatbestand bezogen:

1) Der Mensch vermag mit seinem Verstand, die und die Zusammenhănge zu begreifen.

2) Der Verstand des Menschen kann. .. Zusammenhänge begreifen.

3) Der Mensch ist făhig, in seinem Verstand... Zusammenhänge zu begreifen.

4) Der Mensch kann die und die Zusammenhänge begr eifen. oder ein konkr eteres Beispiel:

1) A făhrt mit dem Wagen auf der Landstraße nach $B$.

2) Der Wagen fährt mit $A$ am Steuer nach $B$.

3) A fảhrt im Wagen nach $B$.

4) A fährt auf der Landstraße nach $B$.

Da die Sătze 1 - 4 insof ern dasselbe besagen als sie denselben Tatbestand beschreiben, ist man zunăchst geneigt, den beteiligten Wörter $n$, dem zur Analyse anstehenden Wort (Verstand, Wagen) dieselbe Bedeutung zuzuschreiben, weil im selben Zusammenhang das Wort doch auch dasselbe bedeuten müsse.

Aber das stimmt sicher nicht, denn in dem jeweils vierten Satz steht das Wort ja überhaupt nicht, obgleich es doch wohl mitgemeint ist. Dèr Beitrag, den die Bedeutungen der am Satz beteiligten Wörter zum Gemeinten leisten, ist offensichtlich unterschiedlich groß. Die Hauptlast trägt einmal dieses, einmal jenes Wort einmal ist dieses, einmal jenes Wort 'bedeutender'.

Bei ein und demselben Gemeinten kann das An-sich-Ziehen von Bedeutungen des einen Wortes nur durch Abziehen von Bedeutungen vom ander en Wort geschehen; das folgt aus den Prämissen B und $H$. Weil in den vierten Sätzen 'begreifen' und 'fahren' die Funktion von 'Verstand' und 'Wagen' wesentlich ubernommen haben, sind diese Wörter so bedeutungs- 
los, daß sie gar nicht mehr genannt zu werden brauchen. Aber besagen diese Sătze nicht etwas über 'Verstand' und 'Wagen', über die Begr if fe ? Sicher, das åndert jedoch nichts an dem Faktum, daß die W or ter 'Verstand' und 'Wagen' nichts bedeuten, d.h. auf nichts bezogen sind. Auch in dem jeweils ersten und dritten Satz sind sie auf weniger Bedeutsames ausgerichtet. Gehen wir davon aus, daß zu einem Tatbestand Tăter und Tat, Tatort und -werkzeug, Tatzeit und -objekt gehören können. Im allgemeinen ist es doch wohl so, daß primär Tăter, Tat und Objekt, sekundär Werkzeug, Ort und Zeit von Belang sind. Diese Gruppierung der Elemente des Tatbestandes in Haupt - und Nebensache kann stil istisch durchaus umgekehrt werden, muß sich dann aber in der Verzeitungsoperation an den Wörtern des Satzes niederschlagen. Ich kann z. B. das Instrument zum Subjekt machen, statt 'umom' 'um' sagen usw.

Im ersten der Beispielsătze ist 'mit seinem Verstand' Prädikation zur Prädikation '(Zusammenhänge) begreifen' und verhindert die vollinhaltliche Zuordnung des Wortes 'begreifen'; 'Verstand' selbst ist aber als letztrangige Prädikation vollbedeutend. Im zweiten Satz ist 'Verstand' Subjekt, von dem a) ausgesagt wird, daß der Verstand des Menschen gemeint ist, b) daß er Zusammenhänge begreifen kann. An sich, d.h. begrifflich, ist der Verstand in beiden Fällen das gleiche Begriffsvermögen, aber die Blickwinkelverengung vom Punkt/Signum 'Verstand' aus auf die I-Ebene ist unterschiedlich stark. Ob das sprachliche Bild 'um' als tätiges Subjekt, das begreift, oder als Begriffswerkzeug in der Hand eines anderen Subjekts denkt oder als Ort, an dem begriffen wird, verändert das Gemeinte geringfügig, den Begriff 'um' als Begriffsvermögen so gut wie nicht, die aktuelle Bedeutung jedoch erheblich. 


\subsection{Abgrenzung des Belegmaterials}

In dieser Arbeit werden nur die von Belinskij um und mit 'um' und 'razum' gebildeten Sătze ausgewertet. Im Zuge der Ermittlung der Bedeutung der beiden Substantive werden selbstver stăndlich auch die Wör ter analysiert, die die Konsolidierung der aktuellen Bedeutung leisten.

Die aus der Wurzel "um abgeleiteten Wörter sind nicht Gegenstand dieser Untersuchung, weil es sich dabei um eigenwertige Lexeme handelt. Das Kriterium der morphologischen Verwandtschaft tritt in einer synchronischen Betrachtung hinter dem Argument der semantischen Năhe zurück; 'rassudok' z.B. steht 'um' năher als irgendein aus "um abgeleitetes Wort.

Die phraseologischen Wendungen werden als Wortgruppenlexeme aus vergleichbaren Gründen ausgeschlossen.

Andere Autoren als Belinskij werden nicht herangezogen; jede Auswahl wăre willkürlich.

Ein zahlenmaßiger Vergleich der Belege besagt nicht viel: 'um' wird von Belinskij in seinen Schriften etwa 1.900 mal gebraucht, 'razum ' rund 350 mal. Läßt man die erstarrten Wendungen außer Betracht, dann kommen auf einen 'razum'-Beleg etwa vier 'um'-Belege. Da das semantische Gewicht des Wortes 'razum' - auch im einzelnen Satz - im Vergleich zu 'um' im Durchschnitt höher ist, sind Schlußfolgerungen auf den Stellenwert der beiden Wörter im Denken Belinskijs nicht möglich. 


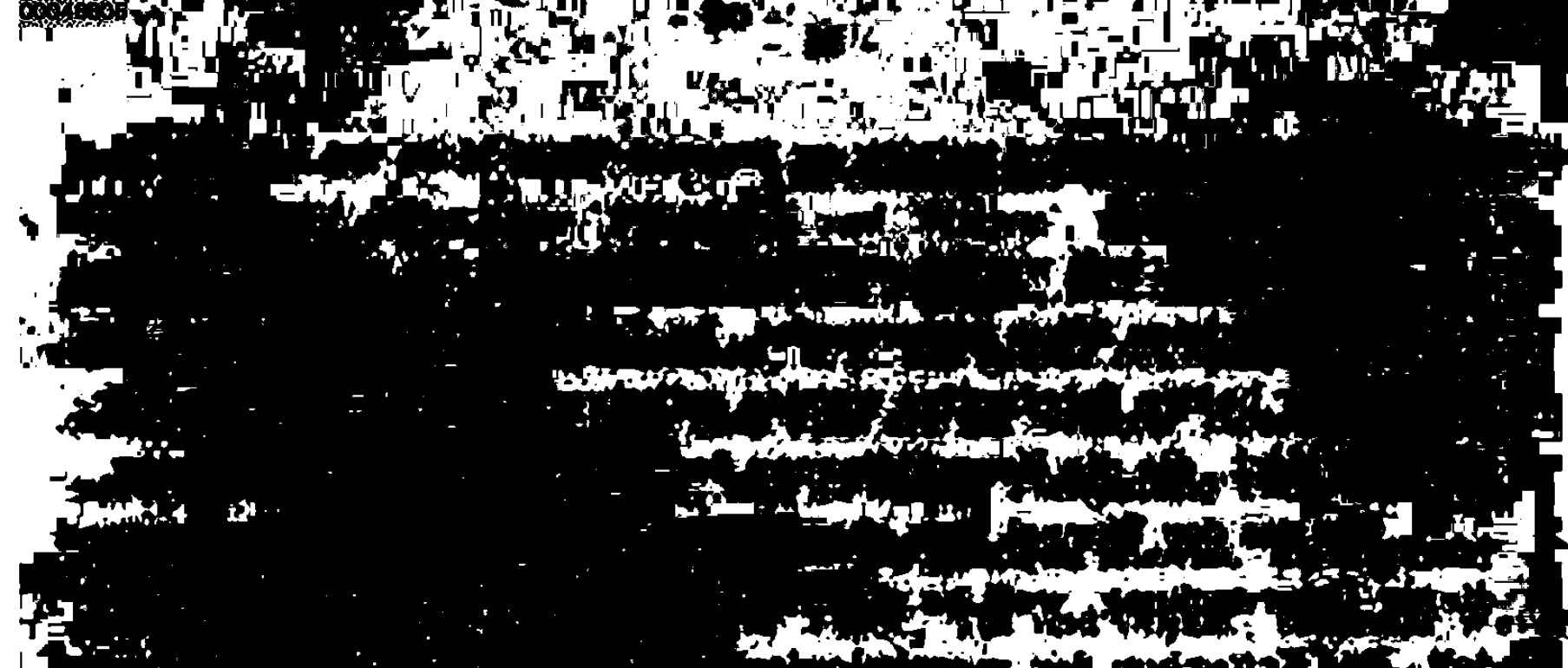

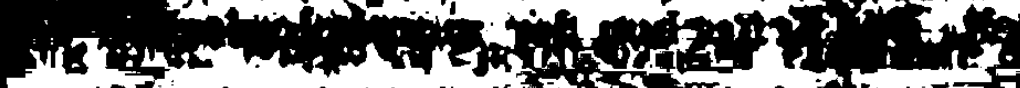

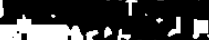

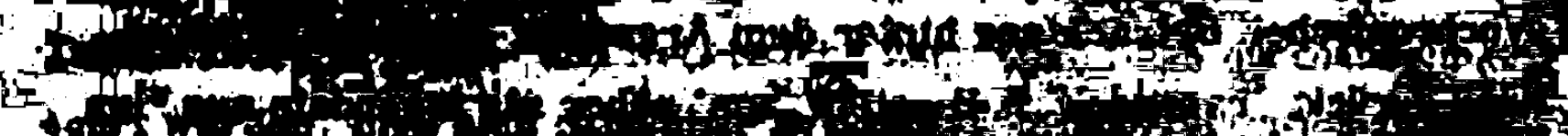

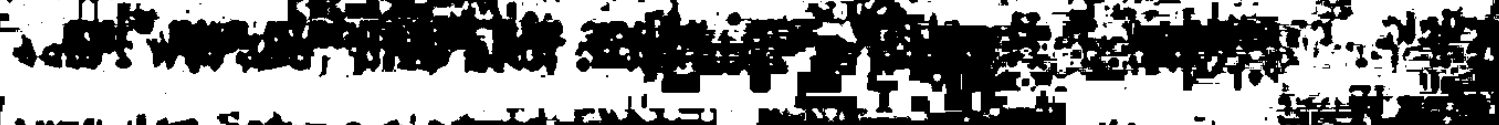

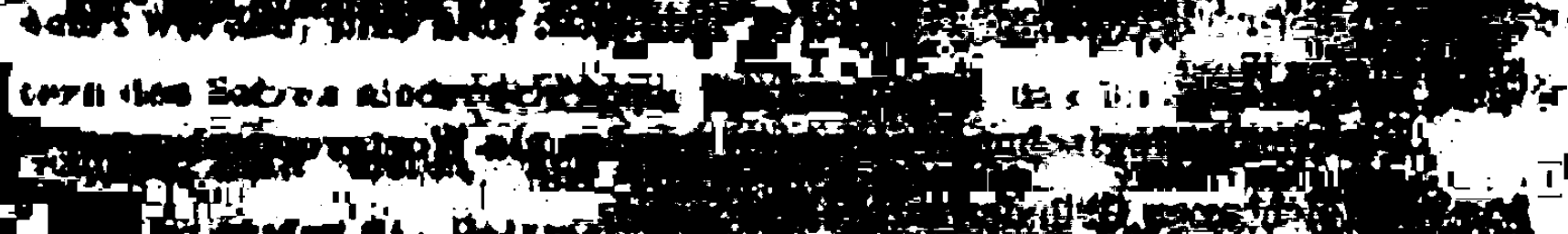

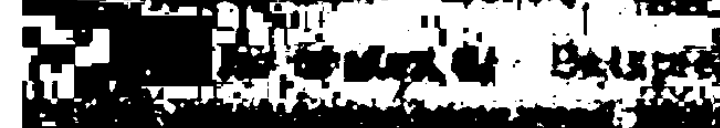

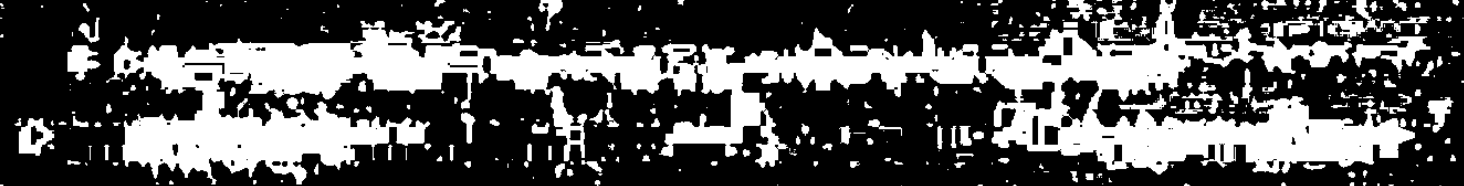
ats $\rightarrow \log ^{2}$ if $=0$ in irien iit?

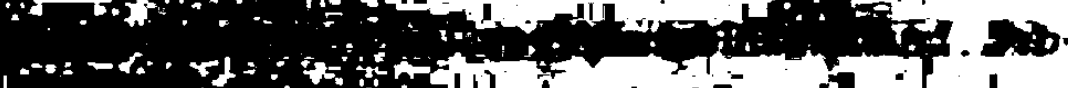
1. anding

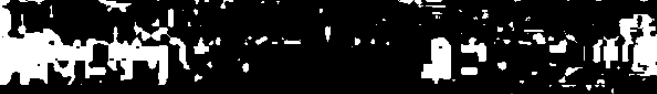

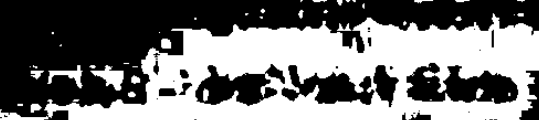

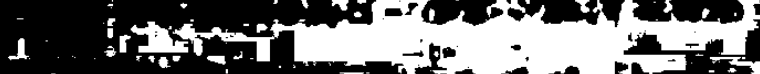

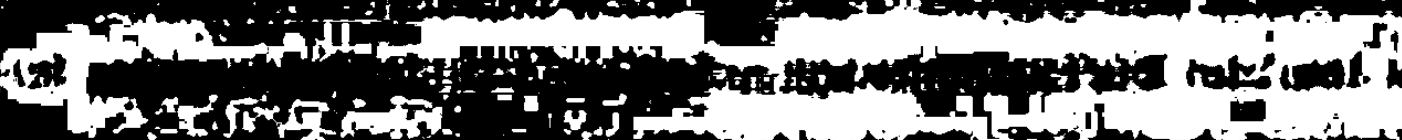

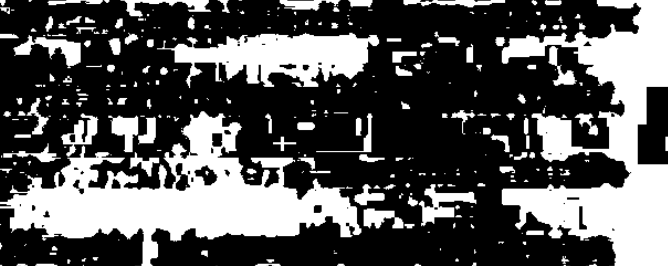
18

a

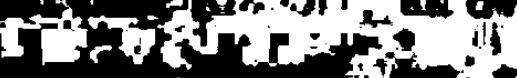

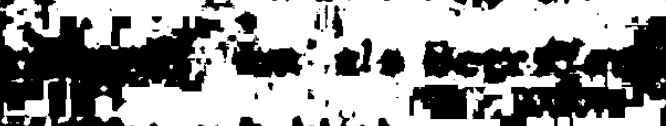

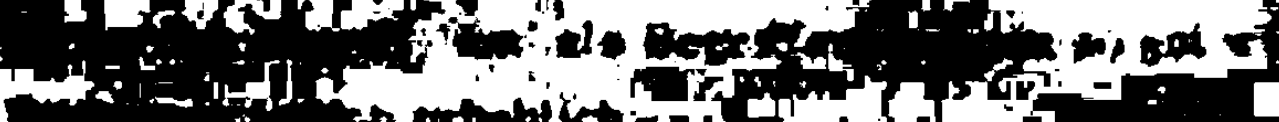

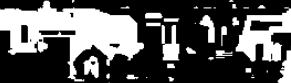
tir.

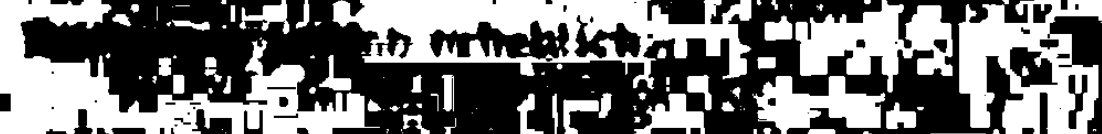
ather 드. iา.

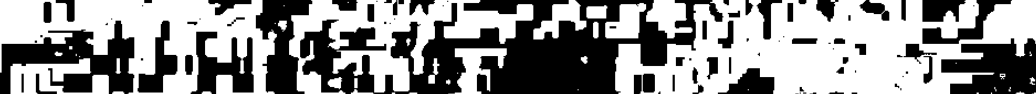
1L년

1.ting

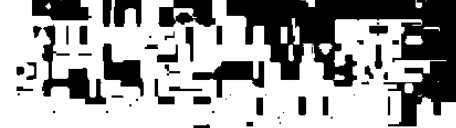

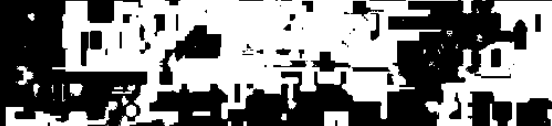

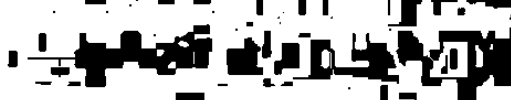

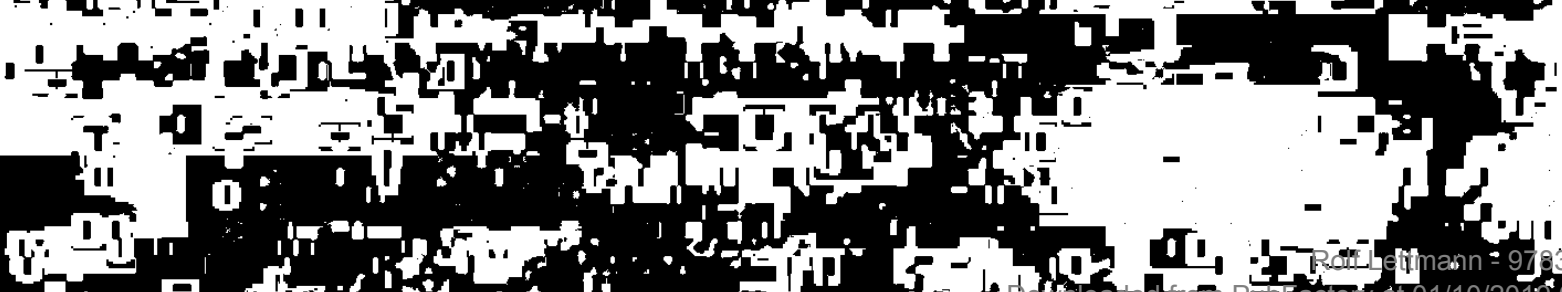
5 of on is: $1 \div$ 


\section{Kapitel}

'UM'

Wohl nicht nur der größeren Bedeutungsweite, sondern auch der schwankenden Einschătzung des jeweils mit 'um' Benannten wegen hat Belinskij an das Wort 'um' einen erheblich größeren Wortschatz gezogen als an 'razum'. Eine subjektiv bedingte Bezugsvariabilitat potenziert die objektiv (lexikalisch) vorgegebene. Umgekehrt könnte man bei 'razum' von einer zeitweise zur semantischen Blockierung tendierenden subjektiven Stabilisierung der ohnehin geringeren lexikalischen Bandbreite sprechen.

1.10 Kaum spürbare Eindămmung des Bedeutungsbereichs.

Zwischen 'Geist' und 'Ver stand' unentschiedene Bedeutung.

\subsection{1 'um' in prädikativer Funktion}

Die Versetzung eines Wortes in den Lokativ verurteilt die benannte Sache zum Peripheren, zum passiven Rahmen um ein Geschehen. Was geschieht, wirft zwar ein bezeichnendes Licht auf den Tatort, führt aber - solange nichts Ungewöhnliches (Unvereinbar es) vorgeht - nicht zur Zusammenziehung des Bedeutungsbereichs.

Belinskij beschreibt die besondere Empfindsamkeit Lomonosovs im Kindesalter: Die Weite des Ozeans habe u.a. "v ego ume" Frage auf Frage geweckt (II,187).

Das Fragen ist eine wesentliche geistige Täigkeit, die das logische Subjekt 'um' impliziert; 'v ume' könnte ohne weiteres fortfallen, und man übersetzte kor rekt mit 'in 'ihm' (Lomonosov). 'um' ist nichtssagend; das kaum vorformende potentielle Urtell ' $v$ ume' wird, da zur Pradikation des aktualen Urteils herangezogen, vollinhaltlich einver leibt, erfăhrt folglich keine weitere Determinierung.

Ein Buch prăgt "v ume našem" ein Bild ein (III, 350; ăhnlich: IX, 258; DX, 318).

Mit der Vor stellung einer Zeitschrift verbinde sich "v ume" eine bestimmte (geistige) Ausrichtung $(X, 235)$.

Gedanken entstehen "v ume" (XI, 35), leuchten auf (XI, 235). Der Begriff sei die unmittelbare Vor stellung "v ume" irgendeines Gegenstandes (II, 581). 
In allen Beispielen ist ' $v$ ume' entbehrlich, weil die Vorgänge schlechterdings nur ' $v$ ume' geschehen können. Zwar sind das Fragenstellen, das Einprăgen, das Verbinden von Begriffen, das Gedankenformen Tătigkeiten des Geistes, des Verstandes; ausgesprochener Tăter sind aber die über den Geist/Verstand Verfügenden. Mit Blick auf die I-Ebene geschieht hier vom Einzelwort 'um' aus die Bezugnahme auf die schwach organisierte Tatbestandskomponente 'Tat-Ort'.

Der Künstler brauche Zeit, um den von ihm "v ume" konzipierten Gedanken zu durchdenken und auszutragen $(\mathrm{DX}, 450)$.

Dieser Satz ließe sich sinngleich so umkonstruieren, daß 'um' einmal logisches und grammatisches Subjekt (um chudožnika) oder Instrument (chudožnik umom...) wăre. 'um' trüge eine speziellere Bedeutung, obgleich die Sătze nahezu dasselbe meinten, d.h. das Gemeinte des synthetischen Zeichens jeweils eine gleiche Zahl von Merkmalen hätte. Als ErkJärung bleibt eben nur, daß die am Satz beteiligten Wörter die Merkmalssumme unterschiedlich aufteilen.

Es gibt Vorgănge (Taten), die nicht notwendig ' $v$ ume' geschehen müssen, also mit dem Raum 'um' ohne weiteres vereinbare, aber nicht unbedingt vereinte sind. In diesen Fällen ist ' $v$ ume' nicht entbehrlich, denn es erfüllt eine deutlich prädikative Funktion.

Potemkin habe während großer Gelage Nägel gekaut und zwischen Spăßen das Schicksal von Völkern "v ume" entschieden $(I, 47)$.

"V ume" die ganze Literaturgeschichte $(\Pi, 13)$, das Leben durchlaufen (II, 108).

"V ume" des Lesers zerfalle das Buch in zwei Teile (IX, 76). In diesen Beispielen ist ' $v$ ume' im Sinne von 'im Geiste', 'nicht tatsăchlich' gemeint; ein reales Pendant zu den fiktiven Tatbeständen ist wenn auch manchmal nur mit Mühe - denkbar.

In einem Urteil sind Subjekt und Prädikation so gut wie nie säuberlich zu trennen. Das Subjekt verhảlt sich auch zum Prädikat prädikativ. In einem Satzausschnitt wie "resat' $v$ ume" wird 'entscheiden' durch 'im Geiste' năher bestimmt; gleichzeitig wird aber auch von 'um' unbeabsichtigt ausgesagt, daß es der Raum ist, in dem entschieden wird. Aber diese Aussage ist im Gemeinten irrelevant; der Sprecher hat die 
andere im Auge. (Hier wird ubrigens die Prämisse $F$ in einem anderen Licht bestätigt: Ist das I des synthetischen Zeichens bekannt und eindeutig, dann ist auch die Urteilsfunktion jedes beteiligten Wortes eindeutig.)

Bei den folgenden Belegen ist man zunăchst geneigt, 'um' in der grammatischen Form ' $v$ ume' als logisches Subjekt anzusehen, denn es liegt eine Aussage über 'um' vor:

Sumarokov habe den Zwe tfel an seiner Genialităt als Unwissenheit, als "pomesatel'stvo v ume" empfunden (III, 288).

Das russische Volk zeichne u.a. "polozitel'nost' $v$ ume" aus $(X, 215)$.

Stünden hier Adjektivverbindungen oder Genitivkonstruktionen (pomesatel'stvo uma - polozitel'nyj um), würde 'um' zu sehr betont, die Aufmerksamkeit abgelenkt. Eben weil 'um' logisch und syntaktisch abseits steht (gänzlich fehlen könnte), folglich in seiner Bedeutung unkonturiert bleibt, wirkt es auf 'polozitel'nost"' und 'pomešatel'stvo' generalisierend: diese Aussagen gehen über 'um' im engeren Sinne hinaus und treffen die ganze geistig-seelische Konstitution.

Ginge es in dieser Arbeit um den Begriff 'um', wären uns nach diesen wenigen Sătzen schon wesentliche Anhaltspunkte an die Hand gegeben:

'um' ist demnach die Fahigkeit

der Akzeptierung der Umwelt (Einprăgen von Bildern, Haben von Vor stellungen),

der Transformierung, Ko-Ordinierung von Sachen und Begriffen (ver einigen, zusammenfließen, teilen, zerteilen),

der Produzierung von Gedanken (konzipieren, wachsen, erwecken, aufleuchten),

aber im Satz haben andere Wörter als 'um' auf diese Fähigkeiten Bezug genommen.

Die Frage nach der sachlichen Vereinbarkeit stellt sich in den bisher besprochenen Beispielen nicht so dringlich, da jeder Vorgang mit irgendeiner Raumvorstellung behaftet ist. Daß durch 'wachsen, aufleuchten, zusammenfließen' andere Bilder evoziert werden als durch 'einprägen, vereinigen', führt nicht weiter.

An der Wendung ' $v$ ume' bewahrheitet sich eine Binsenweisheit: je umfassender (je schwächer organisiert) die intendierte Vorstellung, 
desto mehr Wörter sind 'vereinbar', desto schwerer ist es, 'unvereinbare', d. h. spezifizier ende Wörter zu finden.

\subsection{Gener ell implizierte Aussagen}

Die potentiellen Urteile, die bedeutungsneutrale generell implizierte Aussagen vom Subjekt 'um' treffen, werden auf Grund der übergeordneten Sekundăraussage an die entsprechenden Gliederungskategorien ver wiesen.

Die Aussagen 'svojstvo', 'kačestvo', 'sostojanie', 'priznak', 'ucastie' u. ă. zum Subjektgenitiv 'uma' berühren die Bedeutung nicht, sind absolut sehr bezugsvariabel.

Die Aussagen 'zadaca', 'zanjatie', 'delo', 'dejstvie', 'dejatel'nost" u. ă. sind zwar absolut weniger bezugsvariabel, bezüglich aller möglichen Bedeutungen von 'um' aber ebenfalls indifferent.

Die potentiellen Urteile 'čelovečeskij um' oder 'um celovečestva', sowie alle den Träger des mit 'um' Benannten kennzeichnenden Attribute sind zwar an sich bedeutungsneutral, denn vom 'um' jedweder Bedeutung kann - im Unterschied zu 'duch' - nur die Rede sein, wenn er an eine individuelle oder kollektive Wesenheit gebunden gedacht wird. Unbestreitbar ist aber, daß Zuweisungen wie 'narodnyj', 'krest'janskij', 'russkij', 'francuzskij' u.a. 'um'sehr entschieden festlegen. Diese Prădikate bezeichnen also offensichtlich nicht eine ethnische, soziologische oder geographische Zugehörigkeit, sondern ein Bündel von Besonderheiten dieser Gruppen. Selbst Personennamen können an ihrem Träger vorbei nur ein hervorstechendes Merkmal treffen, z. B. wenn man irgendwo den 'Geist Hegels' zu ver spür en meint.

Die genannten und athnliche Aussagen müssen wie hochspezialisierte, leicht vereinbare Prädikationen behandelt werden, wenn sie mehr als die bloße Zugehörigkeit bezeichnen.

1.13 Auf Grund hoher absoluter Bezugsvariabilităt leicht vereinbare, determinierende Prädikationen

Die Aussagen greifen den Bedeutungsbereich des Wortes 'um' von verschiedenen Seiten an. Die aktuelle Rede kann 'um' mehr auf die dynamische Seite des menschlichen Geistes lenken, das Instrumentale des Verstandes, dessen tătige Anverwandlung der Welt betonen, 
oder aber die mehr statische Seite, die geistige Konstitution, die eigenartige geistige Anlage eines Menschen, einer Gruppe, als den Ge is t hervorheben. Die Vermutung liegt nahe, daß die aktive, die verstandesmaßige Komponente sich in einem konkreteren Wortschatz zeigt als die latente. Vom aktuellen Einsatz des Verstandes als Mittel oder Werkzeug kann man sich leichter ein Bild machen als vom Geist, verstanden als geistiger Be- und Zustand, als Summierung der von Einzelbildern, -aktionen abgelösten Eindrücke, Begriffe, abgeleiteten Bewertungen.

Eine Prädikation kann naheliegend sein, weil sie entweder auf Grund ihrer geringen begrifflichen Organisationshöhe absolut sehr bezugsvariabel ist (Beispiel: bol'soj) oder weil sie bei hohem Spezialisierungsgrad zwar absolut in ihrer Bewegungsfreitheit eingeengt, aber dem Subjekt semantisch nahesteht (Beispiel: velikij). Man kann die spezifizier ende Kraft einer Prädikation als Resultante eines Krăfteparallelogramms ansehen, das aus der Bedeutungsentfernung (Koordinate der Operation der ontologischen Verzeitung) und der Organisationshöhe (Koordinate der Nennoperation) gebildet wird.

Weil die folgenden Aussagen auf einen sehr großen Teil der Sachwelt ausgerichtet werden können, wird ihre Bildkraft schwach, der Aussagewert gering, das geleistete Werturteil undifferenziert sein. Je geringer der Aussagewert eines Satzausschnittes, desto stärker ist wahr scheinlich der Zugriff einer möglichen zweiten oder dritten ubergeordneten Aussage. Ein durch eine durchdachte Nennoperation geschaffenes Bild oder eine begriffich stark differenzierte Aussage kann vom weiteren Satz kaum verädert werden.

Die leicht vereinbaren Prädikationen schaffen zwar durch Zugabe eines Kriteriums Untergruppen des mit 'um' Meinbaren, beschneiden zwar den Bedeutungsumfang, decken aber den lexikalischen Inhalt kaum ab. Die Bedeutung von ' $u m^{\prime}$ wird mehr quantitativ als qualitativ eingeengt. Belinskij stellt einen jungen Mann vor, dessen Seele für ales Schöne und Gute offen gewesen sei, der aber bei glücklichen Anlagen und "pri bol'som ume" bezüglich Aufklärung und gelehrter Bildung zu kurz gekommen war $(I, 56)$.

Die Schauspielerin spiele "s bol'sim umom i lovkost'ju" (VI, 692). 
Man gebe einem (vorher näher beschriebenen) Egoismus gewaltigen Raum, füge "bol'soj um", starke Leidenschaften, die Fähigkeiten, tief jede Wahrheit zu erfassen und zu erfühlen hinzu: dann habe man eine Vorstellung vom Aleko Puskins (VI, 387).

Die Versdichtung erfordere weniger Talent als vielmehr Genialität, und wenn Talent, dann vereint "s bol'sim umom", mit einer starken Natur (XX, 39).

'bol' 'soj' - das hier am besten mit 'viel' wiedergegeben wird, da 'groß' im Deutschen auch Qualitătsangabe ist - erhảt den vollen Bedeutungsinhalt von 'um', mehrt sowohl die Verstandesf ăhigkeiten als auch den geistigen Fundus, schirmt sogar den Zugr iff der konsozilerten Wörter (lovkost', talant etc.) ab, die das bloße 'um' - wie noch zu zeigen sein wird - wie eine Prädikation treffen würden. Die Wendung 'mnogo uma' ist dem 'bol' soj um' fast synonym:

Beltov verfüge iber "mnogo uma, no uma sozercatel'nogo, teoreticeskogo", der sich weniger in den Gegenstand vertiefe als vielmehr darüber hinglitte (X, 321; weitere Beispiele: IV , 593; VII, 222). An diesem Beispiel läßt sich der Prozeß der Bedeutungseinkreisung verfolgen. Beltov wird zunăchst 'viel Geist', werden allgemein große geistige Făhigkeiten und Anlagen zugesprochen, aber anschließend wird durch Hebung par tiell implizierter Aussagen der zunächst unangetastete Inhalt beschränkt. Dem Vorbehalt wird ein schonender Schritt vorangestellt: eine verbreitete rhetor ische Figur.

Der volle Bedeutungsinhalt soll auch in den folgenden Urteilen über'lỉefert werden:

Fonvizin sei ein Mensch "s neobyknovennym umom i darovaniem" gewesen (I, 50; ähnlich VII, 329).

zamecatel'nyj um (VII, 557; X, 245 und 317)

otmennyj um $(X, 219)$

Diese Aussagen sind - verglichen mit 'bol'soj' und 'mnogo' weniger metaphorisch (soweit man bei ' $v$ iel' $^{\prime}$ und 'groß' überhaupt von Metaphern sprechen will), aber sie sind stärker wertbesetzt, treffen mehr die geistige Artung. Die folgenden mindernden Prădikationen sind etwas plastischer als die ungezielt mehrenden:

cinovnik nedalekogo uma (IX,552)

Zenscina ogranicennogo uma $(X, 117)$ 
Es gebe Leute, bei denen reiche der Geist (chvataet uma) nur für einen Auf satz von wenigen Seiten... (II, 37).

ogranicennost' uma (III,402; $\mathrm{XX}, 408$ und 561)

posr edstvennost' uma (IV , 583)

'ograniCennyj' und 'nedalekij' sind durch eine Bedeutungsnuance getrennt, so wie beispielsweise im Umgangsdeutsch die Aussage, daß jemand 'kein großes Licht' sel, etwas freundlicher als die Titulierung 'kleines Licht' klingt. Der Vorwurf geistiger Beschränktheit steht bei Belinskij selten allein. Am so Beurteilten entdeckt er meistens auch andere negative Züge: Jede extreme Haltung sei dumm und unsinnig, "plod ogranicennosti uma i melkosti ducha" (III,402). Dieser Vorwurf gilt dem Goethekritiker Menzel.

'um' und 'duch' überschneiden sich in dem Teil ihrer Bedeutungsbereiche, in dem die geistige Artung angesiedelt ist. "ogranicennost" und 'melkost" unterscheiden sich etwa wie 'bol'soj' und 'velikij"; das eine Wort triff die Menge, das andere die Art. In diesem Beispiel sind die quantifizierbaren geistigen Făhigkeiten (um) deutlich von der qual ifizierbaren geistigen Struktur (duch) abgesetzt. 'um' korrespondiert in der Bedeutung 'Geist' mit 'rassudok', 'duch' eher mit 'razum'. Ganz àhnlich stellt Belinskij an anderer Stelle 'um' und 'dusa' nebeneinander?

ogranicennost' uma, melkost' dusí... (IX, 408)

Hier greift 'dusa' in den Bereich des Geistigen über, hat fast die gleiche Bedeutung wie 'duch' im vorigen Beispiel. Auch in den Reihungen benachbarter Begriffe schirmen die Primäraussagen den Zugriff der sekundären, den prädikativen Einfluß des konsozilerten Substantivs also, ab.

In einer Rezension der "Bednye ljudi" Dostoevskijs spricht Belinskij von einer Selbsterniedrigung, die "bednost' i ogranicennost' uma" zur Tugend erkläre $(\mathrm{X}, 561)$. In diesem Satz sind sicher nicht nur die geistigen Fahigkeiten gemeint, sondern 'ogranicennost' uma' meint 'Einfalt' auch des Gemüts, 'Naivităt'. Ich erwăhne diesen Satz als ein Beispiel dafür, daß eine quantitative Methode da ver sagt, wo Sătze oder Teil sätze in einer bestimmten geistigen Tradition eine spezif ische semantische Aufladung erfahren haben. Dann konsolidieren weder Satz noch Auf satz die Be- 
deutung, sondern - wenn man so sagen darf - der Ansatz, als ăußerster der 'Kontextkreise'. 'bednost" und 'ogranicennost' uma' addieren in der Reihung nicht bloß ihre Bedeutungen, sondern wachsen zu einem Zei-

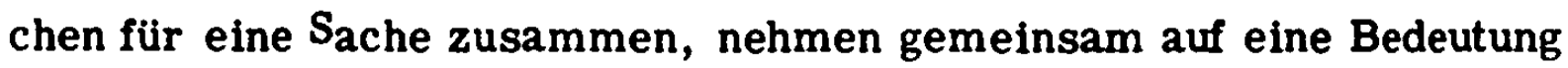
von ganz anderer Qualităt Bezug: 'Unschuld, Nichtver stricktsein in die Welt'. Von einem Wortgruppenlexem kann man jedoch bei derartigen Konsoziationen noch nicht sprechen. 
1.20 Merkliche Begrenzung des Bedeutungsbereichs.

Auf 'Geist', 'geistige Anlage' gerichteter Blickwinkel.

Die folgenden Beispiele sind Belege für die Bedeutung 'Geist' im Sinne der charakteristischen, individuellen geistigen Veranlagung eines einzelnen Menschen (subjektiver Geist), einer mehr oder weniger großen homogen gedachten Gruppe (objektiver Geist).

Aussagen, die die statische Komponente 'Geist' im Wort 'um' hervorheben, treffen als Nebenaussage insofern auch die dynamische 'Verstand', als die Geistesart/haltung als Ableitung der aktuellen Verstandesfunktionen begr iffen werden kann. In den folgenden Sätzen kann 'um' nicht mit 'Verstand', 'Intellekt', 'Urteilskraft' u. ă. über setzt werden. 'rassudok' ist zur Wiedergabe der hier herausgestellten Inhalte nicht zu befăhigen, 'razum' kann selten, 'duch' häufiger synonym verwandt werden.

1.21 Naheliegende hochspezialisierte determinier ende Prädikationen

Die Prädikationen der Bestimmungsurteile sind von begr ifflich mittlerer bis hoher Organisation, absolut in ihrer Bewegungsfreiheit zwar eingeschrănkt, aber - da auf mit dem Subjekt verwandte Sachbereiche hin spezialisiert - leicht vereinbar. Im Bild des Kräfteparallelogramms gesprochen, bezieht die auf den Bedeutungsbereich wirkende Kraft ihr Maß aus dem Spezialisierungsgrad (stark bemühte Nennoperation), nicht aus der semantischen Entfernung (kaum erforderliche Verzeitungsoperation). Die vermittelte sinnliche Vor stellung ist blaß, nịcht - wie bei den Beispielen des vorigen Abschnitts - weil die Prädikationen sachlich indifferent, also absolut bezugsvariabel sind, sondern weil sie Merkmale bündeln, die von verschiedenen Bildern abgelöst wur den und auf den gemeinsamen Nenner eines abstrakten Bewertungsvor schlags gebracht worden sind.

Um noch einmal die Gründe der Kategorisierung am Beispiel der Bestimmungsurteile durchsichtig zu machen, soll die unterschiedliche Beanspruchung der noetischen Operationen an den Aussagen 'bol'soj', 'velikij' und 'ogromnyj' verdeutlicht werden. In jedem Fall wird mit den Aussagen beabsichtigt, die Abweichung vom Durchschnitt zu benen- 


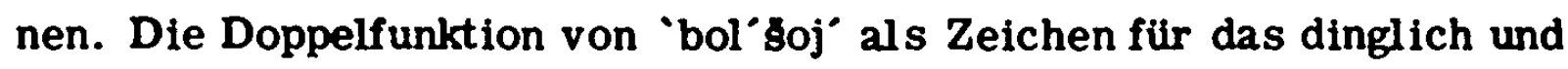
geistig Große wird in der Steigerung auf zwei Wörter aufgeteilt. Man kann sagen, daß die geistige Komponente im Wort 'velikij', die dingliche in 'ogromnyj' verlăngert wird.

Die Wahl des Wortes 'bol' 80 ' $^{\prime}$ erfordert einen sehr geringen Gedanken- (Urteils-)aufwand von der Nennoperation. Wird 'velikij' eingesetzt, kann man annehmen, daß der Tatbestand merkmalsreicher war, seine Erfassung mehr Beobachtung erforderte und der Sprecher die Eindrücke bewertend unter das Dach eines Oberbegriffs bringen mußte: die Nennoperation war komplizierter. 'ogromnyj' vertritt ebenfalls eine Summe von Qualităts - und Quantitätsmerkmalen; während aber 'ogromnyj" als ein auf die Welt des sinnlich Wahrnehmbaren hin spezialisierter, sehr plastischer Begriff nur mit Mühe an 'um' gebunden werden kann, die Operation der ontologischen Verzeitung also von Haus aus heterogenes Sein (wesenhaft Bedeutungsfremdes) verknüpfen, ' $u m^{\prime}$ in ein sehr konkretes Bild einfassen muß, forderten 'bol' 'soj' und 'velikij' als absolut bzw. relativ bezugsvariable Wörter wenig von dieser Operation. Die Prognose, daß die Aussage 'bol' 'soj' eine allgemeine Bedeutung des Wortes 'um' konsolidiert, 'velikij' eine speziellere und 'ogromnyj' eine hochspezialisierte, wird durchweg bestätigt: 'bol'soj um' vermittelt die umfassende Bedeutung 'große geistige Fahigkeiten und Anlagen'; 'velikij $\mathrm{um}^{\prime}$ verlagert das Augenmerk auf die Innenseite 'Geist', die aber zur Außenseite 'Verstand' hin durchlässig ist; 'ogromnyj' zieht 'um' ins konkret Faßbare: das dichte Bild deckt bis auf die Bedeutung 'Intellekt' alle anderen ab.

Selbstverständlich sind auf Grund der Bildhaftigkeit allen Sprechens auch die folgenden Aussagewörter auf eine konkrete Grundbedeutung zurückzuführen. Aber entweder ist sie gänzlich verlor engegangen, oder die übertragene Bedeutung hat sich so ver selbständigt, daß zur vordergründigen fast keine Beziehungen mehr bestehen, sie nicht oder nur noch schwach miterlebt wird, das Wort de facto ein Homonym ist. Außer 'velikij' seien als Beispiele für eine schwach mitschwingende konkrete Bedeutung 'vozvy Sennyj', 'vy sokij' und 'glubokij' genannt. Diesen Wörtern 
haftet aber auch konkret schon die Empfindung des nicht mehr Erfahrbaren an. Bedeutungen, die nur schwerlich erlebbar gedacht werden können, sind ja besonders anfallig für Nebensinne, die der erste Schritt auf dem Weg zu einer übertragenen, vergeistigten Bedeutung sind.

Bei aller Betonung der geistigen Innenseite lassen Attribute dann den Bezug zum Objekt durchscheinen, wenn die Aussagen gleichsam vom Gegenstand auf das Subjekt übertragen wurden. Ein 'glubokij um' z. B. besagt einmal etwas uber die Dimension des Geistes, zum anderen auch etwas uber das, womit er sich beschaftigt. Die Bedeutung 'Geist, Geistesart bleibt zum operativen Verstand hin offen: er wird - im Doppel sinn des Wortes - als ein 'vertiefter' vor gestellt.

Die Phantasie sei nur eine der wichtigsten unabdingbaren Fähigkeiten des Dichters; sie allein mache ihn noch nicht aus. Es bedürfe eines "glubokij um", der die Idee im Faktum, die allgemeine Bedeutung in der besonderen Erscheinung erschließe (VIII, 89).

Hier ist 'tiefe Einsicht, Vernunft' gemeint, die Fähigkeit, die Realität zu durch-schauen. Eine ganz ăhnliche Bedeutung hat Belinskij bereits neun Jahre früher in seinen "Literaturnye mectanija" (1 834) an 'um' gezogen:

Das Kunstwerk solle die Frucht eines erhabenen Geistes ("vozvysennyj um") und eines glühenden Gefühls sein, frei und unbewußt aus der Seele fließen $(I, 34)$.

Wăhrend hier zwar - ganz im Schellingschen Sinne - die Idee den Dichter durchdringt, dort aber die ins Hegel sche 'Allgemeine' uberführte 'ewige Idęe' erschlossen werden muß (die Seele der Vernunft den Platz gerăumt hat), decken sich doch die Bedeutungen von 'glubokij' und 'vozvy §ennyj'. Hier wie dort ist sowohl das Uber-den-Dingen-Stehen als auch das Tiefund-erhaben-Sein des Geistes gemeint.

Um diese und ahnliche Beispiele mit der hier verwandten Methode zu erfassen, muß man über die determinierende Funktion der Prădikation 'glubokij' hinaus deren in der Nennoperation versteckten relationierenden Charakter sehen, wobel der Bezugspol nicht unbedingt genannt zu werden braucht. 
Auch in den folgenden Beispielen unterstreicht das aktuale Urteil die im potentiellen determinierenden verborgene Relation. Wenn jemand uiber einen großen Geist verfügt (obladat' velikim umom - II, 90; VII, 593), dann steckt sowohl im russischen "obladat" als auch im deutschen Wort 'verfügen' einmal die Bedeutung 'besitzen', zum anderen aber auch 'zum Einsatz bringen'. Die Bedeutung von 'um' liegt folglich zwischen 'Verstand' und 'Geist'. Auch am Gegenteil - dem oberflächlichen Geist (poverchnostnyj um - VI, 361; VII, 278; XX,82) - werden Subjekt und nicht năher bezeichnetes Objekt beleuchtet.

Auch ein 'prostoj um' kann sein Attribut in der Beschaftigung mit einfachen Dingen verdient haben. Aber das Wort 'prostoj' gehört andererseits zu jenen, die letztlich nur der Denkansatz semantisch konsolidiert. Das Zusammenrücken der Begriffe 'ewige Idee' - 'das Allgemeine' 'das Erhabene ' - 'die Einfalt' gegen 'das Besondere' - 'das Niedere' 'die Vielfalt' ist Bestandteil des Überzeugungskerns Belinskijs. 'prostoj" kann so gesehen in dreifacher Bedeutung verwandt werden: 'einfach' im konkreten Sinne der ăußeren Simplizităt; 'einfach' im abstrakten Sinne für das Merkmalsarme, Undifferenzierte schlechthin; 'einfach' im hochspezialisierten Sinne der 'edlen Einfalt'. Die letzte Bedeutung ganz deutlich in den folgenden Sătzen:

Belinskij fragt, worin die sittlichen Eigenschaften der Frau seiner Zeit bestehen sollten. Er gibt die Antwort: "v strastnoj nature i vozvy šenno-prostom ume". Die leidenschaftliche Natur bestehe in der lebendigen Sympathie für alles, was die sittliche Existenz (nravstvennoe sušcestvovanie) des Menschen ausmache; der erhaben-einfache Geist bestehe im einfachen Verständnis auch hoher Gegenstände, im Sinn für die Wirklichkeit (Vח,163).

Belinskij postuliert die Harmonie von Kopf und Herz. 'um' ist durch die Attribute befähigt, auf Bedeutungen Bezug zu nehmen, die sonst dem Wort 'razum' vorbehalten sind. Von einem 'prostoj um' im Sinne der Einfaltigkeit ist auch im folgenden Beispiel nicht im entferntesten die Rede:

Kurz vor seiner Heirat im November 1843 schreibt Belinskij seiner künftigen Frau, daß er sie um ihrer Liebe, ihres Leidens, "za ee vozvy Sennyj i prostoj um", um ihres glühenden Herzens und threr edlen Seele willen liebe (XI, 230).

Belinskij erreicht diese erhabene Bedeutung von 'prostoj' durch die Nach- 
barschaft des Wortes Vozvy sennyj'. Fehlt die Absicherung durch dieses oder ein ahnliches Wort, wird 'prostoj' zu einer schwach spezialisierten, absolut bezugsvariablen Pradikation:

In einem Auf satz Odoevskijs stehe kein Wort von Äquator, Ekliptik und thnlichen Weisheiten, "nepostizimich dlja prostogo uma" (VI, 687).

Belinskij sichert intendierte Bedeutungen hăufig so stark ab, daß manchmal ein schulmeisterlicher Ton in seine Aussagen gerăt:

Lomonosov sei ein Mensch von erhabenem Geiste (vysokij um), genialen Fähigkeiten, von starkem Charakter und großer Gelehrtheit gewesen $(\mathrm{DX}, 188)$.

Man könne Lomonosov weder eine bemerkenswerte dichterische $\mathrm{Be}-$ gabung noch Geistes- und Seelengröße (velikij um - velikaja duša) absprechen (IV, 422).

velikij um - sposobnosti - sila charaktera $(\mathrm{III}, 337)$

udivitel'nye sposobnosti - glubokij um $(\mathrm{XX}, 500)$

tvor Českaja fantazija - glubokij um (VI, 89)

velikij um - mudrost' (DX, 80)

um vozvy sennyj, obrazovannyj (II, 367; IV , 89)

'um' als das begr iff sbildende Vermögen läßt Attribute nicht zu, die höher organisiert sind, die Merkmale verkörpern, die der bloße Verstand nicht erfüllen kann. Insofern setzen z. B. Aussagen wie 'genial'nyj' (V,144; VII, 126) die besondere Ausprăgung der Begriffsfăhigkeit bereits voraus, zielen über 'Verstand' hinaus auf den hohen Reffegrad, die besondere Ver feinerung der inner en Verfassung des Geistes, ja, treffen den Menschen als geistiges Wesen insgesamt. In dieser von den Einzelheiten der geistigen Ausstattung abgehobenen Bedeutung wird 'um' mit dem Menschen gleichgesetzt. Auch 'obrazovannost" kann nicht einem Moment des menschlichen Geistes allein zugesprochen werden; der Tatbestand des Gebildetseins ist durch bloße Auspr ägung des Verstandes nicht erfüllt. Es macht kaum einen Unter schied, ob man jemandem 'obrazovannyj um' zuspr icht oder inn damit identifiziert. Das Stilmittel 'pars pro toto' hebt sich auf, wenn das Teil so groß wie das Ganze erscheint. (Dagegen fallt eine Identif ikation z. B. mit 'ostryj um' wegen des Organisationsgefalles ein sehr viel härteres Urteil über den Menschen als das entsprechende Bestim- 
mungsurteil. ) Im Plural 'umy' hat sich die Synekdoche 'Geist' für 'Mensch' lexikal isch verfestigt. 'umy' ist als eigenstăndiges Lexem zu betrachten (da es außer der genannten keine andere Bedeutung mehr tragen kann) und insofern nicht Gegenstand dieser Arbeit .

In den folgenden Bestimmungsurteilen wird die Bedeutung von 'um' der höher en begrifflichen Organisation der Prådikation wegen gedehnt:

obrazovannyj um $(I, 102)$

genial'nyj um (II, 279)

um vysokij (VI, 179)

samyj položitel'nyj um (VI,165)

del'nyj um (VII, 287)

In den nachstehenden potentiellen Urteilen drängen sich die Attribute vor, machen sich den Geist gleichsam zu eigen:

gosudar stvennyj um (VIII, 291; VII, 63) - Staatsmarn

sceniceskij um $(\mathrm{IV}, 132)$

- Theatermensch

literaturnyj um $(\mathrm{II}, 175)$

- Literat

Die Komponente 'Verstand' wird buchstäblich übergangen.

Belinskij nennt Kol'cov einen "prostoj, jasnyj i smelyj um" (IX,540). 'prostoj" - in der übertragenen Bedeutung sehr merkmalsdicht - gibt den Ton an; 'jasnyj' und 'smelyj' verweisen - jedes für sich genommen - 'um' an die Bedeutung 'Verstand' (starke Bildhaftigkeit, auf Grund der andersartigen Spezialisierung semantisch entfernt). Die Unvereinbarkeit der jeweils evozierten Bilder führt zu deren völliger Verdrängung; die Aussagewörter werden durch die gleiche Wertbesetzung zusammengehalten. Außenund Innenseite von 'um' werden gesondert besprochen; es werden einzelne Summanden, nicht die Summe selbst genannt (der Oberbegr iff könnte z. B. 'položitel'nyj' heißen). Die Anforderung der Bedeutung 'Geist' (hohe Or ganisation, semantische Nahe) wird in diesem Beispiel durch Addition auf mehrere Wörter verteilter Merkmale und Anhebung der wertnennenden, abstrakten Seite durch wechsel seitige Verdrăngung der bildhaften, konkr eten erreicht. 
$\mathrm{Da}$ 'um' und 'celovek' weitgehend synonym verwandt werden können, liegt es nahe, Wörter, die eine wesenhafte Bedeutungsbeziehung zum Menschen unterhalten, auch an 'um' zu binden, wenn der Sammelbegr iff 'Geist' bedeutet werden soll. Entwicklungsstufen, Reifegrade werden mit den folgenden Wörtern bezeichnet:

molodoj, molodoj igrivyj um (III, 313; III, 277); junyj, neopytnyj um $(\mathrm{X}, 105)$; neopytnyj (VII, 300), nerazvityj (razmy sleniem i naukoju) um $(V, 415)$.

sozrevsyj (VII, 305), obrazovannyj (I, 344) um;

um prosvešcen $(\Pi, 450)$.

Wăhrend 'molodoj' und 'junyj' weitgehend Synonyma für 'Unerfahrenheit, Unwissenheit' sind, steht 'mladenceskij um' für Naivităt, für eine Denkweise, die Belinskij - ganz im Fichteschen Sinne - 1836 so definiert:

Der naive Geist (mladenceskij um) mache zum Grundgesetz seiner Spekulation (umozr enie) nicht eine in ihm selbst liegende Idee, sonder $n$ irgendeine Naturerscheinung. Folglich leite er die Idee aus den Fakten und nicht die Fakten aus der Idee ab (II, 239).

Die naive Unverbildetheit, den Geist, dem noch nicht die Vielfalt der Kenntnisse den Blick verstellt hat, der die Kategorien seines Denkens, die Maßstäbe seines Wertens aus der natürlichen hierarchischen Ordnung, dem natürlichen Rhythmus von Licht und Dunkel, Wärme und Kälte bezieht, zitiert Belinskij mit entsprechenden Attributen:

prirodnyj (I, 61; V,134 und 143); normal'nyj (XII, 332); tivyj i oserdecennyj (XII, 271); zdravyj i żivyj (IX, 60I); zivost'uma (VIII, 504). Gemeint ist hier die 'mens sana', nur selten der enger gefaßte 'gesunde Menschenver stand' (zdravyj smysl).

Auf hervorstechende Merkmale wird der Blick in den folgenden Sătzen gelenkt. Die Prădikationen sind dem Vokabular zur Charakterisierung des Menschen entnommen und sind in ihrer Bewegungsfreiheit sehr beschrănkt. Das Bedeutungserlebnis ist so eindeutig an eine menschliche Wesenart gebunden, da $\beta^{\prime}$ um' auch dann mitgedacht würde, wenn es ungenannt bliebe. Im Gegensatz zu den Aussagen vom Typ 'genial', 'erhaben' etc. werden die einzelnen Momente der geistigen Ausstattung (Verstand, Wissen, Făhigkeiten) nicht der hohen begr ifflichen Organisation sondern der festen Bedeutungsbindung der Prädikationen an den Menschen wegen über sehen: 
tonkij i chitryj um (VI, 411) -

Feinsinnigkeit und Schlăue;

veselyj $i$ ciniceskij um $(X, 103)$ -

Witz und Zynismus;

prazdnyj um (VII, 71; VII, 405); prazdnost' uma (IV, 243) -

geistiger Müßiggang,

ljubeznyj i igrivyj um (II, 214) -

Liebenswürdigkeit und Lebhaftigkeit, Charme;

svetskij um (VII,477) -

weltmännisches Gehabe,

Auf Grund ihrer Bildhaftigkeit gehören einige der folgenden Attribute nicht in diese Abteilung, müssen aber der semantischen Năhe wegen hier abgehandelt werden:

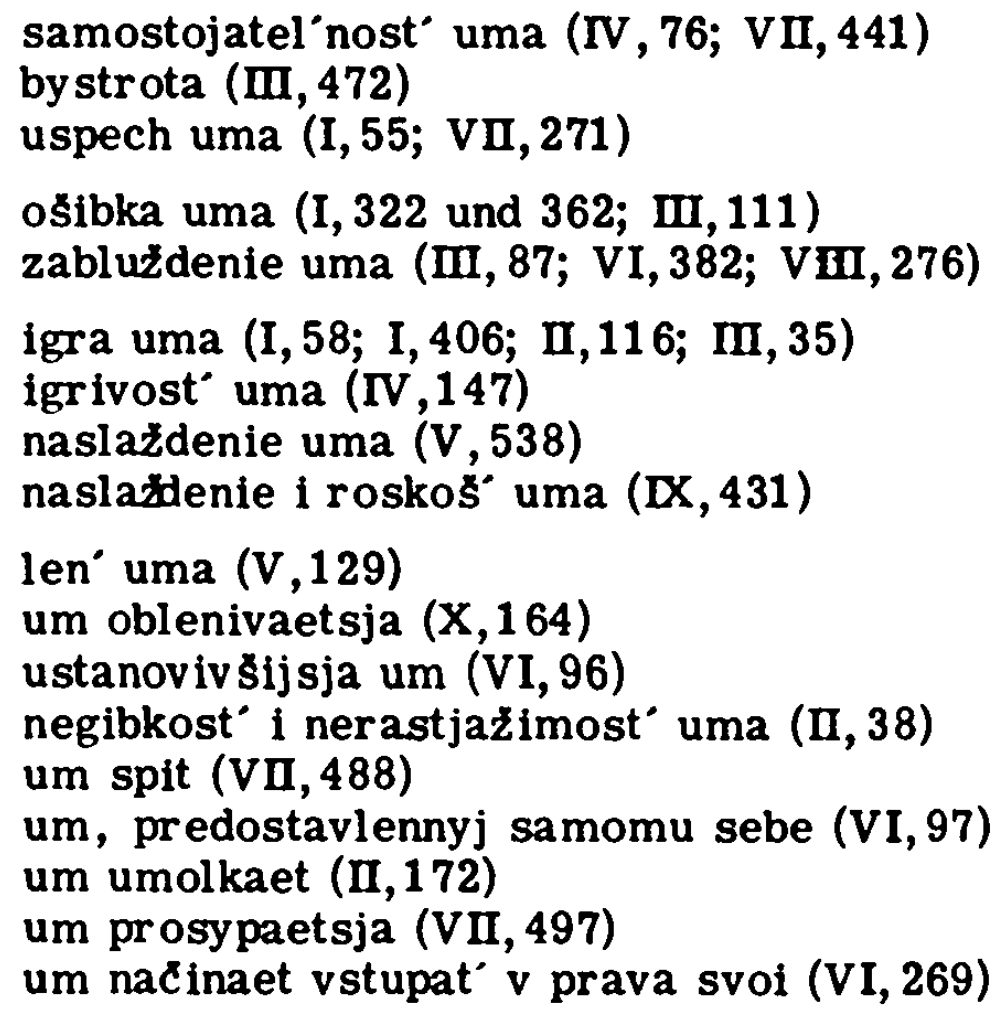

Wie schon erwăhnt, können Aussagen über den Trăger des Geistes oder Verstandes nicht nur den Umfang, sondern auch den Inhalt der Bedeutung des Wortes 'um' beschränken. Wenn vom 'um' irgendeines unbedeutenden Menschen die Rede ist, wird das ihn bezeichnende Genitivattribut den Inhalt unangetastet lassen. Ist dagegen z. B. vom 'um Fichte' die Rede, dann bezeichnet der Name Fichte offensichtlich mehr als nur die Person, ja, er bündelt gar nicht einmal in erster Linie die Eigenschaften dieses bestimmten Menschen, sondern die bedeutenderen, ihn 
überragenden seines philosophischen Systems. So wie hier der Personenname zu einer übertragenen Bedeutung gelangen kann, können auch Attribute, die vorderhand eine ethnische oder soziologische Zugehörigkeit bezeichnen, zum Namen für ein Bündel charakteristischer Merkmale der benannten Gruppe herangezogen werden und so die Funktion hochorganisierter Prădikationen erreichen. Die Bedeutung von ' $u m^{\prime}$ ' ist in diesen Fállen fast immer 'Geist' im Sinne der Geisteshaltung, Geistesart; die Bedeutung reicht zuweilen weit in die Bereiche 'Gemüt, Seele' hinein. Das Übergreifen auf Irrationales führt zu einer gewissen Verschwommenheit der Begriffe, die in vielen Făllen jedoch von der näheren Umgebung des potentiellen Urteils aufgefangen wird. Wörter wie 'narodnyj' und 'russkij', wohl auch 'krest'janskij' erfuhren in der Romantik eine besondere semantische Einfärbung.

An einigen Volkserzăhlungen rühmt Belinskij, daß sich in ihnen "narodnyj um, narodnyj vzgljad na vesci i narodnyj byt" artikuliere $(V, 671)$.

Belinskij befürchtet, daß ohne Bildung der Geist des Volkes in List, Verschlagenheit usw. umschlage (VIII,156).

Bei aller Wertschătzung des 'russkij um' hat Belinskij auch weniger er freuliche Züge gesehen:

russkoe sibaritstvo i russkij um $(I, 49)$

lukavyj russkij um $(V, 668)$

Aber im allgemeinen findet 'russkij um' eine sehr positive Beurteilung:

Schon 1834 spricht Belinskij von der praktischen Philosophie des russischen Geistes (um), die im Werk Derzavins als "narodnost" sichtbar werde $(I, 50)$.

Der Geist Derzavins sei ein russischer gewesen: positiv (polozitel'nyj), fern aller Mystik, aller Geheimniskrämerei $(I, 49)$.

Der russische Geist (um) liebe die Freiheit, die Klarheit, die Entschiedenheit (opredelennost ${ }^{\circ}$ ); reine Spekulation umneble ihn nicht (cistoe umozrenie ego ne otumanit) $(I I, 125)$.

Diese realitătsbezogene Geisteshaltung ist auch gemeint, wenn Belinskij 1845 von der "russischen Seele, dem klaren, positiven russischen Geist (um), der Kraft und Tiefe der Gefühle" (IX,438) spricht.

Zu einer eigenstăndigen Entwicklung brauche der russische Geist den Anstoß von außen (XX,600). 
Diese Überzeugung hatte Belinskij schon sehr früh verkündet:

Erst unter Peter I. sei der russische Geist erwacht $(I, 46)$, ihm sei Freiheit gegeben worden, und der russische Genius habe mit ausgebreiteten Armen zu gehen begonnen $(I, 47)$.

Mit dem Wort 'krest'janskij' wird Grobschlăchtigkeit, Einfältigkeit, ja Dummheit bezeichnet. Mit 'Bauernschläue' hat 'krest'janskij um' nichts zu tun; die Übersetzung 'bäurisches Gemüt' trifft die Bedeutung noch am besten.

Weil die hier besprochenen Attribute auffällige Eigenschaften der geistig-seelischen Artung der bezeichneten Gruppe bündeln, wird 'um' das Übergreifen auf die Bedeutungsbereiche ermöglicht, aus denen auch die Attribute ihre Merkmale gezogen haben. Nur so ist zu erklären, daß 'um' zwar mit 'Geisteshaltung' korrekt übersetzt wird, aber die Bedeutung von 'um' in 'francuzskij um' eine spürbar andere ist als in 'russkij um'. Dort neigt der Nebensinn dem 'esprit', dem Witz, dem Künstlichen zu, hier mehr dem Gemüt, der Seele, dem Natürlichen. In 'francuzskij' sind offensichtlich mehr intellektuelle Merkmale eingegangen, in 'russkij' mehr irrationale. Daß 'francuzskij um' mehr im eigentlichen Bereich von 'um' bleibt, wäre dann mit der geringen semantischen Entfernung zu erklären; 'francuzskij' paßt also wohl besser zu 'um' als 'russkij' - man könnte das eine semantische Verfestigung von Vor eingenommenheiten nennen. Die folgenden Aussagen sind von 'russkij um' kaum denkbar: ostrota francuzskogo uma (III, 455; X $\Pi, 447)$ samyj vkusnyj $i$ aromaticeskij plod francuzskoj poèzii, fran cuzskogo uma, francuzskoj fantazii i francuzskoj zizni (III,492).

Das Attribut 'celovečeskij’ kann zum einen den selbstver ständlichen (generell implizierten) Tatbestand meinen, daß der 'Geist', der 'Verstand' menschlich sind, zum anderen den Geist als Einheit, als gemeinsamen Besitz einer individuell gedachten Menschheit vorstellen. So wie in den vorangegangenen Beispielen das Volk, das russische Volk als eine Wesenheit gedacht wurde, so wird hier das Kollektivum 'Menschheit' personifiziert, ihre Jeschichte und die ihres Geistes als Ontogenese gesehen. 'um' kann häufig mit 'Geistesgeschichte' übersetzt werden. 
bessmertnye proizvedenija uma celoveceskogo $(I, 379)$

uspechi uma $c$-ogo (X, 229 und 273).

torzestvo c-ogo uma (XI, 524)

estestvennyj chod $c$-ogo uma (DX, 230)

preryvat' chod $\mathrm{C}$-ogo uma $(\mathrm{I}, 35)$

\subsection{Relationale Urteile}

In den folgenden Satzausschnitten fehlen ausgesprochene Relator en; die Art der Beziehung ist mit der Nennung der Beziehungsglieder selbstverstăndlich gegeben, weil sie sich bedeutungsmåßig nahestehen. Diese potentiellen Satze lassen sich nicht ohne weiteres in aktuale übersetzen. In einem Satz wie 'on celovek obrazovannogo uma' ist das potentielle Urtell 'obrazovannyj um' leicht in ein aktuales umsetzbar. In der Wendung 'on celovek obrazovanností i uma' verhảlt sich 'obrazovannost" zwar auch prádikativ zu 'um', aber die Art der Beziehung ist nur eine über 'Celovek' mittelbare.

Faßt man die 'um' konsozilerten Beziehungsglieder als indirekte Aussagen über 'um' auf, dann kann man sie entweder der bisher untersuchten Gruppe der leicht vereinbaren, hochspezialisierten Prädikationen zurechnen oder den partiell implizierten. Auf Grund der Art der semantischen Beziehung $\mathrm{zu}$ 'um' lassen sich die konsozilerten Substantive so unterscheiden:

1) Worter, auf deren Bedeutung auch 'um' bezogen werden könnte. Beispiel: um i rassudok

Prognose: sehr enger Spielraum für 'um'; hochspezialisierte Bedeutung.

2) Worter, die Wirkungsweise, Wirkungskreis des Vermögens 'um' nennen.

Beispiel : um i istina; um i nabljudenie

Prognose: enger Spielraum; spezialisierte Bedeutung.

Die Bedeutensweise dieser beiden Beleggruppen ist der der Bestimmungsurteile mit partiell implizierter Prädikation nah verwandt. Die Beispiele werden unter 1.40 behandelt.

3) Wörter, die dem menschlichen Geist bei- oder nachgeordnete Fähigkeiten, Eigenschaften vorwiegend intellektueller Natur zur 
Sprache bringen.

Beispiel: um i talant; um i darovanie

Prognose: größerer Spielraum, aber deutliche Akzentsetzung.

4) Wörter, die zwar benachbarte, aber artverschiedene Phänomene der geistig-seelischen Ausstattung nennen.

Beispiel: um i cuvstvo, serdce, duša

Prognose: wenig eingeengter Spielraum; Betonung des rationalen Moments.

5) Wörter, die zwar naheliegende, aber wesensverschiedene Erscheinungen im Umkreis der menschlichen Existenz bezeichnen.

Beispiel: um i sila, zizn'

Prognose: kaum berührter Bedeutungsbereich; schwache Akzentsetzung.

\subsubsection{Konsoziationen}

Die in den folgenden Teilsätzen genannten Begabungen und Eigenschaften treten in wechselnder Kombination auf. Die beigeordneten Wör ter decken häufig im Gegensatz zu den durch 'um' repräsentierten intellektuellen Fähigkeiten die intuitiven ab, oder meinen die Anwendung in Absetzung von der Theorie.

'um i talant' sind bei Belinskij fast zu einem Zeichen zusammengewachsen; 'talant' rundet die Bedeutung von 'um' einerseits in Richtung 'Gespür', andererseits auch in Richtung 'Umsetzung der latenten geistigen Fahigkeiten in Produkte - meist künstlerischer Art' ab. 'talant' und auch 'darovanie' sind sehr dehnbare Wörter.

Belinskij preist "um $i$ talant" Fonvizins, weil er erraten habe, was in seiner Zeit möglich und notwendig war $(V, 537)$.

Der Humor sei ebensosehr Geist (um) wie Talent (VII, 64).

weitere Belege: VI, 513; 575; VII,48; VIII, 294; 483; 576; DX, 77;

$348 ; X, 44 ; 55 ; 216 ; 427 ; 455$.

um i darovanie (I, 413; II, 516; IV, 85).

Wenn von einem Menschen gesagt wird, er sei ein Mensch von Geist, oder von einem Buch, es sei mit Geist geschrieben worden, dann werden dem so Beurteilten auch Begabung, Talent und Geschmack bescheinigt. Insofern kann auch 'um' diese Eigenschaften mitbedeuten; wenn ihnen ein eigener Name gegeben wird, dann, um die Aufmerksamkeit 
des Hörers/Lesers zu lenken, um im Bedeutungsbereich Akzente zu setzen. Durch Doppeldeckung der Rănder des Wortes 'um' wird das Gewicht verlagert. Man kann diese Konsoziationen explikative nennen, den unterdrückten Relator oft mit 'das heift' übersetzen. Dagegen sind Reihungen wie 'um i curstvo' komplementäre, deren Relator mit 'und', 'sowohl als auch $^{\prime}$ u. ă. wiedergegeben werden muß.

Wenn Belinskij in einem Buch "um, talant 1 izjascestvo" $(V, 153)$ findet oder an einem Menschen "vkus, um i darovanie" (VI, 72) erkennt, dann werden dem Geist die Kritikfähigkeit und das Vermögen der Umsetzung des Erkannten in die Tat, in das Werk bescheinigt. Umgekehrt werden dem Geschmack und Talent geistige Fundiertheit nachgesagt. Die semantische Einfärbung ist also wechselseitig. 'um' ist seiner großen Bedeutungsweite wegen jedoch besonders auf die Sinnbeschwerung angewiesen; 'um' bedarf der Vorformung wie kein anderes Wort im Bedeutungsfeld des Geistig-Seelischen. Die folgende Zusammenstellung der beigeordneten Substantive für vorwiegend intellektuelle Eigenschaften vermittelt einen Eindruck von den Möglichkeiten der Bedeutungsschattierung:

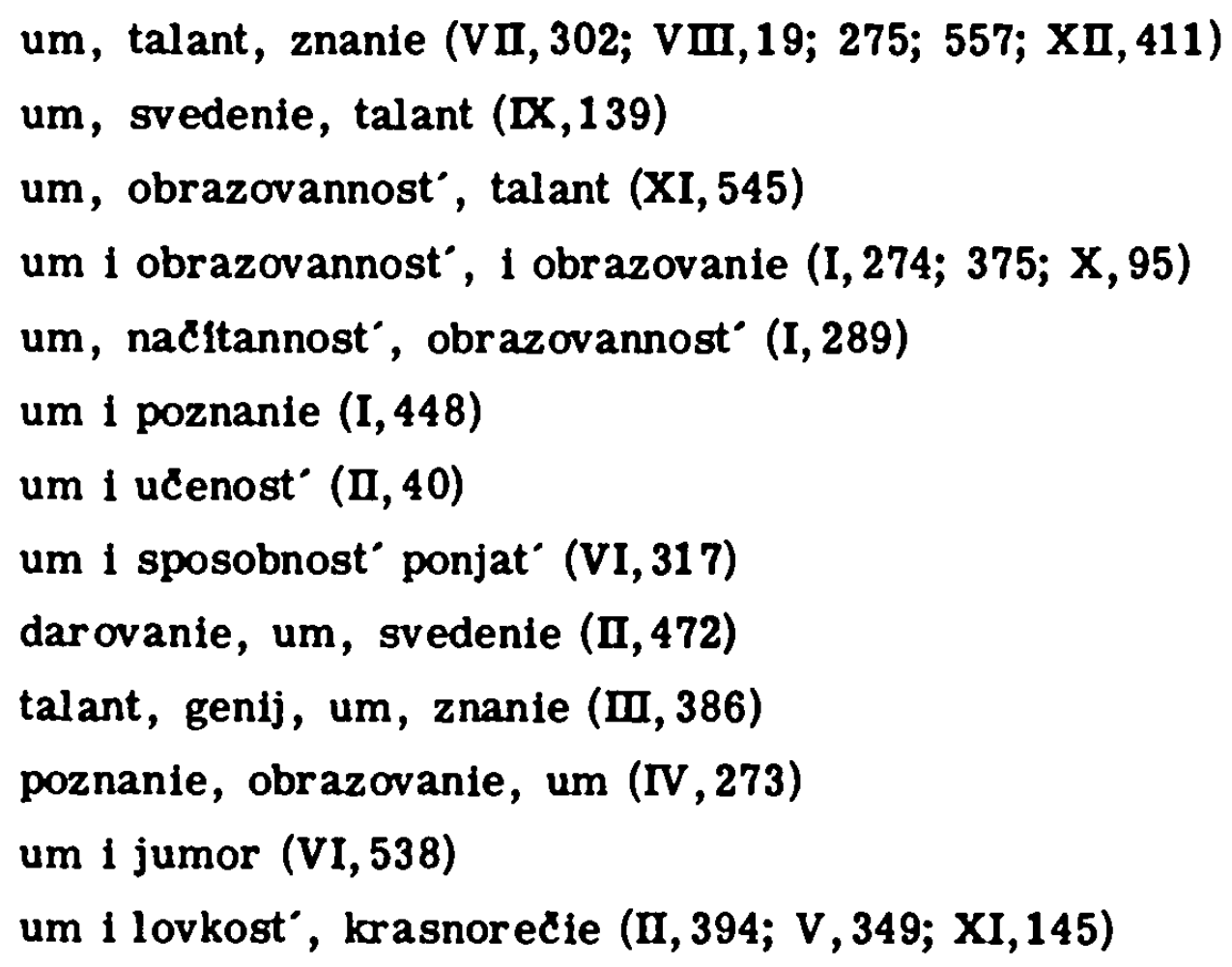

Von einer gewissen Länge an ist der stilistische Wert einer Wortkette fragwürdig: 
Von Kraevskij schreibt Belinskij, daß er weder über Geist (um) noch Talent verfüge, weder eine Uberzeugung noch Wissen habe und ohne Bildung sel... aber er gebe eine Zeitschrift heraus! (XII, 421)

Das ist temperamentvoll gesagt, und die Aufzăhlung aller Mängel ver stärkt den Eindruck, daß von einem ganz und gar geistlosen Menschen die Rede ist. Diese Reihung lăßst sich also durchaus stilistisch vertreten, ebenso wie die folgende:

Der Wirkungskreis des Franzosen sei das Parkett, auf dem er den Glanz seines Geistes (um), seiner Kenntnisse, seiner Talente, seines Scharfsinns, seiner Bildung ver sprühe $(I, 29)$.

Das Bild des Glitzernden legt auch eine Bedeutungsfacettierung des Wor tes 'um' nahe. Aber oft reiht Belinskij eine solche Fülle von Wörtern für benachbarte Begriffe, daß die Bedeutungen sich gegenseitig fast ersticken. Auf einem viel zu kleinen Bedeutungsbereich drängen sich viel zu viele Wörter. Statt den Bereich mit einem oder zwei Wörtern abzudecken, belädt Belinskij das Gemeinte solange mit gerade greifbaren, annăhernd zutreffenden Wörtern bis er glaubt, getroffen zu haben, was er sagen wollte. Analog zum semantisch überladenen Wort kann man hier von einer verbal überladenen Bedeutung sprechen.

Das mittelmåßige Talent versuche u. a. mit üppiger Phraseologie, mit den Früchten seiner Belesenheit, seines Geistes (um), seiner Einbildung, seiner Lebenserfahrung den Leser zu tăuschen (I, 289).

Bei allem Geist (um), bei aller Begabung, Gelehrtheit und Bildung... (VI, 303)

Das Theaterspiel sei von Geschmack und Anstand, von Geist (um) und Grazie erfüllt gewesen (VIII, 543).

Belinskij erklärt das Mehr an Wohltătigkeit zu einer der erfreulichsten Erscheinungen der modernen Zivilisation, der Erfolge des Geistes (um), der Aufklärung und der Bildung (X, 302).

In all diesen Sătzen läßt Belinskij den Leser am Ringen um das Wort teilnehmen, statt eine definitive Aussage zu bieten, m.a.W. er offenbart ein Zuwenig an Nennoperation.

Die Einwirkung der konsozilerten Substantive in den bisher besprochenen Beispielen bestand in der verbalen Doppelbesetzung eines Teils des Bedeutungsbereichs von 'um'. In den folgenden Sătzen treten zu diesen semantisch beschwerenden Substantiven Wörter hinzu, die auf Bedeu- 
tungen bezogen sind, die - obgleich benachbart - keinesfalls von 'um' gedeckt werden können.

Karamzins "Bednaja Liza" habe die Gesellschaft überzeugt, daß auch ein Russe "i dusa, i serdce, i um, i talant" haben kann (III, 311) Belinskij versucht hier, mit 'duš' und 'serdce' den seelisch-gefühl smäßigen Bereich, mit 'um' und 'talant' den rationalen abzudecken. 'dusa' und 'serdce' haben die Funktion eines Sekundärurteils, das auf das durch 'talant' primär vorbelastete 'um' einwirkt, und zwar verstärkt der Kontrast das rationale Moment. Das vorderhand vierteilige potentielle relationale Urteil kann als zweigliedriges mit vorbelasteten Beziehungsgliedern angesehen werden. In der Reihung 'vkus', 'cuvstvo', 'um', 'poznanie' (I, 323) rücken vergleichbar 'vkus' und 'Cuvstvo' als intuitive Vermögen gegen 'um' und 'poznanie' als intellektuelle zusammen.

'talant', 'darovanie' und 'vkus' sind Eigenschaften, die manchmal mehr im Umkreis von Seele und Gefühl, manchmal mehr im Umkreis der Ratio gesehen werden; daruber gibt die Reihenfolge Aufschluß:

um, znanie - vdochnovenie, talant (VI, 206)

um, zdravyj smysl - blagorodnoe serdce (VIII, 206)

ponimanie, um - cuvstvo (III, 390)

talant, vkus, um - cuvstvo, znanie zizni (VI, 374)

talant, um - oduševlenie, cuvstvo (VI,133)

smysl, tolk, um - vdochnovenie, talant (VIII,163)

um, darovanie - duša (VI, 572)

um, obrazovannost' - Cuvstvo, grust', melancholija (IX,121)

um, talant - volja $(\mathrm{V}, 210)$

um, obrazovannost', talant - blagorodstvo cuvstv (XI,103)

um, talant - fantazija (XII, 271)

Fehlt in einer Reihung ein Substantiv, dessen Bedeutung zu 'um' tendiert, dann bleibt 'um' ein weiterer, weil an keiner Stelle beschwerter Spielraum. Ist $2 . B$. von einem jungen Mann die Rede, der von Natur aus mit 'um', 'Cuvstvo' und 'talant' begabt ist $(I, 102)$, dann kann in dem entsprechenden Satz 'talant' nicht über 'cuvstvo' hinweg auf 'um' einwirken. 'talant' erscheint in dieser Charakterisierung als eine eigene, 'um' und 'Cuvstvo' verwandte Komponente, bzw. im Verein mit 'cuvstvo' auf der 
'um' gegenüberliegenden nicht-rationalen Seite. Ähnlich:

um, serdce, talant (VII, 294)

um, cuvstvo, obrazovannost'(II, 23)

um, duša, vkus $(V, 523)$

Wenn die seelisch-gefühlsmäßige Seite dichter mit Wörtern besetzt ist als die intellektuelle, dann ist damit ein Akzent gesetzt worden: 'um' ist subjektiv oder objektiv gesehen weniger belangvoll:

Die Jugend nehme das als unbedingte $W$ ahrheit an, was vor allem ander en "cuvstvo, voobražnie 1 um" beeindrucke $(\mathrm{XX}, 435)$

um, voobrazenie, strast $^{\prime}(X, 119)$

um, serdce, voobraženie $(X I, 21)$

In allen Reihungen herrscht eine gewisse Ordnung auf Grund lexikalisch vorgegebener Affinităten oder vom Sprecher beabsichtigter Annäherungen. Zweimal scheinen die Wörter wie wahllos in den Satz gefallen zu sein; in beiden Fảlen ist der Tonfall erregt; in beiden Fällen ist die Wortfülle unangemessen:

cuvstvo, um, poznanie, obrazovannost', voobrazenie, talant $(I, 106)$ duš, Cuvstvo, um, fantazija, talant (IV ,141)

Die Wortreihungen werden im übergreif enden aktualen Urteil meistens zur Aussage über einen Menschen oder sein geistiges Produkt herangezogen. Das erklärt, weshalb die konsoziierten Substantive in neun Zehntel aller Fälle geistige und seelische Vermögen bezeichnen. Selbstverständliche Beziehungen bestehen aber auch zu den Erscheinungsformen und Auswirkungen dieser Vermögen, die als objektivierter Geist, als objektivierte Seele greifbar werden:

Wenn die menschliche Existenz eines Volkes im Leben des Geistes (um), der Wissenschaft, der Kunst, der Zivilisation, des Gemeinwesens, der Humanităt in Sitten und Gebrăuchen bestehe, dann habe die Existenz für Rußland erst mit Peter dem Großen begonnen (VII, 629).

'um', 'nauka', 'iskusstvo' meinen 'Kultur', den in Wissenschaft und Kunst objektivierten objektiven Geist. 'civilizacija', 'obscestvennost", 'gumanost'v uvarach i obycach' meinen das Zivilisatorische. Als pră- 
formierte Beziehungsglieder treten 'um' und 'civilizacija' auf. Innerliches und Äußerliches sind auch in den folgenden Satzausschnitten gereiht worden: um, obrazovannost' - znatnost' (VIII, 632) sostojanie, cin, mesto - um, sposobnost $(\mathrm{XX}, 563)$ molodost', zdorovie - bogatstvo - um, serdce (VII, 463) ... ni talant, ni ličnost', ni bezukorizennost' dejatel 'nosti i zizni, ni ubezdenie, ni Cuvstvo, ni um $(\mathrm{IV}, 436)$

Celovek bez poznanii, bez pravil, bez dusi, bez cesti i sovesti $(I, 403)$

'um' kann zwar die Gesamtheit der geistigen und seelischen $\mathrm{Kräfte}$ bezeichnen, aber meistens wird ihm ein besonderes Wort für das NichtRationale beigegeben, wenn diese Gesamtheit gemeint werden soll; 'um' wird dann in seiner Bedeutungsweite entsprechend verkürzt (eine Folge der stärker bemühten Nennoperation). Verbindungen wie 'um i cuv stvo' oder 'i serdce' werden komplementär, nicht antinomisch gesehen. Diese Konsoziationen bezeichnen als Wortgruppe die eine Bedeutung 'Geistigkeit'.

'um i serdce' ubersetzen wir mit 'Kopf und Herz'. Obgleich auch das Russische 'golova' in der Bedeutung 'Verstand, Vernunft' kennt, bevorzugt Belinskij die scheinbar weniger plastische, durch Verknüpfung einer mittelbaren und einer unmittelbaren Benennung zudem stilistisch uneinheitliche Wendung. Aber im Gegensatz zu den deutschen Wörtern 'Verstand ' und 'Geist' wird 'um' sehr viel hăufiger als Bezeichnung für seine Verkörperungen 'Mensch' und 'Kopf' gebraucht; insof ern ist das Bild 'um i serdce' geschlossener als 'Verstand und Herz' oder 'Geist und Herz'.

akter možet probudit' sil'noe dviženie i v umach, i v serdcach (II, 393)

davat' napravlenie serdcu i umu (VII,160)

razvivat ${ }^{\prime} i$ um i serdce (DX,159 und 417 )

In den folgenden Ausschnitten generalisiert 'um i serdce' die Aussage:

zablużenie uma i serdca (III,91) - ein völliger Irrtum

ponjatno i umu i serdcu $(V, 212)$ - leicht begreifbar

obrazovanie uma i serdca (VI, 498) - Bildung in jeder Hinsicht 
Die Unterscheidung von 'serdce' und 'cuvstvo' wäre eine eigene Arbeit wert. Hier nur soviel: 'serdce' ist im allgemeinen 'innerlicher', stärker der Seele zugewandt; 'cuvstvo' ist 'ăußerlicher', den Sinnen, der Sinnlichkeit verbunden (lexikalisch verfestigt in der Doppelbedeutung Gefühl und Sinn).

1) 'um i Cuvstvo' in der Bedeutung 'Vernunft'

Ganz im Schellingschen Sinn schreibt Belinskij 1834, daß Gott den Menschen geschaffen und ihm "um i cuvstvo" gegeben habe, damit er die Idee "umom i znaniem" begreife, daß er sich "v zivom i gorjacem socuvstvii" sie einverleibe und ihr Leben "v cuvstve beskonečnoj, ziždušđj ljubvi" teile (I, 30).

Dem Wortpaar 'um i Cuvstvo' sind 'znanie' bzw. 'socuvstvie' und 'ljubov" prädikativ nachgeordnet. Die Anverwandlung der Idee kann nur gemeinsam von Geist und Gefühl geleistet werden; gemeinsam können die beiden Wör ter auf eine Bedeutung Bezug nehmen, die später 'razum' allein deckt. Insofer $n$ kann man in diesem Fall von einem Wortgruppenlexem sprechen, als hier die Gesamtbedeutung von 'um i Cuvstvo' unter dem Einfluß des Beziehungsgliedes 'Idee' mehr ist als die Summe der Teilbedeutungen. ... das allgemeine menschliche Leben "umom i cuvstvom" aufspïren $(I, 92)$

In Fragen des Seschmacks könne das Urtell nur dann richtig sein, wenn sich "um i Cuvstvo" in vollendeter Harmonie befinden (I, 357; åhnl ich XI, 321).

2) 'um i čuvstvo' als Zeichen für 'Geist und Seele'

In den folgenden Beispielen werden die Bedeutungen von 'um' und 'cuvstvo' addiert, ohne daß sie zu einer neuen Qualität gelangen:

neponjatna dlja uma, neudovletvoritel'na dlja cuvstva... (I, 262)

dejstvovat' na um i cuvstvo (VII, 527)

zagadka cuvstva i uma (I, 275)

ăhnl ich: I, 92; 281; II, 172; 212; III, 383

In der Nachbarschaft zum Wort 'fantazija' wird 'um' auf das Akzeptierende des Verstandes gelenkt, da 'fantazija' - vor allem in den dreißiger Jahren - als die schöpferische Kraft begriffen wird, während 'duša', 'Cuvstvo' und 'serdce' auch als Vermögen der (intuitiven) Weltaneignung erscheinen. 
davat' prostor umu i fantazii (VII, 303)

proizvedenie uma $i$ fantazii $(V, 626$ und 631$)$

udovletvor it' fantaziju i um (IX,418)

Je weiter das konsozilerte Substantiv semantisch entfernt ist, desto mehr Spielraum bleibt dem Wort 'um':

Peter der Große habe gleichzeitig "umom i toporom" gearbeitet (VI, 601).

Das Bell steht hier als Synekdoche für die physische Arbeit; 'um' signalisiert das Geistige schlechthin.

Die Liebe gehöre zum Menschen wie Atmen und Schauen, wie Hunger und Durst, wie der Geist (um) und das Wort $(\mathrm{X}, 24)$.

um i zizn' (XI, 323)

krasota I um (VII, 93)

bogatstvo, um, znatnost' $(\mathrm{I}, 400)$

Die Reihungen mehrerer naheliegender Wörter sind weniger Ausdruck bewußter Urteile als vielmehr halb- oder unbewußter Assoziationen. Die Nennung des einen Wortes weckt die anderen. Die Einflußnahme auf die Bedeutungen besteht mehr in einer Einfärbung, einer Akzentsetzung als in einem absichtlichen Herausschneiden des intendierten Bereichssegments.

1.22.2 Relationale Urteile mit ausgesprochenem Relator zwischen verwandten Beziehungsgliedern

Weil die Beziehung mit der Nennung selbstver ständlich ist, bedarf es nur selten eines Relators. Für die Weite des Bedeutungsspiel raums ist es entscheidend, ob 'um' den aktiven oder den passiven Part in der Beziehung spielt, ob es Subjekt oder Objekt ist. Als Tăter ist 'um' sehr viel stărker bestimmt als in abhăngiger Position, denn die Verzeitungsoperation geschieht eben vom logischen Subjekt aus. Das Verzeitungsindiz, der Relator, verhảlt sich zusammen mit dem abhăngigen Beziehungsglied in erster Linie prädikativ zum Subjekt. In den folgenden Beispielen ist 'um' der Einwirkung ausgesetzt. Die aktiven Beziehungsglieder sind begr ifflich unter schiedlich hoch organisiert und meistens auf ' $u m^{\prime}$ hin spezialisiert. Vorwiegend wird die 
Bedeutung 'Geist als Gesamtheit der intellektuellen Krafte' sonsolidiert.

Um tătig zu werden, bedarf der Geist der Anregung

durch schöne Formen (II,442),

durch Form, Farbe, Ton (VI,13).

Auf der anderen Seite stellen sich der freien Entfaltung des Gei-

stes Hindernisse in den Weg:

'um' wird gelenkt (III, 488),

unterliegt Einflüssen (II, 109),

ist belastet (VII, 513),

trägt Fesseln (VI, 389; V,101),

kann durch eine Heirat behindert werden $(\mathrm{XI}, 285)$.

Die Idee und Form der Dichtungen Derzavins beherrscien den Geist einiger Menschen so sehr, daß für sie nur das Dichtung sei, was den Versen Derzavins ähnele $(\mathrm{XX}, 15)$.

Fruchtlose Wissenschaft lasse den Geist verdorren (IV, 521).

Der Geist (um) könne durch ăußerliche Tiefe erlesener Gedanken verwirrt (VII, 567), durch poetische Gemeinplätze verzaubert werden (VII, 633). 
1.30 Starke Einengung des Bedeutungsbereichs.

Auf 'Ver stand', 'Ratio', 'Intellekt' gelenkter Blickwinkel.

Die folgenden Satzausschnitte konsolidieren vor allem die Bedeutung 'Verstand'; als Uber setzungswörter kommen außerdem 'Intellekt', 'Ratio' und 'Urtellskraft' infrage. 'rassudok' kann oft synonym verwandt werden; 'razum' und 'duch' können nur sehr selten an die Stelle von 'um' rücken.

Die Bedeutensweisen der determinierenden und relationierenden Urtelle waren im vorigen Abschnitt vergleichbar: hier wie dort schwach bemulhte Verzeitungsoperation; Prădikation und Bezlehungsglied waren trotz hoher begrifflicher Organisation leicht mit dem Subjekt bzw. Bezugspol 'um' vereinbar. In diesem Abschnitt sind die Unterschiede größer:

\section{1) Bestimmungsurteile}

Der Verzeitungsoperation obliegt es, die mit der Nennung angesprochenen unterschiedlichen Bedeutungsfelder zu verknüpfen. Die Aussagen sind auf Sachbereiche hin spezialisiert, die vorderhand nichts mit der Sache 'um' zu tun haben. 'um' wird in die Realităt gezogen, in mehr oder weniger konkrete Bilder eingepaßt. Das Bedeutungserlebnis ist sinnlicher und meistens aktueller, an einem oder mehreren, dann aber vergleichbaren Tatbestănden orientiert. Vom 'Verstand' kann man sich ein Bild machen, wenn er in die Welt gestaltend oder anverwandelnd eingreift, sich tatsăchlich an und in ihr niederschlăgt.

2) Beziehungsurteile

In den im vorigen Abschnitt besprochenen Reihungen blieben die Bedeutungen der beteiligten Wörter zueinander offen; herausgestellt wurde das Gemeinsame. Oft waren die Wörter auf ein einheitliches Gemeintes angesetzt; die Bedeutungsbeziehungen waren selbstverständlich. Die fol genden Sătze bringen eine dufferenziertere Betrachtung der Beziehungen zum Ausdruck. Die Wörter werden dadurch stärker festgelegt. Entweder gewinnen sie thre Konturen in der Jegenüberstellung von Position und Ne- 
gation oder in der Beschreibung einmaliger und nicht notwendiger Konstellationen.

Ist die engere Bedeutung in den determinierenden Sătzen eine Folge der bildhaften Fixierung, so ist sie in den potentiellen Beziehungssätzen Ergebnis des Kontrastes, in den aktuellen Produkt der Orientierung am einmaligen Sachverhalt.

1.31 Semantisch fernliegende determinierende Prădikationen

Das vermittelte Bild ist zunächst noch sehr vage; die Prädikatswör ter gehören zum Gesichtssinn, sind also von Haus aus bezugsvariabler, greifen folglich die Bedeutung nicht stark an. 'jasnyj' und 'svetlyj' haben eine relativ feste übertragene Bedeutung, obgleich das Bild miterlebt wird:

blagodatnaja natura, svetlyj um, zerno razumnosti $(\mathbf{X X}, 183)$

terpenie i rutina - svetlyj um, talant (IV,439)

Die năhere sprachliche Umgebung stützt den durch 'svetlyj" vermittelten erhabenen Sinn: 'lichter Geist'.

'jasnyj' ist wirklichkeitsnăher:

jasnyj, opredelennyj um (VII, 227) - ein klarer, genauer Verstand.

Der Vergleich mit dem Gesichtssinn ist so plastisch wie naheliegend. Das Organ der geistigen Wahrnehmung kann 'Geist' oder 'Verstand' genannt werden; beide Bedeutungen vertragen sich mit dem Bild:

Die Gegenstände spiegeln sich "v glazach uma" $(X, 79)$.

Belinskij fragt, was das für eine Wahrheit sel, die die Untersuchung fürchte, die sich "ot vzorov uma" verfinstere $(I, 324)$.

"krugozor uma" (XI,191) meint den Gesichtskreis, das Feld des diesem Verstand Begreifbaren. Er hat per se seine'Grenzen, in denen seine Tătigkeit fruchtbar ist" (XM, 331).

In diesem Abschnitt tauchen überdurchschnittlich viele negative Einschătzungen auf, was als Zeichen für Belinskijs Skepsis gegenüber dem für das Allgemeine, für die Idee unempfänglichen Verstand, diesem Organ für das Besondere, die Vielfalt angesehen werden kann. Für das Vorder gründige wăhlt Belinskij Bezeichnungen wie 'knižnyj', 'vyčitannyj', am hăufigsten aber die synăsthetisch verbundenen Wörter 'cholodnyj', 'suchoj'. 
Erst in der Verbindung mit dem Herzen, mit dem Gefühl, die fast immer 'warm' gedacht werden, wird der Verstand zum lebendigen, gesunden Geist, der Vernunft implizieren kann:

Menschen mit einem büchernen, angelesenen Verstand (um), mit fertigen Urteilen über alles und jedes verstehen niemals, daß Menschen von höher er Natur, die aber von der Bildung übergangen wor den sind, in threr seltsamen Sprache das ausdrücken können, was tief in ihre Seele eingedrungen sei und ihren Geist (um) stark beschustigt habe (XX,540; vgl. auch VII, 484, XII,131).

In ein und demselben Satz nimmt 'um' unter dem Einfluß der unmittelbaren sprachlichen Umgebung ganz unter schiedliche Bedeutungen an.

Belinskij schreibt Comte reiche Kenntnisse, große Klugheit (um) zu, aber sein Verstand (um) sei trocken, ohne jeden Höhenflug (Xח, 329).

Die Übersetzung muß hier verschiedene Wörter wählen, weil die verfügbaren deutschen jeweils enger gefaßt sind, so daß sie diese Gewichtsver lagerungen in ihrem Bedeutungsber eich nicht zulassen.

Den kalten Verstand, den Intellekt (cholodnyj um) setzt Belinskij gegen 'serdce', 'fantazija' und 'cuvstvo' ab, stellt ihn in eine Reihe z. B. mit einer mürrischen Gelehr samkeit (kropotlivaja ucenost' - 1,112). Ende der dreißiger Jahre betont Belinskij jedoch seltener die Antithese Geist : Seele, sondern hăufiger die Synthese:

1835 behauptet er, daß alles von der Phantasie und nicht vom kalten Intellekt (cholodnyj um) Geschaffene wahr, richtig und schön sein. Ein Verstoß liege dann vor, wenn die Phantasie dem Verstand (um) den Platz răume; der Verstand arbeite dann ohne Beteiligung des Gefühls, schöpfe allein aus der Quelle der Erfindung $(I, 360)$.

1837 tauscht Belinskij in einem Satz bezeichnenderweise 'um' gegen 'razum' aus:

Die 'Schöne Seele' wolle dartun, daß das wahre Leben im Gefühl bestehe, daß die Vernünftigkeit (razumenie) der Tod des Gefühls sei. Die Kälte der Urteile, das Vertrauen auf den kalten Intellekt (cholodnyj um) führe ins Verderben... Die Antwort müsse die Dar legung der Begriffe von Vernunft (razum) und Sefühl, ihre wechsel seitigen Beziehungen beinhalten... (XI,188).

1843 schreibt Belinskij, daß es eine Zeit gegeben habe, die, indem sie dem Dichter ein glühendes Herz, dem Philosophen aber "cholodnyj um" zubilligte, dem einen Verstand (um), dem anderen Herz abgesprochen habe (VI, 49). 
Belinskij ist eher geneigt, den intuitiven Kraften ein Übergewicht uber die intell ektuellen zu gestatten als umgekehrt:

Das Urteil "preobladanie teplogo cuvstva nad cholodnym umom" (VII, 422) enthăt keinerlei Vorwurf gegenüber dem so Charakterisierten;

einen Tadel enthăt jedoch die Bemerkung, daß Lomonosov die Phantasie im straffen Zügel des kalten Intellekts (cholodnyj um) gehalten habe $(I, 44)$.

Oder in einem anderen Bild:

Bakunin verfüge über "ogromnyj um" (XI, 344);

"izbytok uma" (I, 225; V, 592) enthălt den gleichen Vorwurf.

Die Vorstellung von einer 'dicken Eiskruste' $(X, 324)$, der (dogmatischen) Erstarrung (IV, 287) ist die konsequente Fortsetzung des kalt gedachten Verstandes. Weniger stark wird der Bedeutungsber eich durch Wörter aus dem Feld des Aktiv-Kämpferischen beschnitten; diese Bedeutungen liegen nâher, sind menschlicher. Die wachger ufenen Vor stellungen sind ebenfalls sehr dicht, sie unterstreichen das Instrumentale an 'um', aber auch das Unreflektiert-Vitale:

'um' ist die "geistige Waffe" des Menschen (X, 79);

das Bild der "Schärfe" stellt sich ein (II, 221; XII, 61).

Dem Manne sei ein "stolzer und wißbegieriger Verstand (um)" eigen ( $(, 225)$.

Im Begr iff des 'starken Verstandes' (sil'nyj um) (VII, 489; I, 357) sind Standhaftigkeit und Selbständigkeit, so etwas wie 'mit beiden Beinen auf dem Boden stehen' eingefangen. Der 'grobe Verstand' (X, 323; VI, 687) enthält den Vorwurf mangelnder Sensibilităt.

Im Bild der Weichheit, im 'mjagkij um' (VI, 683; X, 374) wird dagegen die Bedeutung von 'um' $\mathrm{zu}$ 'Geist' gedehnt. 


\subsection{Relationale Urteile}

1.32.1 Ausgesprochene Vergleiche einer Begriffsr eihe mit einer anderen

Gegenüberstellungen von Begriffsr eihen bzw. einer 'um' einschließenden Reihe mi t einem einzelnen Begriff treffen den Bedeutungsbereich von ' $u m^{\prime}$ 'erst in zweiter Linie; 'um' ist durch die unmittelbar konsoziierten Substantive vorgeformt. Die expressis verbis entgegengesetzten Sekundăraussagen pointieren die primär erlangte Bedeutung:

Die Satiren Kantemirs seien eher eine Frucht "uma i cholodnoj nabljudatel'nosti" als eines lebendigen und glühenden Gefühls $(I, 41)$. Im Vergleich mit der starken Gefühl swärme erkaltet der ohnehin schon durch die Nachbarschaft abgekühlte Ver stand zum Intellekt.

Zu Boris Godunov habe es im Volk - wenn überhaupt - nur im Kopf, aber nicht im Herzen Liebe gegeben. "um i voobrazenie" haben Godunov bewundert, aber das Herz habe geschwiegen, habe sich geweigert, mit dem Verstand und der Vorstellungskraft übereinzustimmen (VII, 519).

Der Gegensatz zu 'serdce' verstärkt das Moment der Nüchternheit des Verstandes. In der Absetzung.moralischer gegen intellektuelle Qualitäten wird vergleichbar das 'Herzlose' im Begriff 'um' unterstrichen:

Die vorrangige Bedingung jeder menschlichen Beziehung sei "prjamota" und "Cestnost" und nicht "umstvovanie, rassuzdenie, um, cuvstvo, genij" (XII, 37)!

cuvstvo, um - opyt $(X, 338)$

um, volja - serdce $(X, 335)$

Hăuufig werden das Analytische des Intellekts und das Synthetische, das Praktisch-Schöpferische des Geistes (duch), der Phantasie, auch der Genialităt gegeneinander ausgespielt:

Als Kopf (um), als Bewußtsein sei Salieri Mozart überlegen, aber als Kraft, als unmittelbare schöpferische $\mathrm{Kraft}$ sei er an ihm gemessen nichts gewesen (VII, 559).

um, sposobnost' - genial'nost' (VII, 522)

um, darovitnost' - genial'nost' (ib.)

nabljudatel 'nost', um, obrazovannost' - talant, fantazija (I, 281)

um, usilie - fantazija, vdochnovenie $(I, 156)$ 
um, obrazovannost', znanie, sposobnost' sil'no cuv stvovat' sposobnost 'tvor it', or iginal 'nost' $(I, 125)$

Ohne natürliches, unmittelbares schø̈perisches Talent sei es unmöglich, Dichter zu sein. Weder Wissen noch Gelehrtheit, noch Verstand (um), noch Charakter, nicht einmal die Făhigkeit, tief zu fühlen und das Schöne zu begreifen, vermöchten es zu er setzen $(X X, 592)$.

Butkovs Erzählungen zeugen von wenig Phantasie, aber von viel Verstand (um) und Herz, wenig Humor, aber viel Ironie und Witz $(X, 39)$.

tvor čskaja fantazija - um, cuvstvo (VI, 592)

ésteticeskoe cuvstvo, vkus, tvor českaja izobretatel'nost' um, nacitannost' (VI,107)

fantazija - um, izucenie $(V, 580)$

Ist die semantische Entfernung zum Gegensatz größer, bleibt der Bedeutungsspielraum weiter:

Belinskij schreibt, daß er keine Ungleichheit anerkennen könne, die auf Privilegien des Standes, der Geburt oder des Reichtums beruhen, sondern nur eine Ungleichheit auf Grund des Geistes (um), der Ehre und der Bildung (XI,142).

Das islamische Gebet beschäftige Rumpf, Kopf, Arme, Beine, Zunge - alles außer Gehirn und Geist (um) (IX,483).

diplomy - um, talant, znanie $(V, 276)$

roždenie - duch, um, cuvstvo (II, 24)

plug, topor - um, cuvstvo, talant $(I, 41)$

So wie der Vergleich mit höheren geistigen Vermögen 'um' vordergründiger erscheinen lăßt, so heben Bezeichnungen für niedere Tätigkeiten den Rang von 'um':

vdochnovenie, um - natjažka, éffekt ( $\mathrm{X}, 363)$

cestnost', blagorodstvo, um, velikodušie - tšceslavie, vostorg (VIII, 45)

trudoljubie, nacitannost ${ }^{\circ}$ - um, talant (VII, 619)

um, sposobnost' - dovol'stvo (VII, 72)

um, cuvstvo - razdrazitel'nost', mectatel'nost' (VI, 524)

um, obrazovannost ${ }^{\prime}$ - ustarevšie ponjatija $(I, 211)$ 
1.32.2 Ausgesprochene Vergleiche des Begriffs 'um' mit einem anderen Begr iff, einer Begriffsreihe

In diesen Fảlen bezieht 'um' seine Bedeutung unmittelbar aus der Konfrontation mit einem ander en Begriff. Die Bezugnahme ist kategorischer, aber auch hier modifiziert die Art der Bedeutungsbeziehung das Ausmaß des verbleibenden Spielraums.

Die Gegenteile von 'um' făchern dessen Bedeutung auf:

bessmyslie (VII, 82)

glupost $(\mathbf{X}, 161)$

idiotstvo $(\mathrm{XI}, 287)$

tupost', glupost' $(\mathrm{X}, 418)$
- (Sinn) Unsinn

- (Klugheit) Dummheit

- (Sinn) Blödsinn

- (Klugheit) Stumpfheit, Dummheit

Absetzungen von Kräften der Seele und des Gefühls steigern das intellektuelle Moment:

Die Bemerkung, daß zum Dichtersein wenig 'um', aber 'čuvstvo' und 'fantazija' nötig seien (I, 232), kann sicher nicht so über setzt werden, daß der Dichter wenig Geist brauche; gemeint ist, daß er weniger Intellekt als vielmehr Gefühl und Phantasie benötigt. Dagegen fordert Belinskij 1844 von der Dichtung, daß sie nicht nur dem Gefühl oder nur der Phantasie, sondern auch dem Verstand (um) etwas bieten müsse (Vm, 347).

$$
\begin{aligned}
& \text { um - fantazija (I, 303; II, 213; V, 560) } \\
& \text { um - cuvstvo, fantazija }(I, 325) \\
& \text { um - strast' (XII,16) } \\
& \text { um - cuvstvo, instinkt }(X, 367) \\
& \text { um - talant (IX, 393) } \\
& \text { um - serdce (I, 60; VII, 289; VIII, 230) }
\end{aligned}
$$

Der Verstand (um) tăusche die Frau oft, das Herz nie (XII, 233). Bei dem einen sehe man vor lauter Herz den Verstand (um) nicht mehr, bei dem ander en sei das Herz gleichsam im Gehirn angesiedelt $(X, 27)$.

Es gebe eine Art von Kunst, in der die Phantasie an zweiter Stelle, der Verstand (um) an er ster stehe $(X, 318)$. 
Die abstrakte Idee sei eine Frucht des Intellekts (um), die poetische eine der Liebe wie der Leidenschaft (VII, 312).

Das Talent benutze manchmal den Verstand (um) wie etwas Niedriges, ihm Untergebenes (XII, 271). An Herzen bemerkt Belinskij dagegen, daß Talent und Phantasie sich dem Verstand (um) hingăben, der dann belebt und erwärmt, mit einer herzlichen, humanen Ausrichtung versehen sei (ebd.).

Bakunin habe eine harte und kalte Natur, fern jeder Leidenschaft, voller Intellekt (um) (XII,16).

Bei einigen Menschen sei die Phantasie auf Kosten des Verstandes (um) entwickelt worden (VII, 443).

Der Verstand (um) verhalte sich zum Gefühl wie die Wissenschaft zum Leben. Was sei eine Kunst ohne Gedanken - wie ein Mensch ohne Seele, eine Leiche (VI, 472).

In all diesen Sätzen, diesen Gegensätzen ist die Forderung Belinskijs nach einer Harmonisierung der intellektuellen und intuitiven Kr zfte zu verspïren. In seiner Kritik an Menschen und Werken mist er den Frad der Ausgeglichenheit und fảlt daraufhin sein Urteil. 
1.40 Konsolidierung der aktuellen Bedeutung durch Anhebung partiell implizierter Prădikationen oder Beziehungsglieder

In den folgenden Bestimmungs - und Beziehungsurteilen kommen wesenhafte Bedeutungsbeziehungen zur Sprache. Die determinier enden Prädikationen und die Beziehungsglieder sind so eng mit 'um' verbunden, daß von einer Verzeitungsoperation kaum die Rede sein kann; dagegen enthălt die Nennung Vorab-Definitionen des Subjekts- und Prädikatsbegr iffs, bzw. der Beziehungsglieder. Subjekt und Prädikat sind hăufig zu einem Wortgruppenlexem, zu einem Terminus zusammengewachsen, in denen die Einzelbedeutung zu einer qualitativ neuen zusammenfallen.

\subsection{Determinier ende Urteile}

Mit dem Ausdruck 'prakticeskij um' wollte Belinskij wohl das wiedergeben, was seines Erachtens unter dem deutschen Terminus 'praktische Vernunft' verstanden wurde. Dem Begriff 'razum' ist die Dimension des Praktischen durchaus eigen, aber Belinskij nennt das Handeln nach Vernunftgrundsätzen an keiner Stelle 'prakticeskij razum'. In die Wendung 'prakticeskij um' wird jedoch so sehr das Verständnis des Begriffs 'um' getragen, daß die Rückübersetzung ins Deutsche mit 'praktische Vernunft' unangemessen wäre.

In der Kritik einer Rede des Juristen Moroskin polarisiert Belinskij 'rassudok' und 'prakticeskij um' gegen 'razum' und 'èsteticeskoe cuvstvo', setzt das niedere Erkenntnisvermögen gegen das höhere ab:

Ein ungewöhnliches $M a ß$ an Urteil sver mögen (rassudok) bedinge keineswegs die $\mathrm{Kr}$ äfte der Vernunft (razum) und des Sinns für das Ästhetische; sie setzen aber umgekehrt notwendig ungewöhnlich viel 'rassudok' voraus... Was "rassudok i prakticeskij um" anbetr effe, sei kein Volk mit den Franzosen zu vergleichen... Die Engländer zeichne aus: 'sila rassudka', 'sposobnost' analiza', 'praktiCeskij um'...

Die Äußerung über die Deutschen und Russen ist aufschlußreicher:

Bei Kant und Hegel werde eine "cudovišcno ogromnaja sila rassudka" sichtbar, und zugleich zeichne - namentlich Hegel - eine 
"cudoviščno ogromnaja sila razuma" aus, abgesehen davon, daß die spekulativen, transzendentalen und phantasiebegabten Deut schen im wirklichen und praktisch-realen Leben (dejstvitel'nyj i praktičeski-polożitel'nyj) in einem nicht überbietbaren Maße akkurat und ver nünftig seien...

So zeichne auch das russische Volk, reich an Elementen der Vernunft (razum) und des Sinns für Ästhetik, sowohl eine ungewöhnliche Findigkeit, Aufgewecktheit, eine praktische Tătigkeit des Geistes (um), Scharfsinn und die analytische Kraft des Urteilsver mögens (rassudok) aus (III, 222).

Man kann die entscheidenden Wörter folgender maßen zusammenfassen:

1)

rassudok

prakticeskij um

dejstvitel'nyj

praktičeski-polożitel'nyj

akkuratnyj

rassuditel'nyj

smetlivost ${ }^{\circ}$

smy slennost'

prakticeskaja dejatel'nost' uma

ostroum

analitičeskaja sila rassudka
2)

razum

èsteticeskoe cuvstvo

umozritel'nyj

transcendental'nyj

fantasticeskij

In den Fabeln Krylovs verspiirt Belinskij "preobladanie rassudka i prakticeskogo uma"; die Poesie bestehe in den sprühenden Funken des Scharfsinns (IV,149).

Die Fabeln geben wie ein polierter Spiegel den russischen praktischen Verstand wieder (IV,150; vgl. auch VI, 290).

Am besten wird 'prakticeskij um' wohl durch 'gesunder Menschenverstand'wiedergegeben.

Die spezifischen Tătigkeiten des Geistes und des Verstandes finden oft Benennungen aus dem Bedeutungsfeld der Sinnesorgane; die uiber tragene Bedeutung dominiert:

nabljudatel'nyj um (I, 97; VIII,420)

nabl judatel 'nost' uma (VII, 536)

sozercajuscij um $(I, 286)$

sozercanie uma (VII, 392) 
Der der Hinwendung folgende Schritt ist die Anverwandlung:

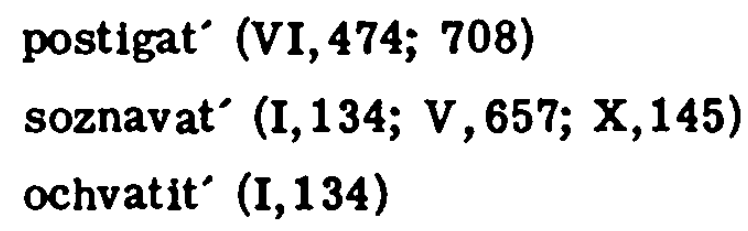

Der Verstand greift in das Begreifbare und Begriffene ordnend ein:

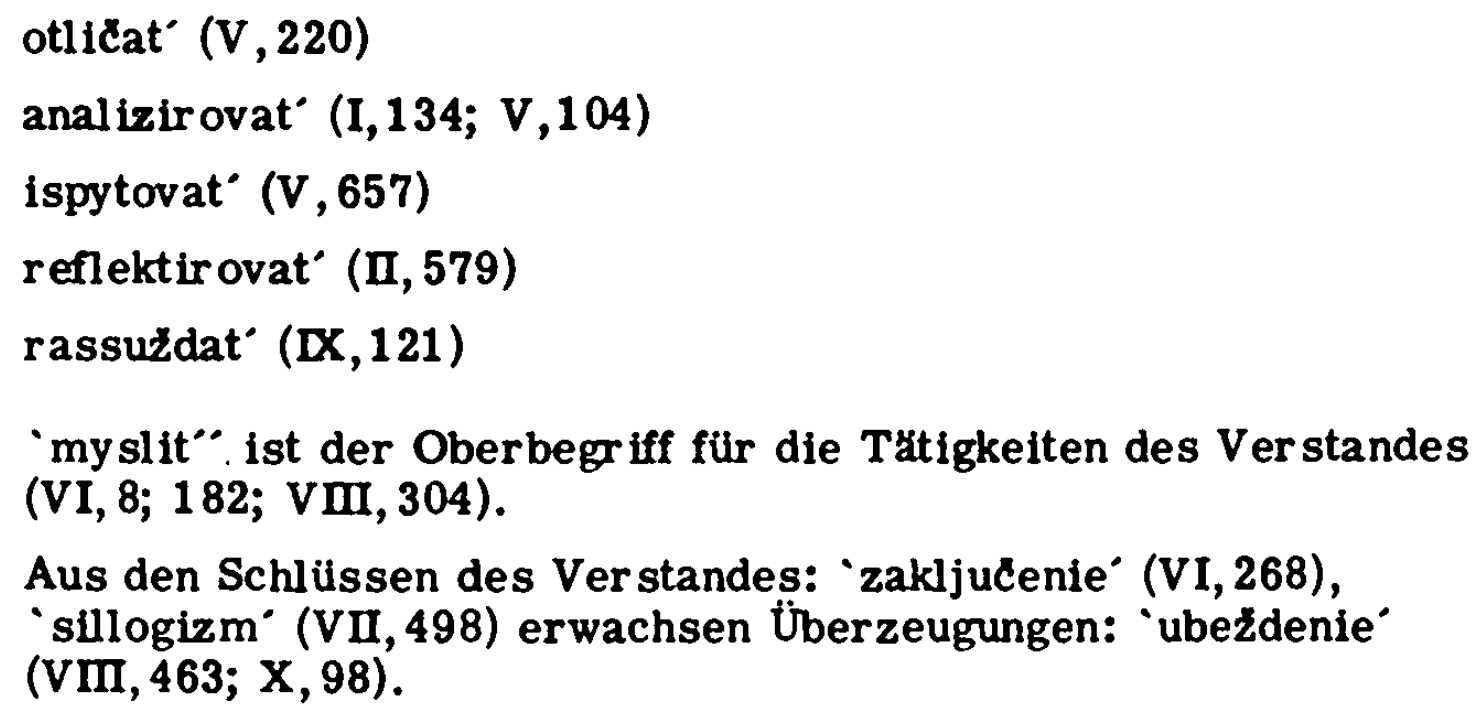

Mehr als Postulat denn als Faktum bestehen wesentliche Bedeutungsbeziehungen zu:

Objektivităt - ob-ektivnost’ (II,124),

Unparteil ichkeit - bezpristrastie (VIII, 275),

systematische Strenge - strogo sistematiceskij um (III, 493).

Von den 'Gesetzen des Geistes' spricht Belinskij nur einmal:

Die "zakony uma" müssen sich in den Taten des Geistes (um) zu erkennen geben $(X \Pi, 331)$.

'um' ist im Verhältnis zu den legislativen 'razum' und 'duch' eher ein exekutives Organ.

Das dialektische Vorgehen des Verstandes bei der Begriffsbildung hat Belinskij einmal ausführlich beschrieben; verkürzt wiedergegeben ist der Gedankengang folgender:

Der Verstand (um) nehme zunächst nur eine Seite des Begr iffs auf, die andere, dieser entgegengesetzte, lehne er als falsch ab. Wenn er die eine Seite als wahr erkannt habe, führe er die Wahrheit ins Extrem, in Wider spruch und Selbstnegation. Habe der Verstand die Unwahrheit der ins Extrem geführten Seite des Begriffs erkannt, verneine er sie und wende sich der Gegenseite zu, wie er auf gleiche Weise zur notwendigen Verneinung führe. Der Verstand merke dann 
plotzlich, daß in jeder Seite Wahrheit und Unwahrheit sei und daß zur gesicherten $W$ ahrheit beide beitragen, daß die diametral entgegengesetzten Seiten verwandt und unwahr nur in der abstrakten Einseitigkeit seien. Die Wahrheit liege in der Vereinigung zu einem neuen und ganzen Begriff $(V, 294)$.

In diesem Zusammenhang wăhlt Belinskij das Wort 'um' und nicht 'rassudok'. 'um' schließt die ander en geistigen Fahigkeiten, die bei der Begriffsbildung beteiligt sind, ein. Das dialektische Vorgehen ist bei Belinskij sonst die der Vernunft (razum) eigene Arbeitsweise.

\subsection{Relationale Urteile}

Die konsoziferten Substantive tragen eine Bedeutung, die auch 'um' tragen kann; sie sind insofern Unterbegriffe.

In einem Satz wie "Bei all seinem Geist (um) und bei aller Gewitztheit (smetlivost') ver steht er nicht,..." $(\Pi, 40)$ geschieht zwischen 'um' und "smetlivost" ein Spannungsausgleich, da beide Wörter die Bedeutung des gegenüberliegenden an sich heran und in den Teil des Bereichs ziehen, in dem sich beide Wörter überschneiden. Dieser doppelt gedeckte Ausschnitt hat keinen eigenen Namen, wird quasi von zwei Seiten angesprochen. 'um' bedeutet 'gewitzter Geist', 'smetlivost" 'geistige Gewitztheit'. Der unterdrückte Relator könnte mit 'das heißt', 'mit anderen Worten' u. ă. wiedergegeben werden. Ähnlich gleichen sich an:

ostroumie (II, 95; V, 236; IX,117; 452; XII,324),

pronicatel'nost' $(\mathrm{XI}, 143)$,

original'nost' (IX,577; VIII,322),

lovkost' $(\Pi, 18)$.

Man kann diese Wörter als Synonyma für 'um' im Sinne von 'Witz, Esprit' ansehen.

Werden 'um' und 'rassudok' - Wörter, die in der Bedeutung 'Verstand' fast immer gegeneinander austauschbar sind - nebeneinandergestellt, dann bleibt 'um' nur der Spielraum 'Geist'.

Im Literaturrückblick 1847 heißt es u.a. : "Man sagt, für die Wissenschaft brauche man 'um i rassudok', für das (künstlerische) Schaffen Phantasie... Für die Kunst braucht man also nicht 'um i rassudok'? Und der Gelehrte kommt ohne Phantasie aus? Falsch! Wahr ist, da $B$ in der Kunst die Phantasie, in der Wissenschaft "um i rassudok' die aktivste und führende Rolle spielen" $(X, 305)$. 
Wenn hier nicht Tautologie vorliegt, dann müssen 'um' und 'rassudok' entweder komplementar im Sinne von Begr iff sf indung und Begr iff skoordination gedacht werden, oder 'rassudok' ist - und das ist wahrscheinlicher - als Erklärung mit einem nicht ausgesprochenen 'das heißt' angehăngt worden. Wieweit Belinskij sich bei der Wortwahl 'etwas gedacht hat', bleibt fragwirdig. Denkbar ist auch eine undifferenzierte Doppelung des Ausdrucks zur Intensitătssteigerung. Um das Gemeinte besonder s zu unterstreichen, sind auch wohl die folgenden Reihungen gewăhlt worden:

$$
\begin{aligned}
& \text { serdce, duša - um, rassudok (XII, 229) } \\
& \text { ljubov', cuvstvo - um, soznanie (VII, 665) } \\
& \text { duch, um - fantazija (V,668) }
\end{aligned}
$$

Eindeutig explikativ ist die folgende Zusammenstellung:

Die Phantasie sei bei Kindern sehr entwickelt; man solle sie nicht anregen oder sie in falsche Bahnen lenken "ko vredu dejatel nosti uma i v osobennosti rassudka i zdravogo smy sla" $(\mathrm{X}, 141)$.

Diese Wortfolge ist klar: "zum Schaden der rationalen Tătigkeit allgemein, des Urtellsvermögens, des gesunden Menschenverstandes im besonderen".

Mit Don Quichote vergleicht Belinskij an anderer Stelle die Menschen, die zwar eine glühende Einbildungskraft, eine liebende Seele, ein edles Herz, auch starken Willen und Geist (um) haben, denen aber 'rassudok' und 'takt dejstvitel' nosti' fehlen (VI, 34). Hier scheint 'um' sogar auf der 'irrationalen' Seite des Satzes zu stehen, meint aber wohl die Gesamtheit der geistigen und seelischen $\mathrm{Kräfte}$, die im Gegensatz zu 'Verstand' und 'Wirklichkeitssinn' als latente gekennzeichnet werden sollen.

Die 'Schönen Seelen' verfügen durchaus über 'um', ihnen fehle jedoch der Sinn für die Wirklichkeit (VI, 672).

'um' erscheint als wirklichkeitsfremdes Vermögen. Dieser Wider spruch ist wohl nur damit zu erklären, daß für Belinskij die Wirklichkeit eine vernünftige ist, die folglich dem 'Verstand' nicht zugänglich sein kann. Unausgesprochen wird ein Gegensatz zu einer Realităt konstruiert, die Domăne des Verstandes - bloß Schein des Seins, bloß farbiger Abglanz eines Leitbildes, Sonderheit des Allgemeinen, der vernünftig zusammen- 
hăngenden Wirklichkeit veranschaulicht. Hier verstrickt sich Belinskij in seiner eigenen Terminologie, zerrt Begriffe auseinander, die in anderem Zusammenhang dann wieder vereint gesehen werden.

In der letzten Gruppe der Beziehungsurteile wird 'um' in seiner speztfischen Umwelt gesehen. Die Beziehungsglieder sind durch typische Relatoren an 'um' gebunden:

der Begriff, der den Ver stand anspricht $(V, 313)$, der ihm fremd ist $(X, 281)$;

der Gedanke, der den Verstand beherrscht (VII,101), der auf inn wirkt $(\mathrm{DX}, 158)$, inn herausfordert (VI, 272), sich ihm darstellt

die Kenntnisse $(\mathrm{V}, 172)$;

die Erkenntnisse, die den Ver stand ber eichern $(1,122)$;

die Wahrheit, zu der der Ver stand str ebt (VII, 276);

die freie Tătigkeit, die er fordert (XI,147);

Vor stellungen, die den Geist beschäftigen (IV , 593);

Systeme, die er schafft $(I, 357)$.

Die Grenzziehung zwischen hochspezialisierten naheliezenden Prădikationen und Beziehungsgliedern und den partiell implizierten ist manchmal anfechtbar. Jedoch schien mir der ausgesprochen definitorische Charakter der in diesem Abschnitt behandelten Aussagen eine Ausgliederung zu rechtfertigen. 


\section{Kapitel}

'RAZUM' - Vergleich mit 'um'

Belinskij hat das Wort 'razum' sehr viel seltener als 'um' verwandt, es aber im allgemeinen überlegter eingesetzt. Ein so bedeutendes Wort hat er nicht so leicht dahingesagt wie zuweilen 'um'. Das Gewicht, das Belinskij der Vernunft beimaß, ist an dieser bedachtsamen Verwendung des Wortes, an dessen semantischer Stabilităt abzulesen.

Eine Definition des Begriffs 'um' hat Belinskij für seine Zeit nicht ver sucht; 'razum ' war ihm dagegen Anliegen, und zwar weniger Gegenstand einer philosophischen Bemühung als vielmehr Herzensangelegenheit, beinahe Glaubensinhalt. Die fast religiơse Verehrung, die Faszination verleiht dem Wort 'razum' zuweilen etwas Magisches, seiner Bedeutung bei aller Begründung der hervorragenden Placierung etwas Unbestimmtes.

Die Beziehung zwischen 'razum' und 'rassudok' ist eindeutig hierarchisch; das Verhältnis zu 'um' gibt sich komplizierter: 'um' als Oberbegr iff für die menschliche Geistigkeit kann durchaus 'razum', verstanden als Teilhabe am Prinzip 'razum', als subjektive Vernunft, einschließen; dem 'um' als dem Verstand des Menschen bleibt die Erkenntniskraft 'razum' semantisch unerreichbar.

2.10 Kaum spürbare Eindămmung des Bedeutungsbereichs

\section{2,11 'razum' in prädikativer Funktion}

Die dem häufigen Ausdruck 'v/na ume' analoge Wendung ' $v / \mathrm{na} \mathrm{raz}-$ ume' ist nur selten belegt. Es kann als Indiz für das semantische Gewicht angesehen werden, daß 'razum' den wesentlichen Teil der Merkmalssumme des mit dem umgebenden Satz Gemeinten an sich zieht, d.h. sich nur selten in zweit- oder drittrangige Positionen abdrängen läßst.

Die Realität bestehe nur "v razume" (II, 239).

Die römische Gesetzgebung habe die feudale Tyrannei durch ein auf die Vernunft (na razume) gegründetes Recht er setzt (VI, 289). In beiden Sătzen bleibt die volle Bedeutungsweite von razum' erhalten. Der dargestellte Tatbestand ist mit der intendierten Vor stellung von 
'razum' ohne weiteres vereinbar, aber nicht wesentlich vereint.

2.12 Dem Begriff 'razum' nahezu generell implizierte Pradikationen

Das Bedeutungserlebnis bei der Nennung des Wortes 'um' ist nicht eindeutig. Keine Bedeutung - weder 'Seist', als Gesamtheit der geistigen Făhigkeiten oder auch im Sinne des durch sein geistiges Vermögen charakterisierten Menschen, noch 'Verstand' - ist so bevor zugt, daß man von einer Hauptbedeutung sprechen könnte, die sich beim bloßen Hören oder Lesen des Wortes einstellt. Anders bei 'razum': Dieses Wort kann zwar auch mit einem entsprechenden Zeichenaufwand befăhigt werden, andere Begriffe zu nennen, aber es hat die Hauptbedeutung ' $V$ e r nunf $t$ '. Dieser Begr iff schließt per definitionem bestimmte Eigenschaften, bestimmte Ver mögen, bestimmte Träger eben dieser Vernunft ein. Wenn hier zwischen generell und partiell implizierten Prădikationen unterschieden wird, dann in dem Sinne, daß einige Aussagen von 'razum' schlechthin, andere z. B. nur von der Vernunft des einzelnen Menschen oder nur von der ewigen, reinen Vernunft, nur von der subjektiven Vernunft oder von der objektiven möglich sind, und wieder andere Prädikationen bestimmte Făhigkeiten, den Wirkungskreis ins Blickfeld rücken.

Di e im Redegebilde zur Sprache gekommenen Ausschnitte des Bedeutungsbereichs, die aktuellen Bedeutungen von 'razum' also, sind im Gegensatz zu 'um' Erscheinungsformen ein und desselben Begriffs 'Ver nunft; der Spielraum des Wortes 'um' reichte dagegen über mehrere Begriffe hinweg. Fur Belinskij ist in der Definition der Vernunft eingeschlossen, daß sie qua Weltprinzip z. B. als höchste, wertsetzende Erkenntniskraft im einzelnen Menschen in Erscheinung treten oder sich in einem Stück Wirklichkeit verkörpern kann.

Das Verhaltnis zwischen 'Geist' und 'Verstand' in dem Sinne, wie diese Begriffe Bedeutungen des Wortes 'um' werden können, ist ein anderes als das zwischen der 'reinen Vernunft' und der 'Vernunft im Bewußtsein' oder der 'Vernunft in der Erscheinung'. 'Geist' ist Oberbegr iff; 'Verstand' eine teilweise Äußerung, die den Rückschluß auf den Geist als Ganzes allein noch nicht zuläßt. 'Geist' ist auch die Summe der von den 
rationalen und nichtrationalen $\mathrm{Kraften}$ geleisteten Erkenntnisse und Empf indungen. Die Vernunft (razum) ist begrifflich nicht teilbar. So paradox es klingt: auch im Teil erscheint sie als Ganzes. Was dort entfernt dem Verhả tnis von Summand und Summe vergleichbar ist, ist hier dem von Integral und Ableitung ähnlich.

Die Prădikationen, die bezüglich jeder Bedeutung indifferent sind, mußten folglich bei 'um' begrifflich sehr schwach organisiert, absolut sehr bezugsvariabel sein. Zu 'razum' sind Aussagen mit höherem Spezialisierungsgrad noch bedeutungsneutral. Auf Grund der Sekundärprädikation müssen die folgenden potentiellen Urteile kategorisiert werden:

zakony, naçalo, aksiomy razuma;

predmet, dejstvie, stremlenie razuma.

Von 'um' jedweder Bedeutung konnte nur die Rede sein, wenn der Verstand, der Geist an eine Wesenheit gebunden oder als deren Äußerung gedacht wurde. 'razum' kann als an und für sich Seiendes begriffen werden. 'um' erschien nur als Besitz oder Produkt des Menschen, 'razum' findet unendlich viele Einkleidungen, verkörpert sich aus sich heraus in allem, was wirklich ist. Von der Vernunft eines Einzelnen, der Vernunft von Gruppen und Völkern ist selten die Rede. Die Sătze mit 'razum' lösen sich meistens vom einmaligen Tatbestand, tendier en zur allgemeingültigen Aussage.

Die Prädikationen, die ihrer geringen begrifflichen Organisationshöhe wegen Wörtern verschiedener Bedeutungsfelder angehăngt werden können, finden sich in der unmittelbaren Umgebung von 'razum' so gut wie nicht. Der gezielten Aussage entspricht die Wahl gezielter Wörter. Man kann über viel oder wenig Verstand oder Geist verfügen; die Vernunft ist insofern nicht quantifizierbar. Wenig Vernunft verdient den Namen 'razum' nicht. Von einer individuell bedingten Begrenztheit der Vernunft kann die Rede nicht sein. Sofern die Vernunft menschlich ist, ist sie begrenztes Abbild der ewigen Vernunft. 


\subsection{Merkliche Begrenzung des Bedeutungsber eichs}

2.21 Naheliegende hochspezialisierte determinier ende Prädikationen

In diese Kategorie fielen die meisten Urtelle über 'um'. Die determinier enden Prădikationen im Abschnitt 1.21, auf Grund ihrer hohen Merkmalsdichte zwar absolut nicht sehr bezugsvariabel, waren auf das Bedeutungsfeld des Menschen und seiner geistig-seelischen Ausstattung hin spezialisiert. Die Nennoperation leistete vor allem subjektive Bewertungen. 'um' im allgemeinen und im besonder en wurde unter schiedlich eingeschătzt; die Stellung von 'razum' ist unangefochten. Die hohen Einstufungen, die 'um' nur gelegentlich erfuhr, sind 'razum' immanent. Das Übergewicht der partiell implizierten Prádikationen in 'razum'-Sätzen ist ein weiteres Indiz für die semantische Stabilităt des Wortes.

An 'um' sah Belinskij hăufig der natürlichen und menschlichen Entwicklung vergleichbare Reifegrade, stellte 'um' oft in eine sprachliche Umgebung, die es 'vermenschlichte'.

Die Wirklichkeit könne der Mensch nur im Mannesalter, mit den mächtigen Umarmungen der ger eiften Vernunft (razum) erfassen (III, 506).

Nur mit aufgeklärter Vernunft (razum) und gebildetem Herzen sei der Mensch făhig, die tiefe Wahrheit der christlichen Religion zu begreifen $(\Pi, 62)$.

'sozrevšij' und 'prosvešcennyj' erwecken den Eindruck, daß 'razum' doch mehr-oder minderbar sein kann. Belinskij meint aber wohl, da $\beta$ sich dem Menschen mehr oder weniger Vernunft offenbare, sie zunehmend zu Bewußtsein komme.

\subsection{Relationale Urteile}

\subsubsection{Konsoziationen}

Auch 'razum' wird oft mit bedeutungsmäßig naheliegenden Wörtern gereiht, jedoch sind die jeweiligen Konsoziationen im allgemeinen kürzer und prägnanter; die Bedeutungsbereiche der beteiligten Wörter ergănzen sich, ohne sich sehr weit zu überschneiden. Wenn Belinskij z. B. den Menschen im Gegensatz zum Tier "cuvstvo, rassudok, razum" 
(IV, 73) zuspricht, dann decken die drei Wörter je fest umrissene Bedeutungsber eiche, die aneinanderstoßend die jeweiligen Grenzen festigen; ohne Lücken und Überlappungen meinen die Wörter zusammen die Gesamtheit der geistig-seelischen Kräfte. "razum, rassudok, opyt, znanie" $(X, 63)$ bezeichnen in vergleichbar strenger Absetzung die Erkenntnisfăhigkeiten 'Vernunft' und 'Verstand', sowie die Ergebnisse 'Erfahrung' und ' $W$ issen'. Bei diesen und den folgenden Beispielen kann man nur insofern von einer prädikativen Einflußnahme auf den Bedeutungsbereich des Nachbarwortes sprechen, als dessen Grenzen sichtbar gemacht werden. Das rationale Moment an 'razum' betonen Reihungen mit Wörtern für das Seelisch-Gefühlsmäßige:

Die Gesetze des Herzens wie auch die der Vernunft (razum) seien stets ein und dieselben (VII,145).

Eine Bibliothek sei dazu da, die Vernunft aufzuklären und das Herz $\mathrm{zu}$ bilden (XI, 21).

Die drei Elemente unseres Geistes (duch) seien Vernunft (razum), Wille und Gefühl (II, 244);

"die Geistigkeit des Menschen, d.h. Gefühl, Vernunft, Wille..." $(X, 26)$.

'razum' und 'cuvstvo' sind nur selten kommentarlos ger eiht worden; Belinskij sah die Begriffe als dialektisch verknüpfte, so daß sie nicht wie das Paar 'um - cuvstvo' als Zeichen für das Rationale einerseits und das Nicht-Rationale anderer seits gegeneinander abgesetzt, bzw. als Summanden einer Wortgruppe auf die geistig-seelische Gesamtheit bezogen werden können. Ähnlich begriff Belinskij 'razum' und 'ljubov" als "dve storony odnogo $i$ togo ze ducha" (VII,49). Die Verbindung addiert die Bedeutungen nicht nur, sondern zieht die Wörter zu einem Zeichen für das Prinzip 'duch' zusammen. Die Einzelbedeutungen heben sich dialektisch zu einer neuen Qualităt auf, und zwar sowohl zum 'Weltgeist' als auch zu dessen christlicher Entsprechung: dem Heiligen Geist, erscheinen so gesehen als Fundament sowohl des Gebäudes der christlichen als auch der idealistischen Weltanschauung:

Die christliche Lehre sei auf Liebe und Vernunft gegründet $(I, 143)$. Gott sei zugleich Wahrheit, Liebe, Vernunft und Gefühl, wie die Sonne zugleich Licht und Wärme verkörpere (XI,146). 
Die Sătze, in denen Belinskij die Beziehung genauer beschreibt, sind Hauptgegenstand der Abschnitte 2.32.2 und 2.42.

Reihungen mit Wörtern für im weitesten Sinne Physisches strecken den Spielraum von 'razum' über Gebühr, da 'razum' nur schwerlich als Zeichen für den geistigen Bereich des Menschen herhalten kann. In einem Satz wie "Das Volk werde voller 'sila' und 'razum' sein" (VII,173) ist 'razum' semantisch überdehnt.

In der 1838 verfaßten Grammatik schreibt Belinskij unter $\$ 3$, daß sich der Gedanke zum Wort verhalte wie die Seele zum Körper, daß das Wort die Decke, das Kleid, die Form, der Ausdruck des Gedankens sei, und der Gedanke der Sinn, die Vernunft (razum), die Bedeutung des Wortes (II, 579).

Der Satz "Mysl' est' smysl, razum, znaçenie slova" ist unverständlich, sowohl für sich genommen als auch vor dem Texthintergrund gesehen.

Der Vergleich mit Leib und Seele kann wohl in dem Sinne fortgesetzt werden, daß sich der Gedanke zum Wort verhalte wie die Vernunft zum Menschen; aber in dieser Parallele lassen sich dann 'smysl' und 'znacenie' nicht unterbringen. Die Konsoziation wäre ohne 'razum' oder ohne 'smysl, znacenie' sinnvoller gewesen, denn entweder kann der Satz den Vergleich verlängern oder aus ihm ausbrechen; die hier gebotene Vermischung ist schlechter Stil, ist Abbild eines oberflächlichen Gedankengangs. Ähnlich unkontrolliert ist der folgende Satz:

Alles, was wir von der Persönlichkeit sagen können, erschöpfe sich darin, daß sie nichts gegenüber "Cuvstvo, razum, volja, dobrodetel ${ }^{\circ}$, krasota" und ähnlichen ewigen und unvergänglichen Ideen sei..., daß es aber ohne Persönlichkeit weder das eine noch das andere gebe $(X, 28)$.

Zwei Jahre zuvor hatte Belinskij diesen Gedanken sehr viel deutlicher ausgesprochen:

Das Allgemeine sei mehr (vyse) als das Besondere, das Unbedingte mehr als das Individuelle, die Vernunft (razum) mehr als die Persönlichkeit... aber das Allgemeine drücke sich im Individuellen, die Vernunft in der Persönlichkeit aus und ohne das Besondere, das Individuelle und Persönliche sei das Allgemeine, Unbedingte und Vernünftige nur eine ideale Möglichkeit, aber keine lebendige Wirkl ichkeit (VII, 307).

Hatte Belinskij dort ohne Rücksicht auf die wechselseitigen Abhängigkei- 
ten, auf die kausalen und dialektischen Verknüpfungen die ihm gerade einfallenden Wörter für das am Menschen Bemerkenswerte gereiht, so ist hier in einem klaren syntaktischen Dreischritt ein ebenso klarer Gedankengang wiedergegeben worden.

(2.22.2)

Die dominier ende Stellung der Vernunft schlägt sich sprachlich auch darin nieder, daß 'razum' meistens den potentiellen oder aktualen Beziehungssatz regiert und nicht Bezugsobjekt ist. 
2.30 Starke Einengung des Bedeutungsbereichs

Die folgenden Urteile zeigen das ständige Bemühen Belinskijs um eine Definition des Begriffs 'razum'. Es werden die verschiedenen Erscheinungsformen der Vernunft vorgestellt, und zwar hăufig als Hinweis auf deren idealen, prinzipiellen Charakter.

2.31 Aus ander en Bedeutungsfeldern entlehnte determinier ende Prädikationen

'um' konnte nur am Menschen und in dessen Hervorbringungen als zivilisatorische und kulturelle Leistung nachgewiesen werden; 'razum' ver äußert sich auch als vom Menschen unabhăngige Wirklichkeit, als Schöpfer und Schöpfung. So wie man sich von 'um' als Vermögen der Anverwandlung der Welt ein Bild machen kann, das die sprachliche Umgebung mit Wörtern für Konkretes nachzeichnet, so auch von 'razum' als wirkender, d.h. sich verwirklichender Kraft.

Der unvergleichliche Rang der Vernunft schlägt sich in entsprechenden Bildern nieder; es werden Namen für Erhabenes, Einzigartiges bevorzugt. Das Bedeutungserlebnis ist oft suggestiv.

Schon im Blick des Kindes sei das strahlende Licht der Vernunft (razum) erkennbar (IV, 73).

večnyj svet razuma (VI,18)

svet razuma (VI, 472; 477)

svetlyj razum (VII, 389)

svetlye luci razuma (VII, 392)

toržestvennyj blesk sol nca razuma (VI, 46)

Noch auf schlußreicher sind die Vergleiche mit Wörtern aus dem Bedeutungsfeld der Herrschaft, und zwar im Unterschied zu 'um' vor nehmlich mit Wörtern für eine absolute Herrschaft:

Die Priorităt der Vernunft begründet Belinskij mit dem idealistischen Denkansatz: Es gebe zwei Methoden, die Wahrheit zu erkunden: a priori und a posteriori, d. h. aus der reinen Vernunft und aus der Erfahrung... Für die Anhänger des ersten Weges existiere allein das Bewußtsein, für sie sei die Vernunft der Zar, der Gesetzgeber, die schöpferische Kraft, die dem Wesenlosen Leben und Bedeutung gebe. Für die anderen liege das Reale allein 
In den Dingen. .. und die Vernunft sei nichts anderes als der Tagelöhner, der Sklave der toten Wirklichkeit... (II, 239)

edinoder zavie razuma $(\mathrm{NV}, 482)$

mogucestvo celoveceskogo razuma (IV ,108)

car stvo razuma ( VII, 399)

torzestvo razuma $(V, 96)$

brazdy razuma $(\mathrm{VI}, 160)$

bespošcadnyj razum (VII, 37)

razum vse pokoril sebe (VI, 270)

pobedonosnyj chod sveta razuma (VII, 65)

Die Vernunft soll den Menschen führen (IX, 382);

er soll den Weg wăhlen, den sie ihm zeigt (III,407).

Wenn Belinskij von einem "apostol razuma" (XII, 55) oder gar vom "OtecRazum" (XII, 71) spricht oder feststellt, daß die Vernunft einzig sei wie allein Gott (III, 334), dann ist die höchste Steigerung der Hochachtung erreicht.

'razum' werden nicht nur Augen (VI, 345) und ein in verborgene Tiefen vordringender Blick (VI, 289) zugesprochen, sondern es ist vom "mikroskop i teleskop razuma" (VI, 268), vom "cistoe steklo razuma" $(I, 66)$ die Rede.

Nur einmal wird von der Vernunft Kälte ausgesagt, aber eine durch die nahere sprachliche Umgebung zur Kühle gemilderte:

Die Philosophie solle leidenschaftslos, ernst und kühl (cholodnyj) wie die Vernunft, aber gleichzeitig begeistert wie die Dichtung sein (Vח, 50).

Im Vergleich zu 'um' (1.31) sind die Bulder im großen und ganzen um eine oder mehrere Stufen erhabener. War von der 'sila uma' die Rede, so von 'mogucestvo' und 'edinoderzavie' der Vernunft. 'svetlyj' fand oft eine Steigerung im Vergleich mit der Sonne oder durch die Zugabe des Adjektivs 'vecnyj'. Vergleiche mit Gott und Zar sind nur der Ver nunft angemessen. Negative Einstufungen fehlen fast völlig. 
2.32.1 Ausgesprochene Vergleiche einer Begr iffsr eihe mit einer anderen

Die große Zahl der ausgesprochenen Beziehungsurteile kann als ein Zeichen für den bewußten Gebrauch des Wortes 'razum' und für eine überlegte Absicherung des Begriffs gegen benachbarte angesehen werden.

In den folgenden Sătzen trifft der entgegengesetzte Begriff die schon durch eine Konsoziation beeinflußte Bedeutung von 'razum'. Durch die Zuordnung von Wörtern wie 'sovet', 'zdravyj smysl' etc. wird die höchste Erkenntniskraft nach unten hin ergänzt:

Man solle nicht im Namen des Alten, sondern "vo imja razuma $i$ zdravogo smysla" handeln $(X, 44)$.

Man solle sich von der Vernunft und dem gesunden Menschenverstand und nicht von den Manilovschen Phantasien leiten lassen $(X, 19)$.

Ein Humanismus der praktischen Vernunft gehört zu den zentralen Forderungen Belinskijs:

Die Chinesen - in den Augen Belinskijs die Inkarnation aller Untugenden - beachten weder Vernunft noch Leben, noch Menschheit, sondern nur ihren alten Kram, so dumm er auch immer sei; sie ersetzen Vernunft durch Zeremonie (IV, 467/468).

Der Kampf zwischen Genie und Volk sei kein Kampf zwischen Menschlichem und Nationalem, sondern einfach zwischen Neuem und Altem, zwischen Idee und Empirismus, zwischen Vernunft und Vorurteilen $(X, 31)$.

Die Masse glaube nur Autorităten, aber nicht ihrem eigenen Gefühl, ihrer Vernunft (IV, 546).

Das Licht werde die Dunkelheit besiegen, "razum pobedit predrassudki" (VI, 96).

svet, razum - t'ma, neveźestvo (VI, 61 2; XI, 556)

Ein Mann des Rates und der Vernunft, ein Anwalt des Glaubens, ein Kämpfer gegen Unwissenheit und Vorurteile (II,171)

Meinungen und vorgefaßte Überzeugungen mit den unabänderlichen Wahrheiten der Vernunft, der Wissenschaft und des Geschmacks verwechseln $(X, 170)$

Belinskij prangert an, daß jeder Mensch leben solle, wie alle leben und nicht so, wie ihm "razum, cuvstvo i naklonnosti" zeigen $(\mathrm{XX}, 383)$. 
In einem Brief an Botkin werden "vse substancial'nye sily, vse predanija, vse cuvstva i ošcušcenija" zum Teufel gewïnscht; "da zdravstvuet odin razum i otricanie" (XII, 27).

Die Polarisierung von 'razum' und 'Cuvstvo' - ein Gewaltakt der Verzeitungsoperation - begegnet selten. 'razum' wird dadurch in die Nähe des kalten Intellekts verdrăngt, 'cuvstvo' in den Bereich der Empfindsamkeit und Gefühlsduselei verwiesen. Unterkühlt erscheint die Vernunft deshalb in den folgenden Beispielen:

Würden in der Liebe nur Wille und Vernunft die Wahl entscheiden, so wäre die Liebe weder Gefühl noch Leidenschaft (VII, 460).

Lomonosov habe als Kind weniger "cuvstvom" als "razumom" begreif en wollen (II, 187).

2.32.2 Ausgesprochene Vergleiche des Begriffs 'razum' mit einem anderen Begriff oder einer Begriffsreihe

Das Bemühen um eine Synthese der rationalen und intuitiven $\mathrm{Kr}$ ăfte ist in Belinskijs Werk unübersehbar. In der Vernunft sah er den Wider spruch zwischen Geist und Gefühl aufgehoben. Eine Kritik der Dichtungen Baratynskijs bringt er auf den folgenden bezeichnenden Nenner:

Das Leben als Beute des Todes, die Vernunft als Feind des Gefühls, die Wahrheit als Zerstörer in des Glücks - hieraus entspringe der elegische Ton der Poesie Baratynskijs und eben darin liege auch ihr größter Mangel (VI, 476).

Das deduktive Vorgehen der Vernunft (a priori) setzt Belinskij gegen das empirische (a posteriori) ab:

Die Lösung der Idee aus der Form sei eine Tat der Vernunft und nicht ein widerlicher anatomischer Prozeß (VI, 270).

Gegen Kolumbus und Galilei habe die Erfahrung gesprochen, aber sie haben ihrer Vernunft geglaubt (II, 242).

Die Franzosen leiten alles aus der Erfahrung und der Geschichte und nicht aus den ewigen Gesetzen der menschlichen Vernunft $a b$ (XI, 152).

Bei den Asiaten hănge die richterliche Entscheidung nicht von der Kraft und Vernunft der Gesetze, sondern von der Weisheit (also der besonderen Erfahrung) des Richters ab $(V, 12)$.

Die Bezeichnungen der Sinnesorgane signalisieren oft Empirismus (so V, 97; IV, 202; VIII, 288); im weitesten Sinne empirisches Verhalten 
meint Belinskij auch, wenn er Instinkt (VI, 472) oder kindliche Glückseligkeit $(\mathrm{V}, 310)$ gegen 'razum' absetzt.

Die folgenden Sătze definieren den Begriff 'razum', bzw. konsolidieren die Bedeutung des Wortes im ausgesprochenen Vergleich mit Begriffen/Wörtern, zu denen 'razum' eine dialektische Beziehung unter hăl. Die noetischen Operationen werden stark bemüht: Das Aufspüren hochspezialisierter Termini fordert von der Nennoperation eine VorabDefinition. Die ontologische Verzeitung der komplexen Begr iffe ist hăufig dialektisch mehrstufig.

An dieser Stelle ist ein Wort der methodischen $\mathrm{Kr}$ itik angebracht. Die im ersten Teil dieser Arbeit entwickelten Gliederungskriterien verweisen zwar diese Beziehungsurteile korrekt an die Kategorie, die eine spezialisierte Bedeutung erwarten lăßt; aber hier ist der Unterschied der Gradzahl des Blickwinkels oft so gering, daß die Messung an Haarspalterei grenzt. Die Sliederung nach dem noetischen Aufwand erweist sich oft als zu grob und bedarf der Ergänzung in Form einer inhaltsbezogenen Argumentation. Die inhaltsfreie Kategorisierung fußt auf der 'Logik der Syntax'; die 'Dialektik der Syntax' ist meines Wissens noch nicht geschrieben worden.

In einem Auf satz aus dem Jahre 1838 erläutert Belinskij seine Ansicht über die Beziehung zwischen 'razum' und 'cuvstvo' für sich verbindlich:

Entweder sei die Welt eine zerrissene, in sich selbst widersprüchliche oder ein einheitliches Ganzes, das sich lediglich in unendlicher Vielfalt offenbare. Im ersten Fall sei die Welt dem Wissen unzugänglich und keine Erscheinung der ewigen Vernunft, die sich selbst nicht wider spricht; im zweiten Fall müsse die Welt eine vernünftige Erscheinung sein, die im Bewußtsein mit der Vernunft identisch ist.

Das Gefuhl sei die unmittelbare Anschauung der Wahrheit, die sinnliche Erkenntnis der Wahrheit. Ohne Gefühl gebe es keine Vernunft. Wer kein Gefühl habe, der habe nur den endlichen Verstand (konednyj rassudok), aber nicht Vernunft (razum), und ihm sei ein tieferes Verständnis des Lebens nicht möglich. Um bewußt zu verstehen, müsse die unmittelbare Empfindung in Begriffe übersetzt werden. So gesehen gebe es keinen Gegensatz zwischen Geist (um) und Gefühl, sondern das Gefühl werde unbewußte Vernunft und die Vernunft bewußtes Gefühl sein $(I I, 558)$. 
Die Erkenntnis ist demnach erst dann eine vernünftige, wenn mit der Er kenntnis auch die Vernünftigkeit des Erkannten, d.h. das Erkannte als Erscheinung der Vernunft erfaßt wird, die Vernunft sich wiedererkennt.

Die Einfühlung in die Wirklichkeit sei eine liebende: Die Liebe sei Verstehen und Verstehen Liebe, weil Liebe Anwesenheit im verbor genen Wesen des geliebten Gegenstandes sei und Anwesenheit eines Subjekts im ander en nichts anderes als Verstehen dieses anderen Subjekts bedeute (ebd.).

Das Moment der Selbstreflexion im Erkenntnisakt, der Aufhebung der Subjekt-Objekt-Beziehung fehlt der Verstandeserkenntnis. Sie sieht die Wirklichkeit als Realităt an sich und nicht als Erscheinung der Vernunft:

Das Begreifen allein mit dem Verstand (razum!) ohne Beteil igung des Gr fühls sei ein totes, lebloses und falsches und niemals ein vernünftiges, sondern nur ein ver standesmäßiges (rassudočnoe) Begreifen (ebd.).

Begriffliche Klarheit war die Stärke Belinskijs nicht. Entweder ist die Vernunft begr iffsnotwendig mit dem Gefühl verbunden, dann verdient sie nach Abzug des Gefühls den Namen 'razum' nicht mehr, oder sie ist auch allein ein Vernunfterkenntnisse leistendes Vermögen, dann können ihre Begriffe nicht 'rassudocnye' sein.

Auf die wechselseitige Bedingtheit von 'razum' und 'cuvstvo' weist Belinskij auch in den folgenden Jahren immer wieder hin:

In der schon zitierten Rezension der Werke Baratynskijs (1842) heißt es:

Verstand ohne Gefühl (um bez cuvstva) mache den Menschen entweder zu einem sittenlosen Wesen, zu einem Egoisten, oder zu einem trokkenen Dialektiker und blutlosen Pedanten, der in allem nur logische Formen und weder Seele noch Inhalt sehe. Offensichtlich seien 'razum' und 'čuvstvo' zwei Kräfte, die einander benötigen und ohne einander tot und nichtig wären. "Cuvstvo i razum - èto zemlja i solnce"; in der Brust des Menschen, in diesem unterirdischen Reich dunkler Vorahnungen und stummer Empfindungen seien die Wurzeln aller lebendigen Bestrebungen und leidenschaftlichen Absichten verborgen, und nur das Licht der Vernunft könne die Empfindungen und Gefühle entwickeln, stärken und zum Gedanken klären, andernfalls blieben sie entweder tierischer Instinkt oder wilde Leidenschaft, schwarze Dămonie, die den Menschen ins Verderben stürze...

Das Gefühl sei die Wirklichkeit der Vernunft, wie der Körper die Wirklichkeit der Seele sei. Ohne Gefühl seien die Ideen kalt... Die Fülle und Vollkommenheit der menschlichen Natur bestehe in der harmonischen Einheit von Gefühl und Vernunft... Wehe dem Menschen, in dem sich das Gefühl gegen die Vernunft, die Vernunft gegen das Gefühl er- 
hebe. Das Gefühl neige zu Behauptungen (polożenie), liebe es, auf bestimmten Resultaten zu beharren; die Vernunft kontrolliere die Behauptungen des Gefühls und verneine sie, wenn sie nicht begründet seien (VI, 473; vgl. auch IV , 237; V, 220; VI, 269).

Die Kontrolle durch die Vernunft kann als antithetische Aufhebung der wirklichkeitsnahen Empfindung zu einer höheren ideellen Wahrheit ver standen werden. Die Vernunft verwirklicht sich im Menschen sowohl im Gefühl als auch im Bewußtsein, als 'bessoznatel'nyj razum' und als 'razum v soznanii'. Die jeweils geleisteten Erkenntnisse erlangen im dialektischen Prozeß die neue Qualităt e in e r Vernunfterkenntnis.

Das 'èsteticeskoe Cuvstvo', der Sinn für das Ästhetische ist - ich verweise auf die besprochene Rezension der Rede Moroškins (S.129) eine vor allem dem Umfang nach eingeengte Bedeutung des Begriffs 'cuvstvo'. Objekt der einfühlenden Erkenntnis ist in diesem Fall nur die künstlerisch relevante Wirklichkeit. Das Attribut reichert 'cuvstvo' mit Elementen von 'vkus' an.

Belinskij macht zum Wertmaßstab das Maß an Harmonie zwischen dem Intuitiven und dem Rationalen:

Im Mittelalter haben "serdce i fantazija" und nicht 'razum' geherrscht (VII, 154).

Es gebe zwei Seiten des menschlichen Geistes (duch): die des Inneren, des Seelenlebens, des Herzens - die Romantik - und die Seite der sich selbst erkennenden Vernunft, die Seite des Allgemeinen (Vח, 158).

Über Jean Paul schreibt Belinskij folglich, daß die in dessen Wesen vorherrschende Seite das Gefühl gewesen sei, ein eher flammendes als der Vernunft unteryeordnetes... Die Phantasie, die zum Reich der Ideen keinen Zugang habe finden können, habe die Vernunft beherrscht (VIII, 231f.).

Der von Belinskij proklamierte literarische Realismus zeichnet sich dagegen durch die vernunftgesteuerte Einfühlung in die Wirklichkeit aus.

So wie "cuvstvo" wird "ljubov" als "sinnliche Vernunft oder unbewußte Vernünftigkeit' definiert (III, 339):

Der Geist (duch) sei Wirklichkeit, 'denn er sei Liebe oder unbewußte Vernünftigkeit (razumnost'), aber dann Vernunft (razum) oder sich selbst erkennende Liebe (III, 437).

Die Liebe sei verwirklichte, in Erscheinung getretene Vernunft, verwirklichte, in Erscheinung getretene Wahrheit $(I V, 74)$. 
Liebe und Vernunft seien zwei Seiten ein und desselben Geistes (duch) (VII, 49).

Es ist eine Folge des kategorischen Denkeñs Belinskijs, daß die Begriffe einer Kategorie austauschbar sind, obgleich sie für sich genommen bedeutungsmăßig geschieden sind. Steht z. B. dem Wort 'razum' 'ljubov"' gegenüber, dann wird es semantisch so aufgefüllt wie sonst 'curvstvo', 'serdce' oder 'fantazija', oder anders gesagt: 'ljubov" ist eines von vielen Zeichen für die These im dialektischen Prozeß der Verschmelzung von Intellekt und Intuition. Die Antithese 'razum' oder 'rassudok', die in Aussicht genommene Synthese 'duch' oder 'razum' zwingen 'ljubov" die Bedeutungsfülle auf, weil sonst die Gleichung nicht stimmen würde.

Ähnlich ergeht es dem Wort 'razum'. Wird es als Antithese verstanden, kann es nicht mehr die Synthese bezeichnen: Belinskij wăhlt dafür dann 'duch'. Andererseits definiert er 'razum' aber im Unterschied $\mathrm{zu}$ 'rassudok' und ' $u \mathrm{~m}^{\prime}$ als die das Rationale und Irrationale versöhnende Instanz. 
2.40 Konsolidierung der aktuellen Bedeutung durch Anhebung jeweils partiell implizierter Prădikationen oder Beziehungsglieder

So gefestigt der hohe Rang der Vernunft für Belinskij ist, so fest ist auch die sprachliche Umgebung vorgezeichnet. Entsprechend zahlreich sind im Vergleich zu 'um' die partiell implizierten Pradikationen und Beziehungsglieder, die zum Wortgruppenlexem tendierenden Wendungen.

\subsection{Partiell implizierte determinierende Prädikationen}

Die folgenden Aussagen sind im Begr iff der Vernunft irsofern generell enthalten, als - wie schon gesagt - 'razum' begrifflich nicht teilbar ist; andererseits haben diese Aussagen aber die Funktion, Ausschnitte des Bedeutungsbereichs anzusprechen:

1) 'razum' als sich dialektisch verwirklichende subjektive und objektive Vernunft

razum - dejstvujušcaja sila (VII,49)

tvorceskij razum (VI, 429; VIII,168)

razlagajušcij razum (VI, 270)

dialektika razuma (VI, 591)

projavlenie razuma $(I, 558)$

otlicetvorenie razuma večnogo (VI, 586)

voploscennyj razum $(\mathrm{IV}, 592)$

otelesivšijsja razum (III, 327)

2) 'razum' als subjektive Vernunft

razum sozercaet tajnstvo mira (IV,501)

soznajusčij razum (II, 248; III, 327)

razum vyrazit svoe ponjatie $(V, 655)$

razum, sudja o prirode (VI, 274)

ispytujušçij razum (II, 562)

analiz razuma $(\mathrm{VI}, 49)$

poverka razuma $(V, 119)$

iskusstvennoe dejstvie razuma (VI, 587) 
Als individuellem Erkenntnisver mögen sind razum' einige Wirkungsweisen mit ' $u m^{\prime}$ gemeinsam, aber es handelt sich bei den Prădikationen um solche Worter, die ihren Bedeutungsumfang vom Subjekt erhalten. Bei gleichem Namen ist die Analyse der Vernunft eben eine andere als die des Verstandes, die Erkenntnis eine tiefere, das geleistete Ur teil in einem ander en Sinn wahr.

\subsection{Partiell implizierte Beziehungsglieder}

'duch' und 'razum' werden von Belinskij weitgehend synonym gebraucht, wenn diese Worter das Prinzip Vernunft im Sinne des 'Weltgeistes' bezeichnen. Belinskij identifiziert 'razum' und 'soznajušcij sebja duch celoveceskij' $(I, 240)$ oder 'sobstvennyj razum' und 'sub-ektivnyj duch $^{\circ}$ (III, 340; ăhnlich: III, 473; VI, 274; 388).

In der Bedeutung 'subjektiver' und 'objektiver Seist' im Sinne der Gesamtheit der geistigen Krafte eines einzelnen Menschen oder einer mehr oder weniger großen Gruppe und auch im Sinn der Geisteshaltung konkurrieren 'um' und 'duch'. Jedoch wird mit dem Wort 'duch' der Geist als Individuation des Weltgeistes, als Teilhabe an der ewigen Vernunft bestimmt. Dieser Unterschied zu 'um' wird deutlich, wenn Belinskij von der Fülle unserer geistigen Existenz (duchovnoe suscestvo), wie sie sich im Wort 'razum' ausdrückt, spricht (IV, 480). So wie 'um' als Summe der geistigen Făhigkeiten und als Summe der Verstandeserkenntnisse begr iffen werden kann, so kann 'duch' sowohl das Gesamt der höheren Erkenntnisvermögen als auch das Gesamt der Vernunftwahrheiten bezeichnen. 'duch' schließt 'um' ein, umgekehrt kann 'um' nicht die volle Bedeutung von 'duch' decken.

'razum' setzt 'rassudok' und 'um', die Vernunft den Verstand voraus. Eine wesenhafte Bedeutungsbeziehung besteht zu 'razum' im Sinne der subjektiven Vernunft. Zwischen den Begriffen gibt es ein deutliches Qualitătsgefalle, das auch dialektisch nicht uberwunden werden kann. Ein Qualitătensprung eines hohen Maßes an 'rassudok' zu 'razum' findet nicht statt, im Gegentell: das Übergewicht des Verstandes wird 
von Belinskij negativ beurteilt. Auf der anderen Seite kann 'razum' nicht zu 'rassudok' gemindert werden; die Wortgruppe 'razum bez cuvstva' z. B. zielt am Begriff 'razum' und am Begriff 'rassudok' vorbei.

Den Unterschied dieser Erkenntniskx äfte hat Belinskij ebenfalls 1838 für sich verbindlich dargelegt. Die Absicherung der Vernunft gegenüber dem Verstand und die Integration des Gefühls ist ja schon verschiedentlich als Überzeugungskern gedeutet worden. Dieser Maßstab hat die Kontinuitast des Denkens Belinskijs bei aller oberflächlichen Begr iff sverwischung, Wortspielerei gewăhrleistet.

Jede der Erkenntniskr äfte 'razum' und 'rassudok' habe ihre Sphäre: die Endlichkeit sei die Sphăre des Verstandes, das Unendliche sei nur der Vernunft zugänglich. 'razum' setze notwendig 'rassudok' voraus, aber 'rassudok' bedinge nicht 'razum'. Wirke der Verstand in der ihm eigenen Sphäre, sei er wie die Vernunft ein göttlicher Funke und hebe den Menschen als bewußtes Wesen über die ganze übrige Natur hinaus. Trete jedoch der Verstand an die Stelle der Ver nunft, dann ersterbe alles Heilige im Menschen, das Leben höre auf, Geheimnis zu sein, werde zum Kampf egoistischer Individuen (II,369f.).

Die Vernunft präge Begr iffe für das Unendliche, sie spreche von dem, was der sinnlichen Anschauung nicht mehr zugänglich ist. Die Definitionen und Aussagen der Vernunft erfassen das Moment des ewigen Lebens des Allgemeinen und Absoluten und enthalten unendliche Möglichkeiten zur Bestimmung weiterer Momente. In den Definitionen des Ver standes sei Tod und Unbeweglichkeit, in denen der Vernunft Leben und Bewegung (ebd.).

Die isolierten, erstarrten Ver standesbegr iffe werden von der Vernunft relativiert, als Erscheinung der ewigen Idee, des Weltgeistes, als Offenbarung verstanden. Der Verstand entreißt die Begriffe ihren Beziehungen, entzieht sie damit auch - so darf man Belinskij deuten - der dial ektischen Höher entwicklung.

Den Rangunterschied zwischen 'razum' und 'rassudok' verdeutlicht Belinskij im folgenden Vergleich:

Die Sittlichkeit (nravstvennost') verhalte sich zur Moralität (moral'nost') wie die vernünttige Erfahrung (razumnyj opyt) des Lebens zur gewöhnlichen (zitejskaja opytnost'), wie das Erhabene zum Gemeinen, das Tragische zum Alltăglichen, wie 'razum' zu 'rassudok', wie Kunst zum Handwerk (III, 407; vgl. auch III, 410). 
Die beinahe zwanghafte Suche nach Gegensätzen führt bei Belinskij wenn nicht zu Widersprüchen, so doch zu Verfal schungen. Was gerade noch auf korrespondierenden Ebenen gesehen wurde, ist plötzlich unzulăssig abgewertet. Im folgenden Satz reißt Belinskij rhetorisch Gräben zwischen Idealismus und Pragmatismus auf:

Der Verstand (rassudok) komme über die 'exakten' Wissenschaften nicht hinaus und verstehe nichts, was außerhalb des engen Kreises des Nützlichen und Alltäglichen liege. Die Vernunft (razum) umgreife die unendliche Sphäre des Unerfahrbaren (sverchopytnogo) und Über sinnlichen, mache das Unbegreifliche klar, das Unbestimmte offenbar, bestimme das 'Unexakte' (IV, 481). 'dejstvitel'nost" ist ein Schlüsselwort im Denken Belinskijs; als Er scheinung der Vernunft zollt er ihr zeitweise eine gläubige Wertschätzung:

Die Vernunft betrachte die Erscheinungen der Wirklichkeit und sehe in ihnen die unbedingten Erscheinungen des Geistes (duch) (III, 415).

Die Vernunft sehe in den Er scheinungen strenge Folgerichtigkeit und unzer störbare Einheit (IV, 589).

Die Vernunft zerstöre die Erscheinung, um sie für sich zu neuer Schönheit und zu neuem Leben zu erwecken, wenn sie sich selbst in der Erscheinung wiederfinde (VI, 270). Sie suche in allem sich selbst und erkenne nur das als wirklich an, wor in sie sich selbst finde (ebd.).

Die Vernunft lebe in der Natur als Erscheinung und im Menschen als Bewußtsein (XI, 189).

Unter dem Wort 'dejstvitel'nost" werde alles, was ist, verstanden: die sichtbare und die geistige Welt, die Welt der Fakten und die der Ideen: "razum v soznanii i razum v javlenii" - mit einem Wort, der sich selbst offenbarende Geist (duch) sei die Wirklichkeit (III, 436; vgl. auch III, 327).

Die Wirklichkeit sei nichts anderes als die verwirklichten Gesetze der eigenen Vernunft (IV, 83).

Das Beziehungsglied 'dejstvitel'nost"' ist so eng mit dem Wort 'razum' verbunden, daß diesem kaum noch ein Bedeutungsspielraum bleibt und 'razum' meistens terminologisch zu 'razum $v$ javlenii' oder 'razum $v$ soznanii' bzw. zu 'cistyj razum’ erstarrt. 


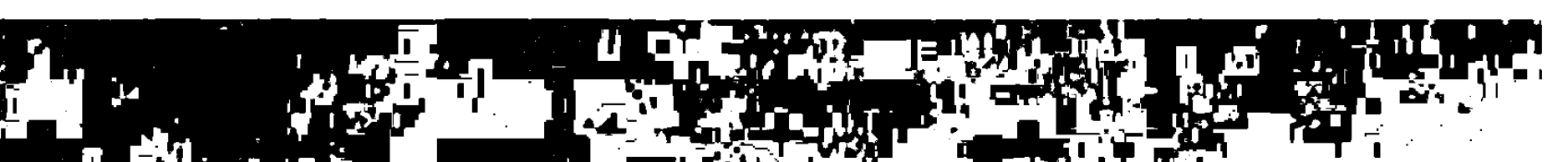

1)

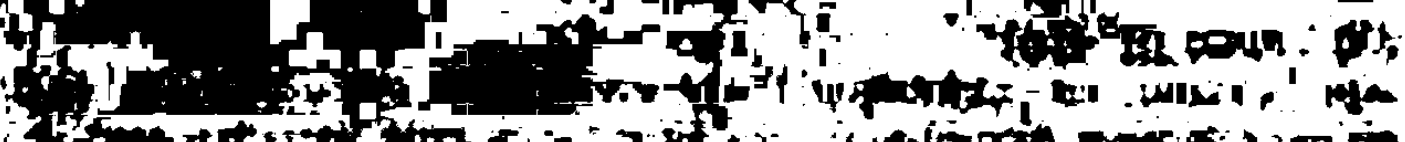

7.

fra

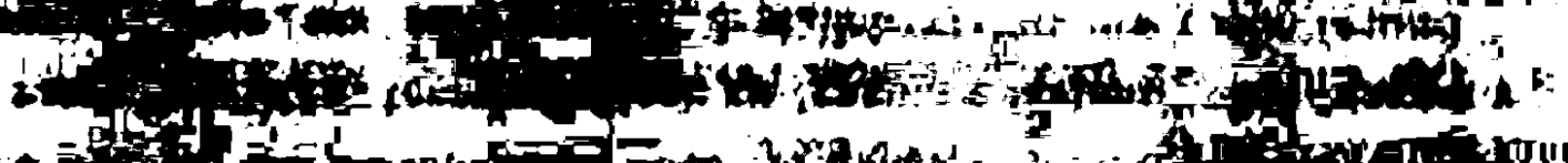

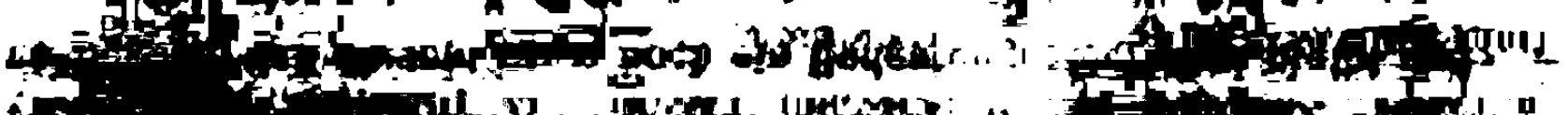

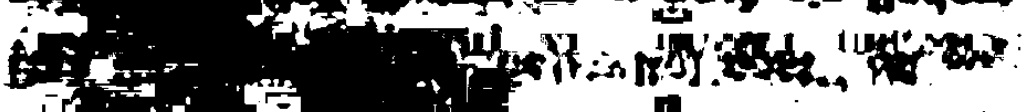

if

is

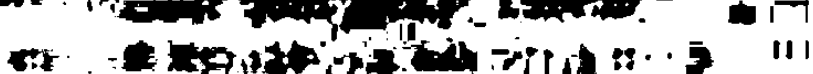

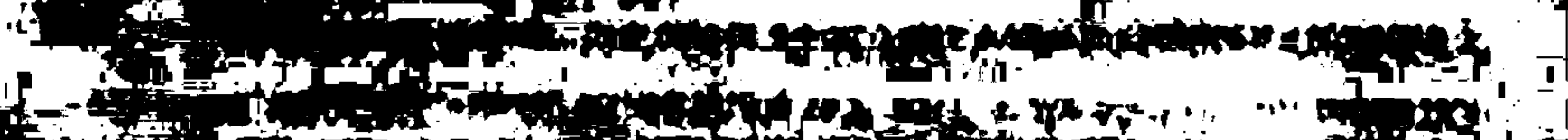

$\Rightarrow$ Gis

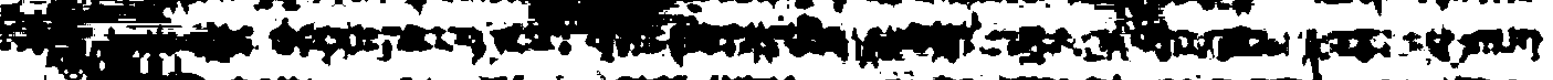

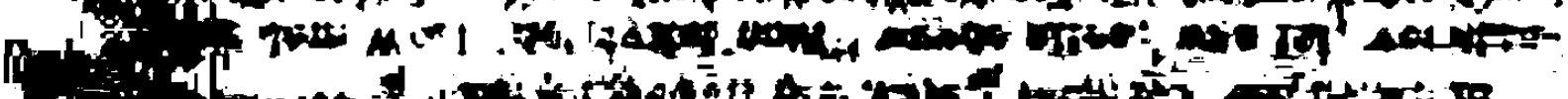

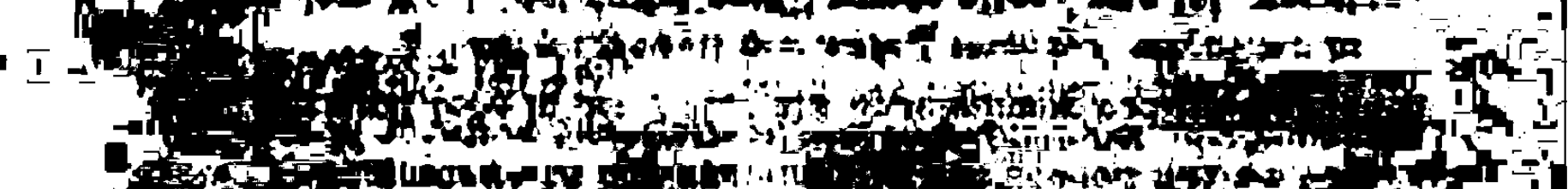
15:

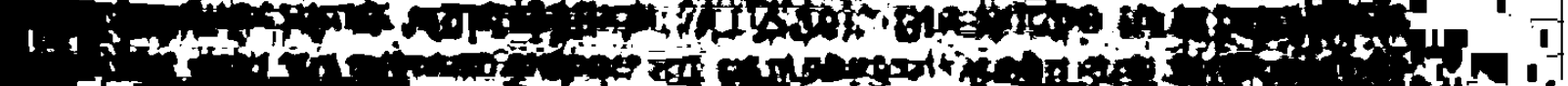

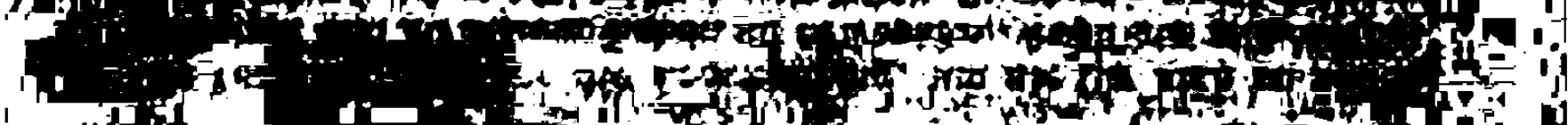

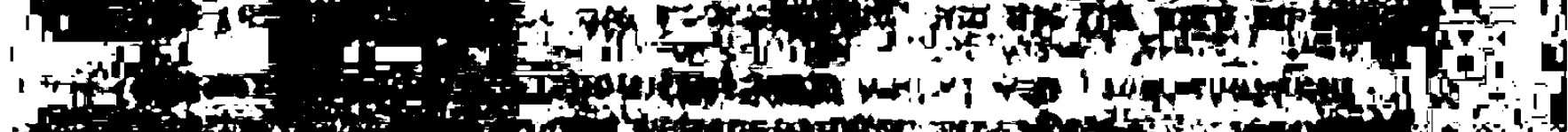
ig - 5 .

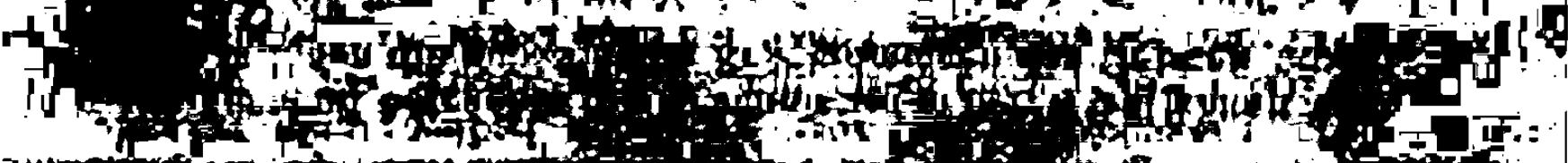

74

I

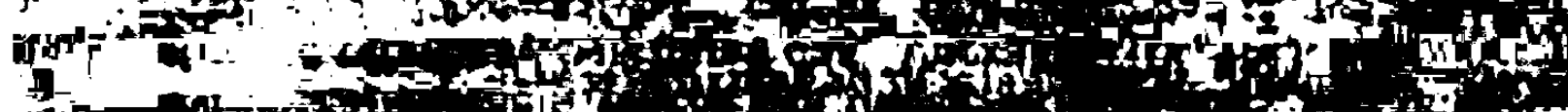

7.

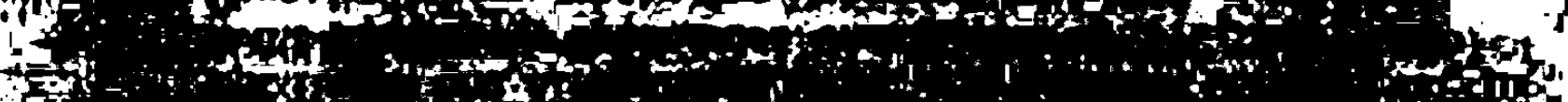

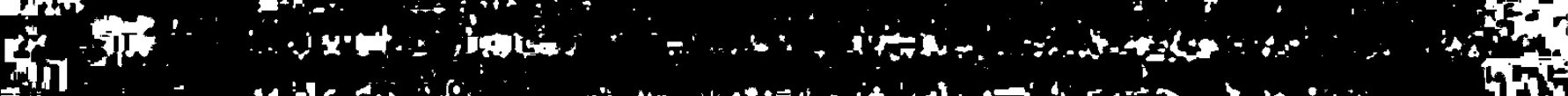

TF it

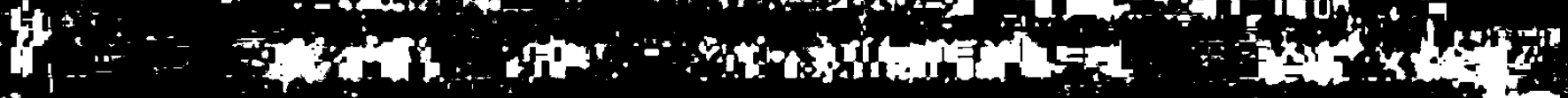

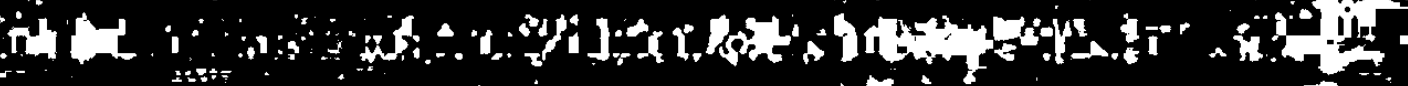
.

1

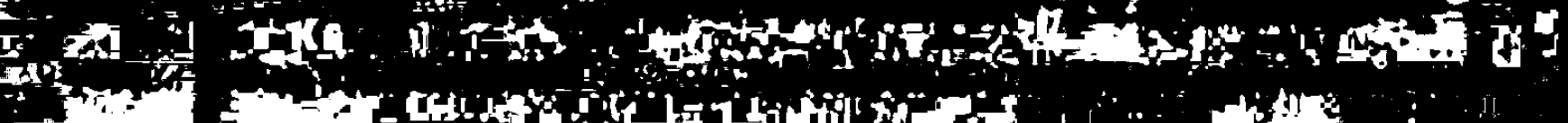

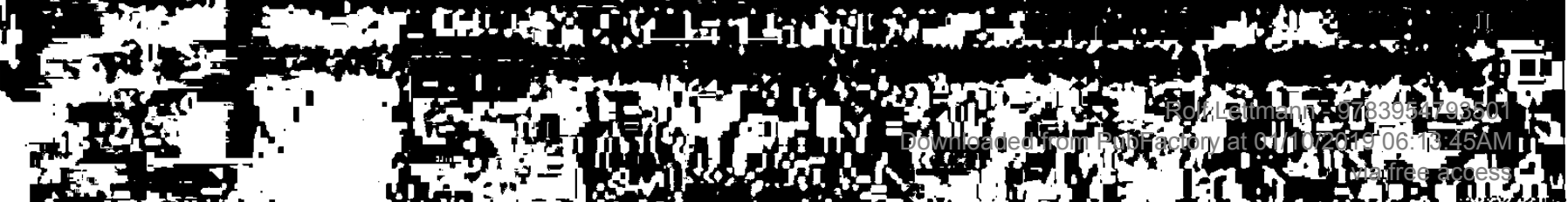

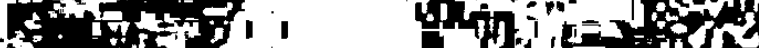




\section{Zusammenfassung}

Im monographischen Abriß (I, 1.20) zeichnete sich die zentrale Stellung des Begriffs 'Vernunft' im Denken Belinskijs bereits als Über zeugungskern ab. Die im zweiten Teil dieser Arbeit ermittelte semantische Stabilităt, ja Blockierung und die eigenwillige Reduzierung der lexikalisch vorgegebenen Bedeutungsweite bestătigen den Rang der Vernunft als unantastbare sinngebende Mitte. Die geăußerte Vermutung, daß der Spracheinfluß Belinskijs wohl eher im Durchspielen aller Bedeutungsmöglichkeiten und weniger im Durchsetzen einer neuen Bedeutung bestehe, konnte nur für das Wort 'um' erhärtet werden. Die Unterschiede in der sprachlichen Behandlung der beiden Worter seien noch einmal aufgezeigt:

Im Gebrauch des Wortes 'razum' ist eine gewisse Befangenheit unübersehbar; gerade dieser Inbegr iff des Dynamischen erfährt kaum eine Entwicklung.

Dem Wort 'um' gegenüber ist Bel inskij unbefangener. Jedoch kann auch hier von einem privaten Bedeutungswandel nicht die Rede sein: die vom Lexikon gewăhrte Freiheit wurde ohne die Absicht einer langfristigen Verlagerung der Bedeutungspole ausgeschöpft.

Mit der Bevorzugung des Wortes 'rassudok' als Zeichen für das niedereErkenntnisvermögen 'Verstand' ist es zu erklären, daß um' trotz der Festlegung des Wortes 'razum' seinen Spielraum gewahrt hat, während 'rassudok' vergleichbar terminologisch erstarrte. Auch die anderen Wörter im Einzugsbereich von 'razum' wurden fixiert. Das Vordringen des Wortes 'rassudok' war bereits an den Wörterbüchern abzulesen; die durch den Synonymenschub bewirkte Verlagerung von 'um' zur Bedeutung 'Geist' - in jeder Schattierung des deutschen Wortes - zeigt sich bei Belinskij deutlich. 
Die Erwartung, daß 'um' und 'razum' eine den deutschen Wörtern 'Verstand' und 'Vernunft' vergleichbare Stellung im russischen Denken des 19. Jahrhunderts eingenommen haben, ist nicht bestätigt worden. 'Verstand' kann nicht in jedem Fall mit 'um' und auch nicht immer mit 'rassudok' uber setzt werden. Die Wiedergabe des Wortes 'Geist' wird einmal auf 'um', ein andermal auf 'duch' zurückgreifen müssen.

Die Methode hat sich im großen und ganzen bewăhrt. Auf einem anderen Wege wäre ich kaum zu einem anderen Ergebnis gekommen. Die Fehlerquote ist jedoch nur deshalb so gering, weil mit inhaltsbezogenen Argumenten falsche Einstuf ungen korrigiert werden konnten. Eine methodische Inkonsequenz hat sich vor allem dann als notwendig erwiesen, wenn die unmittelbare sprachliche Umgebung die Bedeutung nicht konsolidierte, sondern der Denkansatz hinzugezogen werden mußte.

Der Vorzug einer auf der Beziehung zwischen noetischem Aufwand und Bedeutungsbegrenzung basier enden Methode: die Übertragbarkeit auf alle möglichen Wörter und Sprachen - wird mit einigen Nachteilen erkauft:

/ Das Herauspräparier en des Primärurteils zerstört das Satzganze.

/ Die Zusammenfassung der Aussagen unter dem Gesichtspunkt des Maßes an semantischer Entfernung und begrifflicher Organisationshöhe geschieht ohne Rücksicht auf inhaltliche Unterschiede.

/ Für feine Bedeutungsnuancen ist der Maßstab zu grob.

Es hat sich in der Anwendung gezeigt, daß die Unterscheidung in determinierende, realtionale und identifizier ende Urteile zweitrangig ist, weil die einzelsprachliche Syntax die Logik überspielt. Vielleicht kann eine andere Stufenleiter für die in jedem Fall geleistete Determinierung gefunden werden.

Die Trennung der aktualen von den potentiellen Urteilen ist ebenfalls von geringerer Relevanz als ursprünglich erwartet worden ist. Ob die Behauptung eines Tatbestands dem Satz vorausgeht oder im Satz zur Sprache kommt, d.h. vorwiegend von der Nennoperation oder der Ver- 
zeitungsoperation geleistet wird, wirkt sich semantisch nur schwach aus.

Die Verschiedenheit von Logik und Sprache scheint mir auf den Unter schied zwischen Terminus/Begriff und Wort/Bedeutung, auf den Unterschied der Bezugsvariabilităt hinauszulaufen. So wie das Wort beweglicher ist als der Terminus gleichen Namens, so ist die Bedeutung an ihren Răndern unbestimmter als der jeweils intendierte begriffliche Kern. Um dieser Andersartigkeit willen bedarf die Methode, die auf dem Allgemeingilltigen der Semantik aufbaut, der empirischen Ergånzung. 


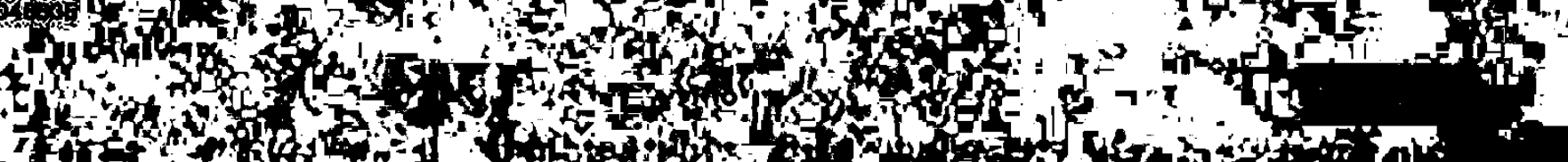

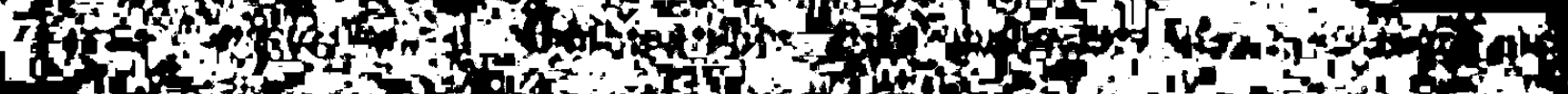

40 (n)

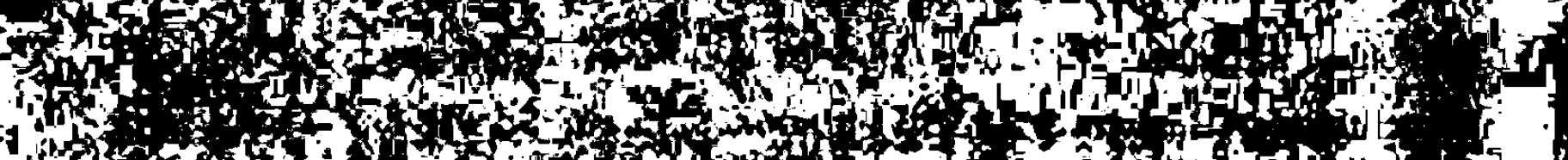

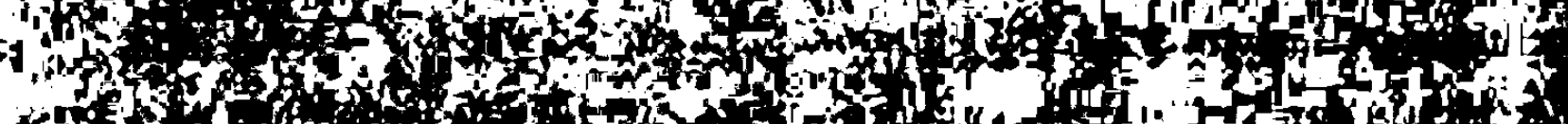
ens

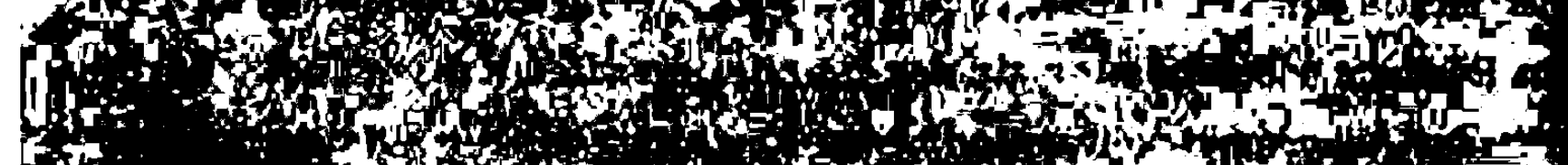
10. A

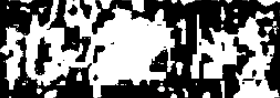

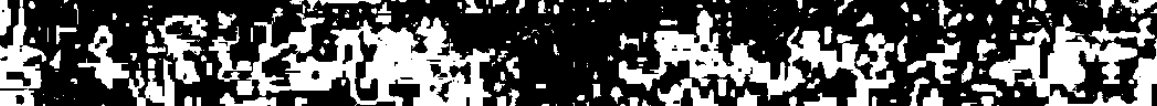

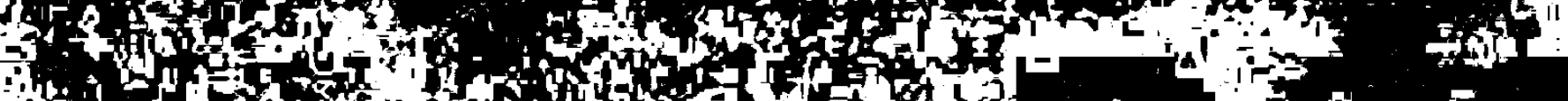

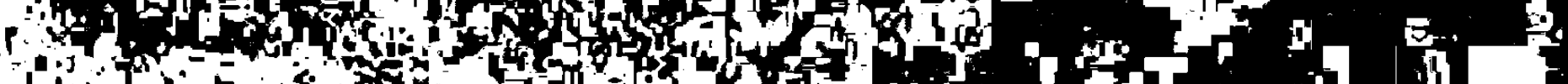

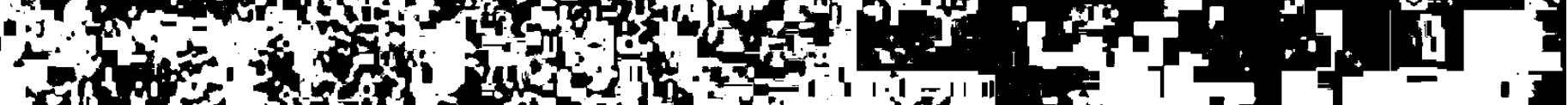

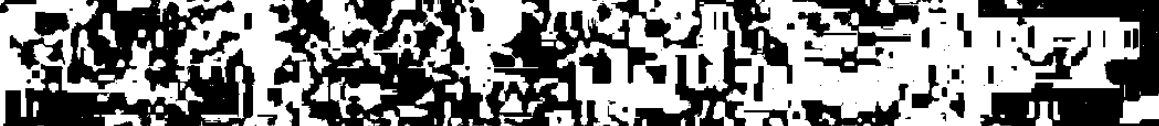
in

$d$ A

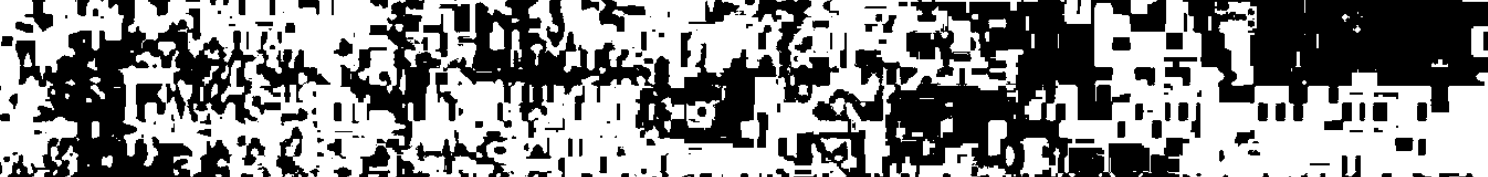
as " and

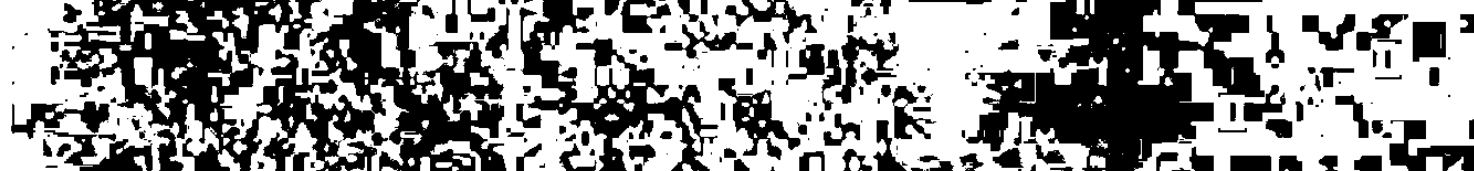

Fof

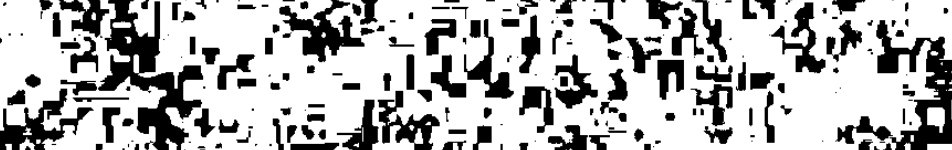
tinte

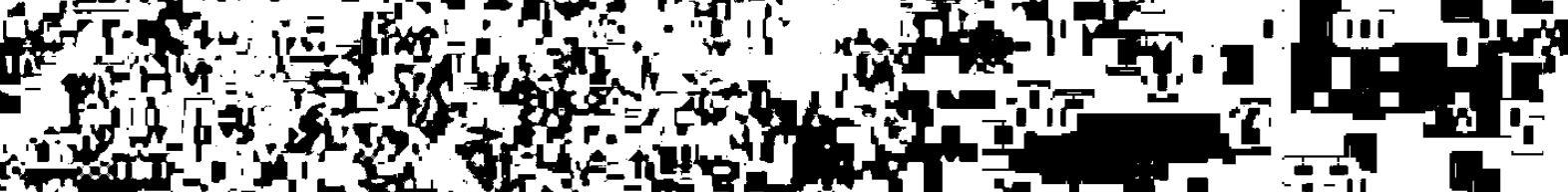

(1)

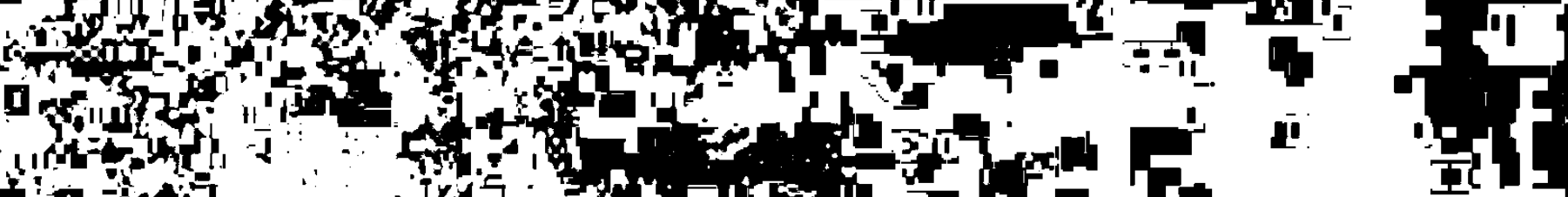
年

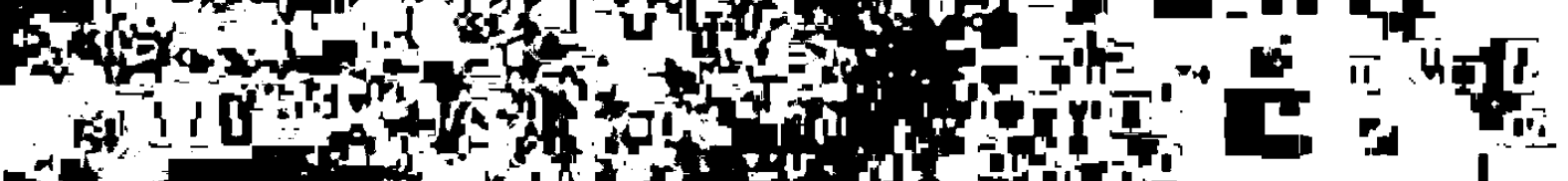

$\therefore$
$\therefore$
$=$

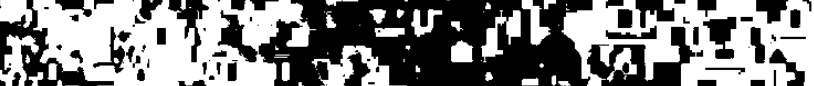

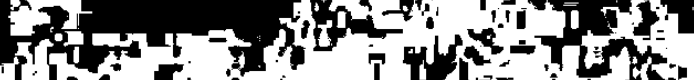

at int

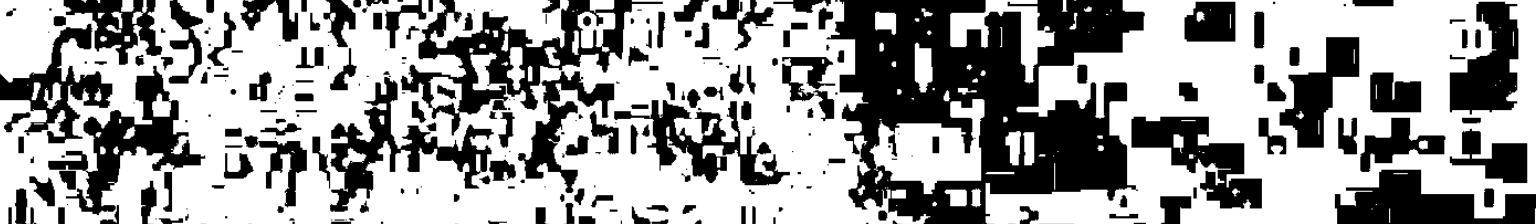

(1)

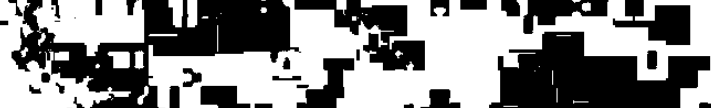

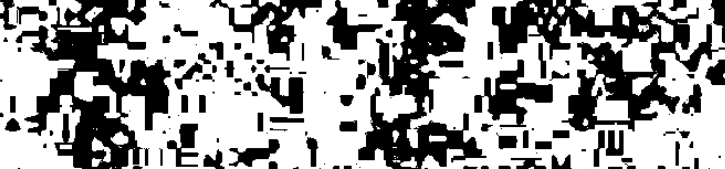

sin 


\section{LITERATURVERZEICHNIS}

Werkausgaben

Belinskij, Vissarion Grigor'evic, Polnoe sobranie socinenij, 13 Bde., Moskva 1953 - 1959

-.- Auf sătze zur russischen Literatur. Ausgewählt und mit einem Nachwort ver sehen von Karl Junghans. Über setzt von A. Kurella, Leipzig $0 . J$.

-.- Hamlet, Berlin 1952

(O klassikach russkoj literatury; dtsch.) Über die Klassiker der russischen Literatur. Zusammengestellt von A.N. Dubowikow. Über setżt von E. Jäkel, W. Lee, E. Kurpat und A. Kurella, Leipzig 1953

-.- Ein Lesebuch für unsere Zeit. Von Gerhard Ziegengeist, Weimar 1956

-.- (Reč o kritike; dtsch.) Rede über die Kritik;

in: Meister der Kritik. Belinski, Dobroljubow, Tscherny schewski. Eingeführt und erläutert von O. A. Bergelt. Übersetzt von Albert Klöckner, Berlin 1953

Ausgewählte pädagogische Schriften, Berlin 1953

Ausgewählte philosophische Schriften. Übersetzt von A. Kurella, Moskau 1950

Wörterbücher, Wortmonographien u.å.

Adelung, Johann Christoph, Grammatisch-kritisches Wörterbuch der Hochdeutschen Mundart, mit beständiger Vergleichung der übrigen Mundarten, besonders aber der Oberdeutschen. Zweyte vermehrte und verbesserte Ausgabe. Vierter Theil, Leipzig 1801

Ballestrem, Karl G. , Russian Philosophical Terminology, Dordrecht 1964

Berneker, Erich, Slavisches etymologisches Wörterbuch, Heidelberg $1908 \mathrm{ff}$.

Bielfeldt, Hans Holm, Russisch-deutsches Wörterbuch, 5. Aufl., Berlin 1958 
Dal ; Vadimir, Tolkovyj slovar' Zivogo vel ikorusskogo jazyka, 4 Bde., 3. Aufl., S. Peterburg - Moskva $1903-1909$

Dornse if $f$, Franz, Der deutsche Wortschatz nach Sachgruppen, Berlin 1959

Dor oszew ski, Witold, Stownik języka polskiego, 10 Bde., War szawa 1958 - 1968

Gej m, Ivan (i.e. Jean Heym), Novyj rossijsko-francuzsko-nemeckij slovar', socinennyj po slovarju Rossijskoj Akademii Ivanom Gejmom, 3 Bde., Moskva 1799 - 1802

Grim m, Jacob und Wilhelm, Deutsches Wörterbuch, Leipzig $1854 \mathrm{ff}$.

Hol ub, Josef - Frantisek Kopečny, Etymologicky slovnik jazyka ceského, Praha 1952

Hüttl -W orth, Gerta, Die Bereicherung des russischen Wortschatzes im 18. Jahrhundert, Wien 1956

Kl uge, Friedrich, Etymologisches Wörterbuch der deutschen Sprache, 20. Aufl., Berlin 1967

L a t z e 1, Siegbert, Vernunft, Verstand und Witz bei Schiller, Diss. München 1958

Le ping, A.A. - N. P. Strachova, Nemecko-russkij slovar', Moskva 1958

Vollständiges Deutsch-Russisches L ex ic on, nach dem großen grammattikalisch-kr itischen Wörterbuche des Herrn Adelung ausgearbeitet, und mit allen zur vollkommenen Kenntniß der deutschen Sprache nöthigen Phraseologien und Erlăuterungen versehen; herausgegeben von einer Gesell schaft von Gelehrten. Zweyter Band, St. Peter sburg 1798

L inde, M.S. B., Słownik jezyka polskiego, 6 Bde., Lwów 1854 - 1860

Mikl osich, Franz von, Lexicon Palaeoslovenico-Graeco-Latinum, Aalen 1963 (Neudruck der Ausgabe Wien 1862 - 1865)

Mrongovius, Christoph Cölestin, Ausführliches polnisch-deutsches Wörterbuch, Königsberg 1835

Pavlovskij, I.Ja., Russko-nemeckij slovar', 3. Aufl., Riga Leipzig 1923 
-.- (Pawlowsky, J.), Deutsch-russisches Wörterbuch, 4. Aufl., Riga - Leipzig 1922

Pfuhl, K. B. , Lužiski serbski słownik, Budyšn 1866

Pok or ny, Julius, Indogermanisches etymologisches Wörterbuch, Bern - München 1959

R e čnik na sưvremennija bưlgarski knižoven ezik, Sofija 1959

R ist ić , Svetomir - Jovan Kangrga, Enciklopedijski nemackosrpskohrvatski rečnik, Beograd - München 1963

--- Rečnik srpskohrvatskog i nemackkog jezika, Beograd 1928

Sl ov a ${ }^{`}$ jazyka Puškina v 4 tt. , Moskva 1956

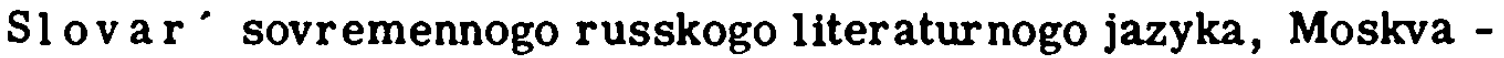
Leningrad $1950 \mathrm{ff}$.

Sl ovník spisovného jazyka Ceského, Bd. 3, Praha 1968

Sreznevskij, I. I. , Materialy dlja slovarja drevnerusskogo jazyka po pis'mennym pamjatnikam, Graz 1956 (Unveränderter photomechanischer Nachdruck der Ausgabe Petersburg 1906)

Ušakov, Dmitrij Nikolaevič , Tolkovyj slovar' russkogo jazyka, 4 Bde., Moskva 1935 - 1940

Vas m er , Max, Russisches etymologisches Wörterbuch, 3 Bde. , Heidelberg 1953 - 1958

Wehrle, H. - H. Eggers, Deutscher Wortschatz, 12. Aufl., Stuttgart 1961

Philosophisches Wörter buch. Begründet von Heinrich Schmidt, 17. Aufl., durchgesehen und ergänzt und herausgegeben von Georgi Schischkoff, Stuttgart 1965

Russisches rückläufiges $W \ddot{r}$ te $r$ buch . Zusammengestellt von R. Greve und B. Kroesche unter der Leitung von Max Vasmer, 2 Bde., Berlin - Wiesbaden 1959 


\section{Literatur zu Belinskij}

B ow man, Herbert E., Vissarion Belinski 1811 - 1848. A Study in the Origins of Social Criticism in Russia, Cambridge/Mass. 1954

Brodskij, N.L., W. G. Belinski, der große revolutionäre Demokrat, Philosoph und Kritiker, Berlin 1948

Ċ erny ševskij, N.G., Polnoe sobranie socinenij, 25 Bde., Moskva $1939-1953$

Diet $\mathbf{r}$ i $\mathrm{h}$, Rudolf, W. Belinskij. Der Begründer der modernen Literaturkritik, Berlin 1948

Ev cuk, M. (Jowtschuk), Einfroßer russischer Denker;

in: W. J. Belinski, Ausgewăhlte philosophische Schriften, Moskau 1950, S. I - LV

Ha r e, Richard, Pioneers of Russian Social Thought. Studies of Non-Marxian Formation in Nineteenth-Century Russia and of its Partial Revival in the Soviet Union, London - New York Toronto 1951

He gel, Georg Wilhelm Friedrich, Studienausgabe in 3 Bănden. Ausgewăhlt, eingeleitet und mit Anmerkungen versehen von Karl Löwith und Manfred Riedel, Frankfurt/M. 1968

Iv a n ov-Razumnik, R. V., Istorija russkoj obšcestvennoj mysli. Individualizm i mešcanstvo $v$ russkoj literature i zizni XIX v. , t. 1, S. Peterburg 1907

J a k ow enko, Boris, Geschichte des Hegelianismus in Rußland, 1. Band, Neue vervollstăndigte Auflage, Prag 1940

Katz, Martin, Mikhail N. Katkov. A Political Biography $1818-1837$, The Hague - Paris 1966

Küppers, Bernhard, Die Theorie vom Typischen in der Literatur.

Ihre Ausprăgung in der russischen Literaturkritik und in der sowjetischen Literaturwissenschaft, München 1966

Laziczius, J. von, Fr. Hegels Einfluß auf V. Belinskij;

in: Zeitschr. f. slav. Phil., 5 (1928), S. 339 - 355

Lukacs, Georg, Der russische Realismus in der Weltliteratur, Berlin 1952

Mezencev, P. , Belinskij - problemy idejnogo razvitija i tvorčeskogo nasledija, Moskva 1957 
Müll er, Eberhard, Russischer Intellekt in europăischer Krise. Ivan V. Kireevskij (1806 - 1856), Köln - Graz 1966

Literaturnoe nasledstvo, Nr. 55, 56, 57: V.G. Belinskij, Moskva 1948, 1950, 1951

Ne ¿ a eva , V.S., V.G. Belinskij, Zizn' i tvor Cestvo 1836 - 1841, Moskva 1961

Puskin, A.S., Polnoe sobranie socinenij v desjati tomach, Moskva $1950 \mathrm{f}$.

Ra m mel meyer, Alfred, Dostojewskijs Begegnung mit Belinskij;

in: Zeitschr. f. slav. Phil., 21 (1951/1952), S. 1 - 21; $273-292$

Ria sanovsky, N.V., Rußland und der Westen. Die Lehre der

Slawophilen. Studie über eine romantische Ideologie, München 1954

$\mathrm{Sch}$ e ibert, Peter, Von Bakunin zu Lenin. Geschichte der russischen revolutionären Ideologien 1840 - 1895, Bd. 1, Leiden 1956

Schultze, Bernhard, Wissarion Grigorjewitsch Belinskij. Wegbereiter des revolutionären Atheismus in Rußland, München Salzburg - Köln 1958

Russische Denker. Ihre Stellung zu Christus, Kirche und Papsttum, Wien 1950

Set schkar eff, Vsevolod, Schellings Einfluß in der russischen Literatur der 20er und 30er Jahre des XIX. Jahrhunderts, Leipzig 1939

S mol ic , J., Westler und Slavophile in der neueren Forschung, Teil 2; in: Zeitschr. f. slav. Phil., 11 (1934), S. $439-449$

Stender - Petersen, Adolf, Geschichte der russichen Literatur, München 1957

Tschizewskij, Dmitrij, Hegel in Rußland;

in: --- (Hrsg. ), Hegel bei den Slaven, 2. verbesserte Auflage, Darmstadt 1961 , S. $145-387$

Vengerov, S. A., Očerki po istorii russkoj literatury, 2. Aufl., S. Peterburg 1907

Wellek, René, A History of Modern Criticism: 1750 - 1950, Vol. 3: The Age of Transition, London 1966

Windelband, Wilhelm, Lehrbuch der Geschichte der Philosophie, her ausgegeben von Heinz Heimsoeth, 15. Aufl., Tübingen 1957 
Sprachwissenschaftliche Literatur

A jduki ewicz, Kasimir, Sprache und Sinn;

in: Erkenntnis, 4 (1934), S. $100-138$

A chmanova, O.S. (Akhmanova), Ausgedrücktes und Nichtausgedrücktes in der zusammenfassenden Semantik des Wortes;

in: Ztschr. f. Slaw., VI (1961), S. $565-573$

Albrecht, Erhard, Beiträge zur Ereknntnistheorie und das Verhälnis von Sprache und Denken, Halle 1959

--- Die erkenntnistheoretische Problematik des sprachlichen Zeichens. Zur Auseinandersetzung mit der idealistischen Zeichentheorie in der modernen Sprachwissenschaft;

in: Deutsche Ztschr. für Philosophie, Berlin 3 (1961), S. 358 - 367

A mosova, N. N., Slovo i kontekst;

in: Ocerki po leksikologii, frazeologii i stilistike II, Leningrad 1958

(UČenie zapiski LGU, Nr. 243. Serija filologiceskich nauk, vyp. 42, S. 3 - 23)

Baldinger, Kurt, Die Semasiologie. Versuch eines Überblicks, Berlin 1957

B et z, W. , Zur Überprüfung des Feldbegriffs;

in: Ztschr. f. vergl. Sprachfor schung auf dem Gebiet der idg. Sprachen, $71(1954)$, S. $189-198$

Brandenstein, W., Über die Annahme einer Parallelität zwischen Denken und Sprechen;

in: Germanisch-romanische Monatsschrift, XII. Jg. (1924), H. 11/12, S. $321-327$

B ühl e r, Karl, Sprachtheorie. Die Darstellungsfunktion der Sprache, Jena 1934

Cassirer, Ernst, Philosophie der symbolischen Formen. I. Teil: Die Sprache, 4. Aufl. , Darmstadt 1964

De m pe, Hellmuth, Über die sogenannten Funktionen der Sprache. Ein Beitrag zur Sprachphilosophie im Anschluß an die Sprachtheorie Karl Bühlers, Weimar 1929

Erdmann, Karl Otto, Die Bedeutung des Wortes, Darmstadt 1966 (Unveränderter Nachdruck der 4. Aufl. Leipzig 1925)

Fil ipec, Josef, Zur innersprachlichen Konfrontation von semantischen Teil strukturen im lexikalischen Sy stem; in: Travaux linguistiques de Prague. 3. Etudes structurales dédiées au VIe congrès des slavistes, Prague 1968, S. $105-118$ 
Fischl, Johann, Logik, 2. Aufl., Graz-Wien-Altötting 1952

Funke, Otto, Innere Sprachform. Eine Einführung in A. Martys Sprachphil osophie, Reichenberg 1924

Gała b , Zbigniew - Adam Heinz - Kazimierz Polanski, Słownik terminologii językoznawczej, Warszawa 1968

Gü nt e rt , Hermann, Grundfragen der Sprachwissenschaft, 2. Aufl., bearbeitet von A. Scherer, Heidelberg 1956

H a g e r , Gertrud, "gesund" bel Goethe. Eine Wortmonografie, Berlin 1955

Hallig, Rudolf - Walther von Wartburg, Begriffssystem als Grundlage für die Lexikographie, Berlin 1952

Hartmann, Peter, Zur Theorie der Sprachwissenschaft, Assen 1961

--- Das Wort als Name. Struktur, Konstitution und Leistung der benennenden Bestimmung, Köln - Opladen 1958

$\mathrm{H}$ a $\mathrm{zf}$ eld, Helmut, Leitfaden der vergleichenden Bedeutungslehre, 2. Aufl., München 1928

H jel m slev, Louis, Structural Analysis of Language;

in: Studia linguistica, Lund - Copenhague, 1 (1947), No. 2,

S. $69-78$

Hu mboldt, Wilhelm, Über die Verschiedenheit des menschlichen Sprachbaues und ihren Einfluß auf die geistige Entwicklung des Menschengeschlechts, Bonn 1960 (Faksimile-Druck der Ausgabe Berlin 1836)

Koschmieder, Erwin, Beitrăge zur allgemeinen Syntax, Heidelberg 1965

Kr on a s er, Hans, Handbuch der Semasiologie, Heidelberg 1952

Le is i, Ernst, Der Wortinhalt. Seine Struktur im Deutschen und Englischen, Heidelberg 1953

L e r c h, Eugen, Vom Wesen des sprachlichen Zeichens. Zeichen oder Symbol;

in: Acta linguistica, Kopenhagen 1939, Vol. 1, fasc. 3, S. $145-161$

L ocker, Ernst, Denksprache und Zeichensprache;

in: Lexis, IV (1954), H. 1, S. $21-24$ 
Me ier, G. F., Ein Beitrag zur Erfor schung der Zusammenhänge von Sprache und Denken und der Entwicklungsgesetzmăßigkeiten der Sprache;

in: Wissenscahftl. Zeitschr. der Karl-Marx-Univer sităt Leipzig, Gesellschafts- und sprachwissenscahftliche Reihe, 1952/53, Nr. 4/5, S. $517-648$

Öhmann, Suzanne, Wortinhalt und Weltbild, Stockholm 1951

Porzig, Walter, Das Wunder der Sprache, 2. Aufl., Bern 1957

Sa ussure, Ferdinand de, (Cours de linguistique générale; dtsch.) Grundfragen der allgemeinen Sprachwissenschaft. Übersetzt von Hermann Lommel, 2. Aufl., Berlin 1967

Sch aff, Adam, Die Bedeutung der "Bedeutung";

in: Deutsche Zeitschr. f. Philosophie, Berlin 1961, Nr. 5,

S. $610-621 ; \mathrm{Nr} .6$, S. $708-723$

--- Essays über die Philosophie der Sprache, Wien - Frankfurt Zürich 1968

Schmidt, Franz, Logik der Syntax, 2. Aufl., Berlin 1959

Schmidt, W., Lexikalische und aktuelle Bedeutung. Ein Beitrag zur Theorie der Wortbedeutung, 2. Aufl., Berlin 1965

Śmelev, D.N. , Ocerki po semasiologii russkogo jazyka, Moskva 1964

Smirnickij, A. I. , Znacenie slova;

in: Vopr. jaz. , 2 (1955), S. $79-89$

Sper ber, Hans, Einführung in die Bedeutungslehre, Bonn - Leipzig 1923

Thü mmel, Wolf, Das Problem der periphrastischen Konstruktionen.

Gezeigt am Beispiel des Slavischen, München 1966

Travnicek, F.R., Nekotorye zamecanija o znacenii slova i ponjatii; in: Vopr. jaz., 1 (1956), S. $74-76$

Trier, Jost, Deutsche Bedeutungsfor schung;

in: Germanische Philologie, Heidelberg 1934, S. $173-200$

-.- Der deutsche Wortschatz im Sinnbezirk des Verstandes, Bd. 1, Heidelberg 1931

Ull ma nn, Stephen, (The Principles of Semantics; dtsch.) Grundzüge der Semantik. Die Bedeutung in sprachwissenschaftlicher Sicht, Berlin 1967 
V in ogradov, V.V., Osnovye tipy leksiceskich znacenij slova; in: Vopr. jaz. , 5 (1958), S. 3 - 29

War tburg, Walther von, Das Ineinandergreifen von deskriptiver und historischer Sprachwissenschaft, Leipzig 1931 (Berichte der Sächsischen Akademie der Wissenschaften, phil. -hist. Klasse 83,1931, I)

We is gerber, Leo, Die Bedeutungslehre - Ein Irrweg der Sprachwissenschaft?

in: Germanisch-Romanische Monatsschrift, 15 (1927), S. $161-183$

--- Das Problem der inneren Sprachform;

in: Germanisch-Romanische Monatsschrift, 14 (1926), S. 241 - 256

W is s e m a n n, Heinz, Erlebte und abstrahierte Wortbedeutung,

in: Sybaris (Festschrift Hans Krahe), Wiesbaden 1958, S. $195-202$

Żirmunskij, V.M., O granicach slova;

in: Vopr. jaz. , 3 (1961), S. 3 - 21

Zvegincev, V.A., Semasiologija, Moskva 1957 